UC-NRLF

|||||||||||-|||||||||||||||||||-||||||||||||

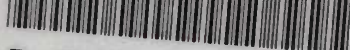

B $3908 \quad 370$ 


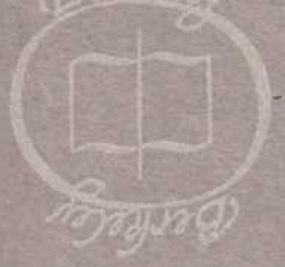

3.

क

28

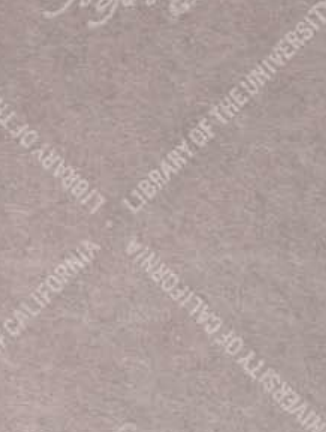

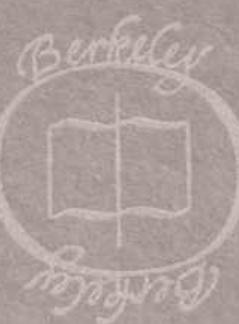

berieces

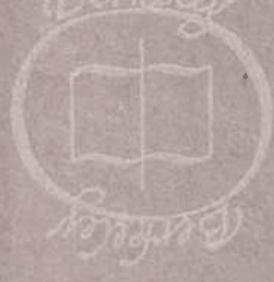

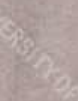

$5^{-5} y^{2}$
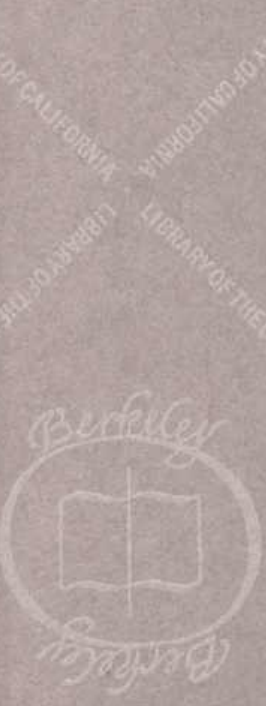

40

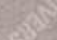

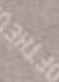




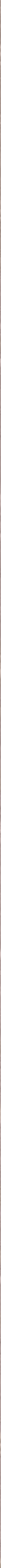




. 


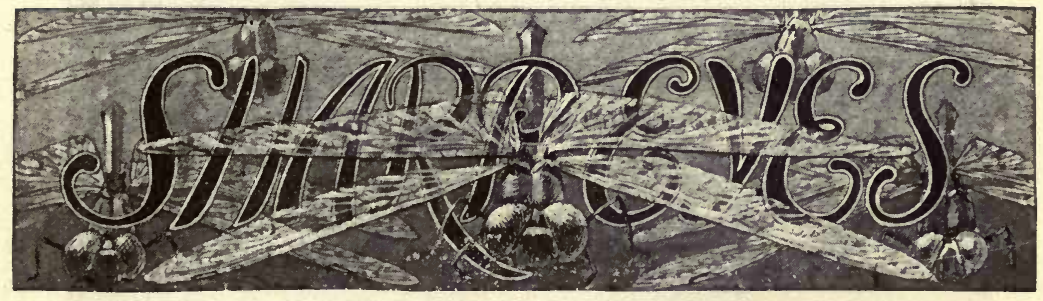




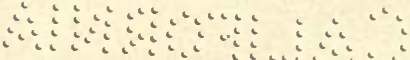

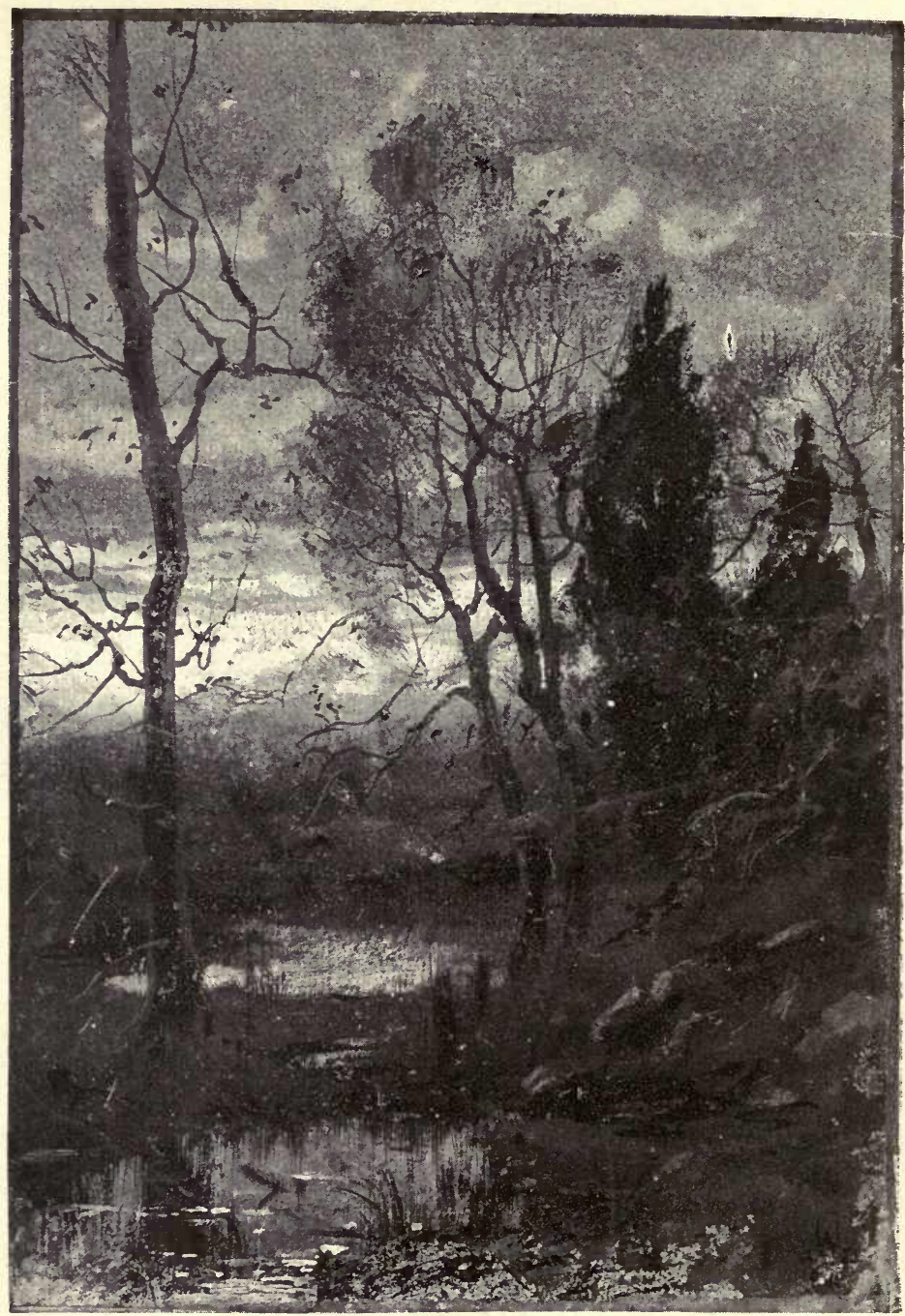




\section{SHARP EYES}

\section{A RAMBLER'S CALENDAR}

OF FIFTY-TWO WEEKS AMONG INSECTS, BIRDS, AND FLOWERS
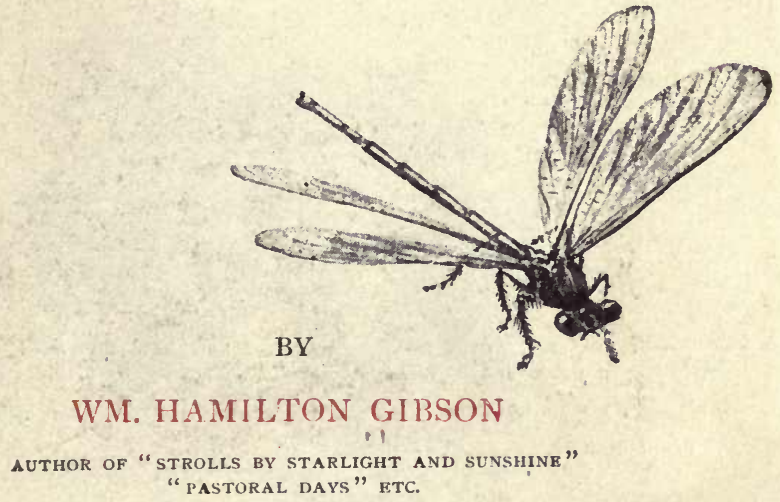

ILLUSTRATED BY THE AUTHOR

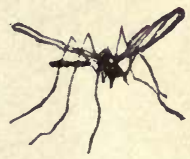

NEW YORK AND LONDON

HARPER \& BROTHERS PUBLISHERS 


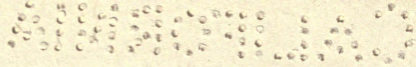

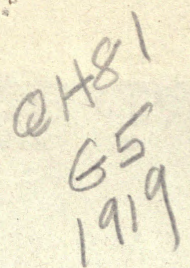

Sharp Eyes

Copyright, 1891, by Harper \& Brothers Copyright, 1919, by Mrs. William Hamiton Gibson Printed in United States of America H-U 


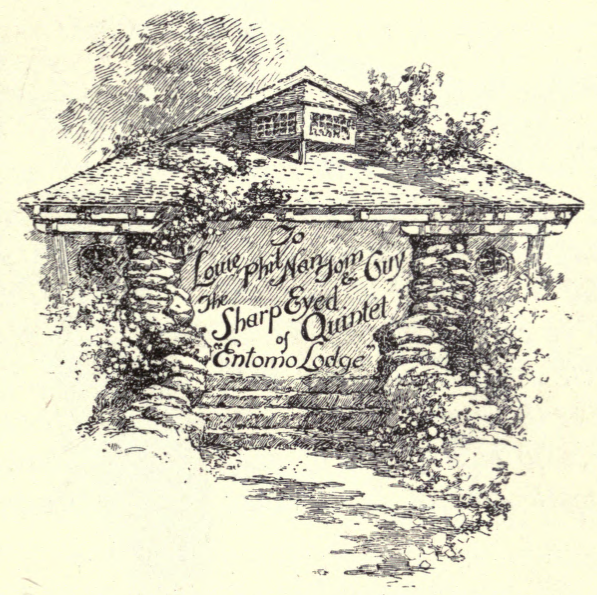




\section{"OF EIES AAND SEEING"}

\section{$x$}

"For the blind man saith, "Thod be no soch thing as sight'... There is the cot pereal maladie of blindnesse, and there $\$ O$ is the mental maladie of blind sight.... In Inood sooth ye are all blinde except the minde and eie doe seek in harmone... Verily there be those who see not though . they doe looke, who having eies of gredt "s bowinge yet walk abroad in staringe

bitadness" 


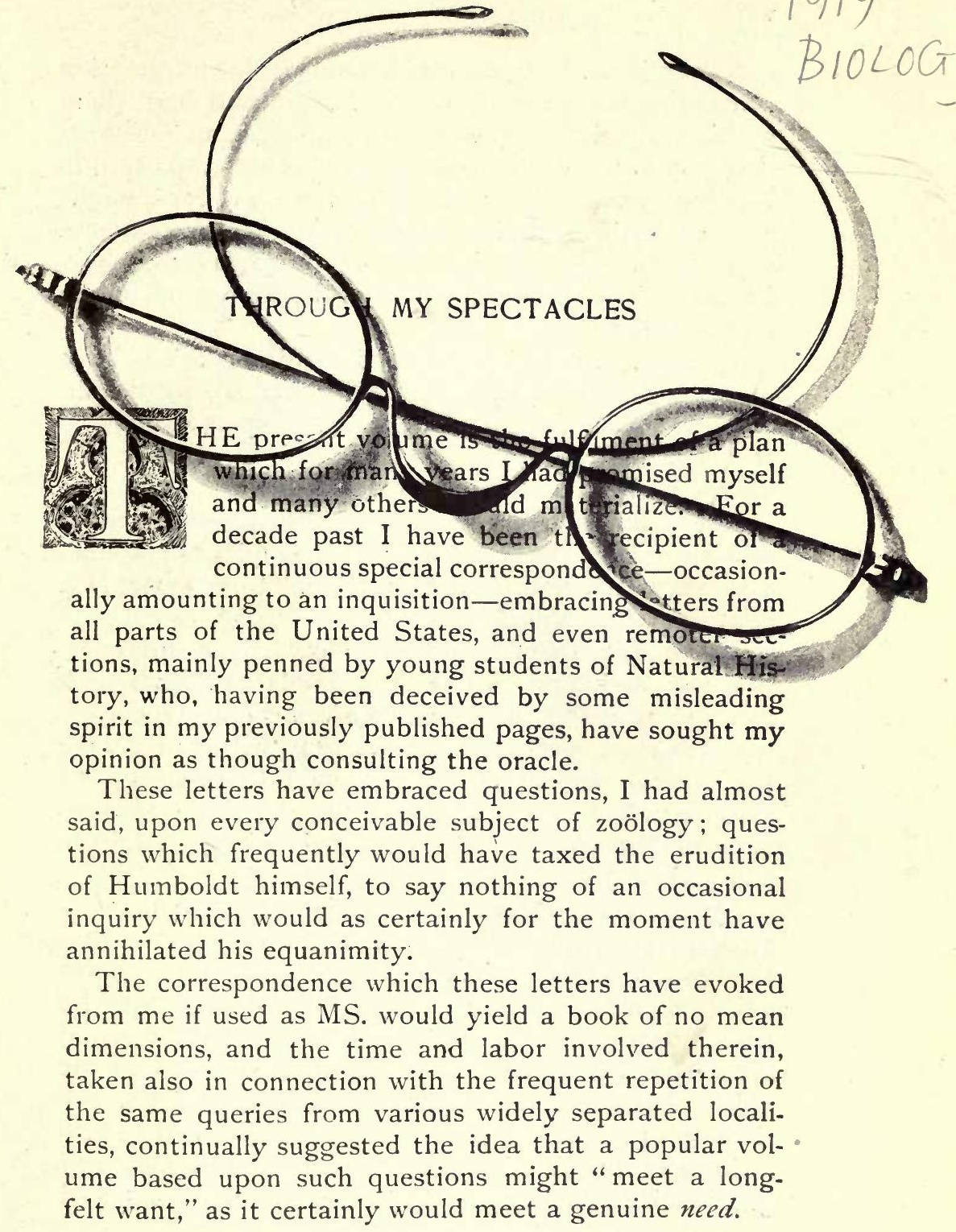


Recognizıng, too, the evident hunger for information concerning every-day objects in Nature, and that where one individual would write for enlightenment one hundred would wonder in silence and ten thousand dwell in heedless innocence, I realized that such a book might also go forth as a missionary to open the eyes of the blind, or at least quicken a desire for a fuller comprehension of the omnipresent marvel and beauty of the commonplace.

To all these considerations and conditions this volume owes its final embodiment. It is, after all, but a hint. If it shall serve as a courier, if only to open the doorto lower the bars, as it were, to these "pastures new," surely it will not have been uttered in vain.

Not a few of my friends will, perhaps, discover familiar words in the following pages; while others, I am assured, will herein recognize the first response of a dilatory correspondent.

Sharp Eyes, then, is, in brief, a cordial recommendation and invitation to walk the woods and fields with me, and reap the perpetual " harvest of a quiet eye," which Nature everywhere bestows; to witness with me the strange revelations of this wild bal masque; to laugh, to admire, to study, to ponder, to philosophizebetween the lines-to question, and always to rejoice and give thanks!

Sharp Eyes is, moreover, a plea for the rational, contemplative country ramble. It is a messenger to that thoughtless host to whom Nature is a closed book-not only unopened, but with leaves uncut-to those who would take a "walk," perhaps, but to whom, it would seem, the only virtues of a walk are comprised in the quickening pulse, the expansion of lung, and the cultivation of brawn. To such, a walk may be an exhilaration and a positive benefit, but scarcely the means of grace which is implied in the stroll or ramble. I would 
lay open a few, a very few, of these uncut pages, which I have learned by heart, that a "little may be read," even as we run. I would give at least one worthy motive for a stroll for every day in the year-storm or shine, summer or winter-conscious that in thus seeing through my spectacles my proselytes will surely rejoice in their conversion.

As to the assumptive tone of my title, I would add a few words. The term "sharp eyes" is, after all, but relative. There are degrees of sharpness of vision even as there are degrees of blindness. An eye may be "sharp" for birds but blind to botany; keen for Indian arrow-heads and dull to entomology, but never omniscient; or, as Thoreau figuratively but forcibly puts it, "a man absorbed in the study of grasses tramples down oaks unwittingly in his walks."

Thus, if the expression of these pages shall appear somewhat pedagogic, the critical reader will bear in mind that they were not intended for the scientist nor zoologist, nor, of course, for eyes sharper than my own in these especial fields. Prompted originally by the numerous juvenile correspondence, and prepared for the columns of a young people's journal, any inference of conscious didacticism in the author may perhaps best be met in the apology of the old Roman proverb: "Inter caecos regnat luscus"-among the blind, a one-eyed man is king. Indeed, are we not all relatively blind? Is not the "sharpest eye" continually reminded of how blind it was but yesterday?

Truly speaks "Fra Lippo Lippi :"

"We're made so, that we love

First, when we see them painted, things we have passed Perhaps a hundred times, nor cared to see"-

an axiom which needs no emphasizing, being borne out in every one's experience. Many of these "things we 
have not cared to see" are the subjects of the following chapterse-things not rare, nor seclusive, nor foreign, which are to be found in almost any of our woods, or fields, or copses, and which any wide-awake saunterer may discern with "half an eye," if that member be properly equipped. Anticipation is an equipment, the surest talisman to discovery, and anticipation may be quickened either by pictorial hint or previous experience. The retina must be on the alert. A boy who has woodchucks in his eye as he crosses the farm is sure to see his woodchuck, while otherwise he never had got a glimpse of him. It matters not in what particular direction the eye is educated; the habit of observation in one field quickens the powers of perception in any other, and the results depend not upon the eye-the camera-but upon the spirit and inspiration behind the retina, for "there is no more power to see in the eye itself than in any other jelly;" in the words of William Blake, "we see through it; not with it," even as through our spectacles.

Moreover, to the average observer, if the eye is ever thus to be a means of grace it must store up its harvest while hearts are light and life is new, when eyes are bright and unbedimmed. How many a prisoner caged in city walls is living on the harvest stored in free, unburdened youth, and which has never been replenished.

"When one thinks of the Greeks," writes Ouida, "playing, praying, laboring, lecturing, dreaming, sculpturing, training, living everlastingly in the free wind and under the pure heavens, and then reflects that the chief issue of civilization is to pack human beings like saltfish in a barrel, with never a sight of leaf or cloud, never a whisper of breeze or bird-oh, the blessed blind men who talk of Progress!'

In the more serious pursuit of scientific study, the wilds offer limitless opportunities to the close observer, and especially to the young whose lives are spent among 
the hills. There is yet plenty of work for sharp eyes to do, many a "common thing" whose secret is yet undiscovered, and few "known" things that are not still a constant rebuke to our self-satisfaction. The first meadow you meet is a great " undiscovered country;" learned, as we thought, in its length and breadth yesterday, it is still undiscovered to-day. The life history of many of our common plants, birds, insects, and mammals yet remains to be truly written. The keen, alert eye of boyhood often has opportunities and leisure for discovery denied to his elder, burdened fellow-beings, and evidences are not wanting to prove that even

\section{"A raw recruit, Perchance, may shoot Great Buonaparte."}

The facts in the following pages are almost entirely drawn from individual experience, largely gathered in boyhood, the apparently random selection being based upon a desire for the greatest variety possible within a limited range of the minor flora and fauna. The dates are apportioned from careful notes, verified through a record of many years. In most cases they are not arbitrary, being fixed at the mean period for each subject. The calendar is based upon the latitude of Connecticut, and while the dates given will, in most cases, be authentic for a district, covering the whole of New England and the Middle States, some adjustments will be necessary for Southern readers, there being at least three weeks' variance in the floral, and inferentially in the whole natural calendar, between the latitudes of Maine and Florida.

Apology for the conspicuous preferment of my dragon-fly as an emblem for cover and title-page will certainly be unnecessary to those who are familiar with this grotesque of the insect world. The natural symbol of om- 
niscience, a creature of the two elements, sharp-eyed alike in both, possessed of a head which is, in fact, all eyes, have we not here an embodied and tangible "qui vive," beside which the fabled Argus of old is a tame conception? The seat of its keen intelligence, doubledomed and literally begemmed with sight, reinforced, too, with wings which convert the horizon to a present kingdom, where shall my volume look for a more apt emblem?

Moreover, what reminders of red-letter days are awaked in his familiar shape-visions of lush green tangles, of water-weeds and lily-pads, of rippling brooks and dipping oars and dancing bobbers; placid lakes, cool forest glades, and meadows redolent with bloom. May we not accept our dragon-fly even as a courier?

\section{W. Hamilton Gibson,}

July ro, 1891.

Washington, Conn.

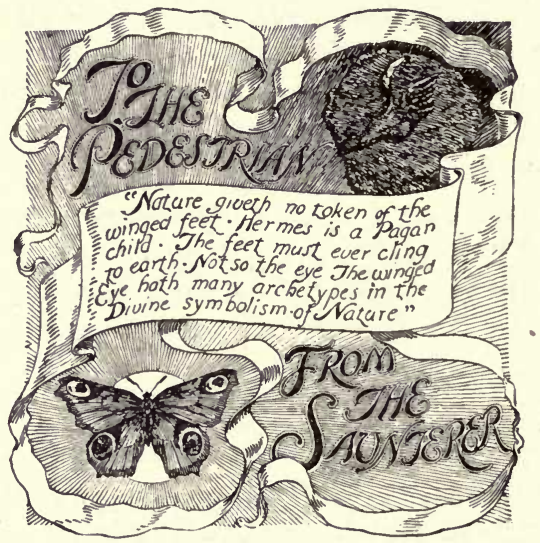




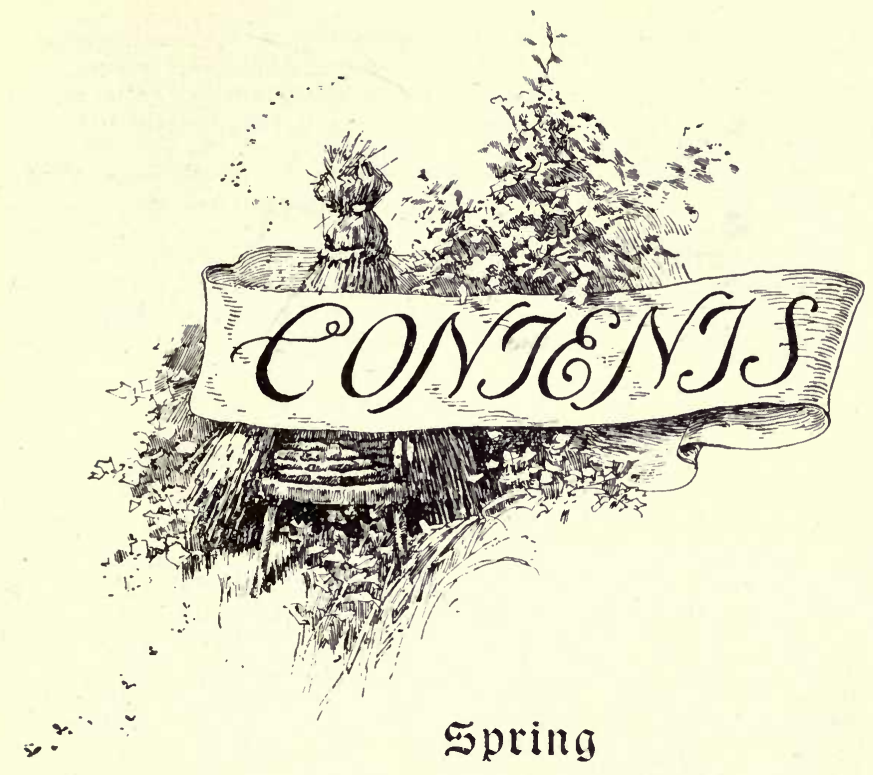

HE earliest blossom, the skunk-cabbage flower, visited by bees in snowy March. -Revels of the sprouting maple-seeds. - Peeping frogs: spring music from the swamp: Hylodes, Hyla, and cricket-frog. Imitation of Hylodes. Treetoads in March.-Vernal greeting from the pines. Clicking cones. Hygrometric hocus-pocus of pine-cone. - The squirrel as a botany teacher. Spiral arrangement of cone-scales. - Spring blossoms: azant-courrières among the wild flowers. Blossoms under snow. Poetical allusions.-Quickening seeds. Clover infants, beech babies, and maples in swaddling-clothes. "Great oaks from little acorns grow." Masquerade of the maple-seeds. - A butterfly serenade: musical wings of the "yellow-edge." Caterpillar swarms of Antiopa.A rosy-winged rattling locust and his agile emerald companion of the spring woods. - A water-fairy: filmy opalescent sylph of the snow-pools. - Birds of April. The poets' harbingers. Bird songs in onomatopœia. The grackles' "clatterin'." The "partridge" and his mysterious "drum." Authorities at odds.-Our loftiest weed. Its beautiful pith. A tall story.-The hay-fever reprobate.-Tenacious oak-leaves defiant of winter storms. - A prehistoric potter; earthen jugs of the vase-maker wasp and their lively contents. - Unfolding buds. Vernal tints in the bourgeoning woods. A poetical bit of mirrored truth. Winter-bud secrets. Beautiful designs in buds. The autumn dogwood bud and its botanical lesson. - A flower that is not a flower.-The toad and his bagpipe. Drowsy drool of the twilight marshes. A frog-song mimic. Mimicry of toad song. A very homely singer. Southern frog music extraordinary. A Japanese frog trio.-May-apples and false May-apples. Dr. Gray's " pigs and boys." The mandrake May-apple described. The sivamp-pink apple and its mission. A poison May-apple.-A blossom in masquerade; 
the flower with a scarlet cloak.-The well-kept secret of the flowering wintergreen, or polygala; anchor flowers underground. - The dwarf ginseng and its sweet "ground-nut." - Bewitched cocoons; Polyphemus and Cecropia cocoons packed full of mischief. A spurious brood: "ugly wasps" instead of beautiful moths. The witch at work. A pulpit theme. - Life under a stone. "Finds" for the naturalist. A beetle with a gun: the bombardier and his shooting propensities. "Three rounds." Utility of the demonstration.-The devil's coach-horse and his wonderful tail: a test for sharp eyes. The "lightning change artist" of the bug circus; from a buzzing fly to a wingless bug in a twinkling. How it is accomplished.-Butterflies as botany teachers. Plants classified into genera before the era of the human botanist. Remarkable botanical instincts of the black "swallow-tail." The wise Archippus and other butterflies

\section{$\tilde{y} \mathfrak{m} m \mathfrak{m e r}$}

$\mathrm{P}$

OISON -SUMACHS and the suspected Virginia creeper. Dangerous species easily distinguished. A simple "jingle" for a talisman. "Expert" advice. The harmless and libelled Ampelopsis, or woodbine, exonerated.-Awakening mummies: queer antics of burrowing chrysalids. A strange resurrection in the June woods. - A glittering-winged gem; pure gold outrivalled. A goldmine among the bind-weed leaves. - Another insect gem; glowing jewels on the dog-bane leaf; a ruby and an emerald combined.-Prize packages on the hazel-bush. A clever piece of hocus-pocus; no string, pin, nor glue. A long-headed clerk and her well-kept secret. Caught in the act at last. Precious bundles.-The scouring-grass and its wriggling spores: what a simple pocket-microscope can show us. A squirming legion. Jumping for freedon. A pretty microscopic hygroscope. - The "scouring-brush" of the Pilgrim housewives. Secret of the bright tins. A mineral frame in a vegetable stalk. A tube of flinty silex which defies nitric acid. Beautiful chemical experiment. Geological significance of the plant.- "How doth the little busy bee." A complete tell-tale record of forage among the flowers. Queer fruits from the bee's "basket." Epicurean and other fodder for bee-babes; melons, tea-boxes, oranges, bombshells, and pepper-boxes. Pollen eccentricities. A pollen flytrap in a milk-weed blossom, and a decorated victim. - Butterfly-net entertainment; harvest of a few sweeps among the herbage. Revelations of the life that peoples the grass. Insects extraordinary.-A midnight walk and its surprises: sleepy-heads, nightcaps, drowsy fringes, and wide-awakes among flowers and leaves. Shuttlecocks on blue-bottle stems. Dew diamonds. Glittering fountain of "horse-tail" plant. The tearful jewel-weed. Titania and the gossamers. - A little known bird-song. The yellow-winged sparrow and its grasshopper music. The meadow grasshopper and its song.- The well-kept secret of the evening primrose. The flowers by daylight, and what they can show us. Blossom-tents and tenants: the primrose's protégé. - The spice-bush and its big-eyed bugaboo. Mystery of that folded leaf. Rustic superstition. -Musical beetles. The insect orchestra and its various instruments. A doughty fiddler. A squeaky trio on the poplar branch. Musical collars. The pretty golden-rod musician.-An eccentric precentor with a double baton and a ready whip-lash. - The club-mosses and their inflammable spores: a fiery explosion in the woods. Fireworks at home. "The rocket's red glare."- 
Vagabond seeds. Gypsy weeds : the beggar-ticks, clot-burrs, and stick-seeds of the woods and road-side. A "rogue's gallery" on one's coat-sleeve. A few tramps identified. A veritable caltrop. - Remarkable "spider's nest" in an old dress. "I "Dead" spiders in a wasp-nest. The mud-dauber and her ways. The lump of mud on the rafters, and its singular contents. A hypodermic injection and a merciful sleep. - The talking fly; his conversation and practice. - Another underground flower and its little hairy peanut. Flowers for show and flowers for use; a singular freak of a common wild vine. - A bowerbuilding caterpillar. A petal-tent among the everlasting flowers, and what it may contain: a testimony from the immortelles.-Ballooning seeds. Buoyant winged fruits with all sorts of wings and parachutes. Milk-weed and thistle pompons for little girls. A botany lesson in a cobweb. The brownie dustbrushes of the silky groundsel-tree . . . . . . . Pages 89-I74

\section{Eิıt $\mathfrak{m} \mathfrak{n}$}

TIIE "fairy ring" mushroom and its compass. Fastidious growth of fungi.-A queer "bumblebee" and a queer letter. A Bombus that catches "horsethies." "Caught in the act." A test for sharp eyes. Some entomological dissertations on flies and bees for the benefit of a rustic naturalist. A carnivorous fly in masquerade.-How to handle a wasp: the secret exposed. IVasps roiled in the fingers without danger. Popular traditions disposed of. A repentant experimentalist. An important "spell" which must at least be memorized. Wasps and wasps. A valuable and suggestive postscript. - Wonders of the fungus. Spore dust. Appalling potential possibilities in a single puffball. Whimsical choice in toadstools and mushrooms. Moulds and mildews. Fairy parasols and mimic birds' nests. A chrysalis and a caterpillar changed into fungus plants, and a queer bundle from the Chinese apothecaries' shop. - Autumn pipers: whistling tree-frogs, toads, and salamanders. The spring peepers among the trees. The brown dead leaves and their own frog. A "lizard" with the voice of a bird. - A murderous burdock and its pinioned chickadee. Puzzling cocoon clusters on grass stems. Nature's " Jack-in-the-box." The "Jack" abroad, and its victim. The cocoon mystery revealed: a resurrection not planned by the caterpillar, and an episode referred to pulpit philosophers.-Witch-hazel witchery. A fusillade from ten thousand double-barrelled guns in the October copse. The gun described.-The salute from the violet. Seed-showers shot from violet pods. Violet blossoms for the world in April, and others for mother earth in October. A violet freak. - A bewitched willow bud: a cone which is not honestly come by. Why the willow has no right to a cone. A magician with a wonder-working sharp-pointed wand. What the chickadee knows about willow-cones. Other witchery among the twigs. A big family housed on a blackberry stem. - The frost-flower. Flowers of three kinds on a common plant, only one of which is generally seen: a showy flower with petals, a flower with no petals, and a flower of ice crystal prettier than either. - Birds of November. November bird songs and birds of passage. Snow-birds and buntings and "kinglets."-The ash-tree and its rustling seeds. The remarkable "paddle," a prehistoric hint of the "oar" in model and timber. Association of the ash and the birch in nature and art. The Indian canoe and the arrowhead model. - Among the birds' nests. Whimsical choice of building materials. The vireo's "sampler" fabric; cobwebs, seeds, caterpillar-skins, hor- 
net-nest, lace, horse-hair, and snake-skins. " Politician" and " preacher." A Scripture text from a " preacher's" nest. A few particular whims in building material.-A snake-skin specialist. The bed of snake-skins in the hollow tree. Suggestive cherry-pits in a deserted nest.-Autumn's lingering wild flowers. November's bouauet. November's own flower. The luminous witchhazel copse. - A calendar garland of dandelions. The perennial chickweed and its winter blooms. A blossoming conservatory in a filmy ice grotto.-A winter bird's-nest. A summer bird-home newly furnished as a snug winter resort. The field-mouse nursery. - The most marvellous drill in the world. A horse-hair gimlet. Ichneumon fly specimens in the winter woods. How and why the drill is manipulated. A rival borer its victim. "Modern" inventions and patents. Infringements on prehistoric models. - Winter rosettes. Symmetrical leaf patterns under the snow. Significant arrangement of leaves . . . . . . . . . . . . . Pages 176-243

\section{vainter}

TORIES in the snow. Tell-tale records of birds and bead-eyed folk. A mouserace and a nest in a stump. Deer-mice at home.-Autograph of the wild hare. A singular discovery. How bunny writes his name. Employment for sharp eyes. - The cocoon harvest. Interesting quest for a winter walk. Artful disguise of cocoons. City specimens. - Some curious twigs in the winter woods. Witches' brooms. Bulby golden-rod. Curious eggs.-Girdler beetle and their remarkable instinct. Hickory pruning extraordinary. The pruner's plans. The well-named horse-chestnut; its " horse" discovered-hoof, fetlock, frog, seven nails, and all.-The "partridge" as a snow-walker. Bare summer feet and winter snow-shoes. Snow burrows and budding-holes. - The "fairy ring" in the snow: strange snow writings of wind-blown grass-blades. - January butterflies. Winter outing in the sunny barn-yard. The angle-wings. Hibernation of the hardy, world-wide Antiopa.-A winged shower from the tuliptree.-A snow-burrowing squirrel. The provident red squirrel and his happygo-lucky neighbor. How the gray squirrel finds his pine-cones through the deep snow. - Winter grist for the birds. Weeds redeemed. Wind-blown weed-seeds on snow. A curious windrow analyzed. - Those specks on the snow. The myriad bird-shaped scales of the snowy woods traced to their source. An innocent catkin with a trick of its own. Opening the door for the swarm.Living specks on snow. Snow-fleas and their history. Entomology and rustic tradition. - The basket-carrying caterpillar. Its puzzling cocoons. Baby basket-makers and their building whims. A patriotic specimen. Life in a hammock. "Pulling the hole in after him." The bag-worm at dinner. Moored for the winter. Strange superstition of a darkey. The queer little black moth.- House-builders under water. Interesting dwellers in every pond and stream. Stone cottages and wooden cabins of the caddis worm. A rare mosaic tube of crystal. Water-proof cement. Various building designs. What the rock-fish knows about caddis. "Around the evening lamp." The "caddis" with which we are all too familiar. A few foreign caddis houses. The whirligig water beetle. . Its mazy dance at the edge of the ice. Thoreau's observations. A winter outing. How Gyrinus "goes to bed." The dive to the depths, with its silvery bubble. Remarkable and unique dual powers of vision. "Sharp eyes" extraordinary. . . . . . . Pages 247-309 


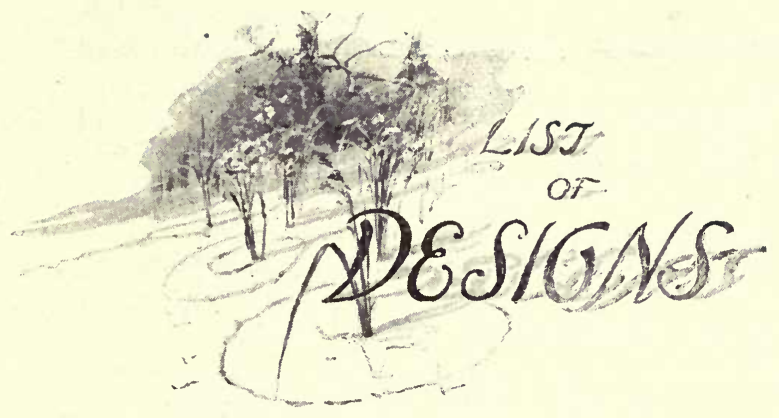

PAGE

Haunt of the Toad [see p. 53] Frontispiece The Great-eyed Snapping-beetle . vi The "Bull's-eye" Moth. Satirnia Jo . . . . . . . . . . xx “

A March Landscape . : . . . I The Calla . . . . . . . . . The Earliest Wild Flower . . . 3 Maple-seed Antics . . . . . . 4 A Wintry Bit .

A Spring Morning .

Peeping Frogs--Cricket and Pickering Frog .

A Spring Soloist . . . . . . . II

The Spring Peeper in October . . I2

Clicking Pine-cones . . . . . I4

Jumping Cones . . . . . . . I5

A Cone in its Bed of Seeds . . . I6

Squirrel and Cone . . . . . I8

"By the snow-bank's edges cold"

Anemone Nemorosa, Claytonia, and Whitlow-grass .
A Nook in the Woods-Dutchman'sbreeches, Rue-anemones, Iiverworts, and Early Everlasting . . 23 "Squirrel Corn" . . . . . . 24 A Maple-seed Masquerade . . 25 Sprouting Acorns . . . . . 26

3 Beech Babes and Clover Infants . 28

4 Antiopa Butterflies . . . . . 30

5 Musical Wing of Antiopa . . . . 3I

Antiopa Caterpillars . . . . . 32 The "Coral-wing" Locust . . . 35

The Fairy Shrimp . . . . . . 37 The Grackles . . . . . . . 38 The Brown Thrasher . . . . 39 The "Drummer" . . . . . 40 The Meadow Lark . . . . . . 4I The Great Ragweed . . . . . 43 The Small Ragweed . . . . . 44 I9 Tenacious Oak-leaves . . . . 45 A Prehistoric Vase-maker . . . . 46 2 I Tail-piece . . . . . . . 47 
Opening Buds-Linden, Horsechestnut, and Hickory . . . . $4^{8}$

The Dogwood Flower, from Bud to Bloom

Puss Willows .

5 I

The Toad and his Bagpipe . . . 53

Toy "Locust" . . . . . . . 54

A Japanese Frog Trio . . . . . 56

Azalea May-apple . . . . . 57

May Woods . . . . . . 58

Mandrake May-apple . . . . 59

False May-apple. . . . . . 60

The "Painted-cup" . . . . .6I

A Meadow Glimpse.

62

The Fringed Polygala . . . . . 63

Tail-piece .

64

The Ground-nut Ginseng .

Edge of the Woods . . . . . 66

Polyphemus Moth and Cocoons.

66

A Bewitched Cocoon

67

68

A Spurious Brood from a Cocoon

69

The Ichneumon at Work . . . 70

The Bombardier Beetle . . . 74

Among the Weeds . . . . 75

A Grassy Wood-road

76

The Devil's Coach-horse . . . 78

The Crusader Beetle . . . . 79

The Asterias Butterfly. . . . . 80

Butterfly Hunters . . . . . . 8I

Asterias Caterpillar . . . . . 83

Archippus Butterfly and Haunt . . 84

The Milk-weed Caterpillar . . 85

Tail-piece . . . . . . . . . 86

Poison-sumach . . . . . . . 89

Poison-ivy . . . . . . . . . 9I

White Berries of Poison-sumach . 93

Leaf of the Virginia Creeper . . . 95

Awakening Mummies . . . . 97

Dryocampa Moth

97
98

The Gold Beetle

Wild Bind-weed . . . . . 100

A Country Road . . . . . . IOI

Dog-bane. . . . . . . . . IO2

Dog-bane Beetle . . . . . . I03

Hazel Packet-roller at Work . . I04

Hazel Packets . . . . . . . I06

The River-bank . . . . . 107

Scouring-grass . . . . . . . I09

The Stone Skeleton of the Scour-

ing-grass . . . . . . . . II

Scouring-grass Brush . . . . III

Nasturtiums . . . . . . . II2

Bees at Home . . . . . . II3

Varieties of Pollen . . . . . . II5

A Victim of Milk-weed Pollen . . I 6

A Grassy Road . . . . . . . 117

Insects from the Sweep-net . . II8

A Pocket Magnifier . . . . . I20

Night-flowering Catchfly . . . I2I

A Midnight Walk . . . . . 123

Horse-tail Plant in the Dew . . I24

Blue-bottles by Day and Night . . I25

Dew Diamonds of Jewel-weed . . I27

A Summer Meadow . . . . I 128

The Yellow-winged Sparrow . . I 29

Haunt of the Sparrow . . . 130

The Meadow Grasshopper . . . 13I

Spice-bush with Folded Leaves - 133

Caterpillar of the Spice-bush . . I34

The Protégé of the Evening Prim-

rose . . . . . . . . . I35

Evening Primrose . . . . . 136

The Evening Primrose Moth . . I37

The Fiddling Beetle (Prionus). . 138

Musical Beetles (Saperda) . . . I40

Zebra Beetle (Clytus) . . . . . I4I

A Titillator . . .. . . . . $\mathrm{I}_{42}$

Caterpillar of Puss Moth . . . I44 
Tail-piece . . . . . . I45

Club-mosses .

Explosive Spores of Club-moss .

The Rocket's Red Glare . .

Seed Tramps (Bidens)

Stick-seed Plants in the Woods .

Too familiar Seeds.

A Landscape Note

The broken "Spider Nest".

Web of the Yellow Argiope Spider

Mud-wasp Nests in Garret

The Carnivorous Fly . .

A Sketching Nook.

The Wild Bean Vine

Wild Bean Pods, from Above and

Below Ground

The Petal-nest of the Hunter's Butterfly

Winged Seeds-Cat-tail and Thistle

Ballooning Seeds

Seed-tufts of the Groundsel-tree

The Fairy Ring Mushroom .

A Mimic Bumblebee (Laphria fly).

A Country Road

The Brown Wasp

Nest of the Polistes

Wasp Drones and Neuters on Golden-rod .

Meadow Landscape

The Chestnut-burr Fungus

Fairy Parasols

The Chrysalis Fungus

A Chinese Fungus Bundle

Autumn Landscape

The Tree-toad (Hyla versicolor)

The Burdock as a Bird-trap .

Parasitic Cocoons on Grass-stem
The Ichneumon Fly and its Victim 200

Tail-piece . . . . . . . 201

Witch-hazel Catapults . . . . 203

Jack in the Box. . . . . . . 204

Violet Pod expelling Seeds . . . 205

Handleaf Violet (Viola cucullata) . 206

The Willow-cone Gall . . . 207

The Blackberry-stem Gall . . . 209

The Frost-weed, Flower and Au-

tumn Crystal . . . . . . . 210

November Birds - Snow - bunting and Kinglet . . . . . . . 214

Paddle-seeds of Ash . . . . . 216

Birch and Canoe . . . . . 217

Birch-leaf and Arrow-head . . . 218

Bird-nest Remnants . . . . . 2 I9

I67 A Vireo's Nest . . . . . . . 220

The "Preacher's" Text . . . . 222

169 The Snake-skin in the Grass . . 225

Witch-hazel Blossoms . . . . . 226

I7I Dandelion . . . . . . . . 228

I73 Chickweed . . . . . . . . 229

I74 A Mouse Nest on Smilax Spray . 230

I78 Feathers for the Nest . . . . 23I

I8I A Winter Snuggery . . . . . 232

I82 Mouse-work . . . . . . . . 233

183 Ichneumon Flies (Thalessa luna-

I84 tor $)$. . . . . . . . . . 235

The Fly on the Wing . . . . . 236

I85 The Pigeon Tremex (Tremex co-

I86 lumba). . . . . . . . 237

I88 A Pair of Pincers . . . . . . 239

I89 Winter Rosette of the Evening

Igo Primrose . . . . . . . . 240

I9I The Rosette of the Moth Mullein . 24I

I93 Pepper-grass and English Plantain

195 Rosettes . . . . . . . . 242

197 The Thistle Rosette . . . . . 243

I99 A Mouse Race . . . . . . . 247 
PAGR.

A Snow Burrower

PAGE

A Mouse Nest in old Stump . . 249

. . . 277

The Wild Hare's Autograph . . 25 I

A Raid on the Red Squirrel's

Bunny's Footprint . . . . 252

Winter Cocoons . . . . . 253

Hoard . . . . . . . . 279

Caterpillar of Cecropia Moth

Winter Weeds and Winter Birds . 28I

Cecropia Cocoon and Emerging

Moth

255

Curious Meadow-crumbs . . . 282

Seed-pods of Indian Mallow . . 283

Curious Winter Twigs . . . . $25^{8}$ Birch-seed Catkins . . . . . . 287

Spiny Rose-galls . . . . . 259 Birch Catkin-scales Magnified . . 288

The Girdler Beetle at Work . . 26r Snow-fleas . . . . . . . . 289

A Winter Glimpse . . . . . . 262 Winter Woods . . . . . . . 290

Horse-chestnut Bloom . . . . 263 Tail-piece . . . . . . . . $29 \mathrm{I}$

The Hoof, Fetlock, and Seven A Curious Swarm from a Cocoon . 292

Nails . . . . . . . . 264 Baby Basket-makers . . . . 293

The Ruffed Grouse as a Snow-

walker . . . . . . . 266

Feet of Grouse in Summer and

Winter. . . . . . . 267

. Haunt of the Caddis . . . 300

Winter Butterflies . . . . . . 27 I Caddis Cases. . . . . . . . $30 \mathrm{I}$

A Winter Outing . . . . . 272 "Around the evening lamp" . . 302

The Antiopa . . . . . . 273 Foreign Caddis Houses . . . 303

The Tree-tulip . . . . . . 274 Whirligig Beetles . . . . . 305

The Seed-shower from the Tulip- The Betlle Diving with Bubble 307

tree . . . . . . . . 275 The Sharp-eyed Gyrinus . . . 308

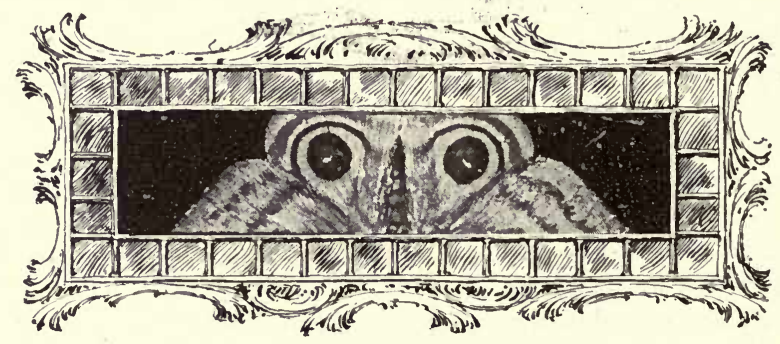




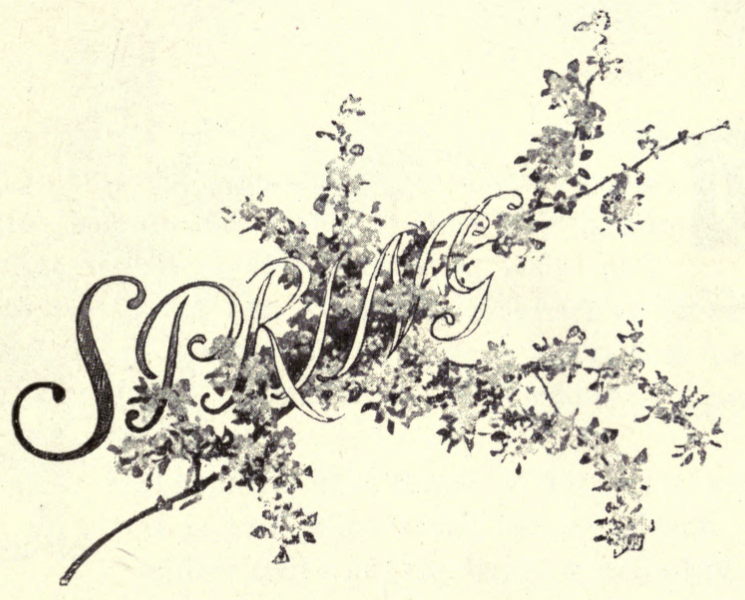



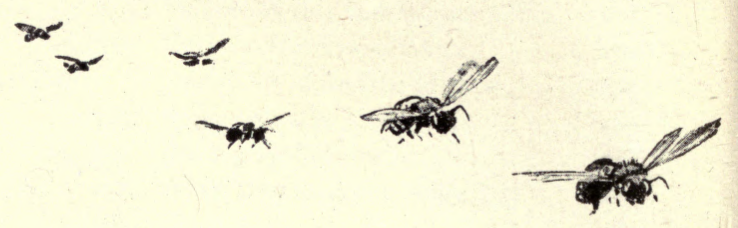

"HOSE who are really awake to the sights and sounds robich the procession of the months offers them, find endless entertainment and instruction. Yet there are great multitudes who are present at as many as threescore and ten performances, without ever really looking at the scenery, or listening to the music, or observing the chief actors. "-D.W. HoLmes. 
trunk of a sugar-maple, while an eager brood have sought the wood-pile, crowding each other in their eager tipple from the sweet fermented exudation on the end of the white-birch log.

But they are not all to be found here. Even as we watch the gathering swarm at the birch-log feast a newcomer speeds swiftly past our ear with an especially eager hum. There is no loitering at the wood-pile this time. Over the barn-yard and garden, and across the white field beyond, we can readily trace its flight until lost in the twiggy mist of the swamp beyond. Another and another follow in its trail, and if we choose to wait and watch with patience we may soon witness the returning procession, each winged forager with his saddle-bags overflowing with golden grist. What a vision of summer in those rounded yellow thighs! Blossoms?

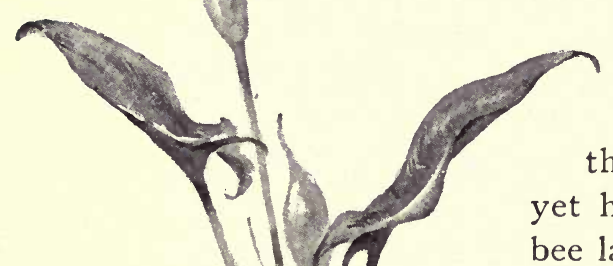
Blossoms? But where? The ground is covered with snow, and flaky ice incrusts the borders of the pools, and yet here is our veritable summer bee laying up its store of pollen. It is now some weeks before the wood bouquet of anemones and bloodroots may be sought with confidence, but the honey-bee knows where to find a pioneer blossom that is fast going to seed when these wood blooms first show their faces. Even to us who know the bee's secret, how often does he give us the hint 
for the search in the bog before we had thought of a courier of spring? No matter, then, how cold or wintry the landscape, go now in early March to the wet lowlands, and get your first vernal greeting from the lowly hermit of the bog. Welcome the prophet that pierces the snow, the pioneer that lifts the barriers of ice to tell us of the message he has received from mother-earth, long before the wood flower hears it in the south wind, or the lisp of the bluebird tells it to the trees! What matters it that our purple-mottled, hooded blossom is not graced with perfume nor blest with a poetic name? What though it may not appear to advantage in a button-hole? The skunk-cabbage hood is as much entitled to the name of flower as its close relative the beautiful calla, while the naturalized European bees have long welcomed it to their posy, and recognized the humble "prophet not without honor save in its own country."

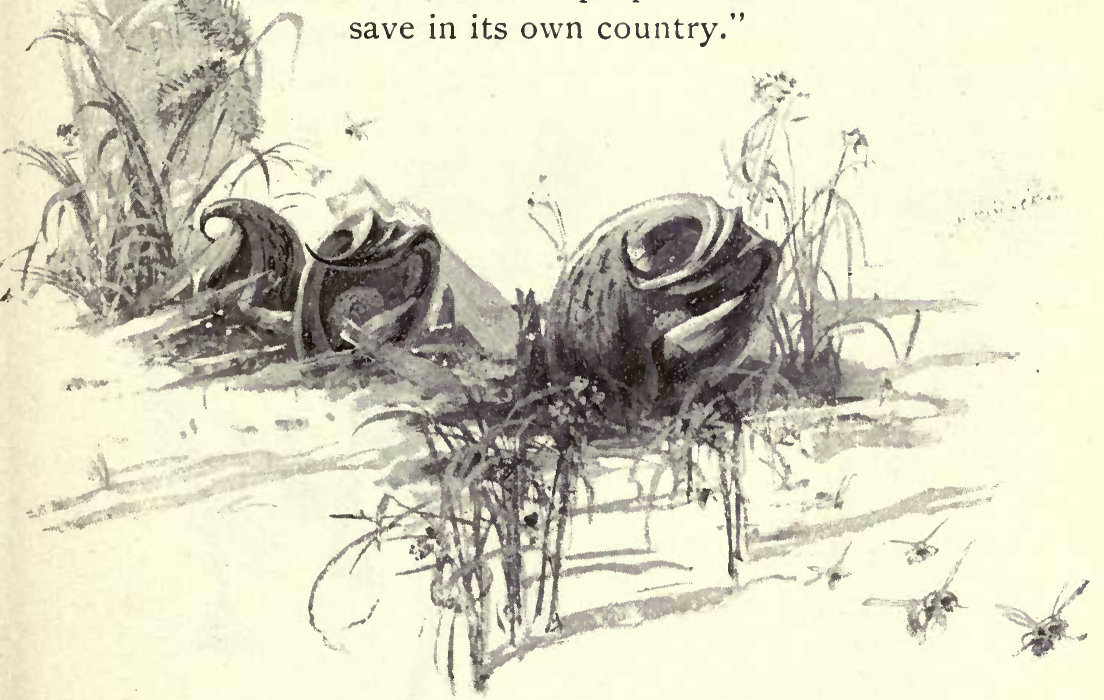




\section{MAPLE-SEED REVELS}

March'roth

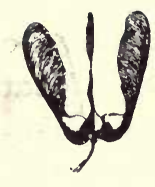

HAT a universal expression of joyous anticipation, what murmurings of gladness might we not perceive in the air during the next few weeks were our human senses sufficiently delicate and inspired! What breathings from unfolding catkins of alder and willow, and from swelling buds everywhere! What tidings from the myriad quickening seeds down against the sod! Only here and there an occasional individual more conspicuous than the rest tells the story of the universal rejoicing. Here is

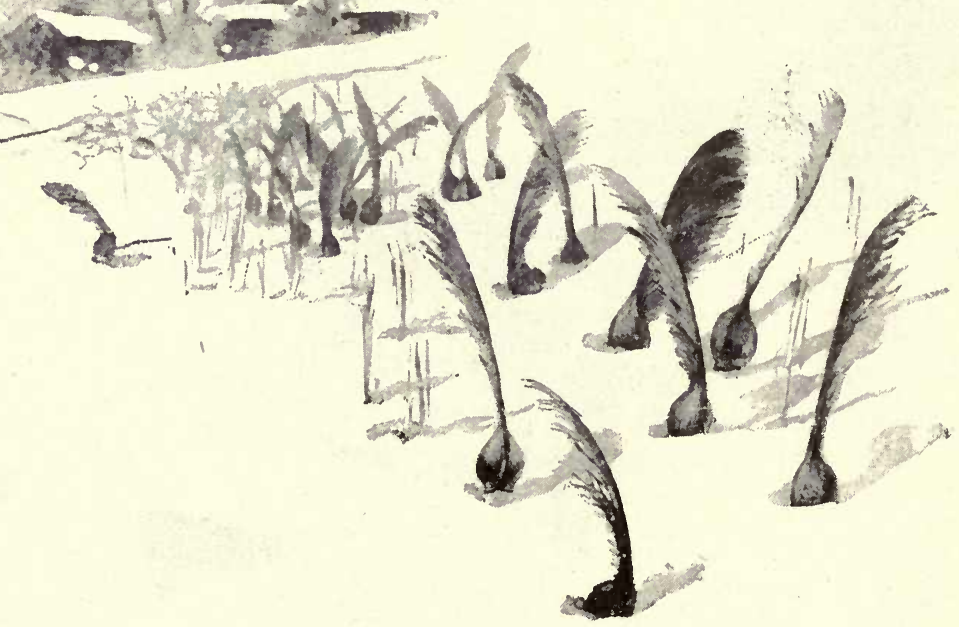


this dancing party of maple samaras on the snowy lawn, for instance. Is this an exhibition of mere botanical germination, a simple seed that has sent out its baby root into the soil, and in so doing has been obliged to take this singular position? Is it not as truly an allegory of the universal rapture of nature in this season of new birth and awakening which is now at hand? No; these are not mere maple seeds that have felt the quickening power of the south wind, but a troop of happy children literally standing on their heads in glee. What thoughts are brewing in those heads, with their fur-lined caps? What deep plans for a future maple grove out there upon the lawn?

Every spring their legions repeat these same expressive revels, and yet it is only as we chance to see them relieved against a late March or April snow that we ever know of their pretty antics here in the grass.

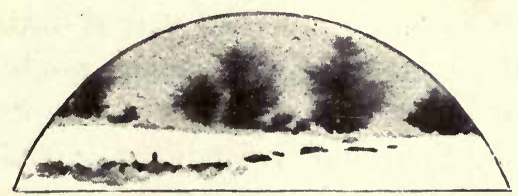




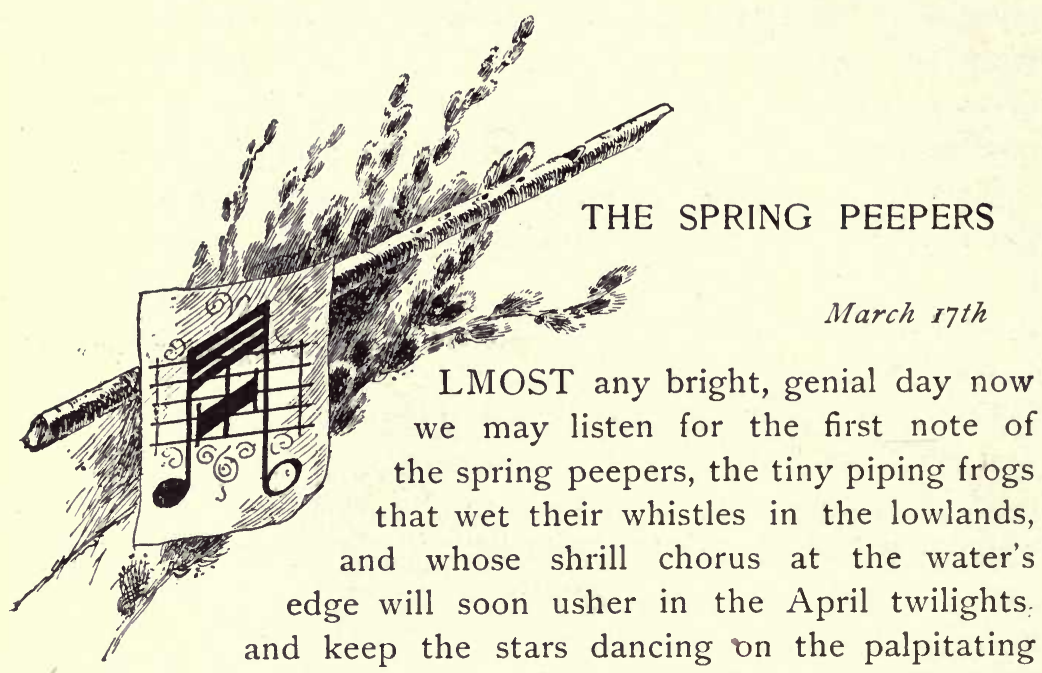
ripples until the dawn. What would our New England spring be without this faithful music from the bog? How many of our sweet-voiced vernal birds, the favorite theme of so many of our poets, might not listen with profit at the swelling throat of the little Hylodes, whose pure strains have voiced the advent of spring without the tribute of a sonnet, or even an appreciative quatrain - $\mathrm{a}$ voice in the wilderness, so far as any worthy recognition in poetic literature can show! Truly has Burroughs said that in Europe, where this swamp music is unknown, such a chorus as that which goes up from our ponds and marshes would certainly have made an impression on the literature.

There are a number of these sprightly piping frogs 


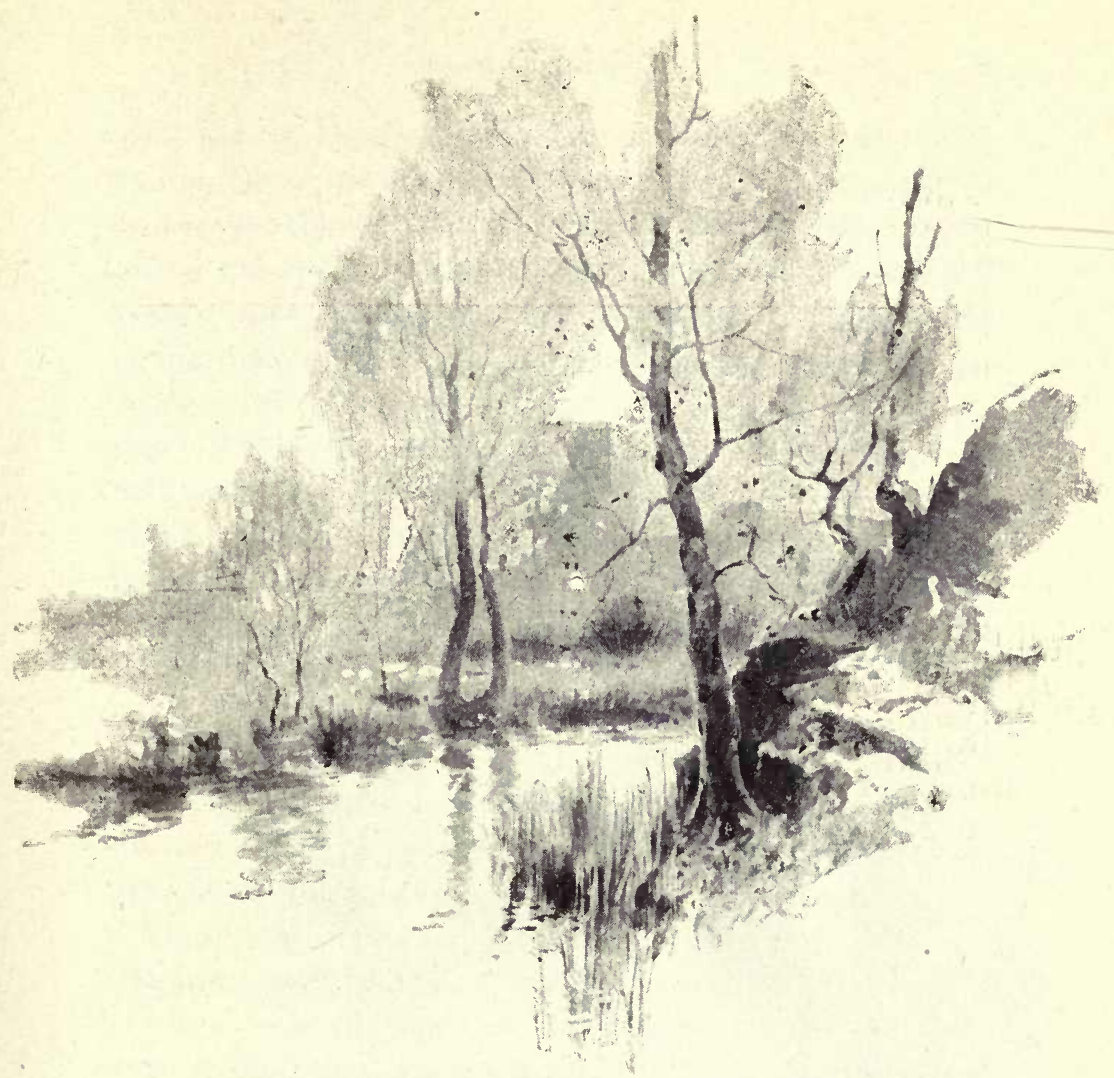

and spring croakers which take to the water-or rise from the mud-even before the ice has melted, each successively filling with music the brief period of its nuptial season, during which the pellucid eggs are deposited in the shallows. But the first voice that now breaks the winter silence, and gives the key-note to the choir which soon shall follow, is pretty sure to be that of the Hylodes, whose bird-like whistle is well known to every dweller in the country, even though the identity of the singer has been a life-long mystery.

Perhaps this first isolated "peep" is borne to us 
across the withered rushes or cat-tails as we skirt the borders of the swamp, or perhaps. from some hollow nook in the woods, where the melting of a snow-drift has left a glassy pool among the leaves, or even from some boggy bay at the brink of the stream-"phee, phee, phee, phee" -ut-

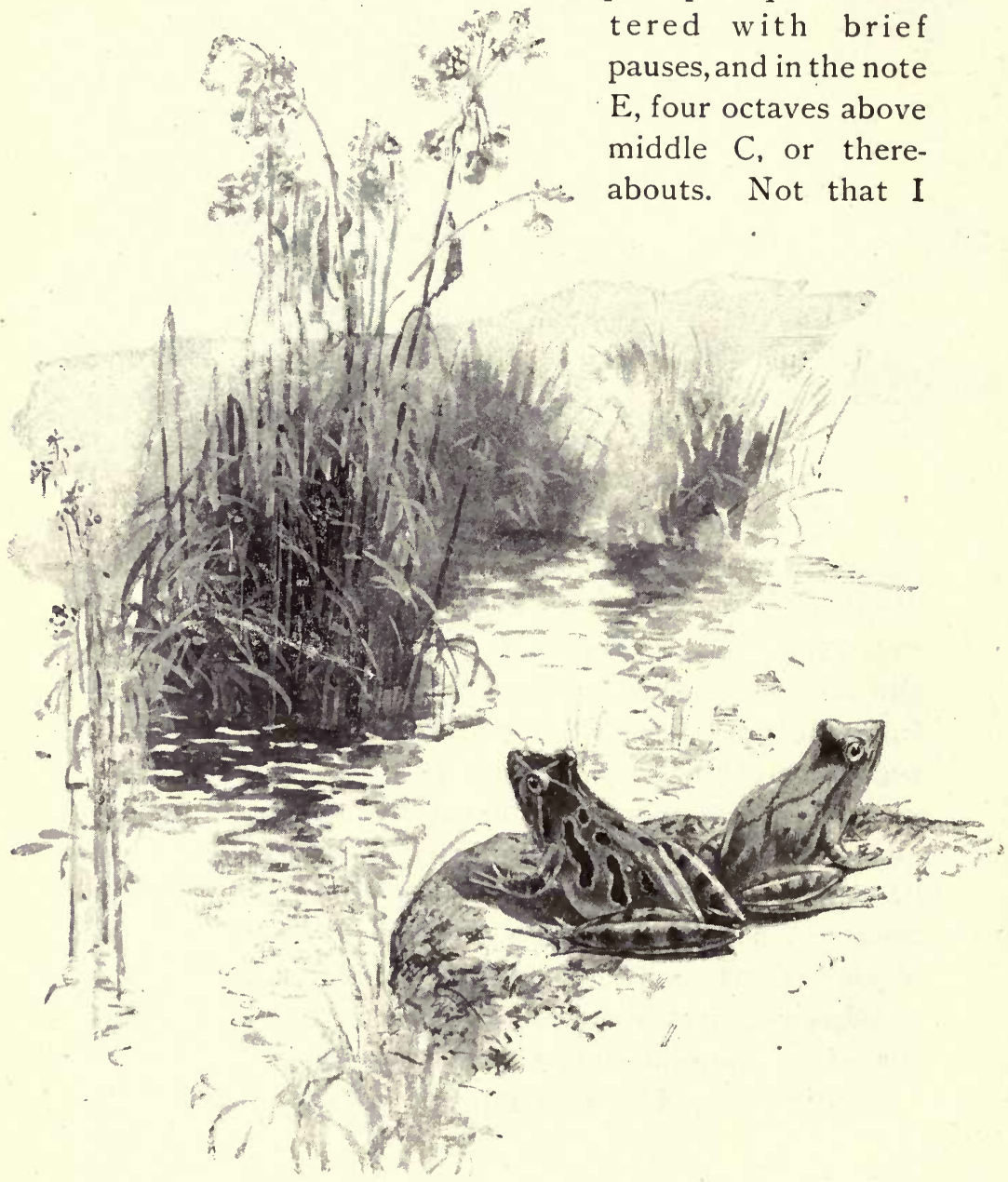


have ever stood in the bog, with a tuning-fork in hand, to test the matter scientifically, but in my frequent effort to mimic the pure, shrill tone with my own inadequate whistle, an effort which, patiently continued, has more than once evoked a lively response from a suspicious though silent pool in the spring woods, I have discovered that no pucker of mine can quite produce the pitch of this fine water whistle of the Hylodes, or Pickering's frog. He is usually from one to three notes above me, while in the matter of quality he leaves me far behind. Thus the limit of my whistle is C, while the peep of the Pickering's frog begins at $\mathrm{E}$ above, as I now recall it, the crescendo being given on $F$. This seems to be the approximate key of the vernal song. What influence the peculiar exuberance of the season may exert on that impassioned voice I know not, but I do know that the mysterious peep which I occasionally hear from the autumn trees-for our Pickering's frog is a "tree-toad" at this season-never seems to possess the peculiar spring quality.

I have said that he wets his whistle. Let us see. For even though we approach near enough to get a good look at the singer, it would probably be difficult to identify him from the pointed nose and the two tiny bulging eyes that are all he permits to be seen above the water; nor even these for long, unless we are very wary.

But we are safe in assuming that we have heard the Hylodes, probably Hylodes Pickeringi; or, if not, we have needlessly confounded him with another related singer, the cricket-frog-Hylodes gryllus of the earlier naturalists, but now designated by Baird as Acris crepitans, and popularly known as the "Savannah cricket." These are the two rival marsh peepers, and it is a "toss 
up" which you shall chance to hear first in your late winter rambles; and if they are ever to be satisfactorily fixed in the memory by their songs, it must be at this season, when an isolated solo is among the possibilities. In the teeming din of the April chorus their disentanglement is a hopeless task. But the "cricket," with his shrill rattling pipe, easily plays the second whistle, and there is not the slightest reason for confounding it with that of the Hylodes. The pure, unbroken tone is from the yellow throat of the Pickering, and when once familiarized will not be forgotten. All those other efforts which fail to meet that standard of purity may be credited to the comical little harlequin with the pretty mottled tights which I have coaxed out of the water, and placed where his pert figure can be seen, side by side with his rival. Whatever confusion there may be in the vocal identity of the two frogs, there is no confounding them when seen out of the water. The Pickering $H y$ lodes is yellowish in tone, more or less mottled with darker tints of the same, the depth of the color varying with different individuals.

What a contrast to the "cricket," with his olive-green coat splashed with black and red, and the large black spots rimmed with white upon the sides! In the water, with nothing visible but the tips of their noses and projecting eyes, and their voices alone to recommend them, the Pickering peeper has the advantage; but lie may well take a back seat on dry land when he appeals alone to the eye.

The markings of the "cricket" vary in prominence in different individuals, occasionally being almost obsolete; but they may always be found upon close examination, and are an unmistakable means of identification. 
Every one who lives in the rural districts should know these two musical messengers of the spring, and with the help of the portraits I have given they may be easily indentified. Note the diminutive size, exactly given in the illustration, neither species being more than one inch, or at most one and a half inches, long in sitting posture"crickets" indeed! Note also the peculiar disk-shaped pads

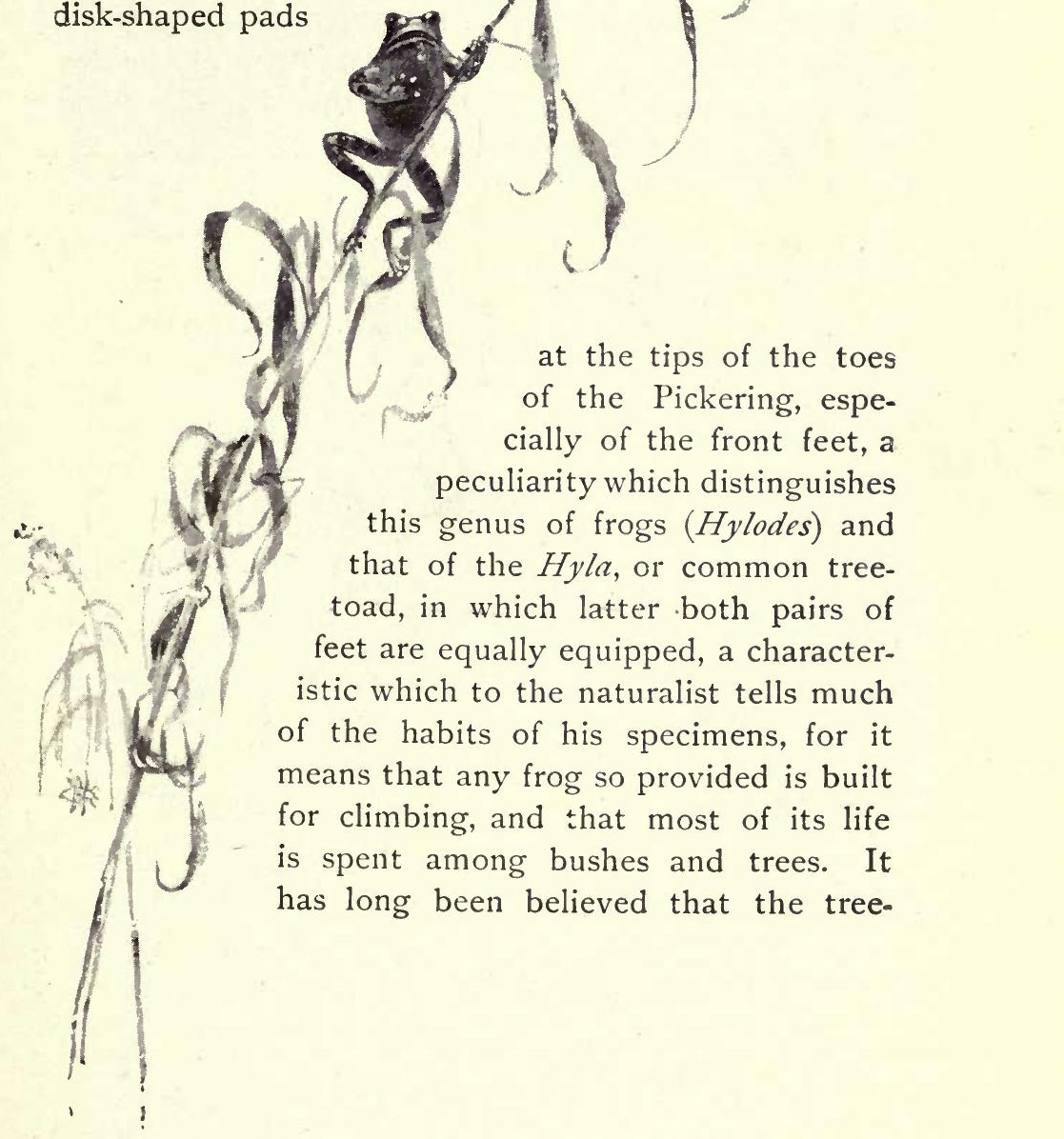


toads spend the winter, like other frogs, buried in the mud at the bottom of the ponds and marshes; but this is now discredited by many observers, who have disclosed them during the winter beneath logs, and in other places far from the water. It is true that on the first approach of spring weather they seek the pools to deposit their eggs, and this supreme function is the impulse of their universal song at this period.

The Pickering frog is the champion climber of his kind, even outvying the tree-toad, or Hyla. The shrill voice from the bog is quite as likely to proceed from some perch among the tall, withered rushes as from the rippling water, while Dr. C. C. Abbott mentions having found one of the agile peepers at the top of a tuliptree, sixty feet from the ground.

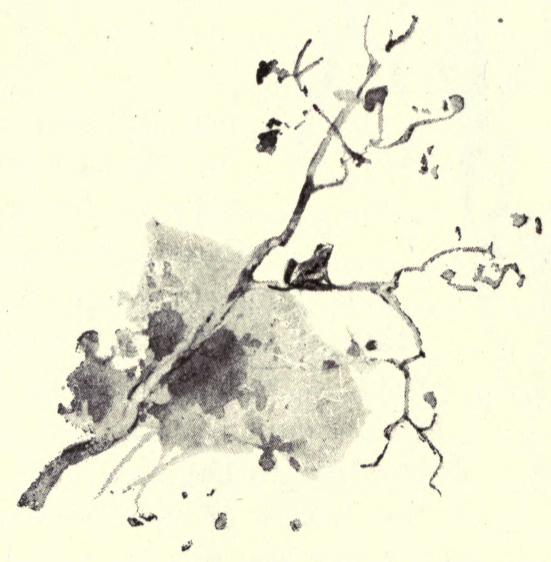




\section{THE CLICKING CONES}

\section{March 24th}
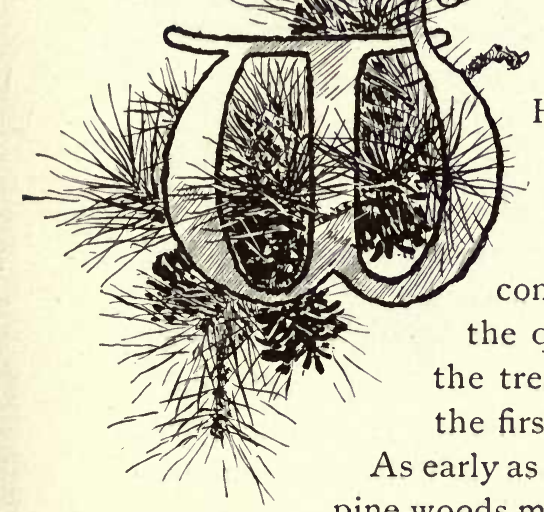

HILE the skunk-cabbage is piercing the snow in the swamp, and the maple seeds are all on end with the good news which has come to them apparently through the quickened sod, the pine-cones in the tree-tops are firing their salutes to the first spring breeze.

As early as February I have heard the pitchpine woods merry with the clicking cones, and seen the fluttering showers of winged seeds flying out upon the snow. To be sure, our botanies mention no such early ripening of the cones, the second autumn after flowering being the stated season for the opening of the scales and release of the seeds. But a pitch-pine wood in any sunny day in early spring is a merry spot nevertheless. Both the Austrian and the Scotch pines, the introduced species of our city parks, are even more lively and communicative. The sharp click of the Austrian pine-cone may be distinctly heard two hundred feet from its source, while the hubbub which we may" hear beneath a Scotch pine-tree on a warm March day sometimes amounts to a bedlam.

It is a frequent pastime with me in my winter walks 


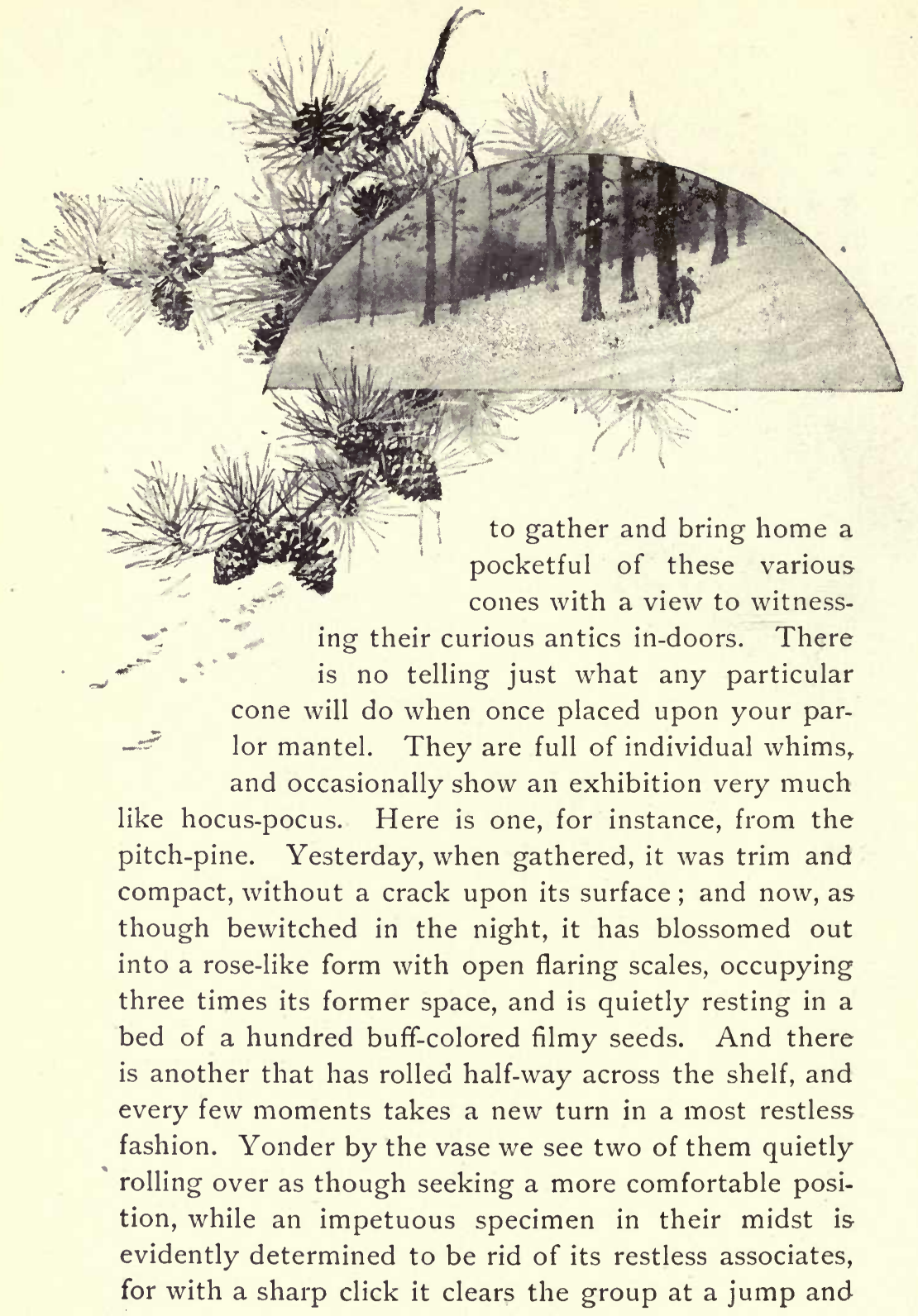



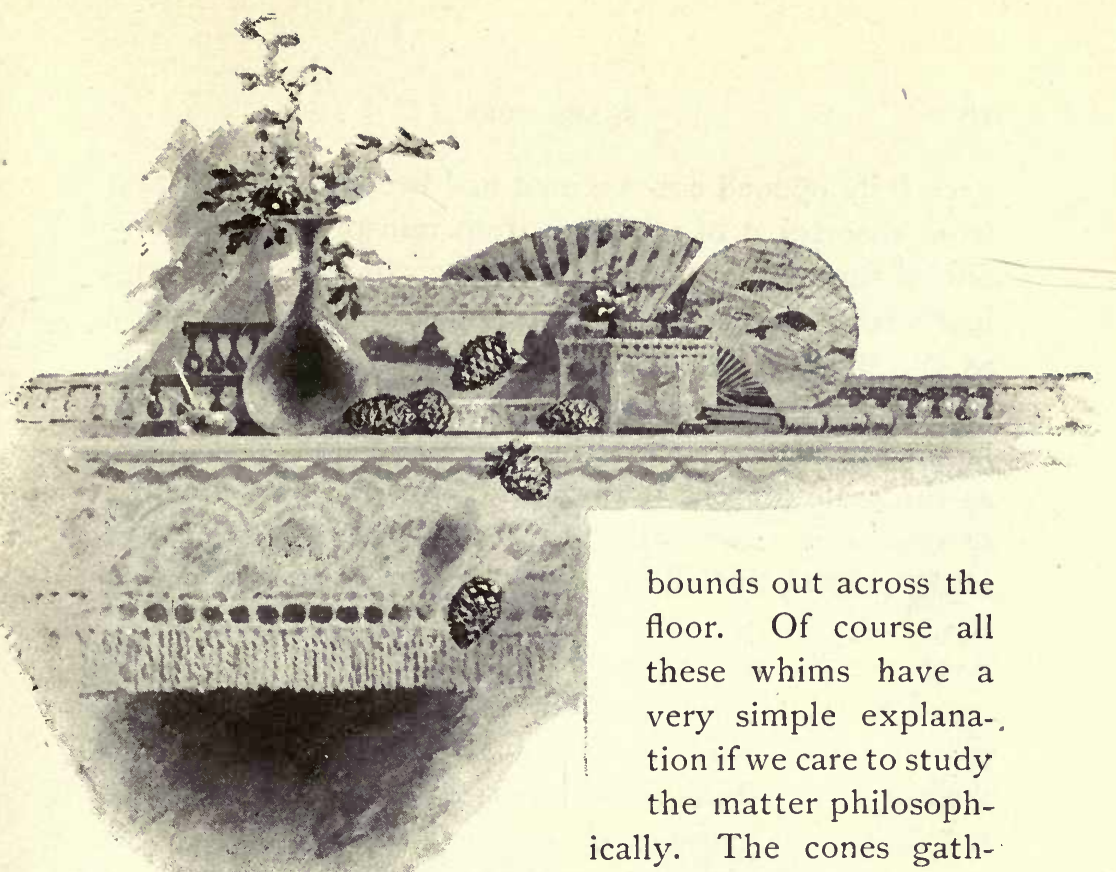

bounds out across the floor. Of course all these whims have a very simple explana-. tion if we care to study the matter philosophically. The cones gathered in early winter are usually the most demonstrative, for their scales are generally intact and so closely glued together at the surface that they are not likely to yield without something very like an explosion, especially in the artificial warmth of the house. The outward tension of these scales during the process of drying is a truly powerful force. When one of the scales becomes detached while held in the hand, it produces a smart stinging sensation, and when that springing scale chances to be on the lower side of the cone, while the same is at rest, the force is sufficient to produce a lively leap.

In the case of the rolling cones and the silent specimen with the bed of seeds, it may be inferred that the scales had been previously rent asunder-tardy ripeners of last autumn, perhaps, that failed to open sufficiently to shed their seeds. The others were doubtless 
once fully opened cones which had become closed again from absorption of moisture from rain or snow, for any one of these flaring open specimens will assume its original form if immersed in water, opening again gradually as the evaporation is more and more complete. The opening of the cone begins at the base, each scale overlapping its fellows spirally in several tiers to the apex; as the scale loosens it turns outward, and the pressure of even one scale being suddenly released, a series of clicks is likely to follow, as each one sets free its neigh. bor.

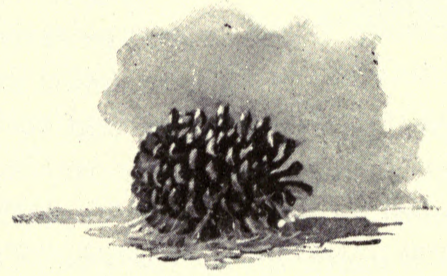




\section{THE SQUIRREL'S BOTANY}

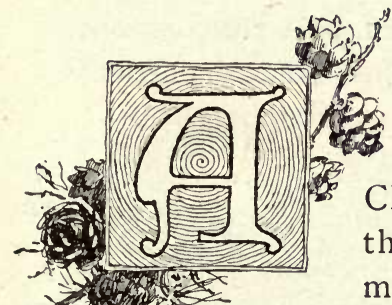

\section{LESSON}

March $: 4 t h$

CHAPTER might be written upon the beautiful symmetrical arrangement of the pine-cone scales. They are well worth careful study. The squirrel may here teach us a beautiful lesson in botany. How well he knows this spiral arrangement of the scales, and the order in which nature intended they should open!

"The squirrel has the key to this conical and spiny chest of many apartments," says Thoreau. "If you would be convinced how differently armed the squirrel is naturally for dealing with pitch-pine cones, just try to get one open with your teeth. He who extracts the seeds from a single closed cone with the aid of a knife will be constrained to confess that the squirrel earns his dinner.

"The plucking and stripping of a pine-cone is a business which he and his family understand perfectly. He does not prick his fingers, nor pitch his whiskers, nor gnaw the solid cone any more than he needs to.... He holds in his hands a solid embossed cone so hard it almost rings to the touch of his teeth. He knows better 
than to cut off the top and work his way downward, or to gnaw into the sides for three-quarters of an inch in the face of many armed [spiny] shields. He whirls it bottom upward in a twinkling, and then proceeds to cut through the thin and tender bases of the scales, and each stroke tells, laying bare at once a couple of seeds. Thus he strips it as easily as if its scales were chaff, and so rapidiy, twirling it as he advances, that you cannot tell how he does it till you drive him off, and inspect his unfinished work."

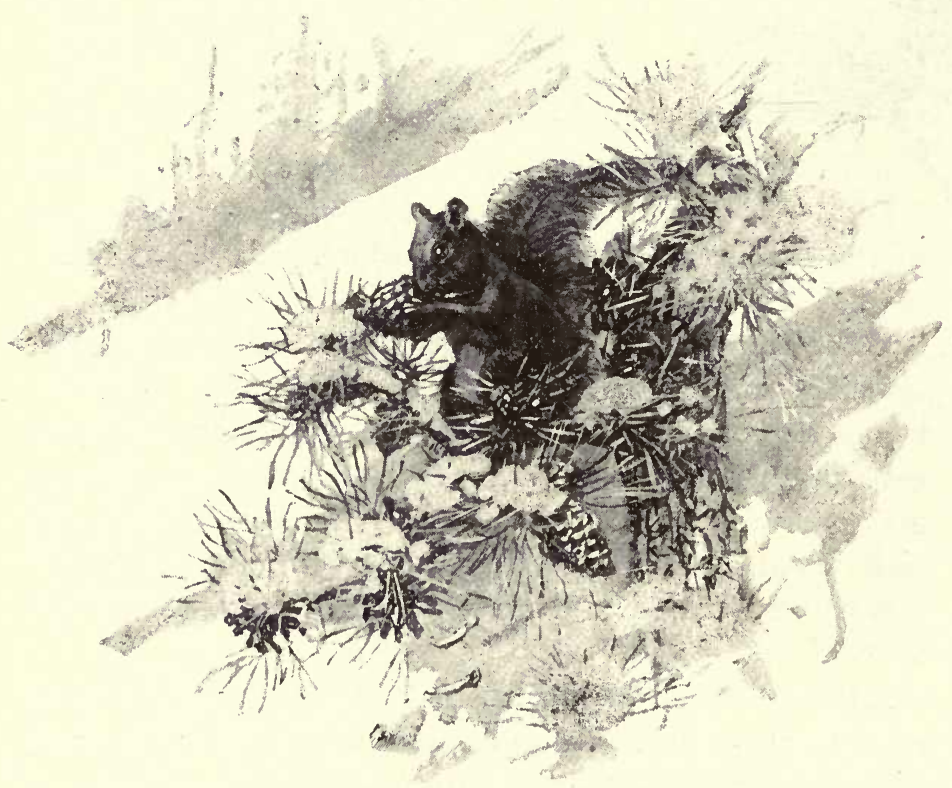




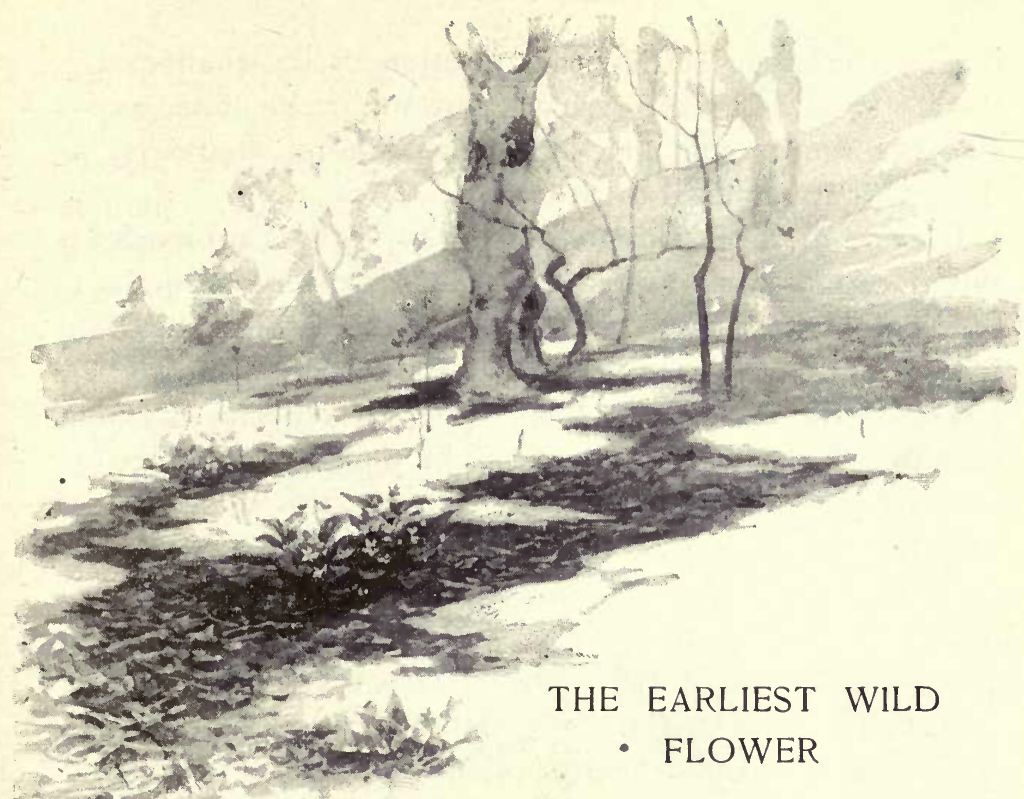

\section{THE EARLIEST WILD \\ - FLOWER}

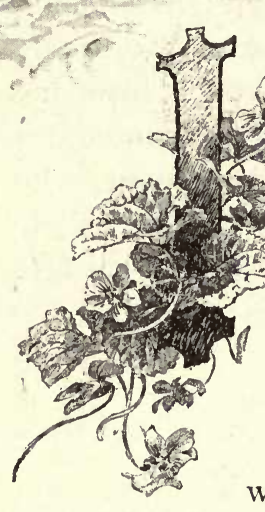

$T$ is now within a few hours of the Ist of April, and already the harbinger spring blossom has bloomed in the woods perhaps a week or more ago. What name shall we give it? What is the earliest blossom-the earliest New England blossom? True, there is the skunk-cab-

bage pioneer down in the bog, which we found some three weeks ago-though only after the bees had given us the hint and already discovered it several days in advance of us-and which has now seen its best days. But by common human consent this plebeian does not count, even though 
the bee has long settled the question of its qualifications. It is a flower, perhaps, but not a blossom, so says the sentimental fiat. Upon what fairer shoulders, then, does its mottled mantle fall?

It were a rash commentator who would approach this question idly in the face of the host of naturalists, botanists, spring poets, and "careful observers," each with his array of facts and dates and witnesses, his unimpeachable note-book, and his especial floral favorite for the vernal honors. The question has been satisfactorily decided by each of them; and by a wisdom born of experience the subject is avoided in mixed botanical councils as one prone to incite to confusion if not to riot. The dogged pertinacity and unreasonableness of the brethren on this matter are past belief. I never knew a botanist or spring poet to be convinced of his error on the subject of the earliest flower, and yet the truth of the matter is as plain as A, B, C. I long ago settled the question absolutely and irrevocably. The authorities who differ from me are all wrong. And what an array of floral candidates they have put in the field! There is Bryant, who voiced the claims of the "yellow violet," which he observed in April "blooming by the snow-bank's edges cold," and which he further apostrophizes:

"Of all her train the hands of Spring First plant thee in the watery mould."

But the yellow violet has never since fulfilled the poet's confidence. Then there's the trailing arbutus, another favorite of the poet, which has so often been found in bloom at the edge of the snow or even be- 
neath it. Bryant, in his "Twenty-seventh of March," pictures it blossoming in company with the liverwort, some days earlier in date than his yellow violet, while in his "Winter Piece" it is the "wind-flower" that heralds the spring. There are many sponsors for the Claytonia, or spring beauty, the Dutchman's-breeches (Dicentra cucullaria), the rock-
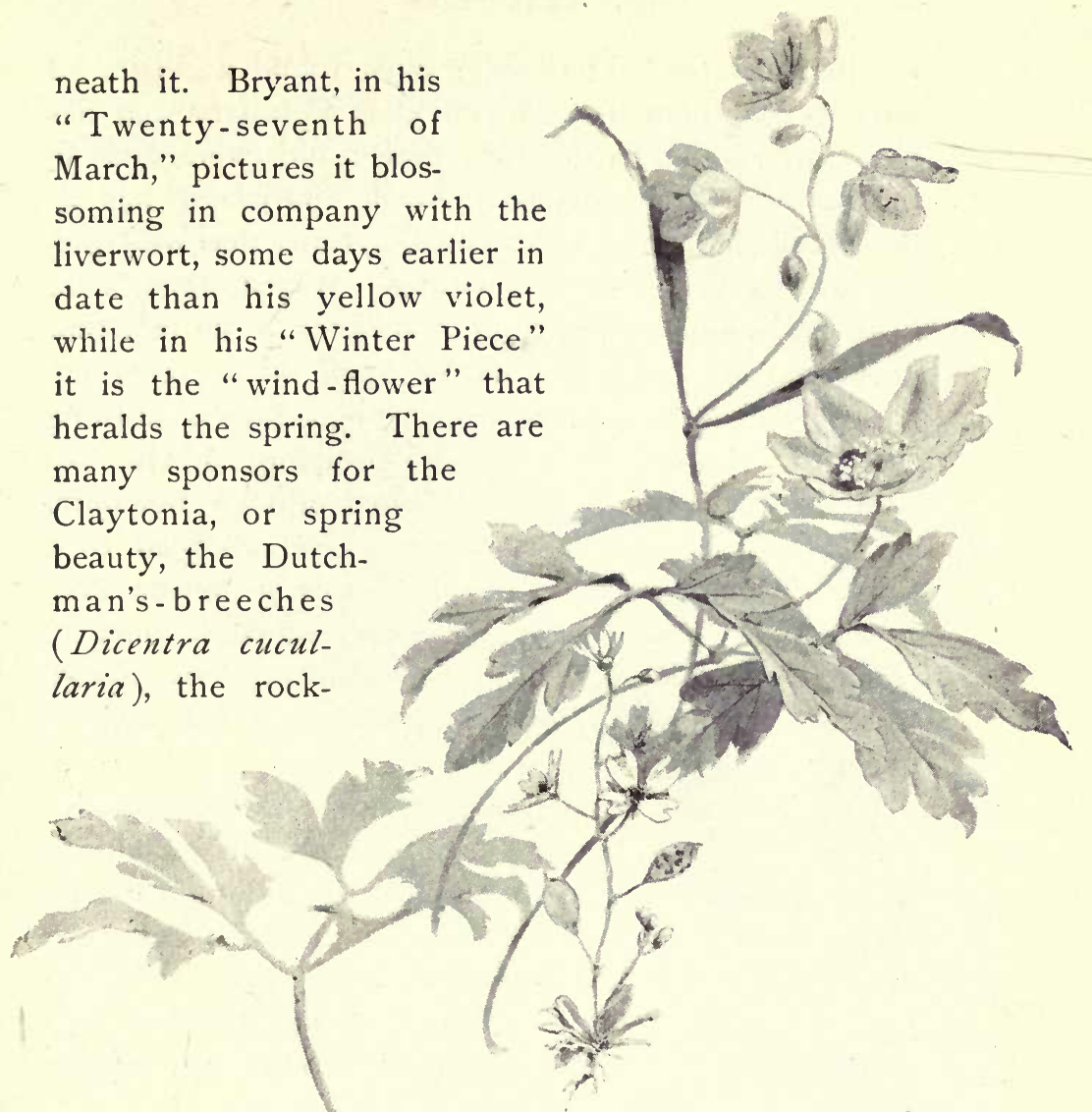

flower (Saxifraga Virginiensis), wild-ginger (Asarum Canadense), anemone ( $A$. nemorosa), rue-anemone, dwarf-everlasting (Antennaria plantaginifolia), bloodroot, and the tiny whitlow-grass (Draba verna). Many of them have been gathered in the snowy woods of March in New England, and some weeks earlier, of course, in more 
southerly States. The writer once found a cluster of arbutus in bloom in Connecticut in February, and has frequently gathered the rock-flower and everlasting in the last of March and early April. Burroughs has occasionally happened upon the Claytonia and wild-ginger as his first spring blossoms. Which, then, shall bear the honor as the avant-courriere? The fact that you discovered the arbutus on April Ist in I889, and the Claytonia a week earlier in 1890 , proves nothing as to the comparative natural chronology of the two plants. There can be no prescribed dates in our floral calendar. The test, of course, must be confined to a single season. In the year 1889 the early flowers were nearly two weeks ahead of ordinary schedule time all along the line in New England, and careful records go to show that a margin of a full month is not impossible during a long period of years.

No; it is not the yellow violet, nor the Claytonia, nor the squirrel-corn, nor the arbutus, nor the bloodroot, nor the anemones that first follow the swamp-cabbage and the silver-maple tassels; and if the rock-flower, or everlasting, or whitlow-grass, or wild-ginger surprises you in your walk in the March woods, accept it as a witness that your true quest is at hand, for they have all paid homage to the hepatica-

"whose just opened eye

Is blue as the spring heaven it gazes at, Startling the loiterer in the naked groves With unexpected beauty; for the time Of blossoms and green leaves is yet afar"-

for that "just opened eye" would doubtless have greeted you several days previous had you chanced this way. 
When I picked my arbutus in February, and when Burroughs and Dr. Abbott gathered their Claytonias - the latter in
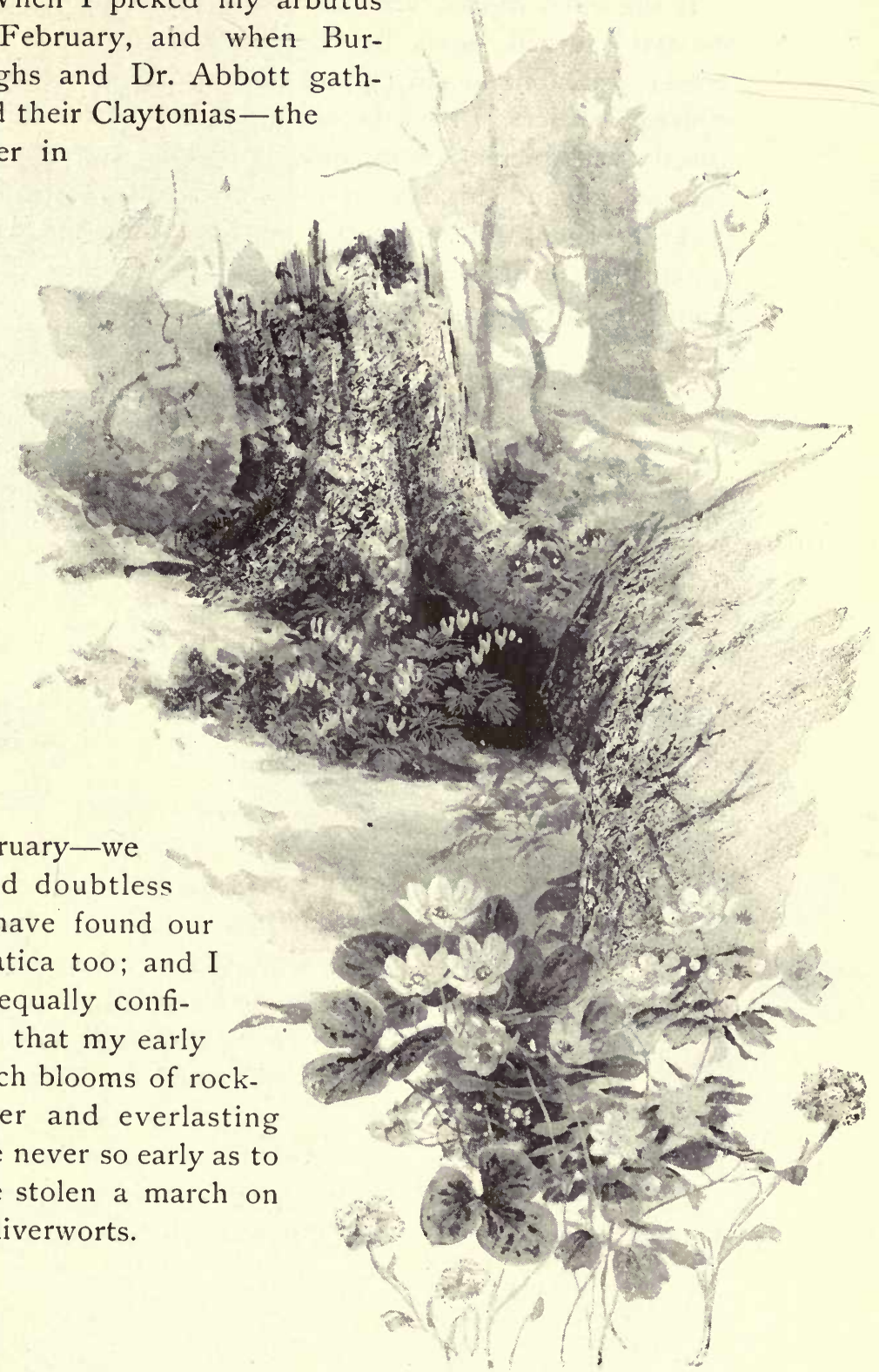

February-we

could doubtless all have found our hepatica too; and I am equally confident that my early March blooms of rockflower and everlasting were never so early as to have stolen a march on the liverworts. 
If the open winter lures any wood blossom to "open its eye," it will surely be the liverwort, even as this flower occasionally anticipates the spring in ordinary winter weather. I have before me a letter from an authority who picked them under a foot of snow on December 9 th, and this, too, in a winter not notably mild.

Truly, then, it is upon the hepatica that the variegated mantle of the swamp-cabbage flower has fallen. Look at its purple-mottled leaf and be convinced.

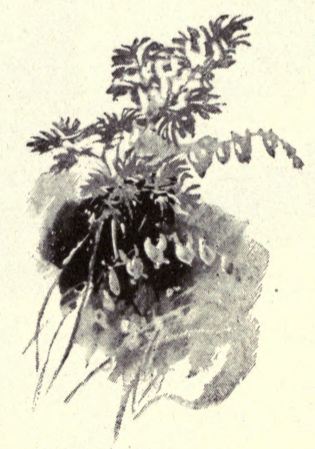




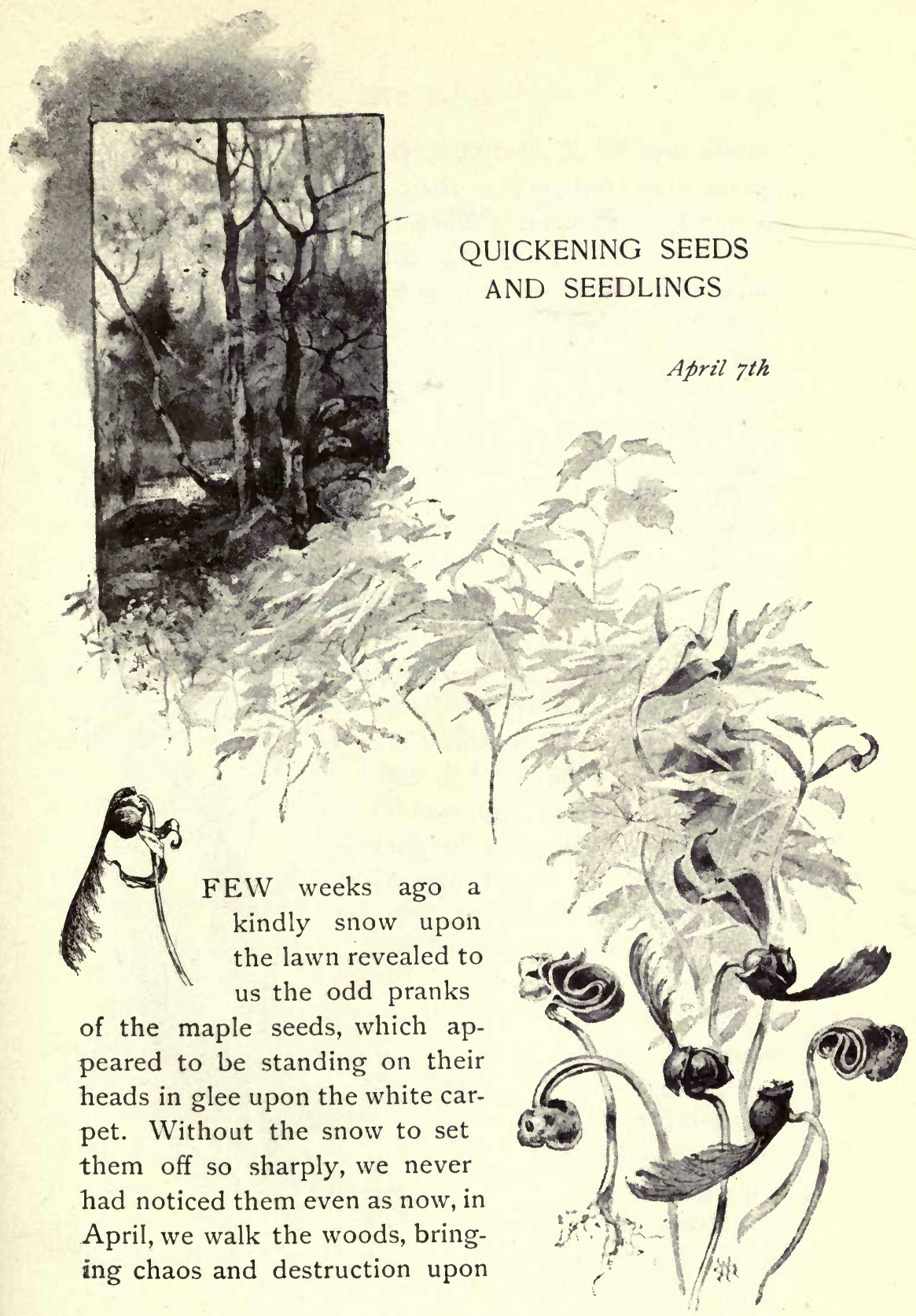


whole broods of merrymakers like themselves, though scarcely as moderate in their doings. Let us look at that maple frolic once more. How has it progressed? "On with the dance! On with the dance!" seems to have been the cry during all these weeks, until now the woods are full of their wild capers. It is no mere quiet and contained exuberance now, but a veritable bal masque, with reel and rigadoon, in which no two of the participants seem to be of the same mind in whim or costume or etiquette, while half of them have literally lost their heads, and the other half their characters, so that I fancy their own mother-tree above them would scarcely recognize the fluttering progeny that she sowed upon last summer's breeze. They are indeed a droll and whimsical lot, this troop beneath the maple-tree. Surely this pretty revelry is more than seeming. It is not easy to consider it as a mere exhibition of germinating seeds. To the poet and the philosopher it brings its most precious message. What to the botanist? Considered as mere quickening seeds, they offer many interesting facts to the student; and inasmuch as they illustrate the beautiful plan of seed-

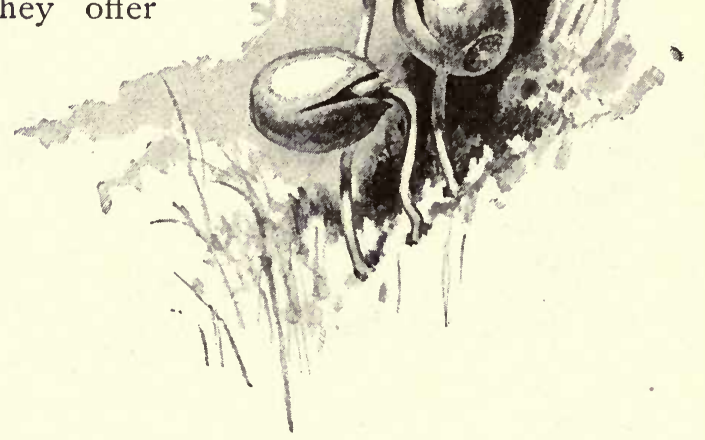


germination in general, it will repay us to learn the lesson which they teach.

Here in this single group we find the baby maples in every condition of growth, from the bursting samara standing on its head against the dry leaves, through all stages of vegetation, to the tiny tree with a half-dozen or more perfect leaves. A few of the infants still retain their telltale winged caps, and are thus easily identified; but the group contains a number of intermediate forms between this and the leafy specimens which, but for their company, would hardly be recognized. Here in the foreground is a winged individual which has matured its root and stem, and stands alone, getting itself in position for a more ambitious spread above, while directly above it are two others which are throw. ing off their swaddling-clothes. All of these are plainly maples; but what of the three which keep them company on either side, and the flapping specimens which wave their double green banners above them? Farther on we see a tiny pair of true maple leaves appearing between these little flags; and, farther still, the unmistakable foliage of young maple-trees. As we look at the various forms we may very naturally ask with Gray in his botanical lesson, "Was the plantlet formed in the seed something as the chick is formed in the egg during the process of incubation, or did it exist before in the seed ready formed? To decide this question we have only to inspect a sound seed, which in this instance requires no microscope nor any other instrument than a sharp knife. We find within the seed the little plantlet already formed, and something else - namely, a pair of leaves [strap-shaped] borne on a stemlet, all snugly coiled up within the protecting seed coat." 


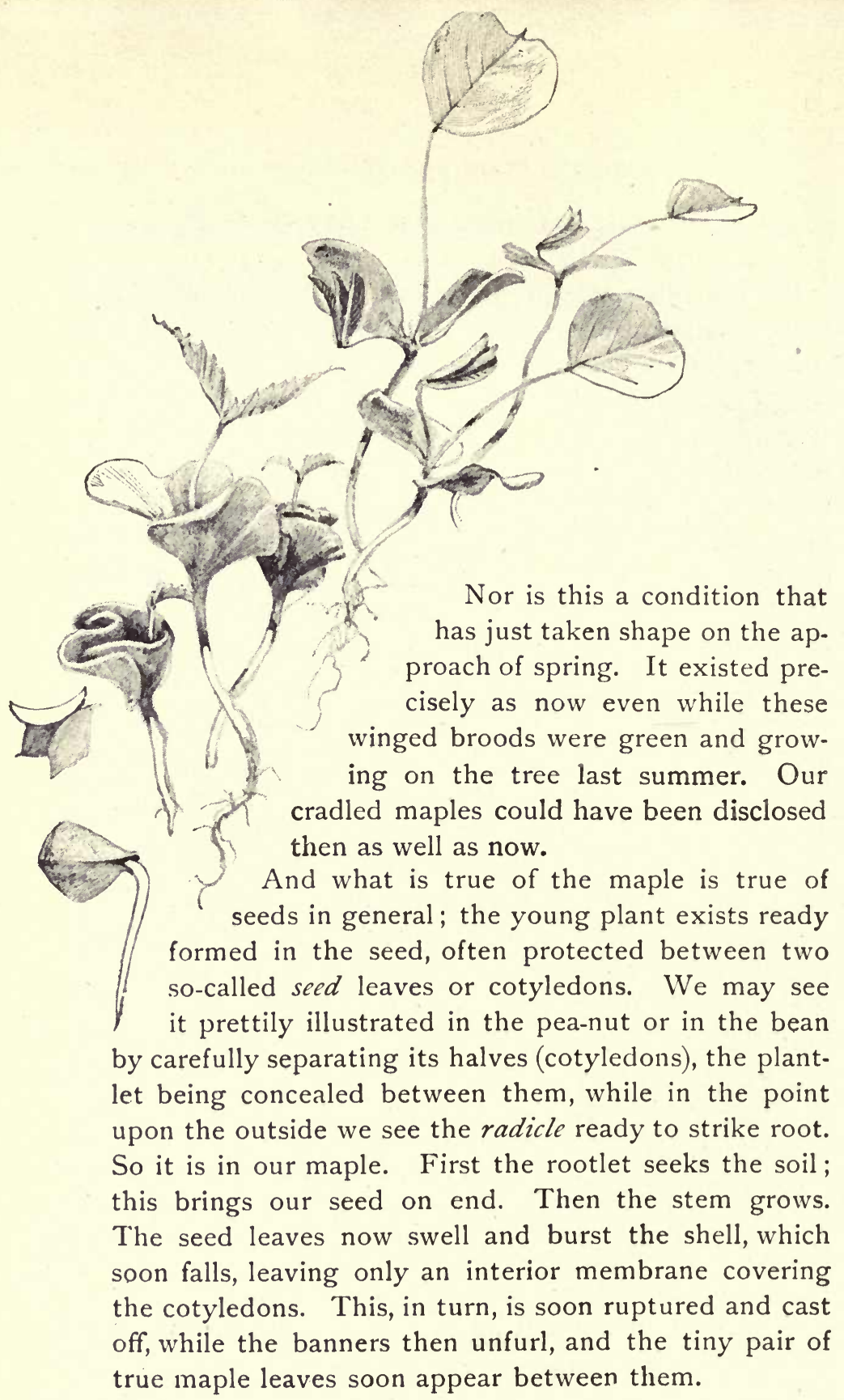


It is a matter of natural curiosity among the uninitiated why there should be this diversity between the early and later leaves of the plant. These cotyledons are not properly leaves, but storehouses of food, and their office is to nourish the infant plant until its root is sufficiently grown to absorb nourishment from the soil.

It is not alone in the maple that this pretty masquerade is to be seen in the spring woods. The little green things among the dried leaves everywhere are full of interest. Here is the acorn with its determined, rosy, pulsing radicle, making eager head-way towards the mould, while its swelling seed leaves are bursting their bonds. The baby beeches are odd affairs, with the sweet kernel of the former nut now unfolded from its snug quarters, and transformed to its two fan-shaped green nurse leaves with the tiny beech-sprout between them.

We have all heard of four-leaved, five-leaved, and many-leaved clovers, but it is, perhaps, not generally known that many of the clover tribe start out in life as one-leaved clovers, though they seem quickly to repent. I do not happen to know just which member of the clover family it was that sat for the portrait I have given; possibly the medic. But there was a whole brood of them, each with its pair of cotyledons, its experimental single leaf, that invariably shrank away, like a wayward child, as far as possible from its outraged younger brother that seemed berating it for its degeneracy. 


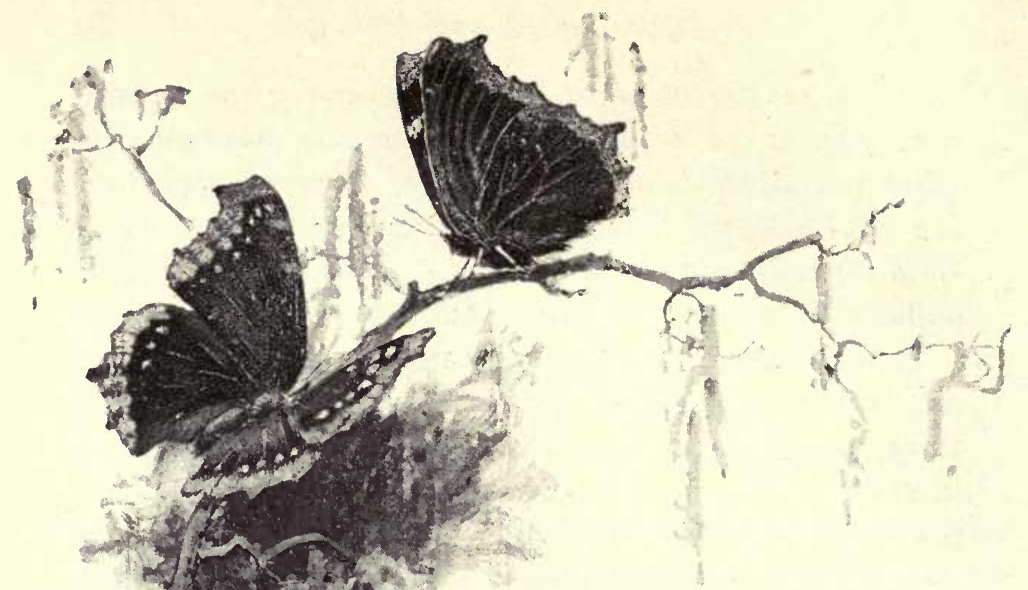

A BUTTERFLY SERENADE

April I $4^{\text {th }}$

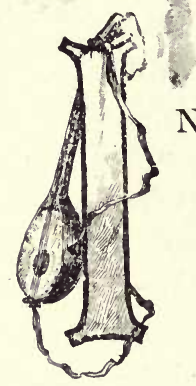

NSECT hunters the world over will need no introduction to the butterfly whose portrait is given above - the cosmopolitan Vanessa Antiopa of the books, the "yellow edge" of the American boy's cabinet, the "Camberwell Beauty" of England, known to every country boy as the first butterfly that flits in the early spring, and a challenge for a chase at any time. But we must make our acquaintance with Antiopa anew, for he has evidently kept a secret from most of us all these years. It evidently has something more to say for itself which few of us have heard.

Here is a matter for our boys to look into. A Mississippi naturalist writes to our Government Entomological Department: "Vanessa Antiopa has a 'voice.' I heard it in Europe, in Lorraine, from two mating $A n$ - 
tiopas on a beech stem, walking around each other, and agitating their wings, with oft-repeated cries." This was new to our Government entomologist, Mr. Riley, and subsequently he received the following letter substantiating the fact from an entomologist in Bedford, England:

"The sound made by this butterfly, without doubt, is the expression of certain emotions, be it of anger or of love; but since it is not made by the breath we cannot, I think, consider it more than elementary voice. It may be that

“' ' in Loraine ther notis be

Full swetir than in this countrie,'

for English entomologists are, I believe, generally of opınion that the sound which butterflies make is caused by their rubbing their wings together in their ardor. The Vanessa Antiopa is only a migrant to this country (Great Britain), and seldom seen, but it breeds in Europe and Northern Asia, commonly along willow bordered streams. I have a few specimens from the banks of the Po, and from one of these I have detached the fore wing.

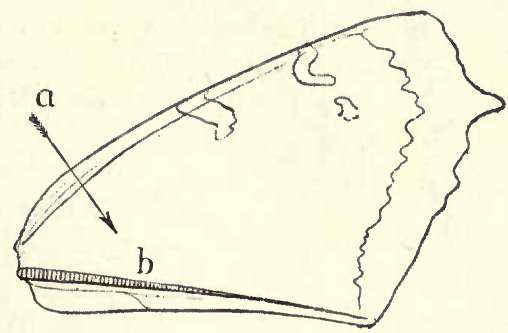
Along the lower edge of this I notice a smooth projecting vein, $b$, which, viewed from the direction, $a$, with a strong magnifier, is seen to be flattened and notched like a file for not quite half its length. This vein, when the wings are expanded, rests on another projecting vein on the hinder wing in such a manner that when the upper wing is moved the notched vein rubs over this vein, as the bow rubbed with resin works on the violin string.

"Let any one now take a dried specimen of this butterfly from the cabinet, and grasping the fore wing by its front edge, rub it backward and forward over the hinder one, so that the bases 


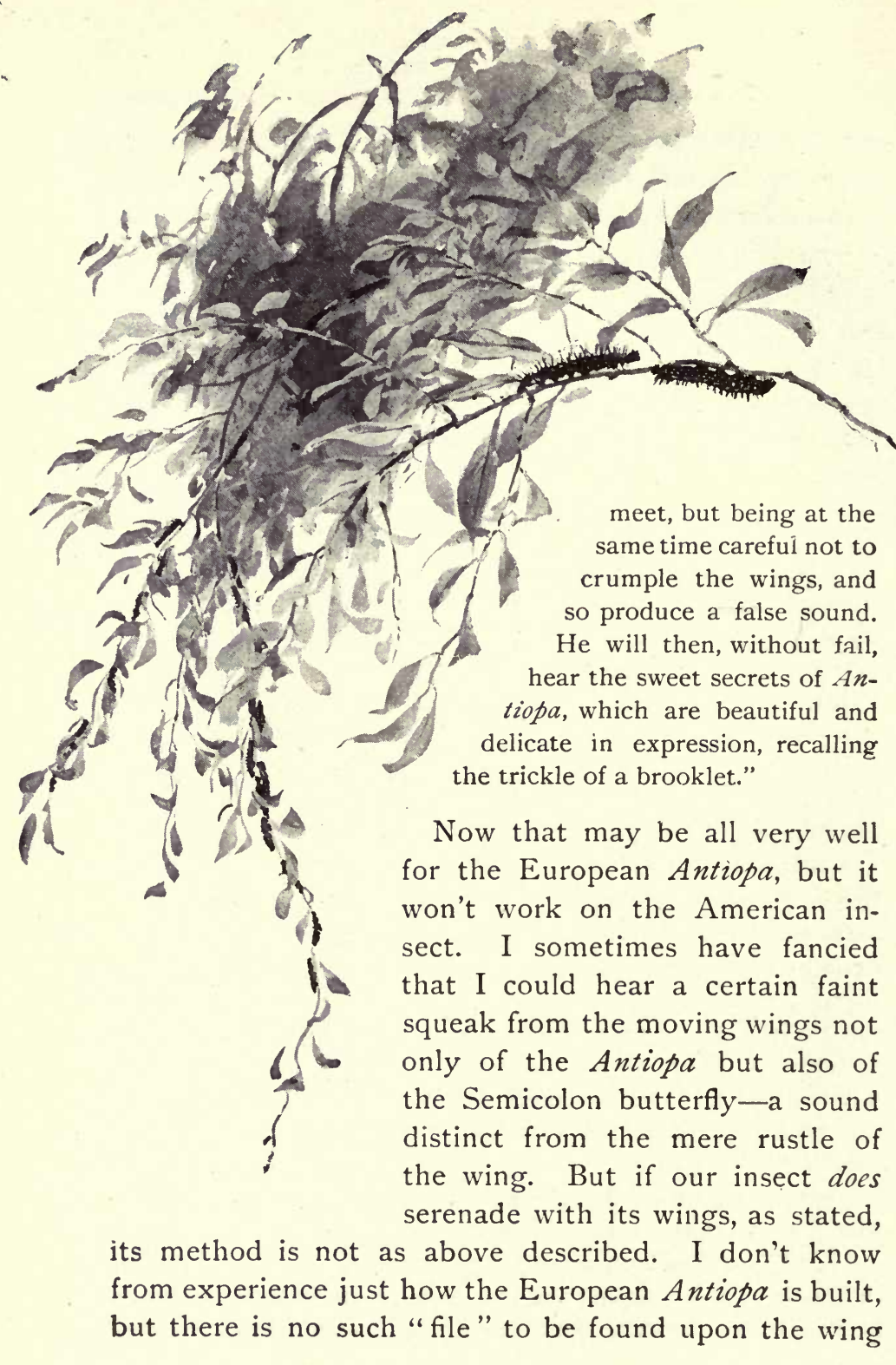


of the American species, at least in the twenty or more specimens that I have examined; nor can the "sweet secrets" or the "trickle of a brooklet" be coaxed out of any cabinet specimen of mine.

I have several times heard of the pretty talk of this butterfly. Who shall tell us more about it? Here is a chance for my young entomologist to distinguish himself. What is this so-called "voice" of the yellow edge? Does it talk wing-fashion, after the stridulous manner of the grasshopper tribe, or with its wings and legs together, as the locust-fiddlers do; or with its head, like some of the beetle tribe, or with its air-drum, like the cicadas? Of course some of these methods are hardly to be considered in relation to the anatomy of a butterfly; but so far as an examination of our American insect would seem to show, any one of them is certainly as plausible as the explanation quoted, which may explain in England, but does not in America.

The matter may be easily studied. The butterflies are now frequenting the tender foliage of the willows by the brook, and in a few weeks the first brood of their black spiny caterpillars will literally weigh down the slender branches as they strip the leaves and leave their cast-off skins fringing the twigs. Hundreds of the caterpillars may be gathered in a few moments, and the walls of your collecting-box will soon be hung closely with chrysalids, nearly all of which will have been transformed into butterflies within a period of a fortnight.

There are two, or, I am led to think, even three of these caterpillar broods during the year; the butterflies from the last in autumn surviving the winter. 


\section{THE CORAL-WING LOCUST}

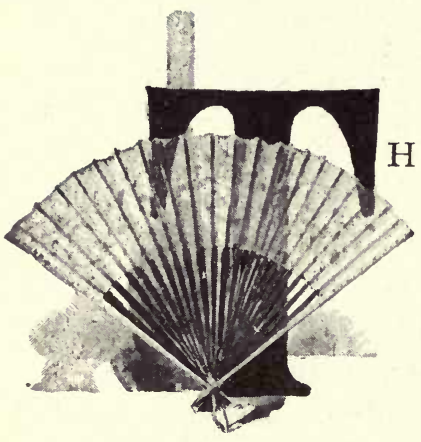

April 14th

$\mathrm{HE}$ conspicuous insects are few and far between at this early season, and are mostly confined to the Antiopa and related Semicolon, Comma, and Red Admiral butterflies. But for two weeks past, almost any bright sunny day in the woods we may have surprised an agile bit of life that starts up, perhaps from an unseen source at our feet in the wood path, and speeds like a rosy streak across the dry leaves, its flight accompanied with a sharp rattle, which can be distinctly heard for two or three rods. Though you note the precise spot where the rosy gleam seems to meet the ground beyond, it will take a sharp eye to locate it definitely until its blossoming wings once more flash in flight. "A tigermoth!" I exclaimed, when I first saw it, as, with eager net, I captured the prize, which proved to be only the coral-winged grasshopper, or more correctly, locust. There can be no mistake as to the "voice" of 
the Coral-wing, though it is not, to my mind, satisfactorily accounted for by the naturalists. I have shown him in the act of flight as I recall him, though merely from my memory. Only the large under-wings bear the bright color, and these are folded like a fan beneath the brown wing covers when the insect is at rest. Above him I have pictured another locust, which frequently keeps him company in the spring woods, and they are a pretty and complementary pair together, the latter being of the brightest green, and though without rattle or even rustle, as agile as a moth upon the wing, and in flight it might easily deceive a tyro entomologist.

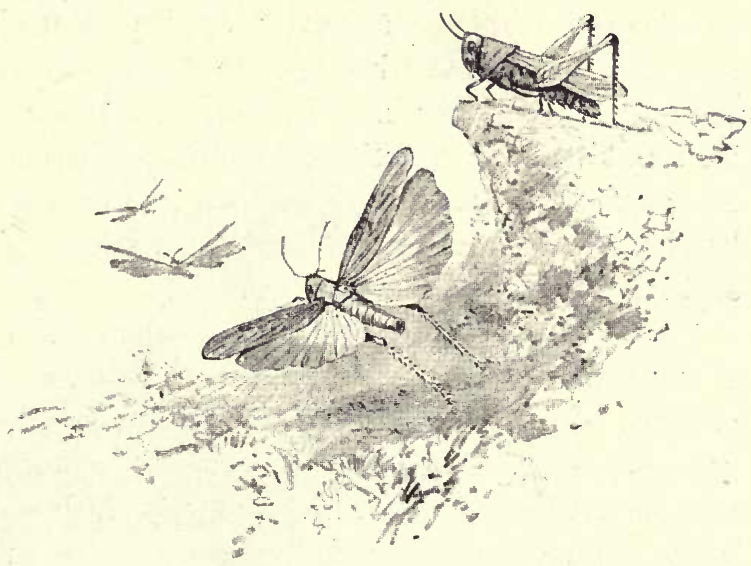




\section{THE WATER FAIRY}

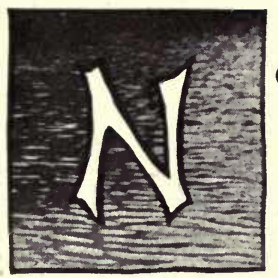

April 14th

OW is the time to go fairy-hunting. Even earlier in the month we might have sought them, but their stay is short, and we must not miss another week, for in a few days more they will have disappeared.

How well I remember the first discovery of my fairy! It was about the middle of April, some ten years ago. The snow and freshet pools had barely dried in the woods, and while dredging in one of them for microscopical animalculce I brought to the surface a creature such as I had never known to exist. It was about an inch and a half in length, and of the consistency of jelly. Its broad head was decorated with two widely separated black eyes, its sides were fringed with scarlet plumy fins, and its rosy tail ended in a long fork.

I quickly turned my attention to the pool, and found it swarming with these filmy bodies in all stages of growth. In its element the beautiful creature was nearly transparent. Beneath the shadow of a floating leaf it was almost invisible, but as it emerged into sunlight the body seemed suddenly shot through with opalescence of mother-of-pearl, and was thus mainly revealed. This iridescence played continually through the diaphanous body in various tints of green and pink as the fairy 
darted or glided about, and certain sunny spots in the pool were distinctly pearly lustred by their numbers. It was like a strangely fashioned palpitating opal dissolving before one's eyes, and the incessant waving accompaniment of the gliding feathery scarlet fringe by which the swimmer propelled itself was beautiful beyond description. I brought home several specimens in a bottle for my aquarium, but they were too fragile for such treatment, and all perished in a few moments.

I made a little sketch in my note-book from memory, simply to aid me in identifying my fairy. It is only a hint, but with my descriptive memoranda made at the time I had little difficulty in naming my specimen. It is the Fairy Shrimp (Branchippus vernalis), under which title my reader may find out all about the beautiful creature. Those who live in the country should not miss a fairy-hunt during the coming week. The Branchippus is a gem indeed for any aquarium.

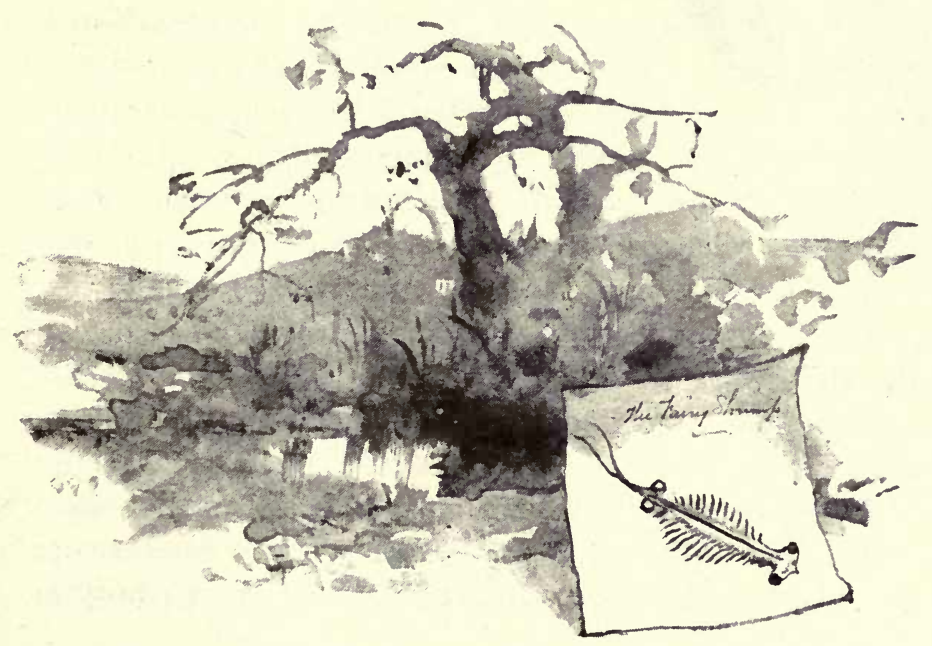




\section{APRIL BIRDS}

April 2Ist
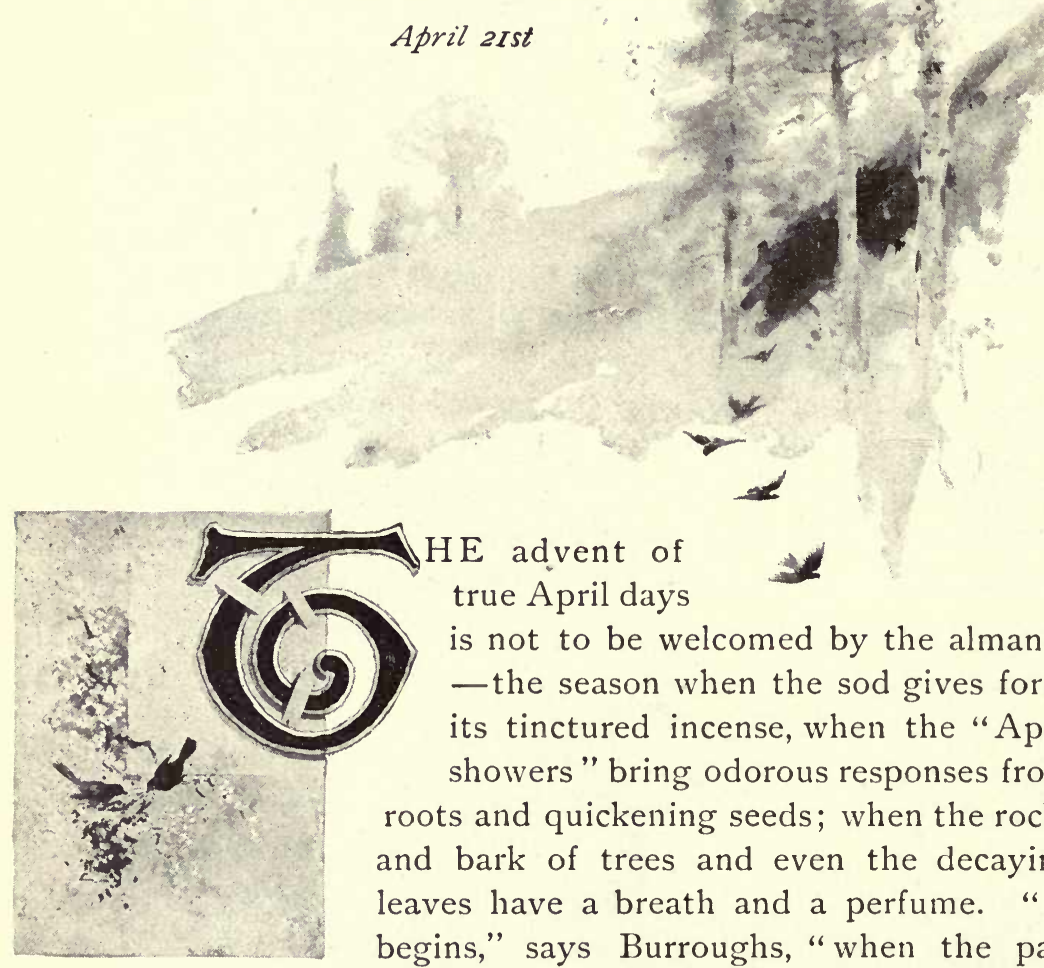

HE advent of true April days is not to be welcomed by the almanac - the season when the sod gives forth its tinctured incense, when the "April showers" bring odorous responses from roots and quickening seeds; when the rocks and bark of trees and even the decaying leaves have a breath and a perfume. "It begins," says Burroughs, "when the partridge drums; when the hyla peeps; when the shad start up the rivers, and the grass greens in the spring runs; and it ends when the leaves are unfolding and the last snow-flake dissolves in mid-air."

The dandelion has been accepted as the first floral "pledge of blithesome May." What is the true feathered pledge of April? Authorities differ. With Emerson, 


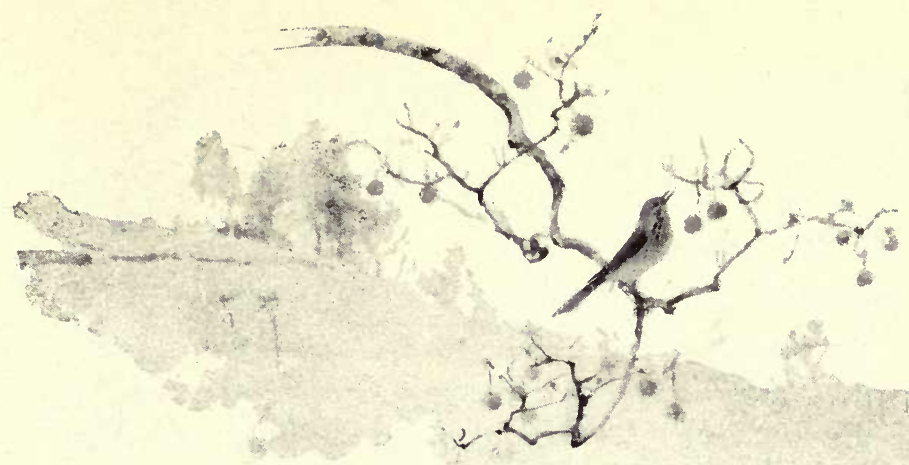

"April's bird,

Blue-coated, flying before from tree to tree,"

is of course the bluebird; but he came in early March, or perhaps has been with us all winter.

With Burroughs it is the robin, "brisk, vociferous, musical; dotting every field and larking it in every grove. He is easily atop at this season, as the bobolink is a month later. The tints of April are ruddy and brown - the new furrow and the leafless treesand these are the tints of its dominant bird." But with me it is not the robin that is associated with the "brown furrows" and the early planting. It is his congener, the mocking brown thrasher, with his "plough it! plough it! hoe it! hoe it!" and whose first counsel is timed with those swelling dog-wood buds, whose full bloom is the "corn sign" of the New England farmer, and the accepted signal for the corn-planting.

But we need not quarrel with the commentators as to the one anointed April bird. Each has his pet protégé, the child of fond association, for there is in truth a whole troop of "April's birds" to choose from, though the great bird choral has yet to come. Almost any genial day now we may confidently listen for the " cheerily, cheerily, cheer up; cheerily, cheerily, cheer 
up" of the robin; the "purity, purity" of the bluebird; the "phebe," the "conkaree" of the redwing in the bog, to say nothing of many other songs which the poets have similarly translated. Every April lover will recall the "quick, quick, quick, quick" of the

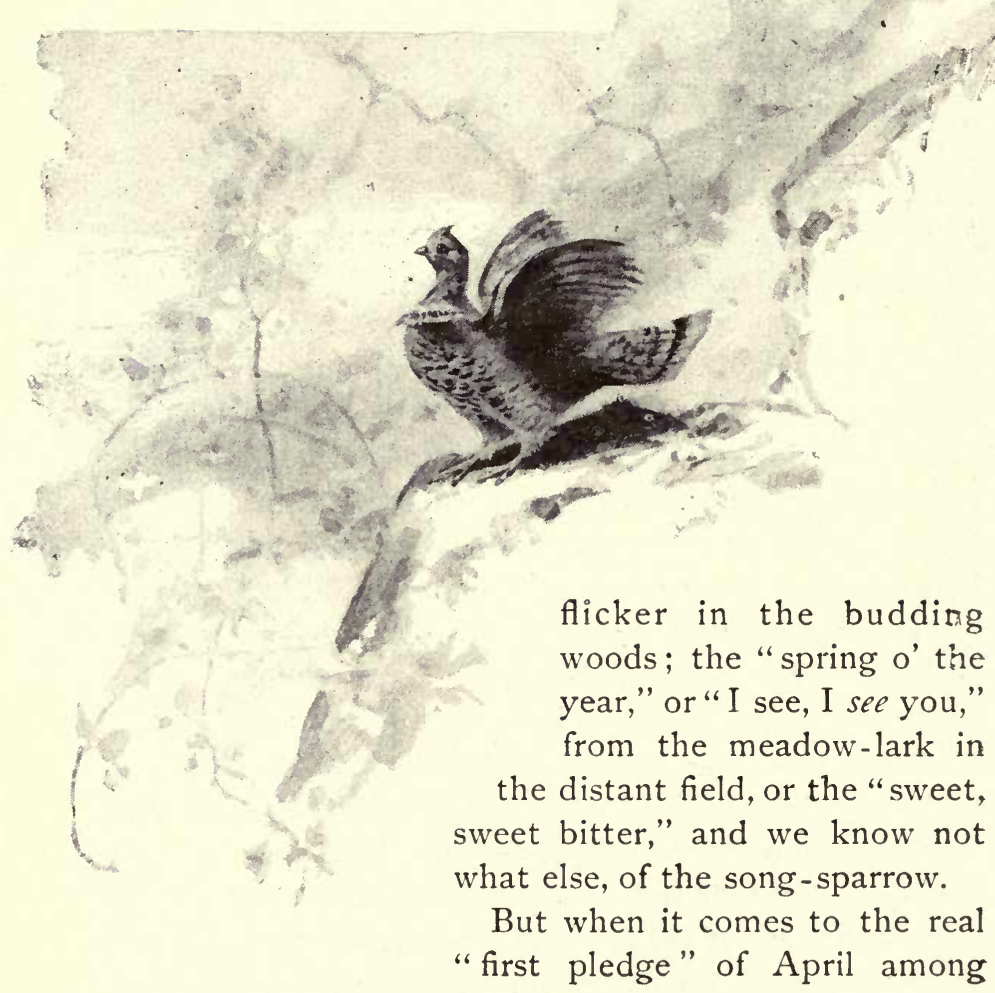


the birds, I am prepared to stand by the testimony of Hosea Biglow,

"First come the blackbirds, clatt'rin' in tall trees, An' settlin' things in windy congresses."

The clamor of the noisy grackles in the pines is easily the most characteristic and conspicuous early

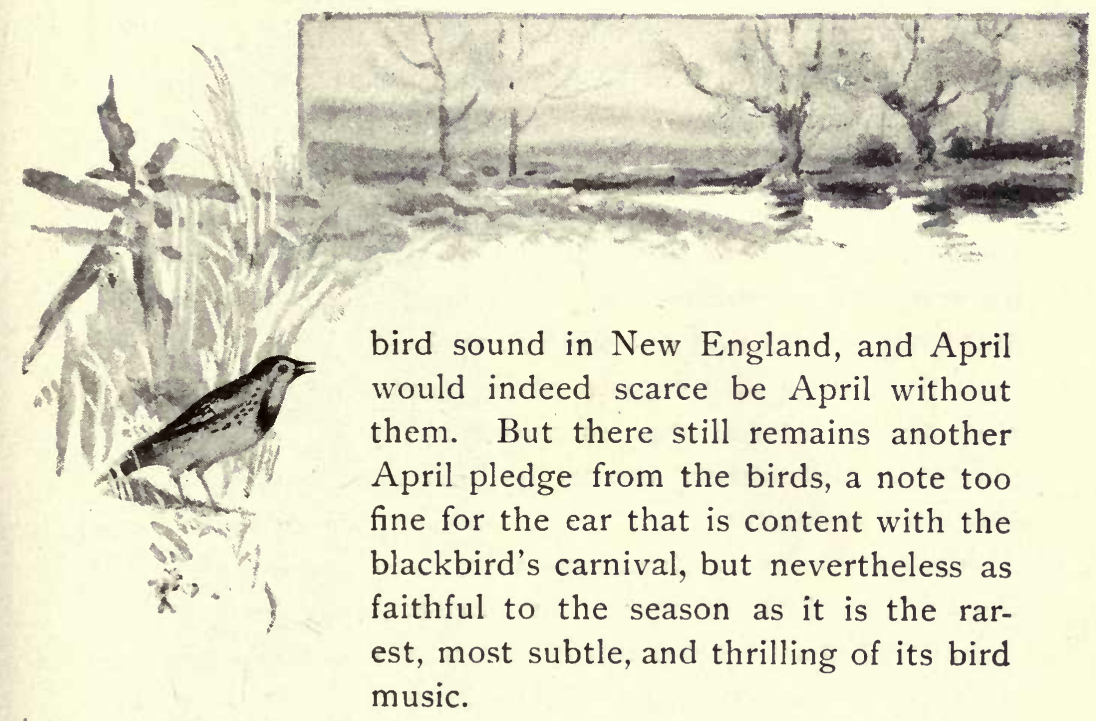

How vividly is it revived in that line of Trow. bridge's,

"The partridge beats his throbbing drum."

There is no bird sound like it, this soft, murmurous tattoo of the grouse in the bare, freshening woods. It is in harmony with the first heart-throbs and accelerating life of exuberant awakening nature - the quickening seeds, the flowing sap, the swelling buds- 
"Puff! puff! puff! puff! puff! p-r-r-r-r-r-r-r-r." In a paper in Harper's Magazine I have had something to say about this drum of the partridge, but I surely cannot let this "April" pass in my natural history calendar without again referring to the bird, particularly as I should thus miss a grand opportunity of sending a host of wide-awake boys on its track to learn its well-kept secret; for this mysterious "drum" has apparently never yet been seen by mortal eye. I have shown my bird as I once saw him at close range, only that his wings of course were in a whirr of motion. He had his drum with him too, and the muffled roll filled the woods. Where did he keep it? Here is the testimony of a few of the prominent witnesses who have seen him in the act. You can take your choice, and then go and find out for yourself.

A host of ornithologists claim that the bird beats with its wings "the log" on which it stands.

Brewer affirms that the wings beat both the log and the sides of the bird.

Audubon says he strikes his sides after the manner of the rooster. [An act which the rooster never performs.]

Burroughs says the drum is "its own proud breast."

Wilson says the bird beats nothing but the air, and Burroughs later comes to the same opinion.

Bryant thinks the same.

Thoreau and Flagg and the writer assert that the wings are struck above the back if anywhere.

All these authorities differ also as to the position which the bird assumes when drumming; some affirming that he stands upright, as a drummer ought, others that he stoops to a horizontal position. Come, boys, which of you can give us the facts? 


\section{RAGWEED PITH}

\section{Aprit 28th}

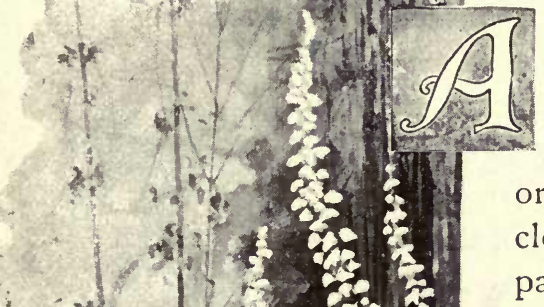

STROLLER in waste places or weedy corners, either during the winter or now, before the copses are clothed in foliage, may weli pause a moment among the skeleton thickets of the great ragweed, in its perfection the tallest of our weeds. One April, a few years since,

I found a stalk eighteen feet four inches in height by actual measurement. But it is not with a tapeline this time that I ask you to tarry. "Ambrosia," the plant is called in 
the botanies- "food of the gods"- " an ill-chosen name for these worthless and coarse weeds," says Dr. Asa Gray. I confess that this indictment seemed perfectly just, until I chanced to discover the contents of their dried stems. What other of the weeds can show a marrow which comes so near to immateriality as this of ragweed? A pith which I will venture to say is lighter and more buoyant than any vegetable tissue of like bulk. It seems almost to float as it falls from your hand, while its cross fracture, with its iridescent sheen, certainly brings reminders of the rainbow in the realm of the gods.

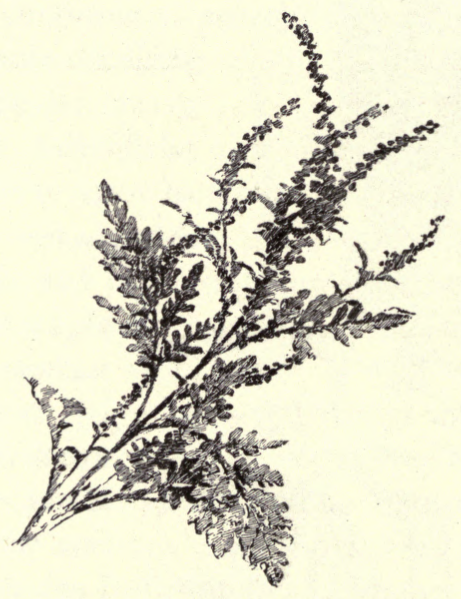



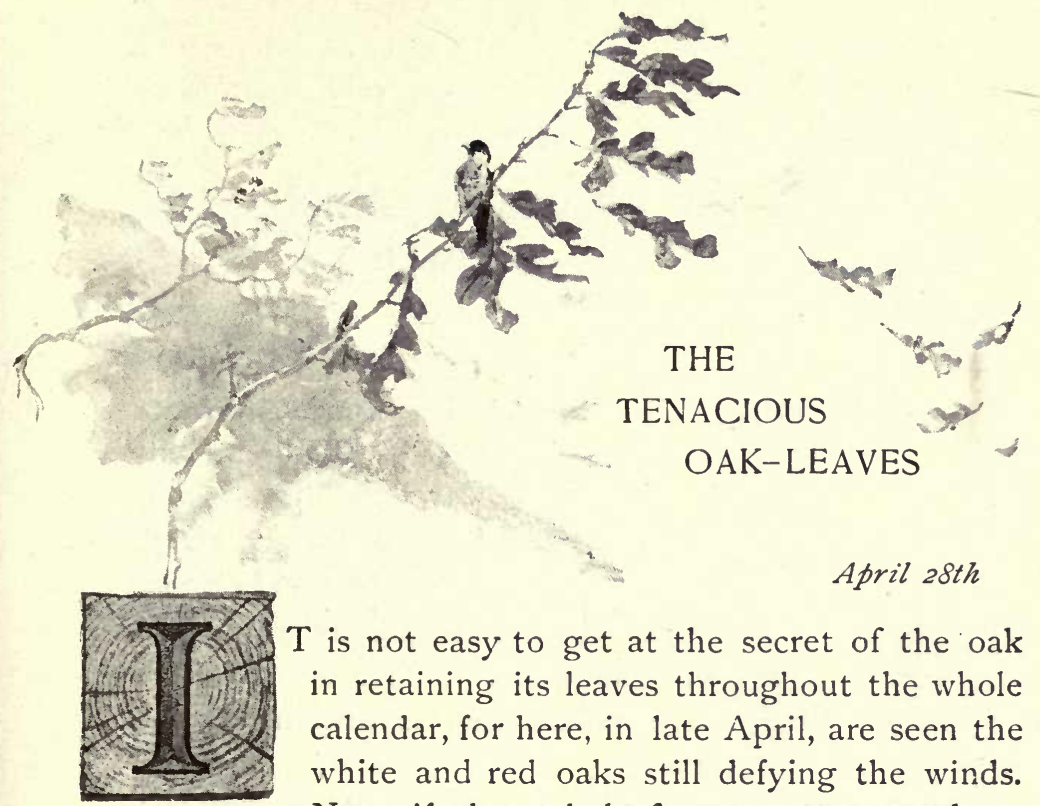

$T$ is not easy to get at the secret of the oak in retaining its leaves throughout the whole calendar, for here, in late April, are seen the white and red oaks still defying the winds. Now, if the oak-leaf were constructed on the plan of the button-wood leaf, whose stem grows like a protecting cup over the bud of the following year, we could readily frame a theory; but it does nothing of the kind. These persistent oak-leaves are placed beneath the new buds, while those of the button-wood fell in early autumn, exposing the tender bud to the winter storms.

If we examine the white-oak branch, we shall find that many of the leaves have been twisted off by the wind, leaving only a short remnant of a stem beneath the buds; and even these adhere so tenaciously as to leave a fresh green scar upon removal. They yield only as they are pushed off by the swelling bud above them. 


\section{THE BROWNIE-JUGS AND \\ THE BROWNIE}

April 28th

LL through the winter months we might have seen our brownie-jugs, as large as hazel-nuts, neatly secured to various twigs in the thickets, but I have passed them until I could bring the reader face to face with the little potter that is responsible for them.

He has been in hiding during the cold months, and was to be known only by his works; but now he is out again, and will soon make his first jug after the pattern that his ancestors have handed down to him; for long before the human vase-maker fashioned his clay upon the wheel these little jugs were being turned out by Eumenes fraterna. Such is the name his historians have given him.

Jugs serve a variety of uses, but none of human fashioning is ever used for precisely such purposes as these of Eumenes, which serve as a receptacle for treasure, a larder, and a home as well.

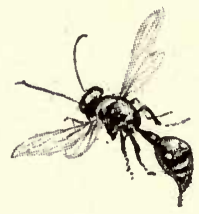


I have seen many a jug catalogued in a bric-à-brac sale that did not have nearly so interesting a history as one of these clay pots of the vase-maker wasp. It is made of sand and yellow mud. When completed, the wasp lays an egg within it, and then proceeds to pack it full of tiny green caterpillars, each of which she has paralyzed, though not killed, by a stab of her sting. The opening of the vase is then plugged up with a mud cork. Presently the egg hatches into a little grub, that feeds for the rest of its days on the living store of food.

By the time the supply has run short, the grub has become a chrysalis, and soon pushes out the plug, and appears a full-grown wasp, like its parent, and it will make as pretty a jug as the one it leaves the first time it tries.

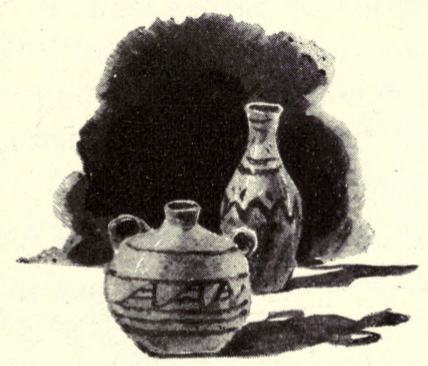



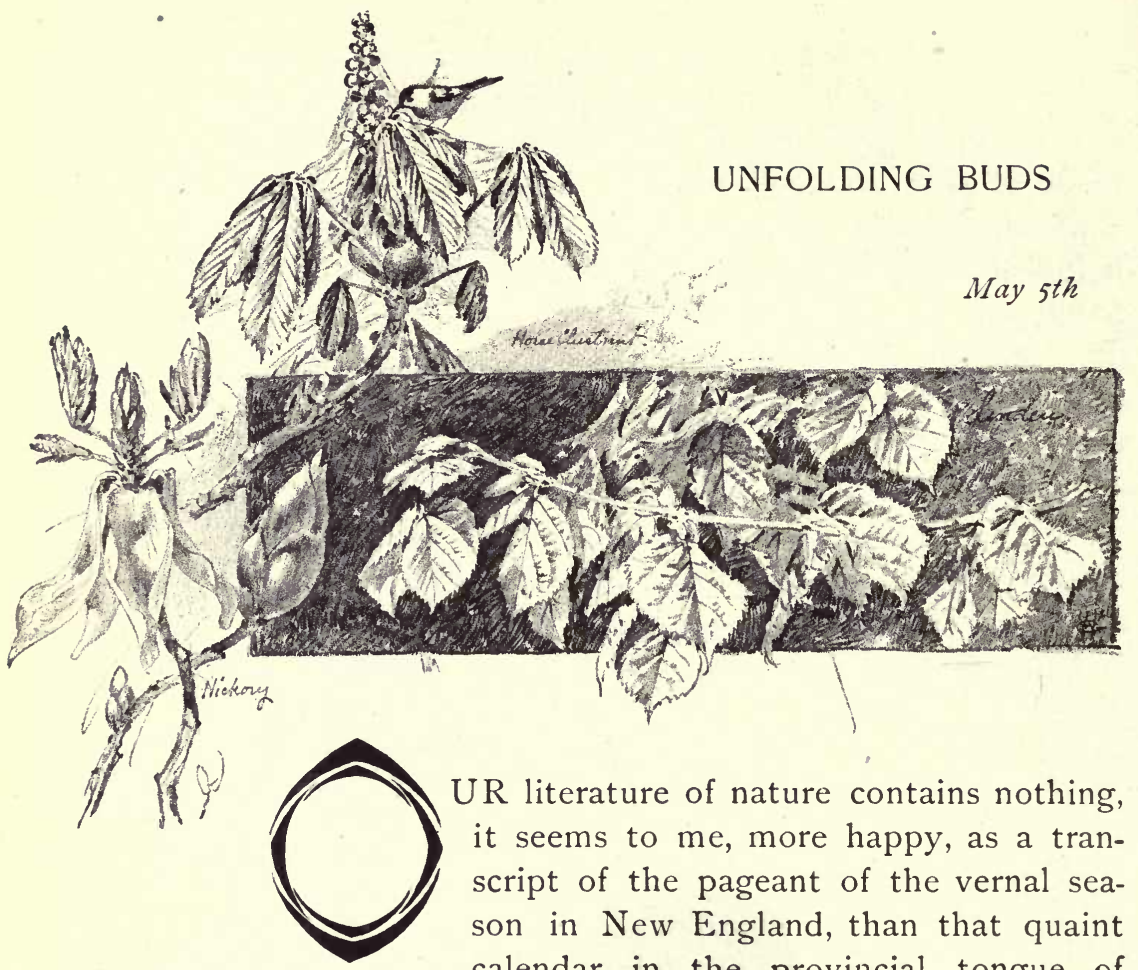

UR literature of nature contains nothing, it seems to me, more happy, as a transcript of the pageant of the vernal season in New England, than that quaint calendar in the provincial tongue of Hosea Biglow, * "Sunthin' in the Pastoral Line," from which the following is quoted.

What mirrored truth is in this picture:

"The maple crimsons to a coral reef;

The saffern swarms swing off from all the willers, So plump they look like yaller caterpillars; Then gray hoss-chestnuts' leetle hands unfold, Softer'n a baby's be at three days old."

Here is another complete and exquisite touch:

"Young oak leaves mist the side-hill woods with pink." * The Biglow Papers. By James Russell Lowell. 
Where is the artist who would lay his canvas beside it as a talisman to memory alone? With the beginning of May the woods are full of color; there is a reflection of autumn in the tender foliage tints; there are bursting buds and budding leaves that mist the hills with pink and white; others that mist the gray thicket with yellow aureole; the shad-tree blooms and the flowering dog-woods hover like white entangled clouds in the distant woods.

Those winter buds which we have seen for months on the bare twigs are now unfolding in endless variety, showing with what wondrous art the embryo leaves and blossoms have been packed away in their warm winter snuggeries. No two seem designed on the same plan or unfold in the same manner. The linden leaves unfold in drooping conical pendants, each sheltering the one below it. The tulip-tree has a beautiful method peculiarly its own.
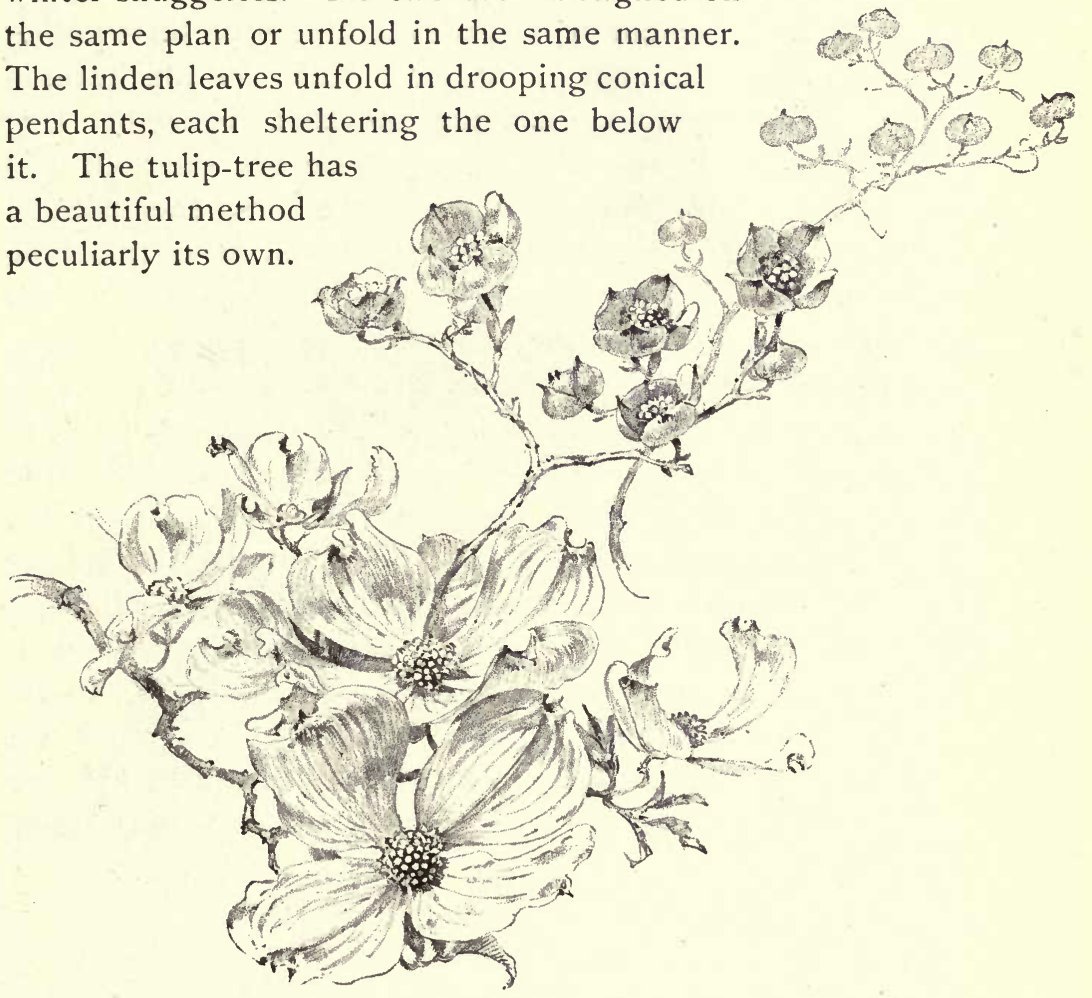
Look at this great satiny hickory bud swollen almost to the size of a magnolia, while another near by has burst into a mimic fleur-de-lis, with golden drooping scales, disclosing the folded leaves and catkins which were to be found last January had we sought them. Any one who has watched the development of the horse-chestnut's varnished bud, with young leaves entangled in the cobwebby festoons of soft brown wool, will appreciate Lowell's apt allusion above quoted, while the bud of each separate shrub or tree in turn will reveal some interesting individual trait.

Let us look at the development of this dog-wood bud. Even as early as last September it was to be found upon the tips of the twigs, making ready for the next year's spread of bloom even before its surrounding leaves had thought of falling. Later in the autumn it had increased in size, and the bare November tree left them all exposed precisely as we saw them all 'winter. In February they begin to swell, and the common belief is that the large white blossom is at this time forming within eager to burst its bounds. Not so. In April these four purple bud-scales finally open, disclosing the cluster of tiny flower-buds at the centre, but no sign of the four great petals, for the dog-wood blossom is not $a$ blossom; it is an assemblage of blossoms, the so-called white petals, being, in truth, no petals at all, but only singularly modified leaves, or what the botany calls a corolla-like involucre enclosing the true flowers.

It is generally supposed that the flowering dog-wood, like other true blossoms, has simply thrown off its winter bud-scales, and bloomed from within; but if we carefully examine these white heart-shaped leaves, we find that no such thing has taken place. The bud scales 
have not been cast off, as is usual with buds, but have simply grown, that purple puckered tip so noticeable in each of the mimic petals, being the identical hollow scale which formerly wrapped the cluster of flowers at the centre, the white floral leaves being simply a continuance of their growth from beneath, having carried them far from their original position, while the true flowers at the centre now bloom and prepare for the cluster of scarlet autumn berries.

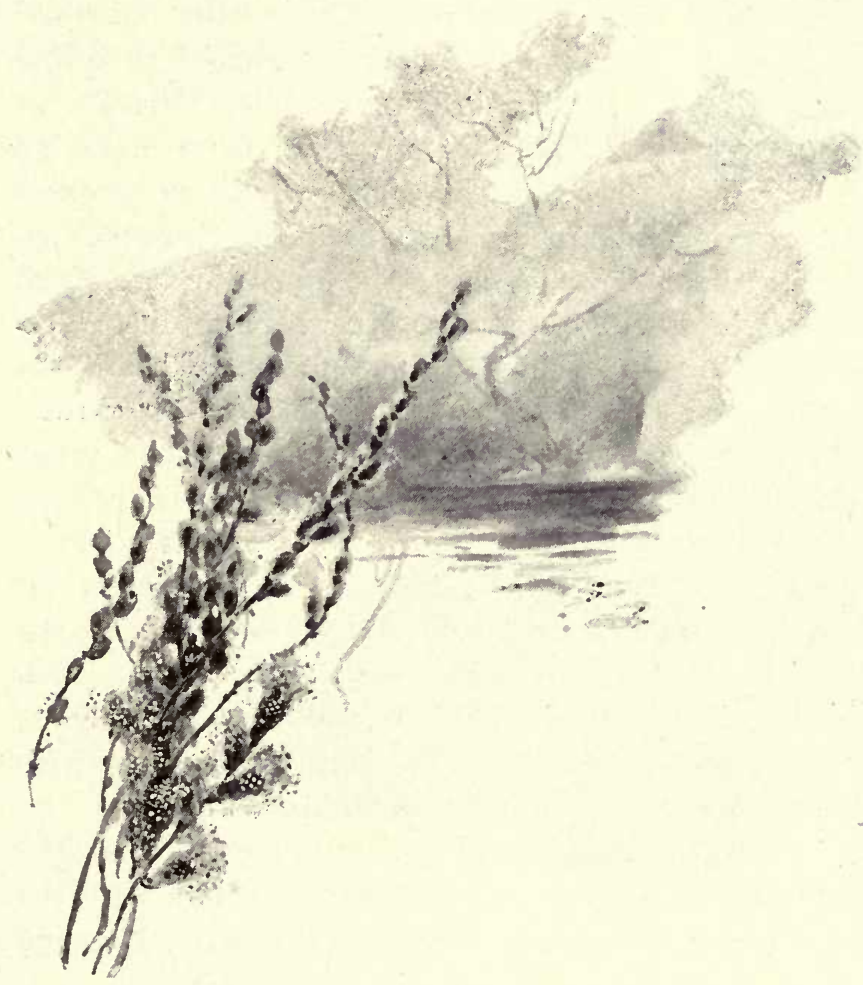




\section{THE TOAD'S BAGPIPE}

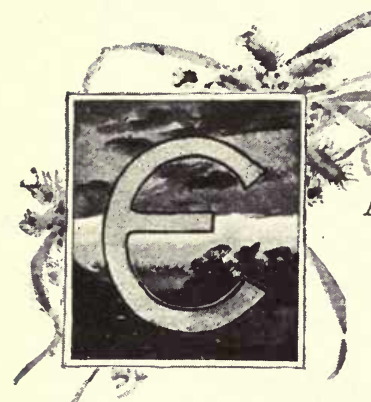

ARI,Y in icy March the swamps sounded their first welcome to spring in the shrill peep of the Hylodes, or whistling frogs, and from week to week since new broods of peepers

have come and gone, filling their brief nuptial period with their own peculiar music, until the late April marshes were palpitating with their teeming din.

Among this later chorus we might have heard the lingering peepers, the occasional " $t-r-r-r-r-r-r-r d t$ " of the gray tree-toad, the harsher note of the green clucking frog, the spasmodic wavering croak of the black-cheeked wood frog, and a certain strange shrill rattle, which we may catch occasionally even now, but whose animated source I have not yet satisfactorily ascertained. It is a peculiarly high, vociferous, exclamatory trill, with an ascending scale and a high crescendo, and may be imitated by means of that noisy toy with which most boys are familiar, and which is called a "locust." As we used to make it, it was composed of the tip of a bottle neck, or a small tin spice-box with the bottom removed, having a piece of kid tightly stretched 
across its opening. A doubled horse-hair was knotted to the centre of this small drum-head, and the slip-loop at its other end passed round the tip of a small smooth stick, on which a groove was made to receive it. When this groove was wet and the drum revolved in the air the "locust" spoke for itself, to the joy of the small boy even if to the nuisance of every one else. If this drum be held firmly in one hand and the stick in the other-the horse-hair being very tightly drawn-a quick twist of the handle, accompanied with a tighter pull on the hair will almost exactly resong in question. I hope some day to decoy and identify my mysterious frog / by this device,

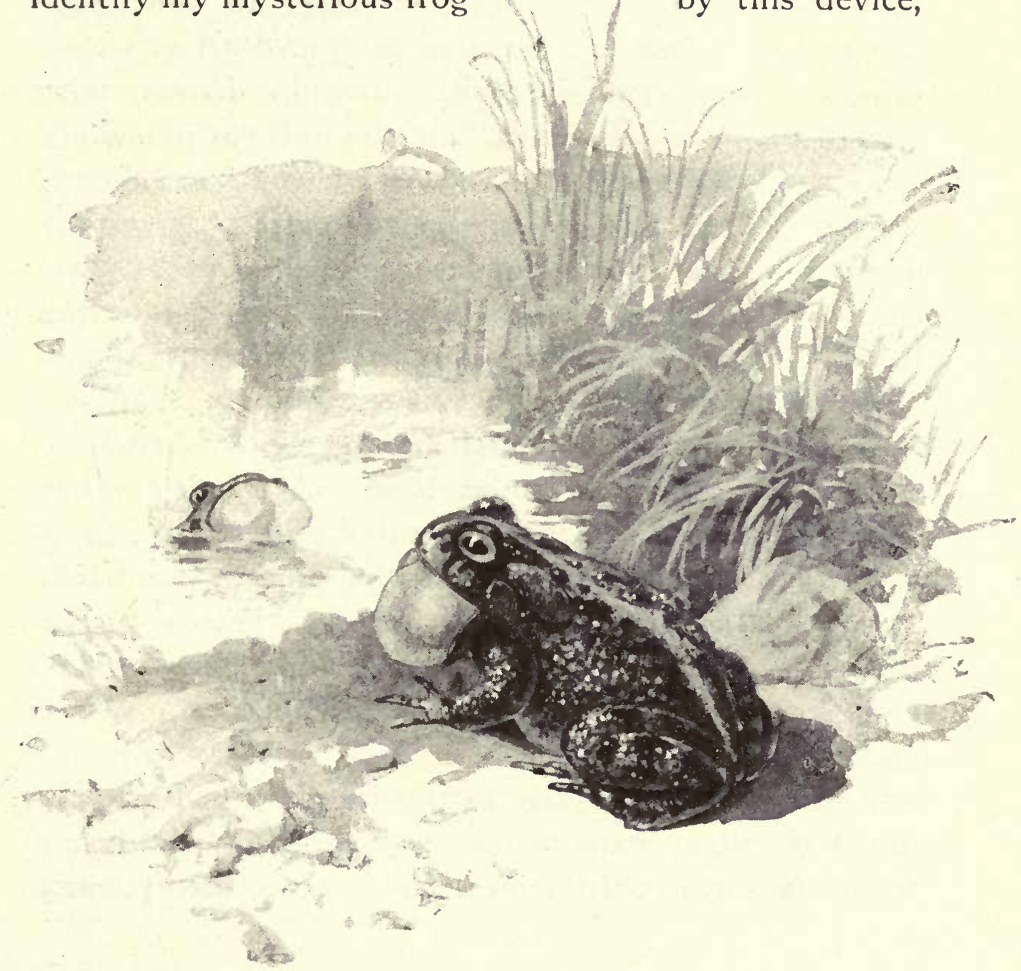


though I suspect he may turn out to be an old friend who has been making sport of me all these years. The little toy may be made to mirnic a number of the frogs and toads.

But the early musicians are now forgotten. A new singer has come upon the scene, and his mellow nocturne in the twilight marshes brings a message unknown to his predecessors. This is no shrill peep that stirs your blood and sets your ears a-tingle, no bubbling rattle or vibrant croak that cries "qui vive" to your eager senses, but a drowsy drool that brings your feet to loitering in the deepening dusk, and whose distant music from the swampy lowlands lulls you on your pillow. It is to me the sweetest sound in nature, the faithful chosen voice of the twilight, one of the most characteristic attributes of late spring, and yet, like the sprightly welcome of the hylodes which ushers in the vernal season, it still remains unsung by our poets, or if occasionally acknowledged the true singer never gets the credit.

Who will immortalize in verse the pensive witchery, "most musical, most melancholy," of this tremorous song of the toad, for it is in truth the uncouth and illfavored toad that now swells his bagpipe in the marshes and fills the night with music? It is one of the beneficences of nature that the twilight glamour throws a veil of obscurity over the performer while it emphasizes and consecrates its music.

I have spoken of the toad's bagpipe. Those who recall the dual tone of the national Highland instrument, with its continuous drone and accessory varia- 
tions, and the inflated source of the combined music, will readily appreciate the allusion as applied to the toad.

There are few who have discovered the peculiar art by which the toad expresses his emotion. Often I have coaxed an encore from him at mid-day by decoying him with a mimic song, which may be almost perfectly produced by combining an ascending prolonged whistle, beginning on the tone of second $\mathrm{D}$ above middle $\mathrm{C}$, and running up to $A$, with a droning sound of the voice near the tone of the second $\mathrm{F}$ below middle $\mathrm{C}$, although a strict adherence to either tone is not necessary.

It is a surprising and saucy response that we receive down there among the lily-pads, as may be conjectured from my truthful portrait, and the familiar sound that comes up to us thus robbed of its twilight attributes gains nothing by being out of season. But this picture is for naturalists, not for poets. It is the song and not the singer that concerns the poet.

I cannot close this batrachian page without offering my commiseration to my friends of the South. The frog-music of Louisiana and Florida, as I heard it two years ago, has left its scar upon my memory; for while I recognized many familiar voices and instruments struggling in the din of those rainy nights, the great burden of the orchestration seemed borne by a legion of nameless instrumentalists, who, judging from their performances, operated on a sort of primitive guitar, presumably consisting of rubber strands stretched across a tomato-can. Yes, as I have said, the spring song of the frog has yet to find its poetic interpreter. But, oh, my poet of the flowery land, beware! A sonnet from you on this theme' would forever blast your hopes for poetic fame, though it might exalt you as a humorist. 
I have a little group of Japanese paper frogs playing on guitars which, with very slight liberties, as shown below, might serve as an illustration to such a Southern poem, while in the foreground I have pictured a double whistle, which I picked up in a Japanese bazaar, and which produces the two veritable tones which the toad voices from his inflated bagpipe. It is evident that the land of the Mikado has a toad song similar to that of Bufo Americanus.

We hear of the toad "swelling its throat" in song like a bird, but few of those who have seen the white flashes at its mouth during that song have imagined the true nature of the toad's bagpipe.

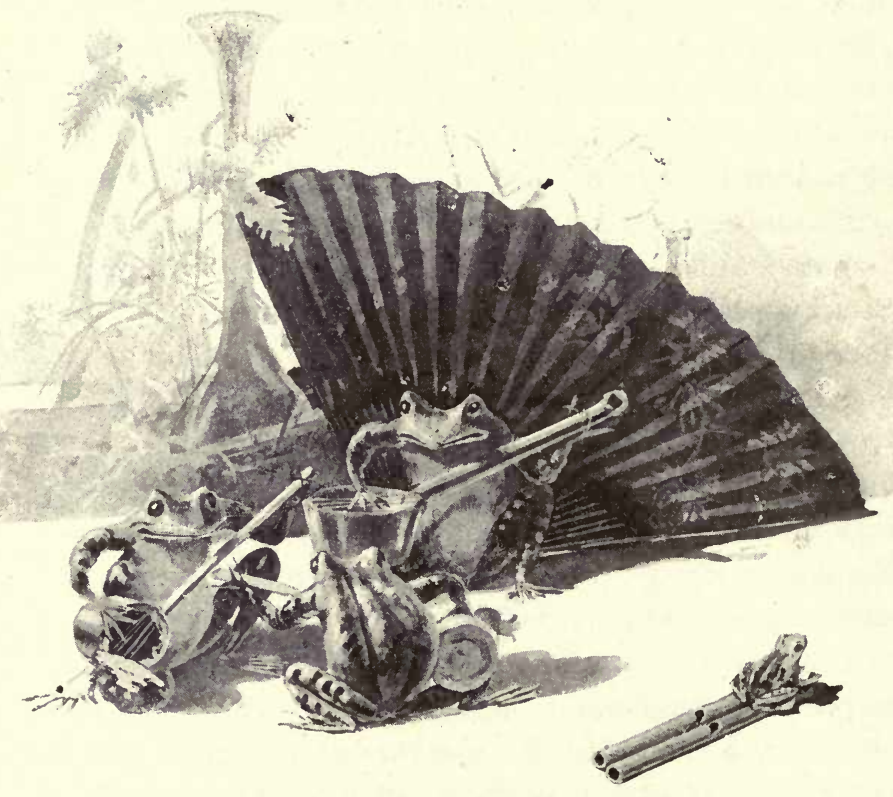




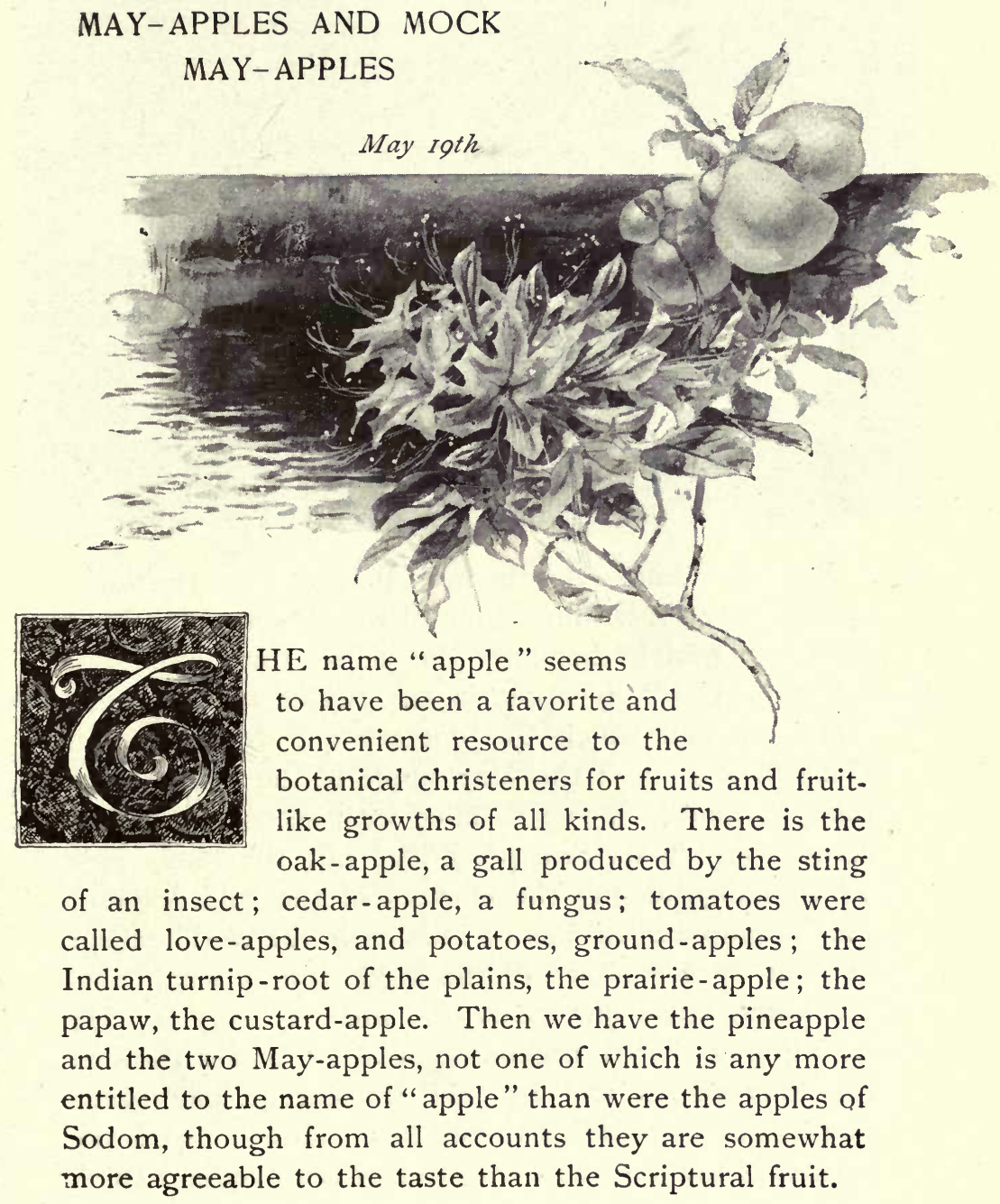




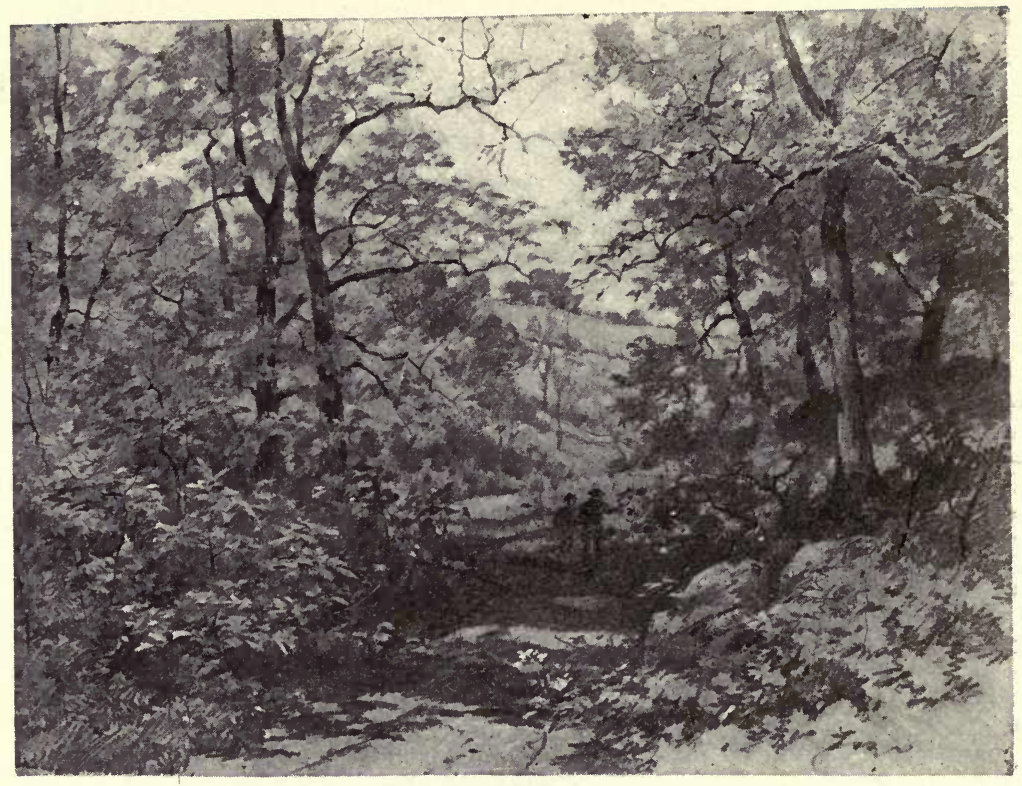

Few New England boys need be told what the Mayapple is-the real May-apple of the swamp-pinks and of the Pilgrim Fathers, not the yellow tomato-like affair known as May-apple in the States farther south and west, and which the doctors and botanists call Podophyllum. No; the May-apple of the South has a selfish errand in life; it is filled with seeds, and is concerned only in its own posterity; but the May-apple which hangs among the clusters of the wild, fragrant pink swamp-azaleas has no mission in the world except to melt in the mouth of the eager, thirsty small boy. $\mathrm{He}$ knows little and cares less what it really is. $\mathrm{He}$ only knows that it beckons him as he passes through the May woods, and its cool, translucent, pale-green pulp is like balm to his thirsty lips. How it makes the corners of my jaws ache with thirsty yearning as I think 
of it! And what a pink whiff of the swamp May-blooms its memory brings!

The May-apple of New Jersey and southward is a

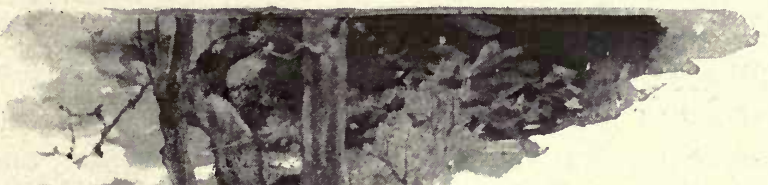

$-x \rightarrow \frac{1}{2}+\frac{1}{2}+2$

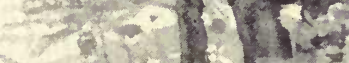
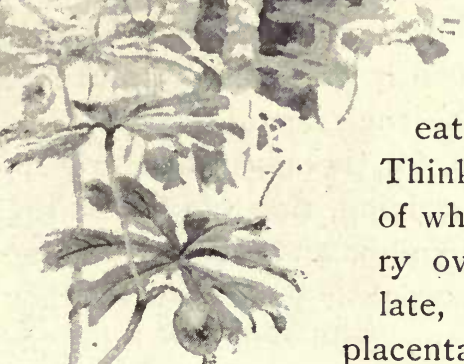

true fruit, which follows a large white flower, and Dr. Gray; the botanist, says " it is eaten by pigs and boys!" Think of it, boys! And think of what else he says of it: "Ovary ovoid, stigma sessile, undulate, seeds covering the lateral placenta each enclosed in an aril."

Now, it may be safe for pigs and billygoats to tackle such a compound as that, but we boys all like to know what we are eating, and I cannot but feel that the public health officials of every township should require this formula of Dr. Gray's to be printed on every one of these big loaded pills, if that is what they are really made of. There is no such formidable indictment to be made against the New England May-apple; the worst that they can say of it is that it is an "abnormal excrescence of cellular tissue and chlorophyll," and of course we all know what that means, and how appetizing it is too. Nor is the small boy obliged to share his mess with the pigs, for the choice New England morsel is held far out of their reach. 
The true nature of the azalea May-apple was long a mystery. Some authorities believed that it was a gall growth caused by the sting of an insect, as in the oakapple. But I believe it is now accepted as a mere modified bud or extraordinary growth of pulp, whatever its origin. It has no seed, and its whole interior is of the same firm consistency.

But there are May-apples and mock May-apples, and the small boy may well beware of the latter poisonous variety. These may be seen hanging sometimes in close company with the azalea apples upon the Andromeda bushes, and are frequently gathered by mistake; and such would seem to be their artful object. But there need be no confusion, for though in outward appearance the similarity is striking, the interior of the false apple is found to be hollow and stringy. These mock-apples turn to black, unsightly pouches when they grow old, and at this season would seem to fulfil the Scriptural account of the "apples of Sodom," which "turn to dust and ashes," the interior of the mock May-apple being filled with ashen powder and remnants of plant-lice, for this growth is of insect origin.

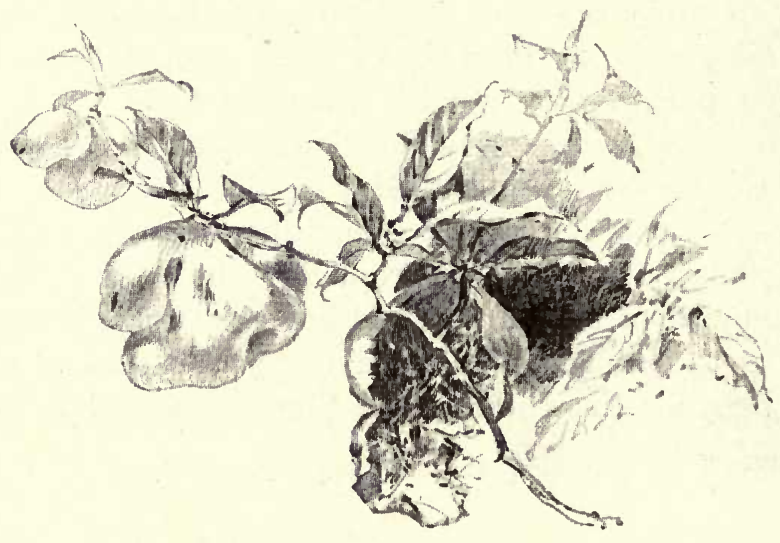




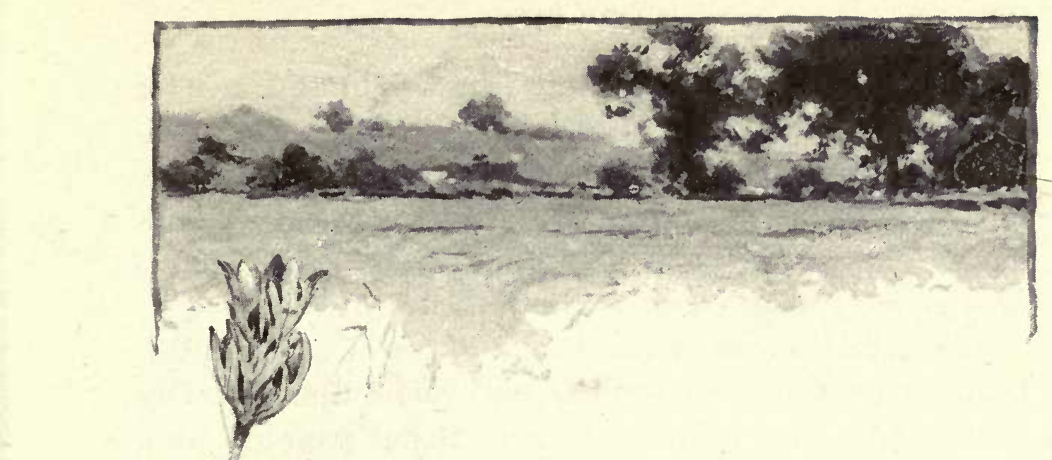

\section{THREE SLY FLOWERS}

\section{May 26 th}

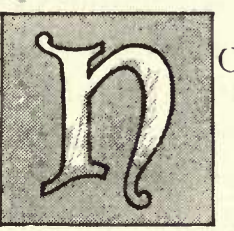

OT many of us have guessed the cunning mysteries of my trio of secretive blooms nor truly merited their confidences. These are the "painted-cup," the fringed polygala, and the dwarf-ginseng. Yes, we know them all; for have we not picked them a hundred times, even though perhaps we may not have known their names? They make

a pretty bouquet upon our mantel; but we little imagine what a quiet frolic is going on there at our expense.

\section{"Scarlet tufts}

Are glowing in the green like flakes of fire! The wanderers of the prairie know them well, And call that brilliant flower the "painted-cup."

Thus sings Bryant of this flower which is not a flower-this glowing display which floods not only the Western prairie, but our low May meadows of the East, with "meadow fire," as it is sometimes called. 
The "painted-cup" is perhaps the brightest touch of color among the whole wild bouquet. Even the cardinal-flower, its only rival, must yield to its intenser glow. A cluster of the flowering plants is dazzling in its brilliancy; and yet when we pay our tribute to the "flower," we are giving credit where it is not due.

The actual flower of the "painted-cup" is an insignificant greenish tube-like cloistered affair that is rarely detected by the ordinary observer, being guarded by a gorgeously attired retinue of leaves that acquire a distinction they do not deserve. The "cup" is composed of many flowers, each waited upon by an attendant leaf, suggesting a three-lobed cape, which seems to have been dipped to its centre in the most vivid scarlet paint. It is the accumulation of these which gives the color effect to the plant, and they are mere leaves in masquerade. Bryant calls them "bright beakers," and pictures them as "holding the dew for fairies." But it is a cup only in general outline, and would prove a leaky "beaker," although it has managed to hold its secret pretty securely from many of us for years.

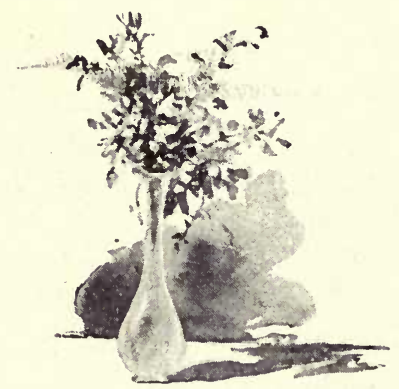




\section{AN UNDERGROUND FLOWER}

\section{May $26 t$ ir}

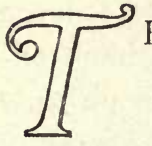

HE stroller in the moist May woods will well remember those mauve-winged blooms among the moss that seem to flutter in the breeze, like a brood of tiny purple butterflies with fringy tails, or in a sheltered nook appear to have settled in a swarm among the winter-green leaves. "False winter-green" the plant is commonly called, its leaves bearing a slight resemblance to those of the aromatic checkerberry.

It is one of our oddest and prettiest spring flow. ers; in its very singular shape quite suggesting an orchid, with its two spreading petals and deep lavender-colored tasselled sleeve. But, indeed, it has long been laughing at us in that

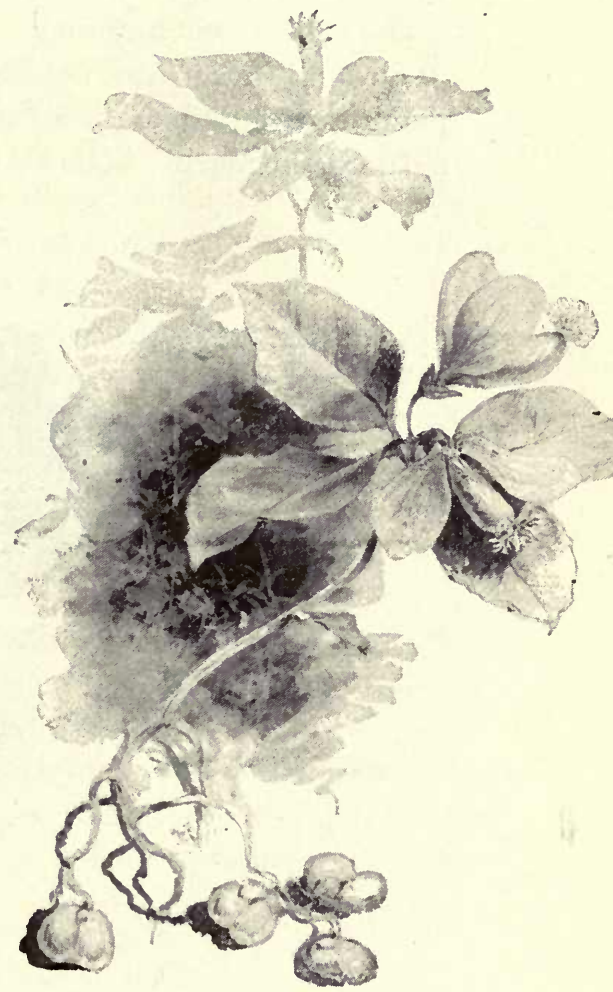


sleeve, as we have brought away its flowers from the woods, while we left its rarest and most important bloom behind us.

For the little polygala found out long ago that some means must be adopted to keep its foothold in the woods, so many were the eager hands that culled it every year. And so it formed a little plan to anchor itself in its home beyond the reach of bouquet hunters, offering one posy for the boutonnière, and another for mother earth-one playful flower for the world, another for serious use and posterity. But for this cunning resource I fear our pretty fringed polygala would have been exterminated in many of its haunts. Let us lose no time to seek the purple broods in the woods, and gracefully acknowledge our humility. These pale, pouch-like underground flowers are not beautiful to look at, but they plant the mould with seeds every year, and thus per. petuate the purple beds of bloom.

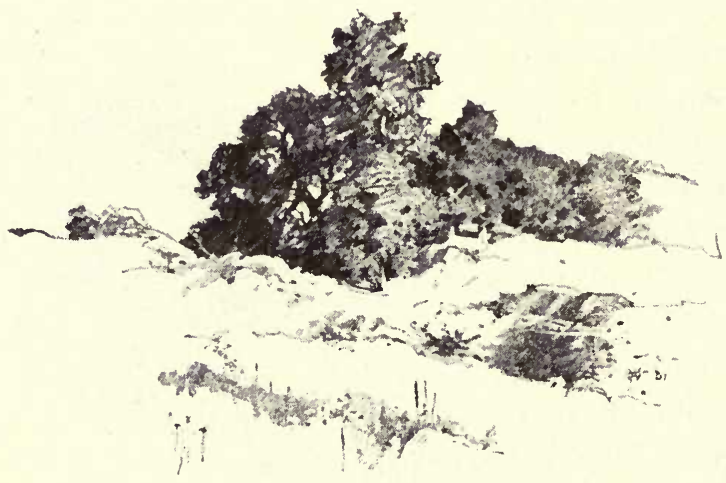




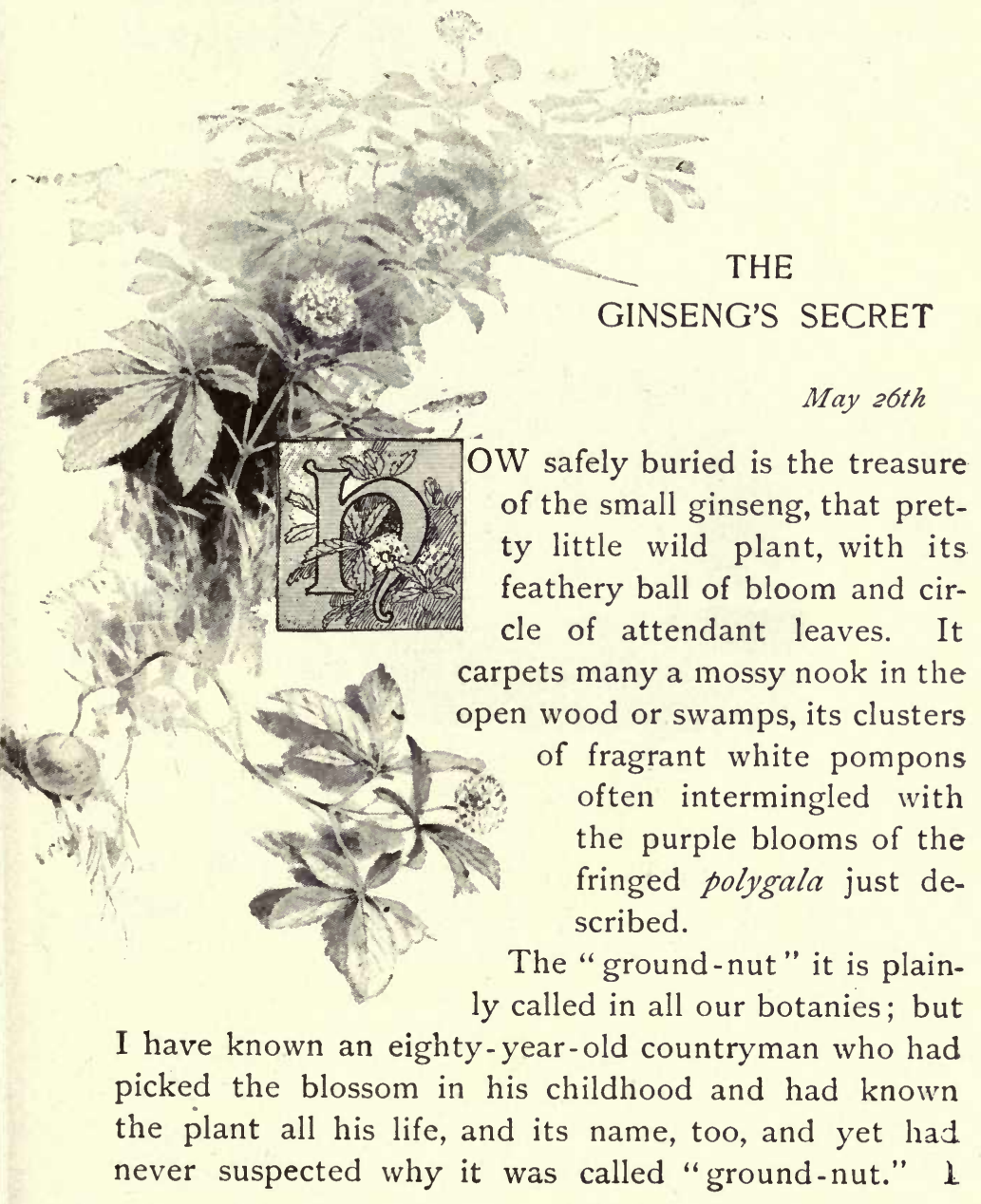


have also heard the plant called "pignut," which reralls Caliban in The Tempeșt :

"And I with my long nails will dig thee pignuts."

But the "pignut" of Shakespeare is the secret of another plant which grows in foreign soil. Nevertheless, not until we follow the example of Caliban and "dig" can we really claim acquaintance with our little dwarfginseng, whose sweet edible tuber deep under the mould, is known only to the few.

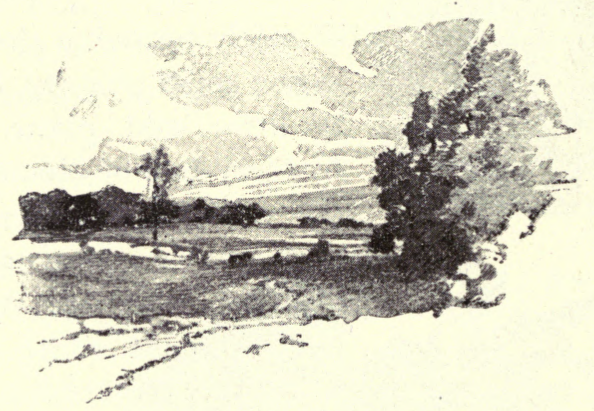




\section{THE BEWITCHED COCOONS}

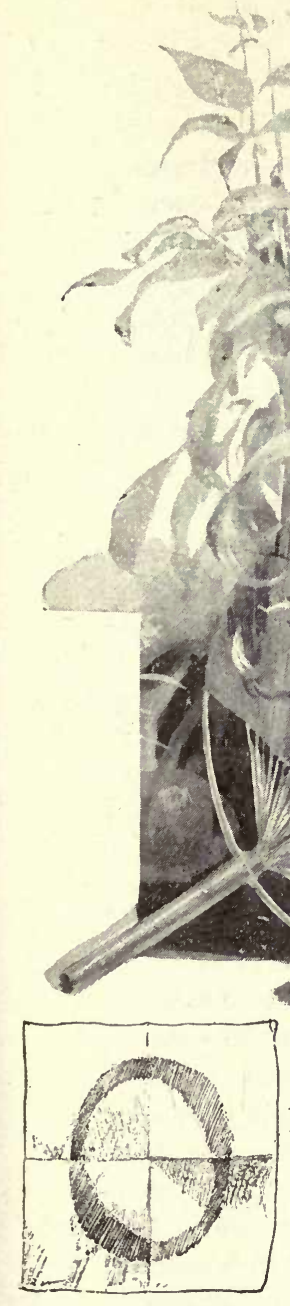

June $2 d$

$\mathrm{N}$ the table before me lies a letter from a young correspondent who has been having some perplexing entomological experiences of so interesting a nature that I have concluded to publish her account, and my answer.

“Dear Mr. Gibson,-I want to tell you what a funny time I had with those three cocoons that you gave me last winter. You remember they were quite large, and all wrapped up close in leaves, and were very hard, like parchment. You said that they 


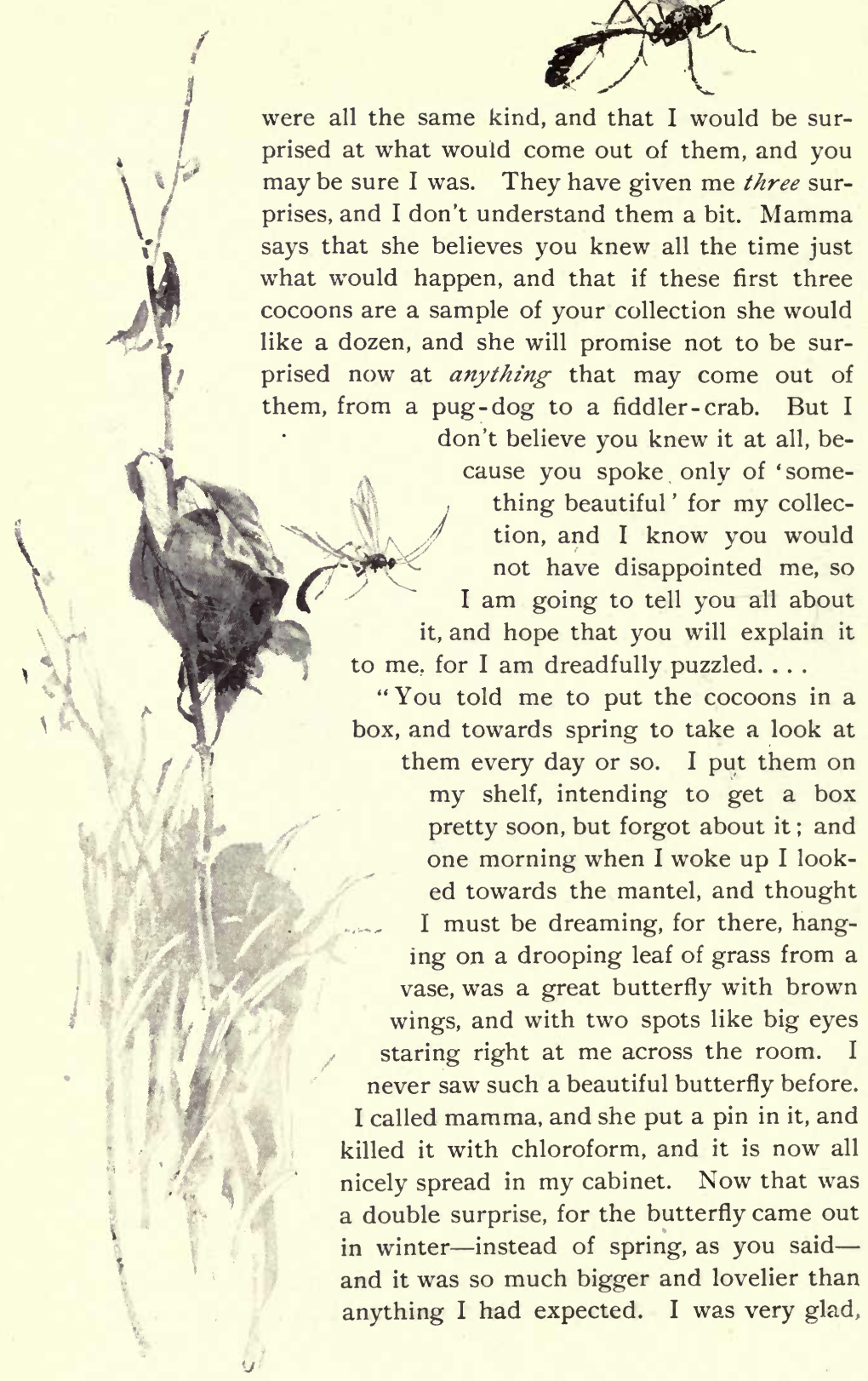


too, that I caught it before it had hurt its wings by flying about the room; and so as to make sure of the others, I put the cocoons right in a box, and looked at them a dozen times a day.

"The next surprise was one I shall never forget. One morning I opened the lid of the box and looked in, and what do you think happened? A great yellow wasp flew up into my face, ard almost frightened me to death. Mamma heard me scream, and came in and drove the wasp out of the window. He was a dreadful ugly thing, and I am very glad he did not sting me.... And this morning came the third surprise, and I don't know as I want any more of this kind of cocoons. I opened the box, and found it swarming with small wasps with red and black bodies and stings half an inch long. I was glad enough to let them fly out of the window. Are they the big wasp's young ones, or what?... Yes, indeed, your cocoons have been 'surprises,' as you promised -real mean frauds, I call them, and I shall not forgive you until you tell me all about them. I begin to believe, as mamma says, that you packed all this mischief into them yourself, just for a lark."

"MY DEAR YOUNG FRIEND,-I was greatly amused at your letter giving the account of your experience with those three Polyphemus cocoons. Never mind whether or not I knew how they were loaded; you may be sure that whatever 'mischief' was 'packed into them' was put there before they came into my possession. Bewitched they certainly were, but not by me. I can make a silver 'quarter' disappear, and mystify you with various card tricks, but I have no such magic touch as the witch that charmed those two cocoons.... I am sorry you did not keep a specimen of the 'ugly wasps' 
for your collection. You have had an instructive lesson in one department of entomology of which you knew nothing before, and those wasps should properly have had a place in your cabinet side by side with the beautiful moth; for, singular as it may seem, nature has designed that these insects should be quite intimately associated-much too intimately to be agreeable to the Polyphemus, as I will explain.

"As I told you, those three cocoons were spun by three caterpillars, exactly alike to all outward appearance, and of the species called Attacus (or Telea) Polyphemus. One of the cocoons has yielded its perfect development in the beautiful moth. The other two caterpillars did their best, poor things! to win a similar future, but that was a matter beyond their control; and their fate may serve the moralist as an illustration of what a sad transformation the deadly thrust of a little sin may bring about.

"The caterpillars were bewitched before they spun their cocoons-'voudooed,' as they say down

South. And the voudoo? Well, you let loose a whole brood of the witches to continue iheir, mischief when those 'wasps' escaped

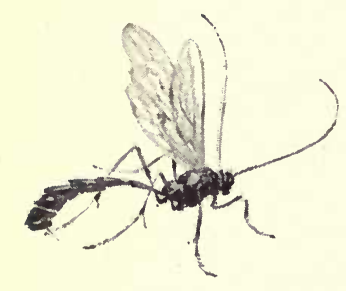


at your window. For your 'wasps' were not true wasps but ichneumon flies; the large one is called Ophion macrurum, and the swarm which you imagined might be the 'young ones' of the 'big wasp' are another species, from the third cocoon, with the same evil parasitical ways. Briefly told, their doings are as follows: These two species know a Polyphemus caterpillar when they see him, and to find them feeding among the leaves is the end and aim of their existence. Once discovered, they alight upon him, either thrust their stings into his body. or simply penetrate the skin, and, much against his will, lay a number of eggs, for the so-called 'sting' of the ichneumon flies is more properly the ovipositor, through which the eggs are conducted into the bodies of their victims. The caterpillars of the Cecropia and Prometheus moths are frequently to be found with their backs speckled with the tiny white eggs nearly the size of the letter $\mathrm{i}$ of this page. We shall get no moths from these caterpillars. The ichneumon fly has sealed their doom. These eggs hatch into minute larvæ that penetrate the caterpillar's. body, and feed upon the fatty portions, avoiding any attack on its vitals, and thus permit it to attain its full growth, and even to spin its cocoon as you have seen.

When once thus securely provided with a warm house for the winter, the ichneumon grubs, now nearly full grown, proceed to devour what remains of the unfortunate caterpillar host, until occasionally no vestige of him remains. With this final repast the larvæ reach their full size, and then proceed each to spin a cocoon for itself, thus filling the cavity of the Polyphemus cocoon with their own silky cases, packed side to side so solidly as to take the hexagonal shape of a honey-comb. The grubs then change to pupæ, and eventually make their exit through small holes in the outer cocoon, and fly abroad, to the terror of future Polyphemus caterpillars - and litíle girls.

"But that larger fly is certainly a formidable affair, and you are hardly to be blamed for a reasonable amount of caution; for though its sting is not so formidable an instrument as the smaller insect possesses, it is capable of ir flicting a severe wound, as I know from experience.

"So here you have the mystery solved-an instance of a phase 
$72 \quad$ SHARP EYES
of entomological life which is full of interest alike to the natl-
racist and the philosopher. I could tell you of other wonders of
ichneumon life even more strange than this; and if you are a
true student of entomology you cannot help but discover many
quite as interesting, only next time don't throw your lesson to
the winds."

4 

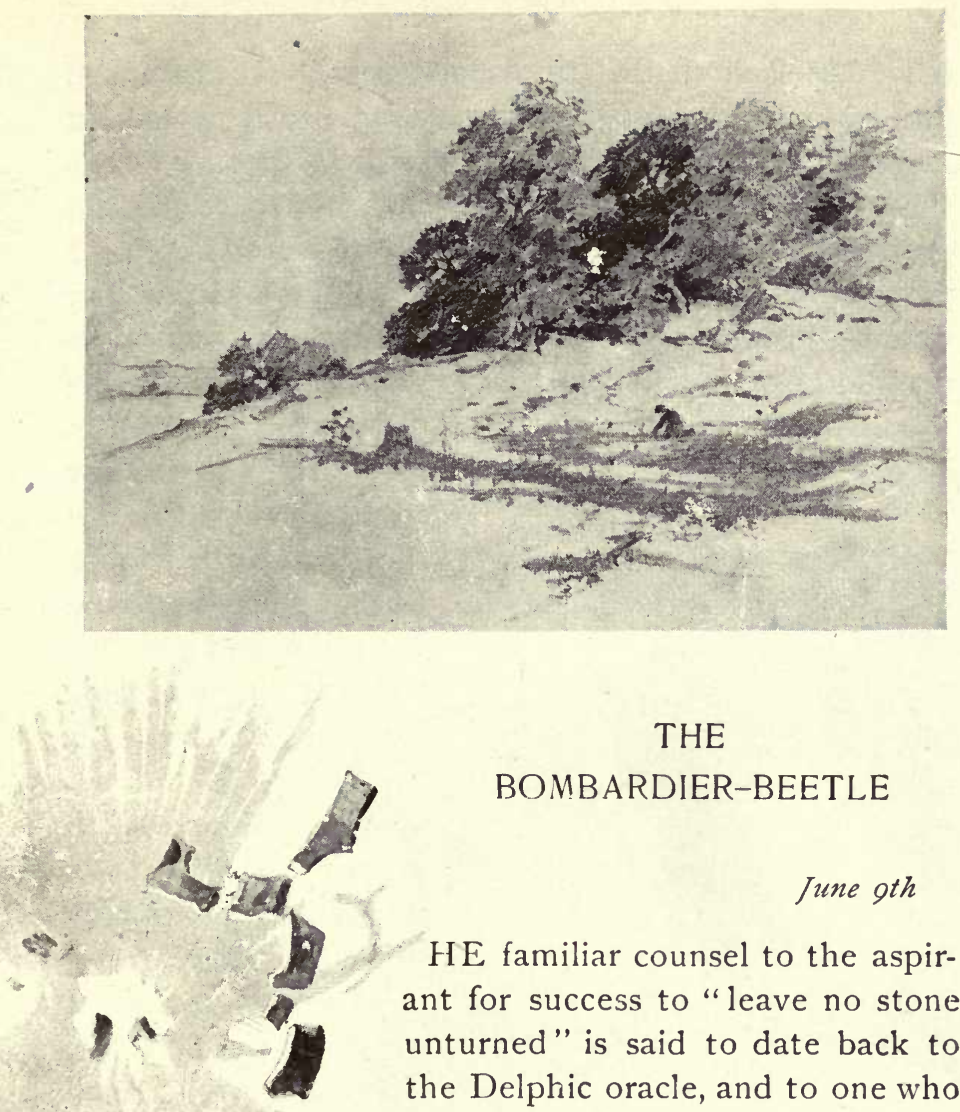

THE

BOMBARDIER-BEETLE

June gth

HE familiar counsel to the aspirant for success to "leave no stone unturned" is said to date back to the Delphic oracle, and to one who persistently follows the precept something worth while is generally sure to turn up. Even in literal fields, the country rambler who will "turn every stone," even in a small corner of the meadow, has many surprises in store for him. It has always been a favorite pastime with me, this overturning of stones, and I know not how many thousands of them, big and little, and even rocks, too, 
have disclosed their dark secrets to me. Under one I find a mouse-nest: another, a snake or toad; the next one may disclose the nest of the solitary bee, or brown wasp, or mud-dauber, or rare spider; and here I find a pretty orange-spotted salamander, or wood-frog, or a rare cocoon, to say nothing of all the host of squirming things-beetles, bugs, caterpillars, centipedes, iules, armadillo-bugs, and ants-which are among the certain dwellers beneath almost any stone in the field. Sur-

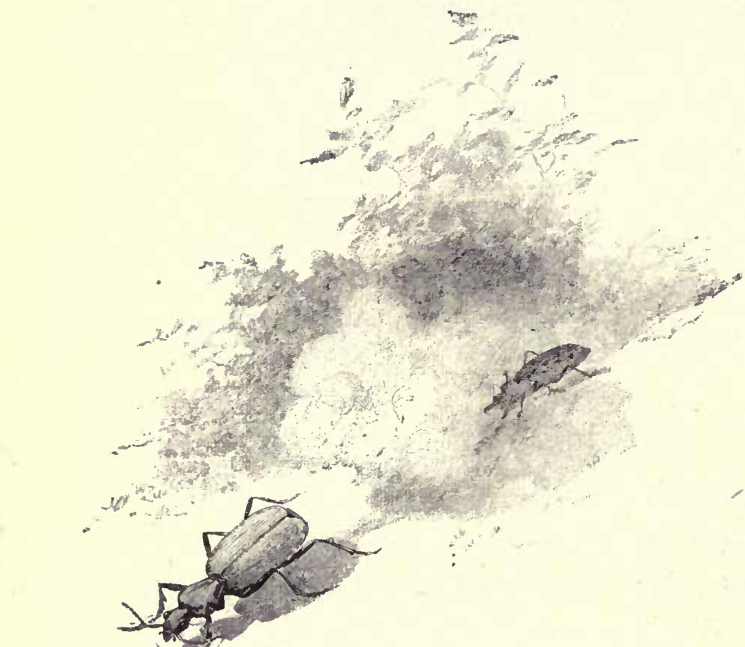

prise after surprise came to me, until at last I thought I had them all. But one day I found out my mistake.

I had lifted a large flat rock and turned it over, when I was immediately saluted with a distinct explosion, accompanied with a tiny cloud of smoke among the border grasses. I quickly parted the grass, and saw a small blue beetle partly concealed beneath a dried leaf. I sought to pick him up, when I was treated to a repetition of the explosive report and another cloud of smoke. Here was a curious freak indeed. A regular sharp-shooter, blue uniform and all. I captured my insect, and placed him in a collecting-box. Shortly afterwards, upon lifting the lid, the prisoner gave me another volley. But no provocation could induce him to further waste his pow- 
der. His ammunition was exhausted, and he evidently carried only three rounds.

I had heard of a beetle with these same bombarding propensities which was found in Europe, and called the "bombardier," but had never known of its being found in this country. After a night's

rest in captivity the explosive spunk of the insect was revived, and I got another round of three shots out of him, the puff of white smokelike vapor staining the tin on the in.

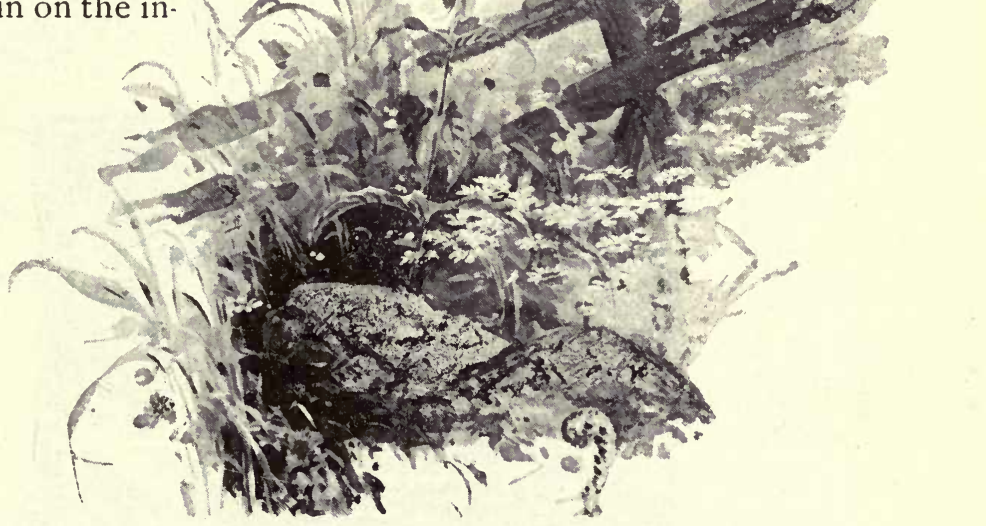

terior of the box and leaving a pungent, acid-like odor.

Since that first discovery I have found a number of the specimens, and their remarkable powers as cracksmen are a never-failing source of mirth, even to those who have served as a target.

It is said by the naturalists that this peculiarity of the bombardier affords a means of protection against its 
enemies, not only in its poisonous chemical properties, but the puff of vapor serves, perhaps, as a screen for escape, throwing dust, as it were, in the eyes of its pursuer, and analogous to the inky cloud of the cuttle-fish beneath the water. But why should the bombardier be thus favored? He has legs and wings like others of his tribe, and needs no such resource of escape.

Shall we dismiss all recognition of any humorous intention in nature? Has travesty no place in the divine scheme? I confess that, excepting as a bit of droll eccentricity, the bombardier has little to pique my philosophy.

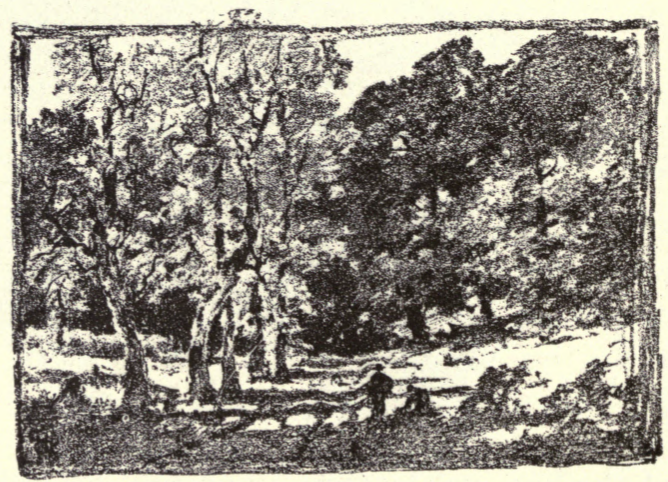



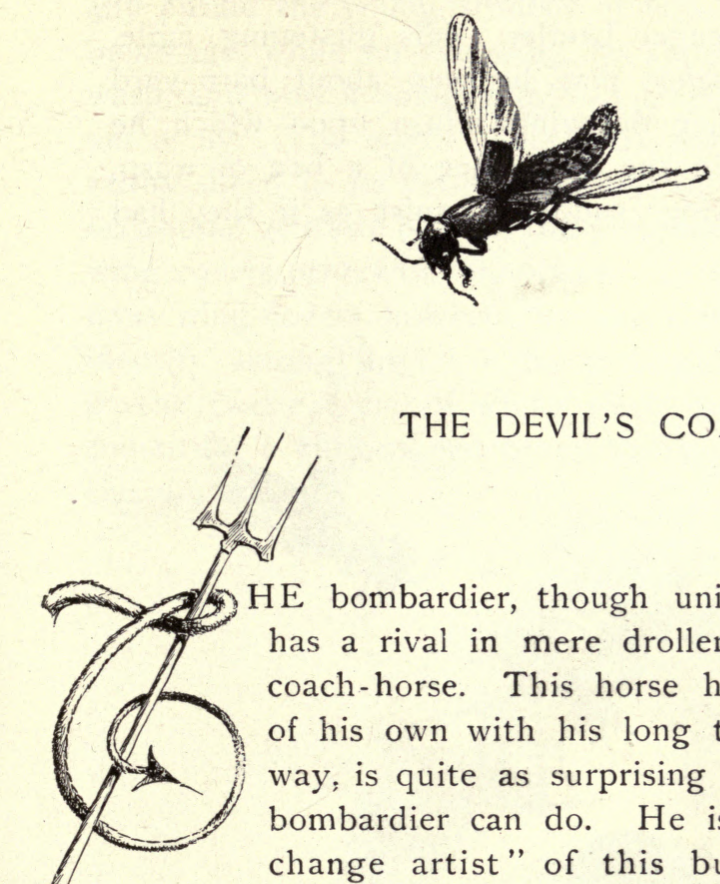

\section{THE DEVIL'S COACH-HORSE}

June gth

$\mathrm{HE}$ bombardier, though unique in his way, has a rival in mere drollery in the devil's coach-horse. This horse has an odd trick of his own with his long tail, which, in its way, is quite as surprising as anything the bombardier can do. $\mathrm{He}$ is the "lightning change artist" of this bug-circus, transforming himself from a buzzing, gauze-winged fly into a lively wingless bug in the twinkling of an eye. Here is a chance for our boys to test their eyes. There is a whole tribe of these profane horses, big and little. A butterfly-net swept among the meadow flowers and grasses will certainly capture a number of them - the smaller species - and their tricks can be observed through the meshes of the net as they fly from side to side. But the best raree-show is to be had from the large species, though it is quite in keeping that we must frequent haunts from which the polite nostril would naturally shrink if we would find the devil's finest coach-horse in his element, for the 
rove-beetle, as he is also called, is one of the tribe of carrion and scavenger beetles. His glistening, agile, and comical presence may be seen about barn-yard compost and other decaying refuse upon which he seems to alight in the semblance of a bee or wasp, when his gauze wings suddenly vanish as if they had dissolved into air.

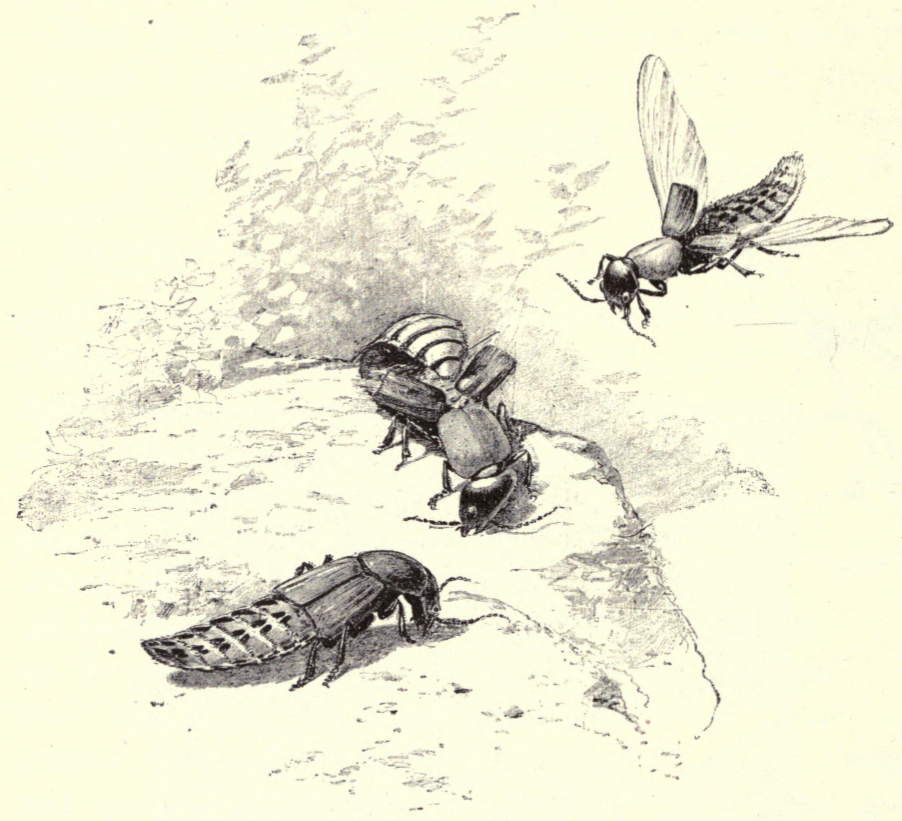

What is the hocus-pocus? Here comes one of the insects buzzing yonder over the grass. Keep your eye intently fixed upon him. Now he alights near by, and, quick as a flash, up goes the agile tail, and with its tip the large filmy wings are folded and tucked away beneath their tiny pair of wing-covers in a twinkling.

The identity of this queer devil's horse would natur. 
ally puzzle the young student of entomology. A moment ago, while on the wing, he appeared a veritable wasp, and now a nondescript - a kind of wingless hornet or fly. The edges of its body flash with a yellow satiny sheen in its various motions in the sun, and an occasional attitude betrays the presence of the two tiny wing covers otherwise unnoticed. In these unconspicuous wing covers, however, we may find our key to his identity among insects - the distinguishing character of the beetle tribe, of which these comical creatures constitute a curious exception and a distinct genusthe staphylinus. 


\section{BUT TERFLY \\ BOTANY TEACHERS}

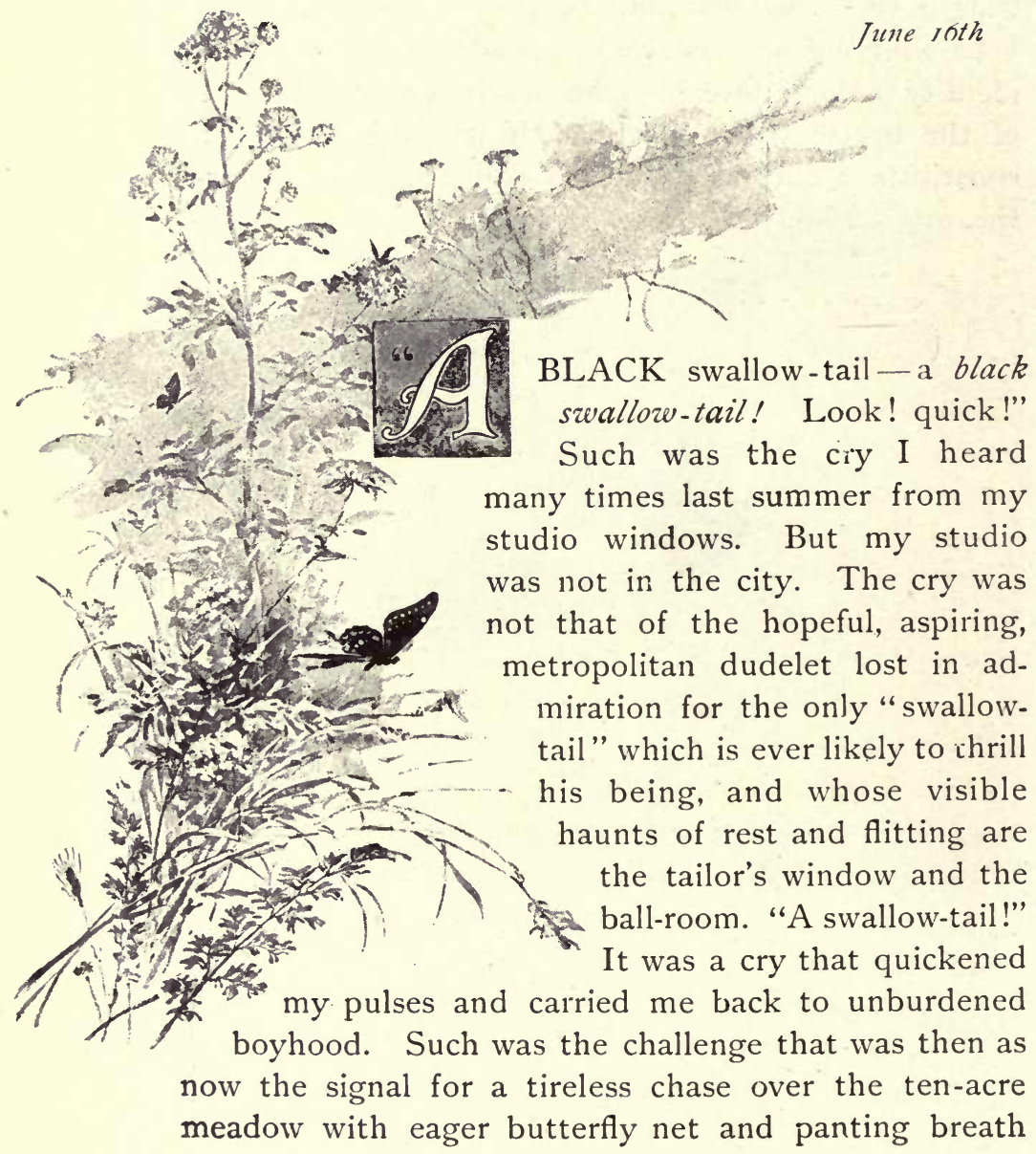


and vociferous exclamation of hope, defeat, or victory. That is only half a country boy who does not know the "swallow-tail" and the butterfly chase.

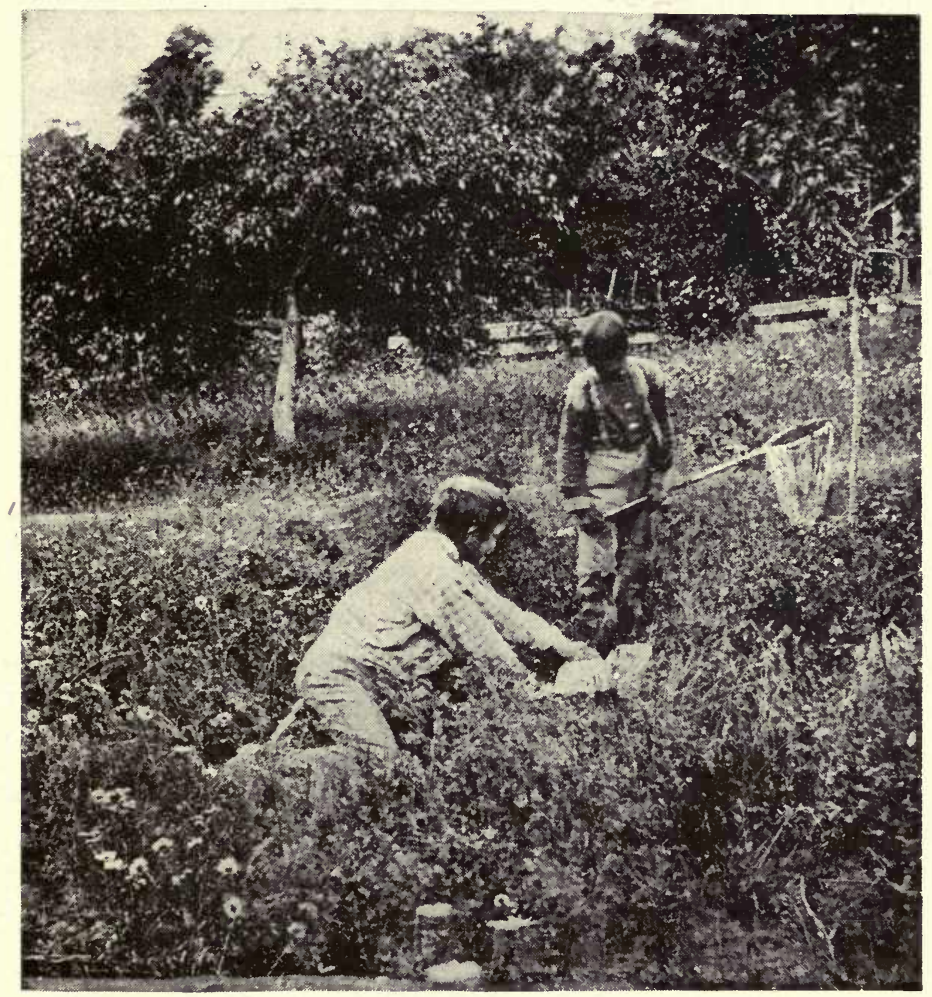

Yes, we country boys all know the velvety "black swallow-tail" butterfly and its fluttering poise above the clover blossoms; its two border rows of yellow spots and cloudy band of azure blue upon the lower 
wings, each with its red eye-spot and long tail. We have caught him in the meadow, we have found his gray chrysalis hanging under the clapboards, and have wished for a few more pairs of hands as we gathered the black-banded, gold-spotted, green caterpillars among the garden beds of parsley and carrot. We will say nothing of those yellow horns which he keeps so carefully concealed, and which he will display upon slight provocation, though, if he only knew it, he appears to much better advantage without this peculiar head-dress.

But while we knew our butterfly all our lives, captured him, mounted him, and with learned label, "Papilio Asterias," stowed him in our cabinet in the comfortable conceit that there was little else to be known about him, how few of us have thought of what a rare lesson in botany this Asterias has been wasting on us all these years?

In a previous volume * I have devoted a chapter to the botanical instincts among butterflies as seen in their selection of food plants for their young, and this Asterias is one of the most remarkable examples. Under his guidance during a single day we may learn a surprising lesson in botany.

We have too long thought only of the "idle butterfly" of the poet as the type of charming heedlessness, the "gay idler"-

"The sportive rover of the meadows .

Kissing all buds that are pretty and sweet,"

and sipping honey in "quiet ecstasy."

* Strolls by Starlight and Sunshine. 
Idle, indeed! Observe the insect carefully, my poet! Does my butterfly alight and linger on yonder leaf of carrot for honey? And now on the parsley leaf, and here again on the celery. For honey? Are there any flowers for it to "kiss" on yonder feathery leaf of fennel or caraway? And now it floats off across the field, joined by two or three more like itself. Let us follow their rounds, and carefully note the plants that they visit, excluding those visits in which the honeyed flowers are so evidently the sole attraction. Here is the list which you may count upon in advance, and upon each plant the eggs are laid that hatch into

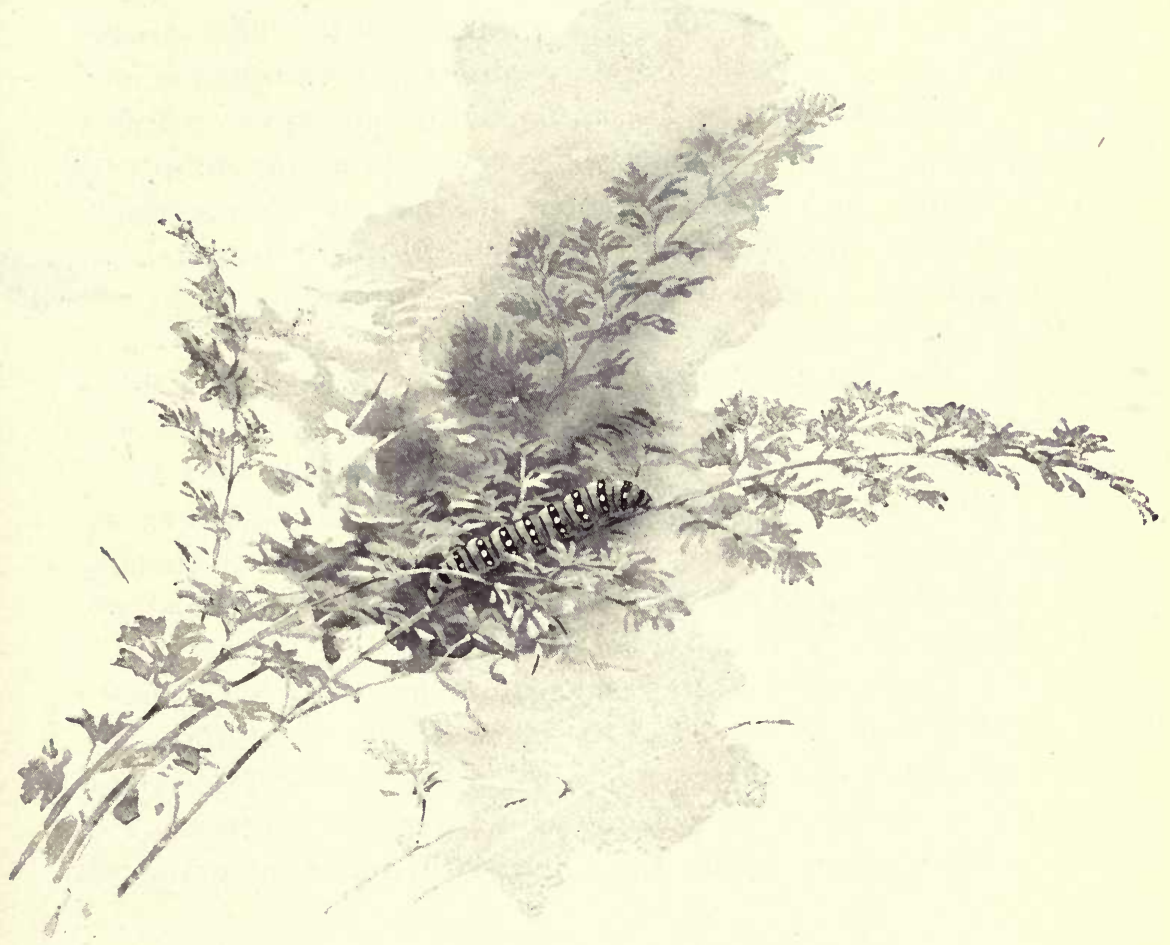




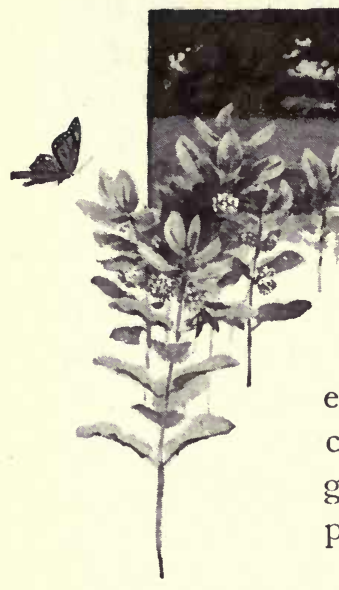

those beautiful green caterpil. lars: parsley, fennel, carrot, celery, poison-hemlock, cicuta, sium, dill, caraway, anise, wild-carrot, sanicle, angelica, archangelica, lovage, and waterpennywort.

This list in itself would not strike the ordinary observer as especially remarkable, and would seem haphazard enough to justify the poet's charge of heedlessness. It is not until we turn to our botany with our list that we learn its surprising meaning. Here we find all these plants grouped under the one order, Umbellifera, or the "parsley family."

The Asterias butterfly is an expert specialist in this one family of plants, and has never been known to go outside of it in its selection of food plants for its young. Remember, then, those caterpillars and the lesson that they teach, for upon whatever plant you find them, you may instantly class it as a member of the parsley family.

Then there are the Semicolon and Comma butterflies that will lead you to all the plants of the "nettle" family, while the little yellow butterfly picks out all the Leguminosa, or bean family, and so the list continues.

We all know the Archippus, with her deep orange- 
red wings veined with black, her black-and-yellow banded caterpillar that hides beneath the milk-weed leaves, and her emerald-green chrysalis studded with golden buttons. And what can she teach us? Her lesson is an interesting one, for I suspect that the $A r$ chippus can see further into the milk-weed tribe of plants than most of the botanists. The common silk-weed is her favorite, but if you search you may find her caterpilla: broods on various of our other milk-weeds, of which there are a dozen or more.

But how is this? Here I find them upon the dog-bane! What does our botany say to this? The dogbane is not included in the milk-weeds, though it is the next family in the flora, while its opposite leaves, milky juice, pods with silky seeds, and other resemblances in the flower, would certainly seem to entitle it to admission in the family. And as we look back into

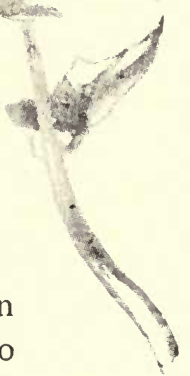


the history of the plant, we find that the earlier botanists, did include it in the family from which it has been removed only within comparatively recent time. It is really a question which is right in the matter, the butterfly or the botanist. I shall live in hopes of seeing the scientific brethren united in giving the priority to Dr. Danais Archippus, who doubtless classed the dog-bane with the milk-weed ages before the world knew a human botanist. 


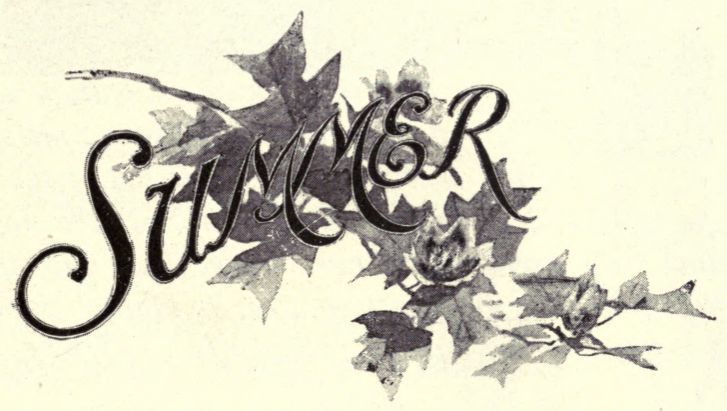


"NTOMOLOGY extends the limits of being in a new direction, so that I walk in Nature with a sense of greater space and freedom. It suggests, besides, that the universe is not rough-bewn, but perfect in its details. Nature will bear the closest inspec. tion; she invites us to lay our eye level with the smallest leaf and take an insect view of its plain. She has no interstices ; every part is full of life." -THOREAU. 


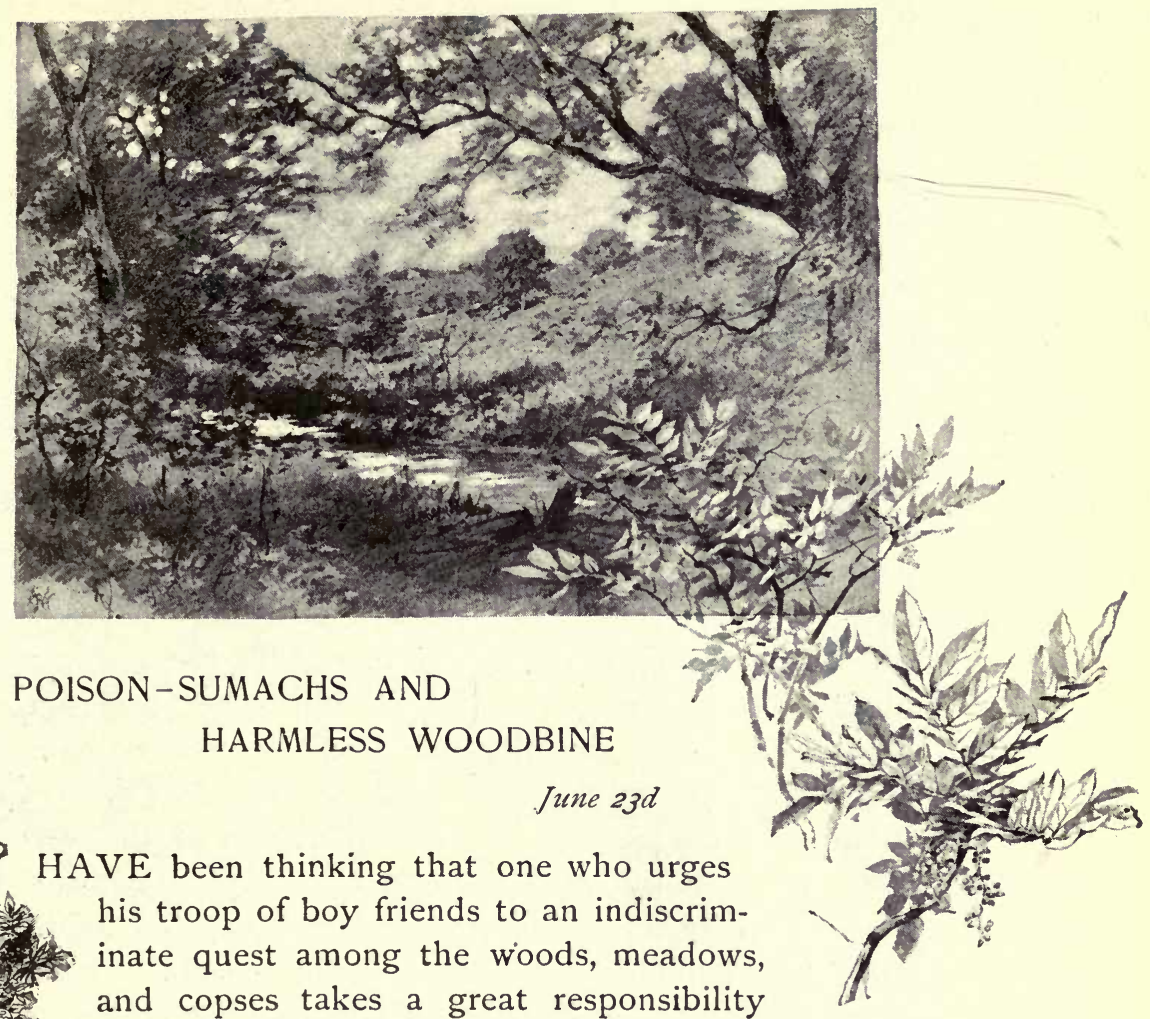
and copses takes a great responsibility upon himself if he fails to caution them of the dangers which they are certain to meet. I do not speak of wild-cats or snakes, but of a much more sly and perilous foe, the poison-sumachs, which lurk in every corner, and seem to lie in wait for their victims by every wall and in every thicket.

There is one page of botany which every dweller in the country should learn. The short chapter on the Rhus, or sumach, is easily committed to memory, and a few moments' study will equip any boy to meet the dangerous tribe on their own ground and give them a welcome or a wide berth, as they may deserve. 
There are five species of sumach which are more or less common in the eastern United States. The sixth species of the genus, Rhus aromatica, being especially found westward. Of these but two are poisonous--the Rhus venenata and the Rhus toxicodendron.

The first of these is a truly venomous plant, frequenting swamps and wet thickets, where its foliage blends with the alders and willows. It bears the popular names of poison-sumach, poison-dogwood, and poisonelder, and is a shrub varying from six to twenty-five feet in height, with foliage as suggested in the accompanying introductory illustration, consisting of about five pairs of opposite and a terminal leaflet, the form called "odd pinnate" in our botanies. To the ordinary observer it appears somewhat like the other sumachs, though on careful examination it will be seen to have a distinct, pert, mischievous, "all on end" look about it, caused by a peculiar upward inclination of the leaflets. Its swampy haunts should also serve in a measure to identify it; and though in the summer it might easily be encountered unawares, in the autumn it need never so waylay us, for, as Thoreau says, "it blazes its sins as scarlet" in its haunts, and is conspicuous.

The other poisonous species, Rluus toxicodendron, would scarcely be considered a sumach at all by the ordinary observer; its popular name of "poison-ivy" being quite expressive of its peculiar habit of growth. The other common name of "poison oak" applied to the same plant would seem to be rather inconsistent with the first, but the two are scarcely as inconsistent as they appear, for the Rhus toxicodendron masquerades in a variety of guises both as to foliage and manner of growth, the two extremes being so widely at variance as 


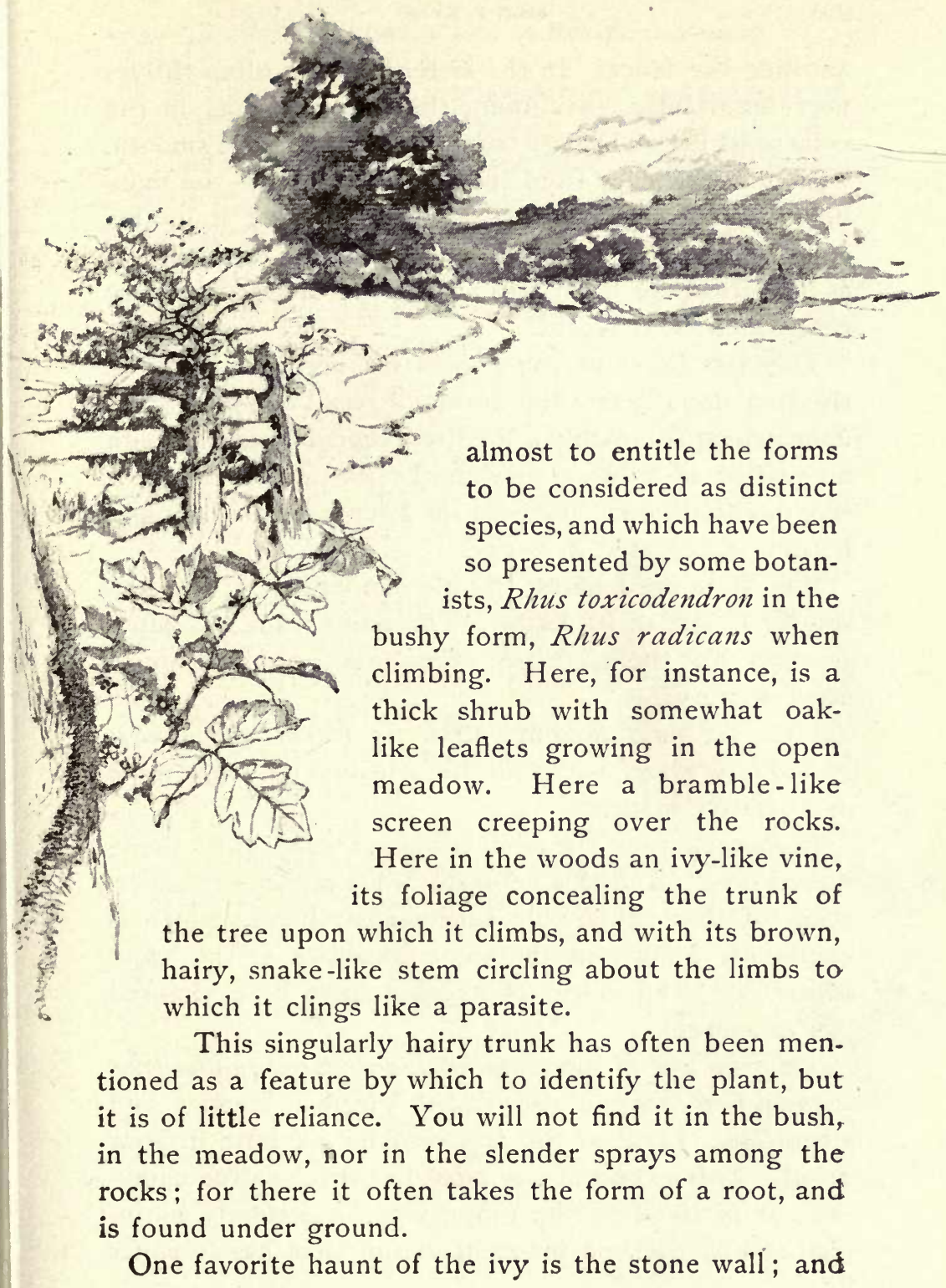


another, the fence. In the latter haunt it often thrives very luxuriantly, enveloping the decaying post in the coils of its brown shaggy trunk, and sending out smooth, bush-like branches from the summit quite in the manner of the true European ivy, not as we see it in this country, where it usually clings close to its wall, but as it everywhere luxuriates among the castle and abbey ruins of the Old World.

This last habit of the poison-ivy occasionally gives rise to a singular tree-like form. I recall one such specimen, which is possibly a hundred years old, and though no vestige of a fence now marks its neighborhood, it was doubtless once fostered on a fence-post which has become obliterated in decay.

But there need be no trouble in identifying the poison-ivy in any of its forms. The hairy trunk will often serve us, but there are two other features which are of much more value.

First let us remember that its leaves are always grouped in threes whatever the outlines of their more or less wavy margins.

In some sections the plant is always called the "threeleaved ivy." And this naturally leads me to a consideration of that other vine with similar habits which is commonly known in the same localities as the "fiveleaved ivy," and a leaf of which I have here pictured (see tail-piece).

This is a leaf of the Ampelopsis quinque-folia (quinquefolia - five leaves), also called Virginia creeper and woodbine. Look at the leaf, and fix its form in your mind. This is one of our most beautiful native climb. ers. It is allied to the grape-vine, is perfectly harmless, and is the one innocent victim that has to suffer 
from suspicion, being often destroyed under the impression that it is the "poison-ivy."

The writer knew of a person who possessed a beautiful nome upon the Hudson, and whose deficiency in knowledge of this one little page of botany cost him a severe ioss. His children were suddenly prostrated with ivypoisoning, and one of his " ninth hour" neighbors came in to offer him some learned advice-something in this style, as it was narrated to me:

"Well, Squire, it's fetched 'em at last. I've been tellin' Betsy all along that the pesky stuff would ketch ye arter a while. Well, thar, goodness and truth! Time an' time agin, when I've been goin' by the gate an' seen them air children playin' in the summer-house yender, it's made me feel 'tarnal ticklish, an' I've sed time and agin, an' tole Betsy so tew, that I'd bet my best gobbier they'd be broke out afore a week, an' now they've done. it; an' if you take my advice, you'll cut the pesky weed down an' burn it afore the hull on ye is ketched. You needn't look so surprised, Squire. What I'm tellin' ye is fer yure own good. That air weed is pizen-shumake, an' it'll nigh on to kill some folks."

Such advice, coming from a practical farmer in whom the "Squire" had perfect confidence, was immediately, acted upon. The vines which had embowered the beautiful arbor for a generation were sawed off at the ground. And to think that a peep into the botany might have saved them!

Four things need to be committed to memory to insure safety against our poisonsumachs:

First. The poison-ivy has three leaves.

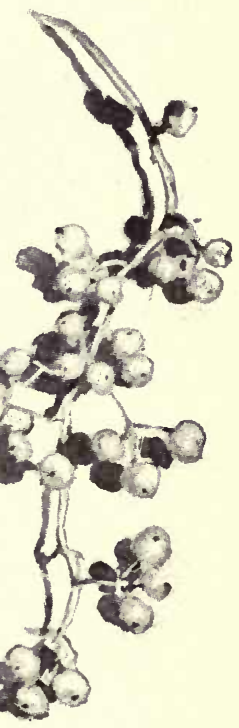


Second. The five-leaved is harmless.

Third. The poison-sumachs have white berries.

Fourth. No red-berried sumach is poisonous.

Both the poison-ivy and the poison-sumach, though unlike in appearance of foliage, have similar white berries growing in small slender clusters from the axils of the leaves. In all other sumachs the berries are red, even in the other three-leaved species Rhus aromatica, and in close bunches at the ends of the branches, and far from being dangerous, yield a frosty-looking acid which is most agreeable to the taste, and wholesome withal.

With these simple precepts fixed in the mind, no one need fear the dangers of the thickets. But for the benefit of that numerous class who " can't remember which it is, whether the five-leaved or the three-leaved that is poisonous," I would offer the following simple sixline jingle, which may easily be committed to memory and will prove an ever-ready guide in their walks:
Berries red,
Have no dread!
Berries white,
Poisonous sight!
Leaves three,
Quickly flee!

a perfectly safe mental talisman against danger. But to which I may also add as a postscript, in consideration of the one harmless three-leaved species, Rhus aromatica, which is else under the ban:

Leaves three, with berries red, Fragrant sumach, have no dread. 
No account is here taken of the five-leaved because it is not a sumach, and need not trouble us. With this at one's tongue's end, no one need repeat the hazardous exploit of two young ladies whom I know, one of whom, as a committee on church decoration in a country town, brought her arms full of the scarlet autumn branches of the venomous sumach; while the other once sent the writer a really beautiful group of carefully arranged rare grasses and mosses generously decked with the white berries of the poison-ivy. Both of these rash maidens, I believe, paid the severe penalty of their botanical innocence.

The harmless "Virginia-creeper" is occasionally a law unto itself as to the number of leaflets, not contenting itself with the five prescribed in its natural christening. A correspondent recently sent me a dozen or more leaves of this plant presenting the unusual multiplication of its leaflets to six, seven, eight, and even nine in one instance, all of course springing from the central common stem, as in the appended illustration of the typical leaf, an innocent plant which every lover or the country should recognize as a friend rather than ari enemy.

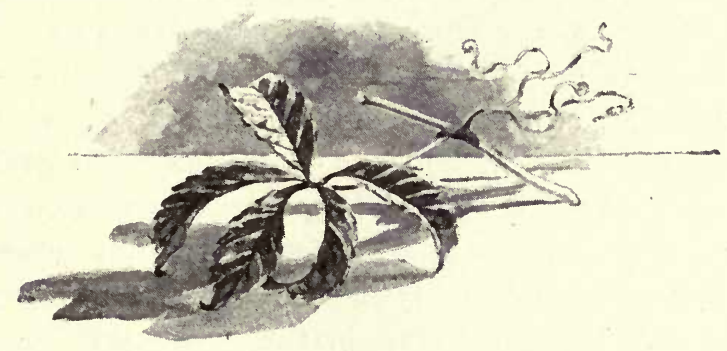




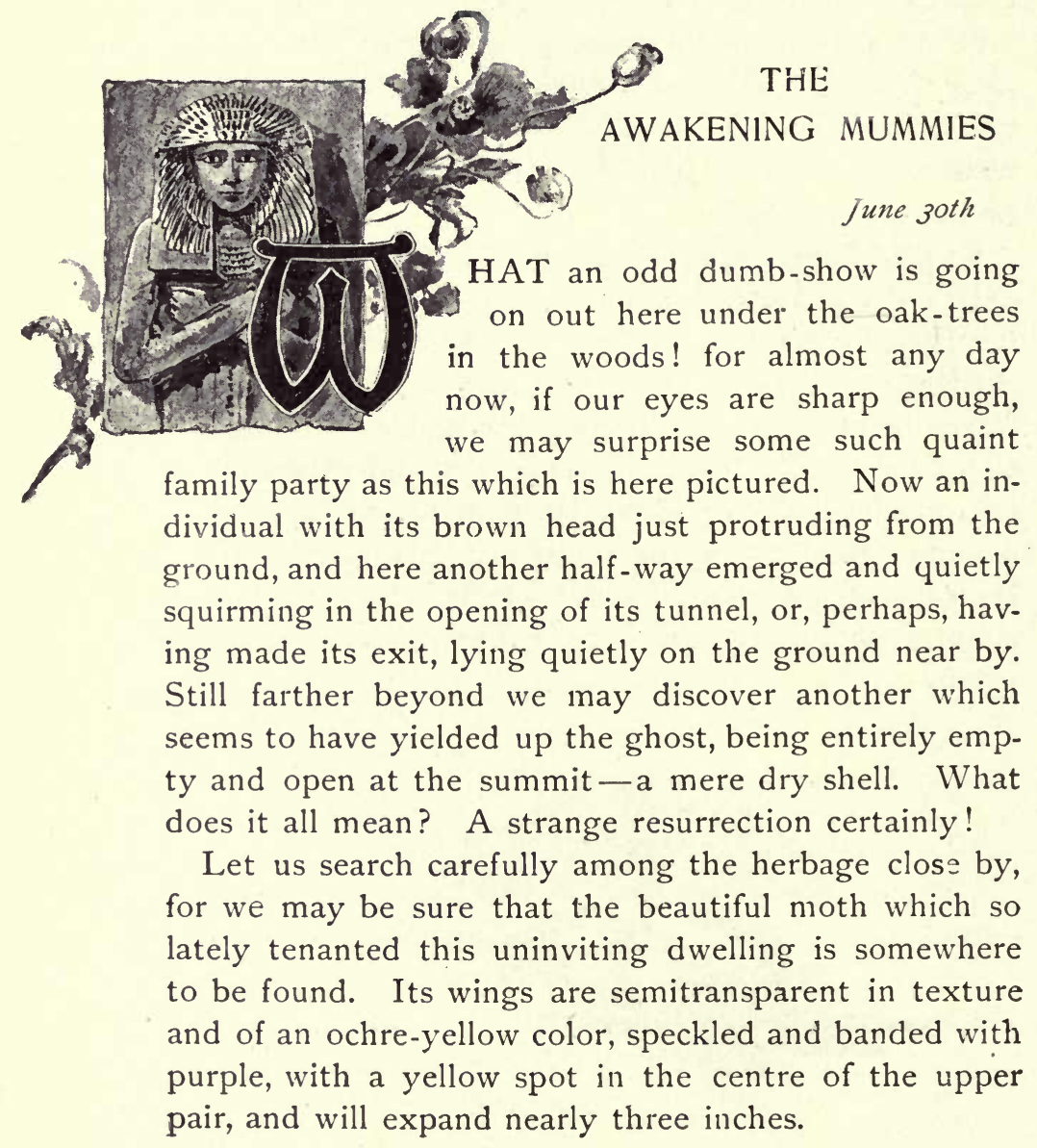




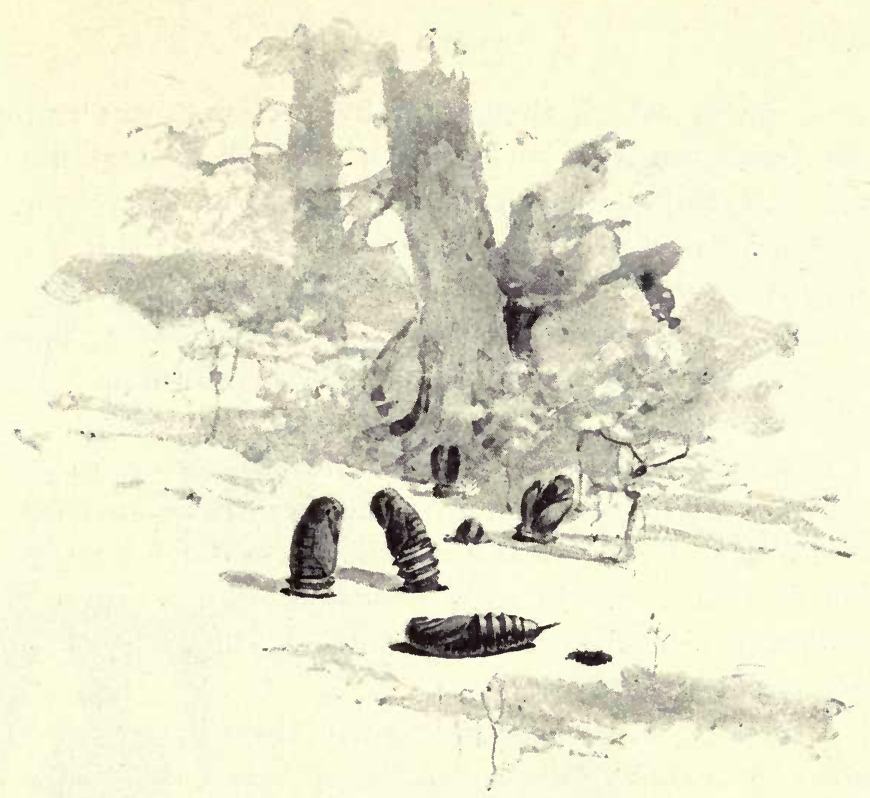

An hour ago this fuzzy creature nestled snugly in yonder mummy standing in its burrow, and when the twilight steals through the woods it will expand its filmy wings, and later, perhaps, flutter about the evening lamp upon our table. It is the pretty oak-moth (Dryocampa senatoria), a common insect known to nearly all juvenile collectors, but not all of them have seen the little pantomime of the chrysalids beneath the trees.

The episode affords an illustration of an interesting resource in the lives of many insects whose transformations take place underground.

The black and yellow striped caterpillars of the Dryocampa live in swarms upon the oaks, often completely stripping the boughs of foliage. When full grownat which time they will measure some two inches in length - they descend from the trees, and burrow in the ground to the depth of several inches, and within an 
oval cavity, which they form by persistent squirming, are transformed to chrysalids, which will average about an inch and a quarter in length. Here they remain through the winter, and in the last of June and beginsing of July, the moth being then almost ready to emerge, they work their way to the surface of the ground, and this explains my queer pantomime under the oak-trees. The ground beneath almost any oak which has been known to be infested with the caterpillars is certain to contain a number of the chrysalids, and if such a spot in the woods be carefully cleared of leaves with a rake in early June, the search, during the following weeks until the middle of July, is quite certain to be rewarded.

There are other exactly similar chrysalids from the same group (Dryocampa) which you are quite as likely to find - that of the "rosy moth," perhaps, whose caterpillars live upon the maple.

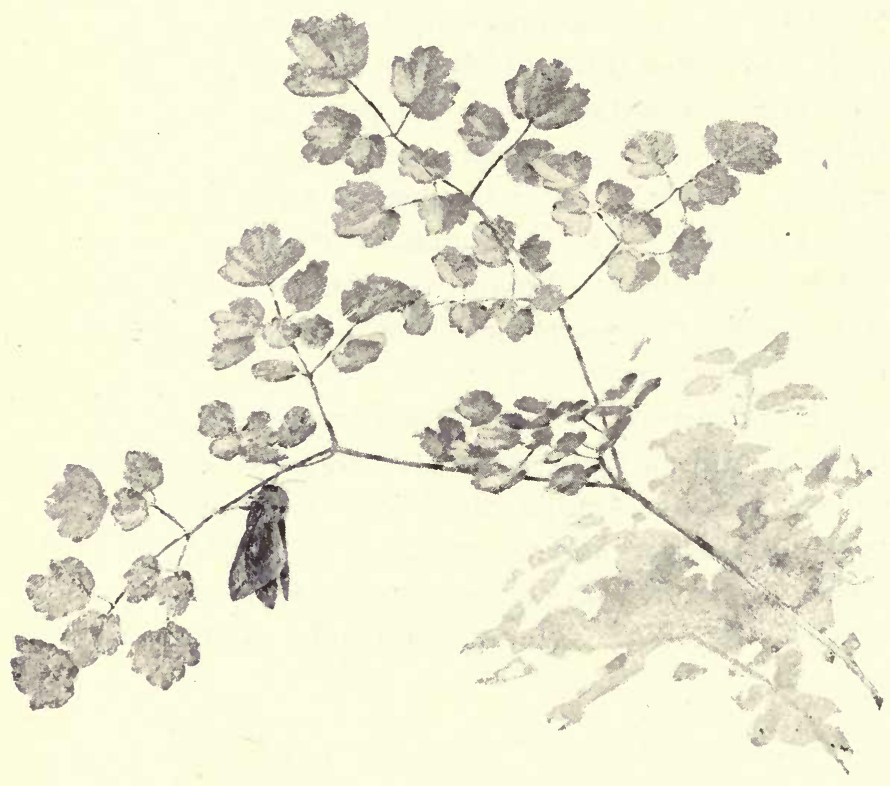




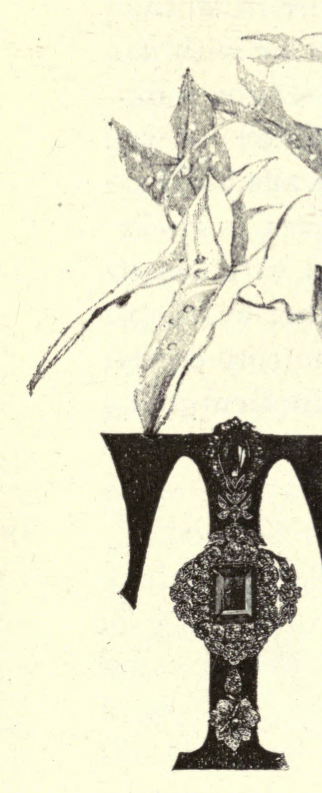

A WINGED GEM seen many entomological enthusiasts who have exclaimed with wonder and admiration at the brilliant beetle of the tropics, little dreaming that a few moments' walk along their own garden fence perhaps might have shown them a hundred native specimens which may challenge the Brazilian species for brilliancy. We have two notable examples, and while neither of them is very large, they are marvels of glitter and refulgence.

There is the little gold beetle, for instance, which should have the first place-Cassida aurichalcea. Where can he be matched in the world for the pure lustre of burnished gold? He is the brightest gem of concentrated metallic glitter that the whole beetle kingdom

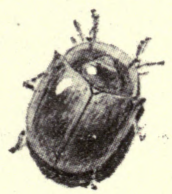


can show; and yet who ever sees him, even though in one short walk in the country lane he may have passed perhaps ten thousand of them-a gold mine in truth?

During the coming week the Cassida will be with us. But where shall we look for him? Wherever the pinkblossomed bind-weed blooms he also is sure to be found. This vine often clothes the stone walls for several yards beneath its arrow-shaped leaves. These leaves are generally more or less perforated with small holes; and if we quickly turn them one by one, or, stooping, look beneath them, we may surprise the tiny creature feeding, and appearing like a drop of molten gold, clinging like dew to the leaf. But you must be quick if you would capture him, for he is off in a spangling streak of glitter. Nor is this golden sheen all the resource of the little insect;

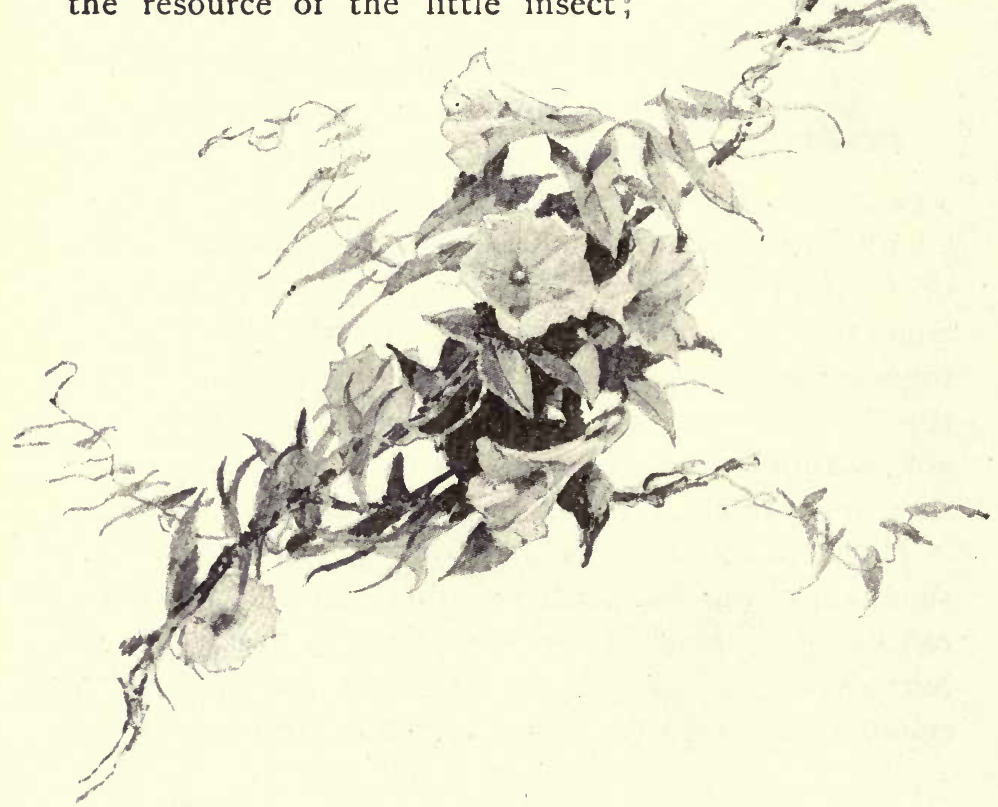


for in the space of a few seconds, as you hold him in your hand, he has become a milky, iridescent opal, and now mother-of-pearl, and finally crawls before you in a coat of dull orange.

A few of the beetles kept in a box and supplied with leaves, changing from gilt to mother-of-pearl or dull coral, as the whim suits them, are an interesting study.

Beneath the bind-weed leaves one may also find numbers of small black larvæ with a singular black lattice held suspended flat over their backs upon their forked tails. These are the inconspicuous and uncouth grubs from which our golden beetles have sprung, and a little search among the leaves will also disclose numbers of the tiny chrysalids suspended by their tails.

Don't let the summer pass without making the acquaintance of the Cassida. After the Ist of July he may be found until late autumn. You must see him at home if you would see him at all, for the dead insect loses all this wondrous lustre. The wild bind-weed is the favorite haunt of the insect, but the cultivated morning-glory even about our porch is often begemmed with these living jewels without our having suspected their presence.

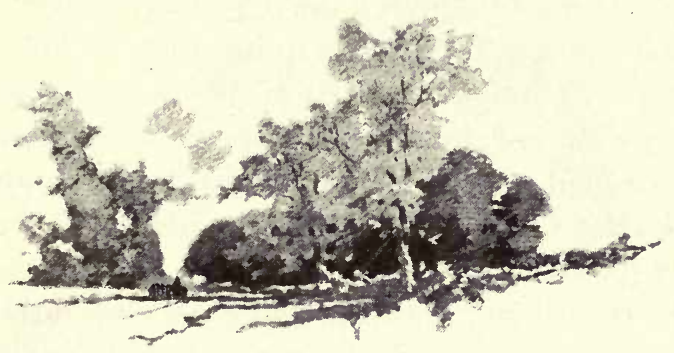




\section{THE DOG-BANE JEWEL}

Jine 30 th

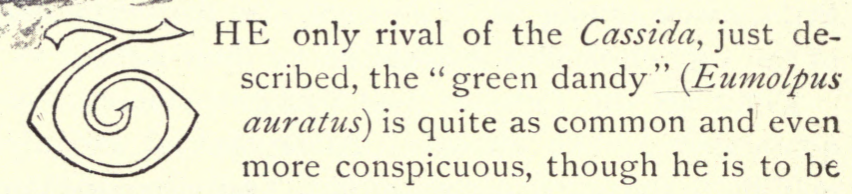
found only upon his single favorite plant, the dog-bane.

If the reader does not know the dog-bane plant (Apo. cynum androsamifolium), the accompanying sketch will serve to identify it, with its bell-shaped pink and fragrant flowers and long pods. It is a quite common plant, and favors the border thickets of woods and lanes and old walls.

During the coming week the dog-bane begins to deck its jewels, and the botanist is quite likely to find himself studying entomology instead of his favorite pursuit as he plucks his specimen of dog-bane, and discovers its leaves studded with glittering emeralds and rubies. For the dog-bane beetle is not golden-yellow like the Cassida, as its scientific name implies. It is not easy to describe its brilliant, burnished hue, which is either shimmering green, or peacock-blue, or purplish - green, or refulgent ruby, according to the position in which it rests. 
The beetle is nearly half an inch long, and is unsurpassed in the intensity of its color by any native insect of its tribe, while it suffers little by comparison even with some of the most brilliant tropical species.

As with the Cassida, the collector must act with promptness in capturing the beetle, for while it lacks the agile wing of the gold-beetle, it has an odd trick of drawing up its legs and dropping among the grass as you would lay your hand upon it.

Unlike the preceding, the intense color of the dogbane beetle is perfectly retained in the cabinet specimen, and a few of them judiciously disposed add greatly to the effect of a collection of insects.

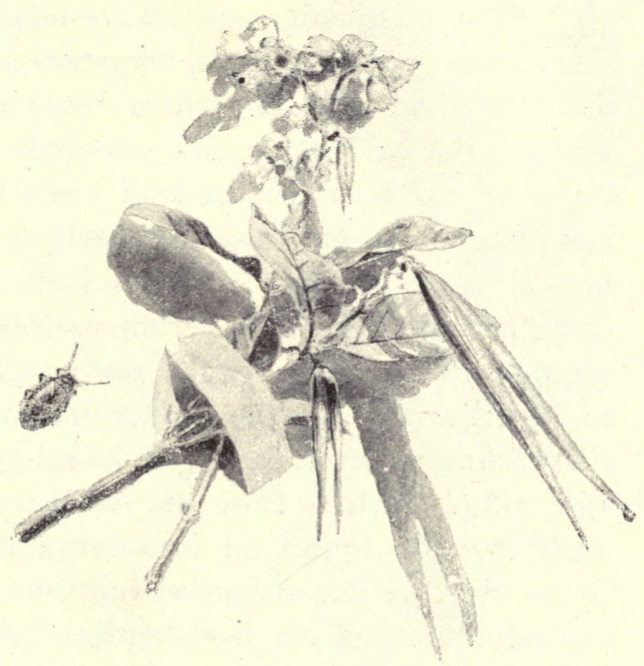




\section{THOSE HAZEL PACKETS}

\section{July 7 tis}

OR years I have seen these curious packets on the hazel, and similar ones on the alder. I have found them by the dozens brown and dry, and needing only a touch to dislodge them as they hung from their attachment; and I have found them fresh and green, as if the mysterious clerk that had done them up had left them for a moment to get a string. But no matter how patiently I waited for him, he never would return, and for years his identity was a complete mystery. Last summer I determined to catch him at his work, and I did; and am now able to give some account of his clever hocus-pocus - or rather, I should say her hocus-pocus, for my little clerk proved to be feminine. If the reader has never seen any of these curious little packages hanging upon the hazel and alder bushes, they are well worth looking up. They may be found all summer, and occasionally are to be seen by dozens on a single bush. In each case the same method has been adopted, the leaf being first folded face to face along the midrib, and then tightly rolled from tip to stem, and here retained in its com- 
pact coil by a true touch of jugglery, for there is no resort to pin or string, nor even a web to be seen.

There is a real knack about it all, as we may very easily learn by trying to do up one of the packages ourselves.

I had long suspected a tiny brown beetle, which I had occasionally observed suspiciously near the bundles, as their author, and last summer I was fortunate enough to see my suspicions verified. Chancing upon a hazel bush which was hanging full with the little packets, many of which were still fresh and green, a careful search disclosed one of the tiny insects at its work, and here is the process, the secret magic tie, and the deep-laid plan which it all involves: The beetle first bites through the leaf to the mid-vein close to the stem, and partially through the midrib also, leaving barely sufficient of the same to retain the weight of the leaf, which soon wilts in the hot sun, and in its limp condition is ready to be rolled. It is then folded face to face along the mid-vein, the bee-

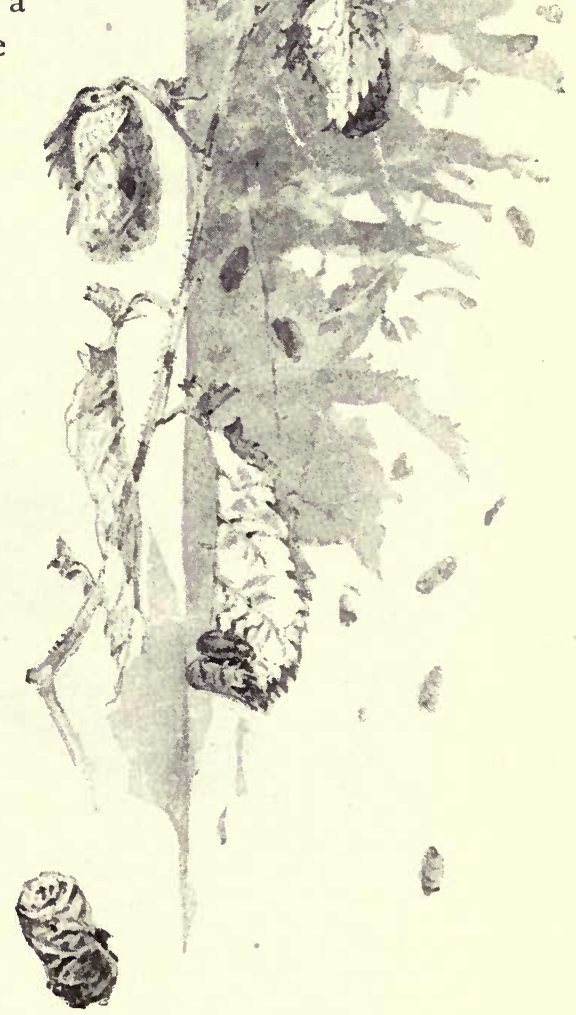


tle compressing it with its legs. A tiny yellow egg is then deposited at the extreme tip, and the weevil, standing sideways, and holding firmly to the leaf with its upper feet, passes its three lower legs beneath, and starts the fold, the roll being thus carried to the sum. mit, the insect alternately taking a fresh grip farther up the leaf with each successive pull. Upon reaching the top, a loose cut edge of the leaf is turned backward to overlap the last fold of the coil, and thus serves to. hold it in place. Without this deft touch the coil would unroll. The bundle soon bakes brown in the hot sun, and shortly falls to the ground. The tiny egg subsequently hatches into a minute grub, which feeds upon the dried interior, and at length, the following spring, emerges a perfect beetle.

I have seen the ground beneath the alder bushes: strewn thickly with the little packets, hundreds of them in a small space; and, considering the industry and number of the package clerks, it is singular that I could have waited so long to discover them; but this is explained in a sly trait of the beetle, which cuddles up its legs and drops to the ground on your approach, unless you are very wary.

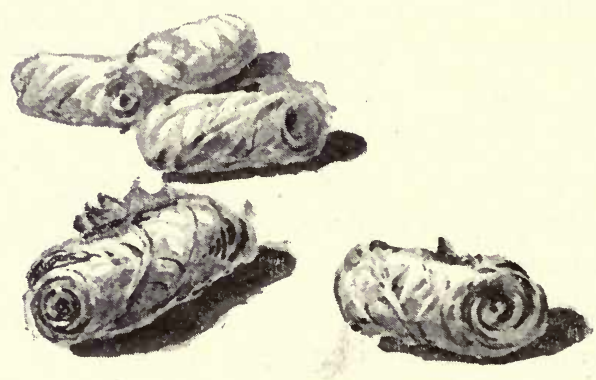


named Equisetum, or "horse-tail." In place of seeds, it perpetuates its kind by the aid of spores, which are secreted in the fruit-like heads at the tips of the stems, and when ripe are shed in clouds in the wind. Each fruiting head is composed of a compact arrangement of six-sided cells, and beneath each of these the spores are formed. They float out like yellow dust, upon every passing breeze. But it is lively dust, indeed. Let us pick this opening fruit, and shake a little of the powder upon the glass of our pocket microscope. Upon looking through the lens we see a myriad of motionless yellow spheres covering the field; but in a moment it becomes a wriggling, squirming mass of life, and in a moment more the entire legion are jumping for freedom, and sailing off with their buoyant wings. A pinch or so of the spores shaken in the hollow of the hand appears like mere yellow powder; but even with the naked eye, after the lapse of a half-minute or so, it may be seen to transform, gradually swelling to a bed of yellow downy fuzz, occupying several times the space of the original powder. If a drop of water is allowed to fall upon it, the fuzzy tuft appears to melt and contract; and as the water evaporates, the same downy development is repeated. A person seeing these squirming legions in the microscope for the first time would certainly suppose he was looking upon the liveliest swarm of living animalculæ. Alive they certainly are; but, in spite of appearances, the curious objects are mere vegetable spores endowed with this singular faculty to insure their propagation. When first seen upon the microscopic slide they appear as yellow spheres circled with four small ridges; but as the whim takes them, these ridges suddenly uncoil, and after a brief period of 
twisting and wriggling the spores leap from the glass, and the wind then takes care of them.

The secret of it all is very simple, however. These strange antics being merely the singu-

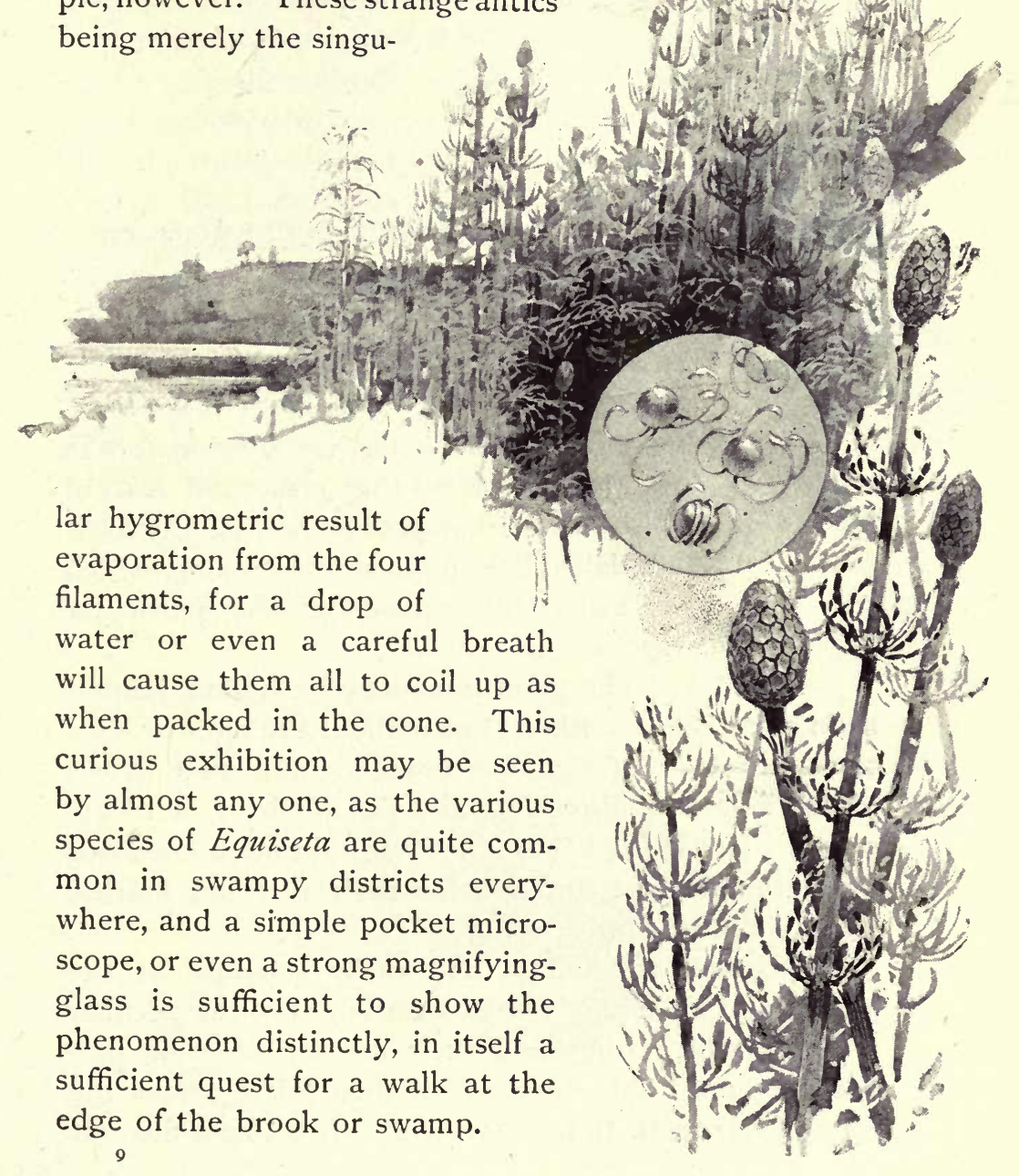




\section{THE STONE SKELETON OF THE SCOURING-RUSH}

\section{July $7_{\text {th }}$}

MUST not omit a further allusion to the other very interesting structural feature of our scouring-rushes, particularly as it explains this popular christening, which is especially applied to one particular species--E. hyeriale.

The plant consists of a hollow jointed main stem like the others, but without the circular clusters-whorls-of fringe-like branches, and often grows to the height of three feet and the diameter of a leadpencil. It was from these that our old-time housewives made the scouring-brushes for their tins and kettles, already alluded to.

The stems are hollow, and easily separate at the joints; and if we would satisfy ourselves of the peculiar property which suggested their use for scouring purposes, we need only draw one of their joints across the edge of our teeth to be convinced. It is like a file. It 
THE STONE SKELETON OF THE SCOURING-RUSH

II I

is, in fact, as much a mineral as a vegetable tube that we have here, as may be shown by a very pretty chem. cal experiment.

If we take a small vial of nitric acid and immerse any ordinary leaf therein, we shall quickly see it dissolve - literally eaten up by the acid. But what does the scouring-grass do under such treatment? Immediately upon its introduction to the acid the sizzling process begins; the green pulp of the stem is gradually consumed, the tube, however, still retaining its shape, becoming paler and paler in color, until, after a few hours, our specimen is transformed into a pure white alabaster-like column, which defies any further attack from the acid. Upon taking it from the vial and washing it carefully in running water we hold in our hands a beautiful tube of pure glassy flint or ilex, and an object of great microscopic beauty of construction. Our scouring -rush is no longer a vegetable, but a mineral, and, in its skeleton of stone, we easily understand the secret of its utility as a scouring -brush. 


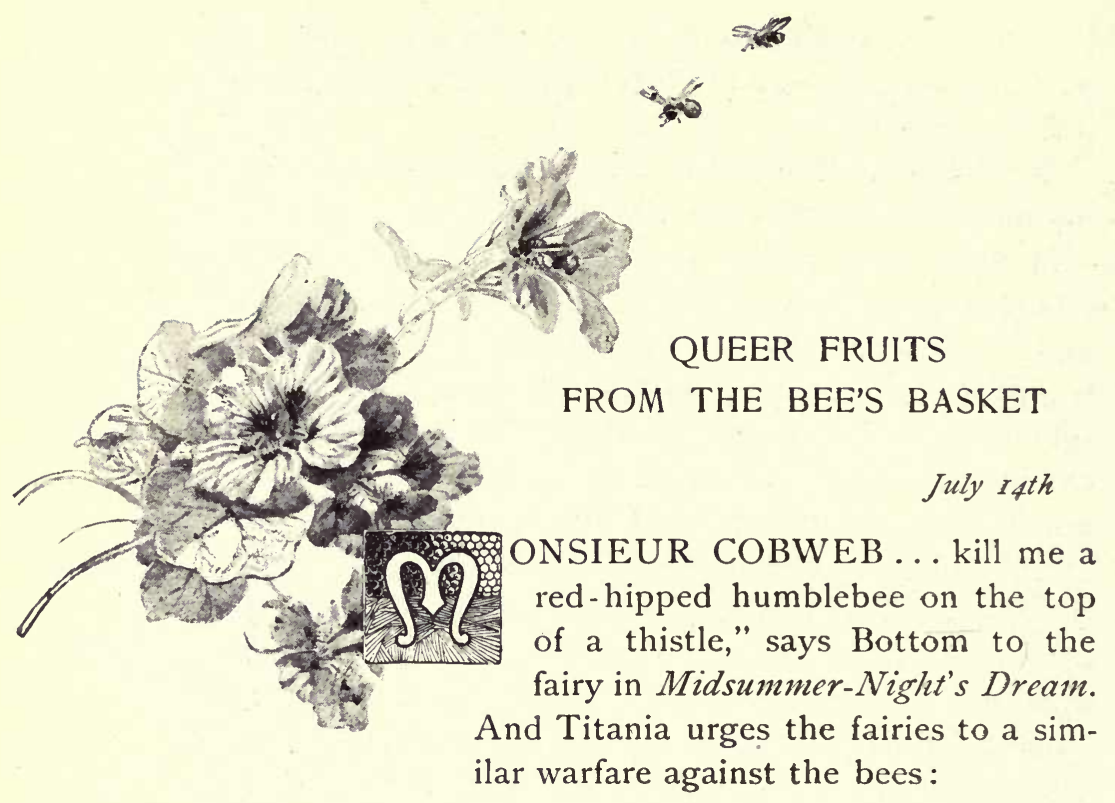

"The honey-bags steal from the humblebees, And, for night-tapers, crop their waxen thighs,"

but Shakespeare gave expression to a very common error when he implied that these "thighs" of the bee were laden with wax. The bee, whether the honey-bee or the humblebee, has two distinct errands in his visits to the blossoms. "He gathers honey all the day," 'tis true, but he also plunders the flower of its golden pollen at the same time, as we all know, from the plump "baskets" which we see him carrying as he hies back to the hive.

But these yellow "saddle-bags" are not "wax," as Shakespeare implies, nor have they any connection with the structure of the honey-comb. They are, in truth, 


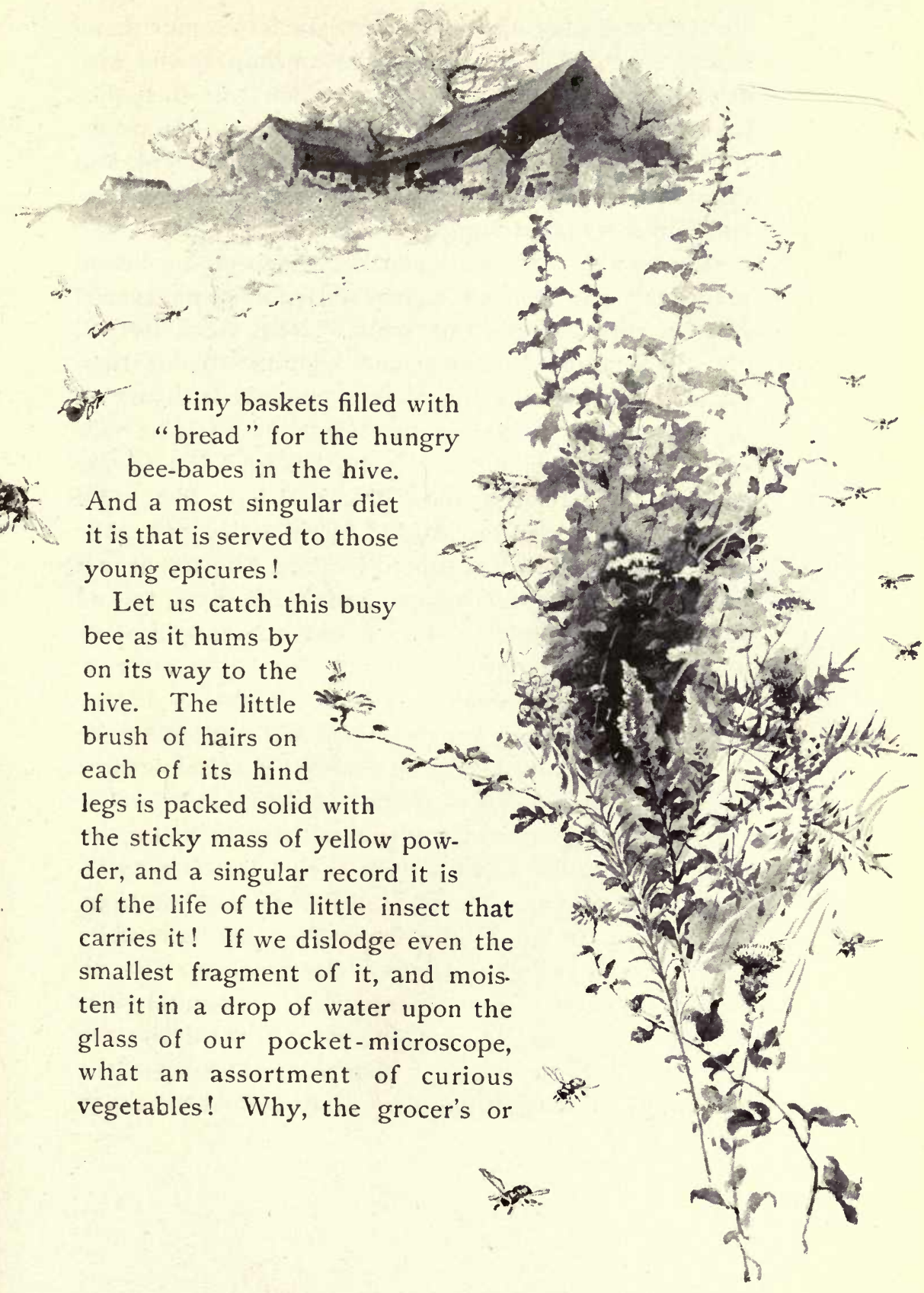


fruiterer's display upon the sidewalk is not a circumstance to it. There seems to be no limit to the varieties of rare and curious fruits which this busy bee manages to find in his visits to the flowers. Here are tiny melons and eggs and pears, prickly oranges, and decorated marbles, queer tea-boxes, bomb-shelis, bricks, and odd sorts of packages of all kinds.

It is true that this particular bee which we have captured may have shown a partiality for some special form of fruit for this one week. Next week he will give his little ones a change, and again the week following, or with a special bill of fare, perhaps, from day to day. But at any time we are sure to find quite a variety of choice foreign fruits in his basket. Indeed, are they not all foreign to most of us? I have pictured a few, and the reader can decide for himself; and while he need scarcely expect to find this full assortment in a single field of his microscope, he is quite likely to find some of them; and if not, is certain to see still other forms of equal strangeness and interest.

Did you ever imagine for a moment what a display of rare watermelons your fair friend has sported on the tip of her nose after one close sniff of the meadow-lily? Look at the microscope slide and be convinced.

In the foreground of my group there is a singular three-lobed affair which is from the enchanter's nightshade. A little to the right of this is another triangular shape. Who would ever suppose that this webby pollen of the twilight primrose was made up of such particles as these? The generous mountain-laurel gives us four tiny oranges in a bunch; for such is the singular atom which those jumping stamens scatter upon the soft wings of twilight moths. That curved specimen 
with spherical ends is blown by myriads from the blossoms of the pine, as is also the funny pepper-box far above, though you need not expect to find either of them in our bee's basket, for the wind always takes care of these. Above this is seen a grain from the garlic flower, and the spirally grooved sphere of the musk flower is shown beyond. The prickly form which is shown at the left is the tiny explosive bomb from the big melon blossom, blowing off one of its caps and discharging its powdery contents; the smooth-banded prickly specimen at the centre is a similar product of another of the melon tribe-the common wild star cucumber, whose clambering vine screens many a fence by country lane or roadside. Between these melon tokens we see the pretty manysided box which is turned out by the thousands

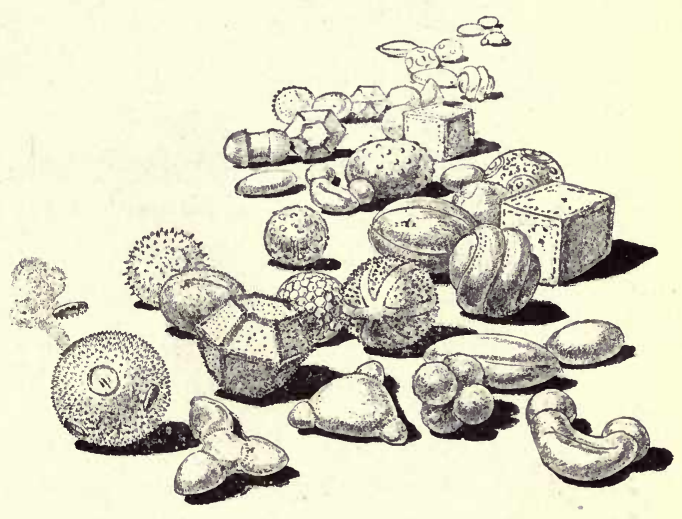
from every blossom of the blue chicory, while the square chest near by is the form of package preferred by the basella flower. The clover, the daisy, the thistle, the golden-rod, dandelion, hollyhock, phlox, trailing arbutus, nasturtium, have still other forms; and, indeed, each separate flower is true to some precious whim in the shape of its pollen, and among them will be found an endless variety of forms with all manner of exterior decoration-bands, checks, spots, reticulations, grooves, punctures, and other sculptured devices. 
These atoms are all interesting and beautiful objects under the microscope, and to the botanist who examines the bread-basket of the bee they may form a complete telltale record of the insect's round among the flowers.

But this golden grist of the bees is not always an unmixed blessing. Like its prototype in human affairs it occasionally reduces its owners to the most complete slavery. The milk-weed blossom will afford a ready illustration of this, and will well repay a careful examination. The pollen of this flower is concealed from view, and is a veritable trap. It does not wait to be gathered, but clasps the legs of unwary insects, and often accumulates in such quantity as to prove a serious handicap to the flight of its victim. I have found bees thus helpless, and a careful search upon almost any cluster of milk-weed blossoms will disclose some diminutive or weak insect held prisoner by the pollen which it had not strength to remove, and thus made a helpless prey to the first prowling ant that chances its way.

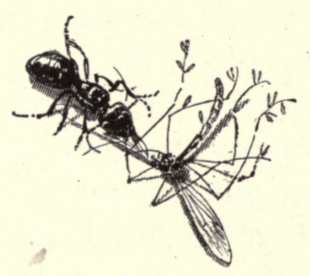




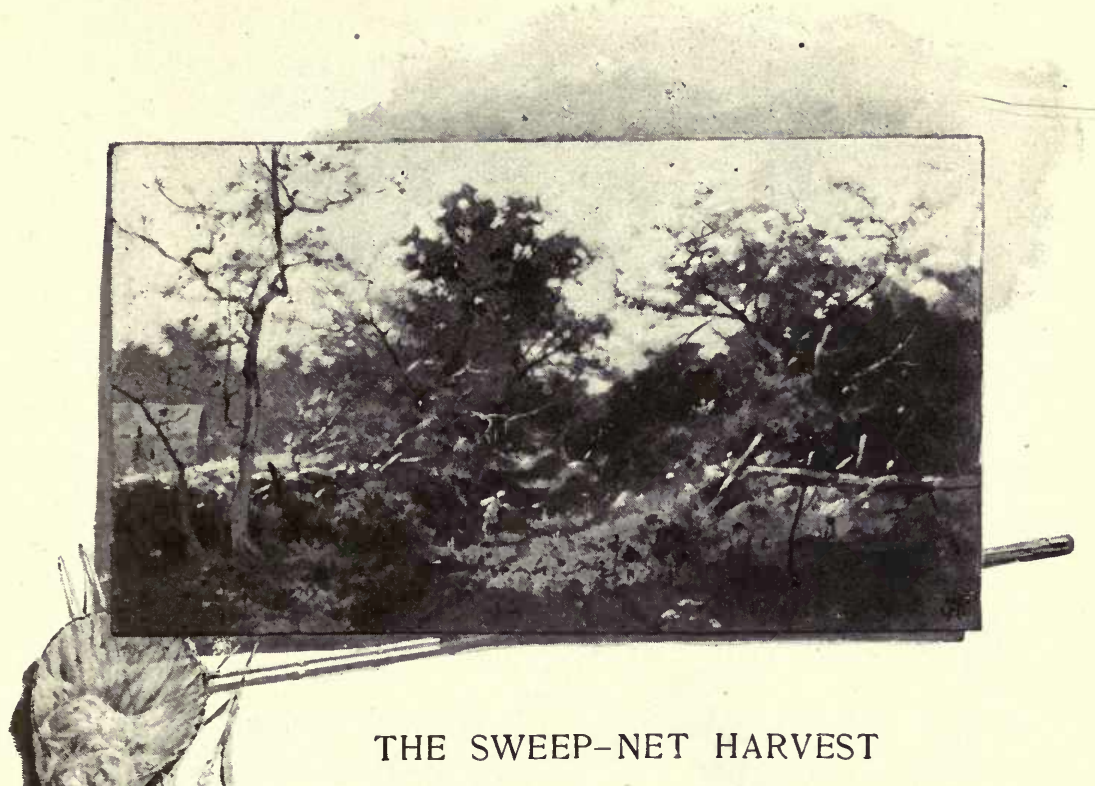

\section{July 2Ist}

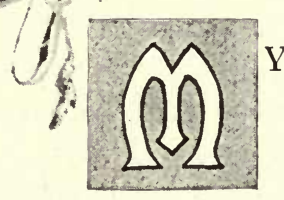

$\mathrm{Y}$ butterfly-net and pocket magnifying-glass are rare companions for a walk in the country. I have often had occasion to recommend these simple means of quiet entertainment on a sultry August day beneath the trees, and I would not let my summer calendar pass without again calling attention to the sprightly instructive harvest which our sweepnet may bring us.

What a revealer of the teeming life that peoples the grasses! One or two trips across this open sunny spot, with such a light sweep-net skimming the grass-tips and herbage, will bring in under your shady tree or 


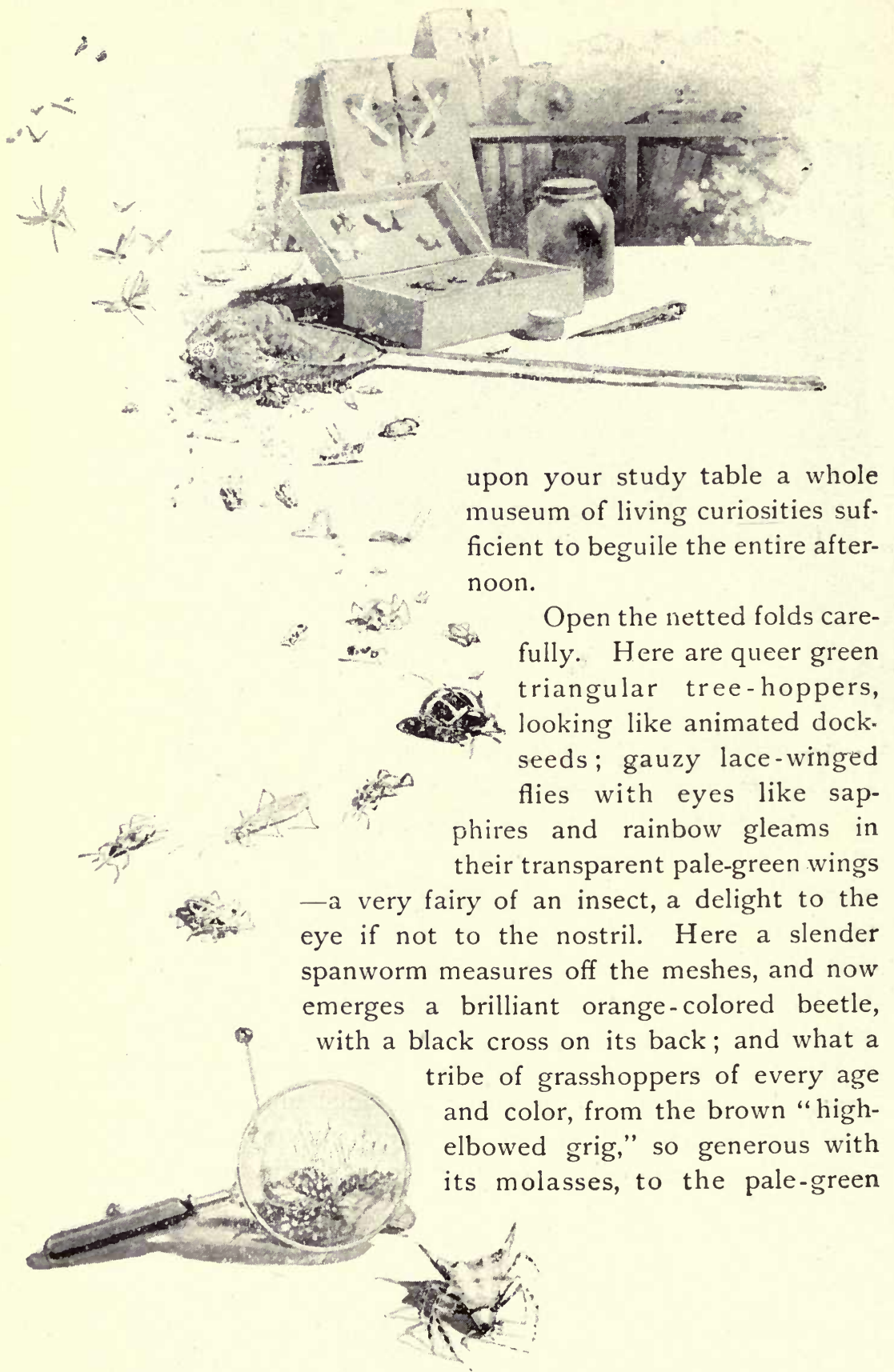


tree-cricket, whose shrill song you so abruptly brought to an end with your stroke of the net! Here, farther down, we observe a slight commotion among the animated chaff and grass seed, and a brilliant gem of a beetle creeps forth, green as an emerald and lit with ruby reflections, almost the brightest jewel among our native insects, and whose presence here in the net is conclusive proof that yonder plant of dog-bane must have come within the sweep of your net.

The lively procession continues to emerge as you open the netted folds. Here are spiders of every shape and size and hue-yellow and brown and green, round and flat and three-cornered-glittering tinselled flies, perhaps a leaf-cutting bee, ants and aphides, longlegged crane-flies, aphis-lions, and jumping "snapbugs."

Even the sedimentary accumulation at the bottom of the net is now seen to be animated with insect life; the dust of pollen and withered anthers of the grasses are alive with agile atoms-tiny creeping soldier-bugs, with beaks upraised for war, feather-headed gnats, lady-birds in variety, tiny orange-colored grubs - parasites from the bodies of the very grasshoppers in your net. Quick! Turn your glass upon this frail plumy-winged moth which now creeps from the folds. And now this spry black midge; see with what marvellous rapidity it curls upward the tip of its agile tail, and tucks its buzzing wings beneath those tiny covers on its back after each short flight among the meshes - an atom of a rovebeetle, with the same dexterous trick of the devil's coach-horse, which I described and pictured a few weeks ago.

Nor have I named all the surprises in store for you 
even from this one "haul" of your net, while each successive sweep is sure to bring in its sprightly novelty. Don't let the summer pass without making the ac. quaintance of the broods that dwell among the grass. 


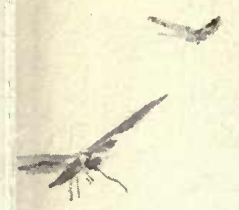

WHAT THE MIDNIGHT

\section{CAN SHOW US}

\section{July, $28 t h$}

$S$ not the midnight like Central Africa to most of us ?" asks Thoreau, and not without reason, for even the best-informed student of daylight natural history may visit his accustomed haunts in the darkness as a pilgrim in a strange land.

Our summer calen. dar would indeed be incomplete without at least one stroll in the dewy starlight, for it has a host of surprises in store for us.

I have already written two essays giving my experiences and my surprises and discoveries in the midnight woods and meadows, 
and in the present calendar series of papers I will present a summary of a few items of especial interest in the form of a list for ready reference in a lantern stroll, any item of which is well worth a walk in the dews.

In the pretty pranks of the dew alone we may find a varied entertainment, for upon careful examination no two plants will be found to possess the same whims.

The Plantain is drenched and dripping, its parallelribbed leaf and grooved stem feeding the roots all night long in a tiny runnel of dew.

The Burdock and the Cabbage.-See how the great glittering drop, "scarce touching where it lies," chases among the deep courses of the netted veins, gathering in size as it dances, until it is precipitated either along the stem or from the edge of the leaf.

Nasturtium (Tropceolum).-You will generally find the leaves all turned edge upward, and they flash with a fine frost-like sheen.

Horse-tail (Equisetum).-The reader will remember the "scouring-rush" of the early settlers, described a few weeks ago, a plant with jointed hollow stems and circular fringes of articulated leaves, so common in the swamps. There are various species of the "horse-tails," some of which, like the true "scouring-rush," are almost destitute of leafy growth, while others are densely plumed with curved and drooping whorls of slender spray. They are pretty enough by day, but in the night they are transformed to very marvels - fairy fountains of glittering brilliants, each joint in the thousands of drooping leaves being set with a diamond. Taken all in all, with its antique lineage for the geologist, its curious squirming spores for the microscopist, its gritty stems for the housewife, its flinty tube for the chemist, 


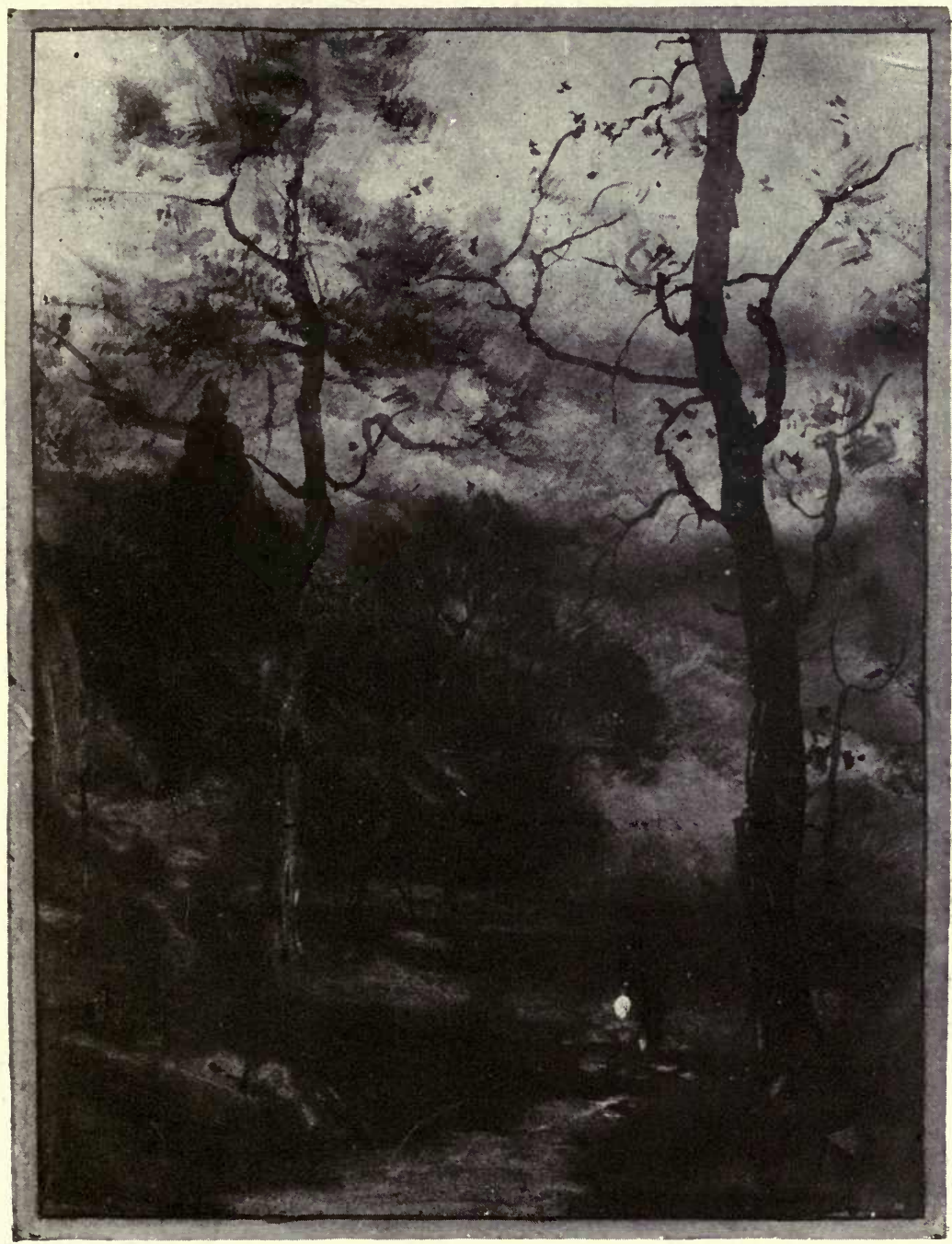




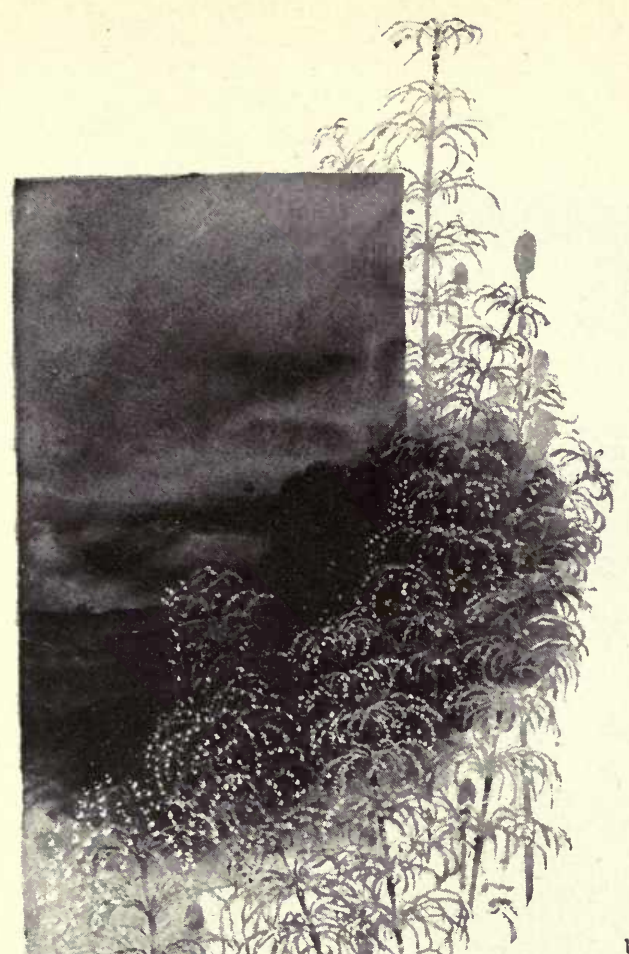

and its dewy revelation for the midnight poet, who shall henceforth tread our Equisetum underfoot in heedlessness?

The Ferel-weed.This is the dewy night's rarest treasure. It is indeed a jewel. Upon the approach of twilight each leaf droops as if wilted, and from the notches along its edge the crystal beads begin to grow, until its border is hung full with its gems. It is Aladdin's lantern that you set among a bed of these succulent pale-green plants, for the spectacle is like dream-land.

Gossamers.-Both the perpendicular and the prostrate webs are beautifully decorated with the dew, and in the night the spiders seem to have spread the entire fields with their silk festoons, entirely unseen by day. But Titania finds them, and strings them all with gems.

In the night you cannot be certain of recognizing your best daylight friends among the flowers, for they take on all sorts of disguises in their sleep. Here are night 
notes of the capers of a few plants which are well worth a visit in the dark hours:

Red Clover. - The two side leaflets are folded together, and the odd leaflet bowed over and slightly clasping them. White clover and many other clovers follow the same prayerful fashion.

Beggar-ticks (Desmodium). - The three leaflets droop as if broken at their stems, or even close against each other, back to back, below.

Bush Clover (Lespedeza).
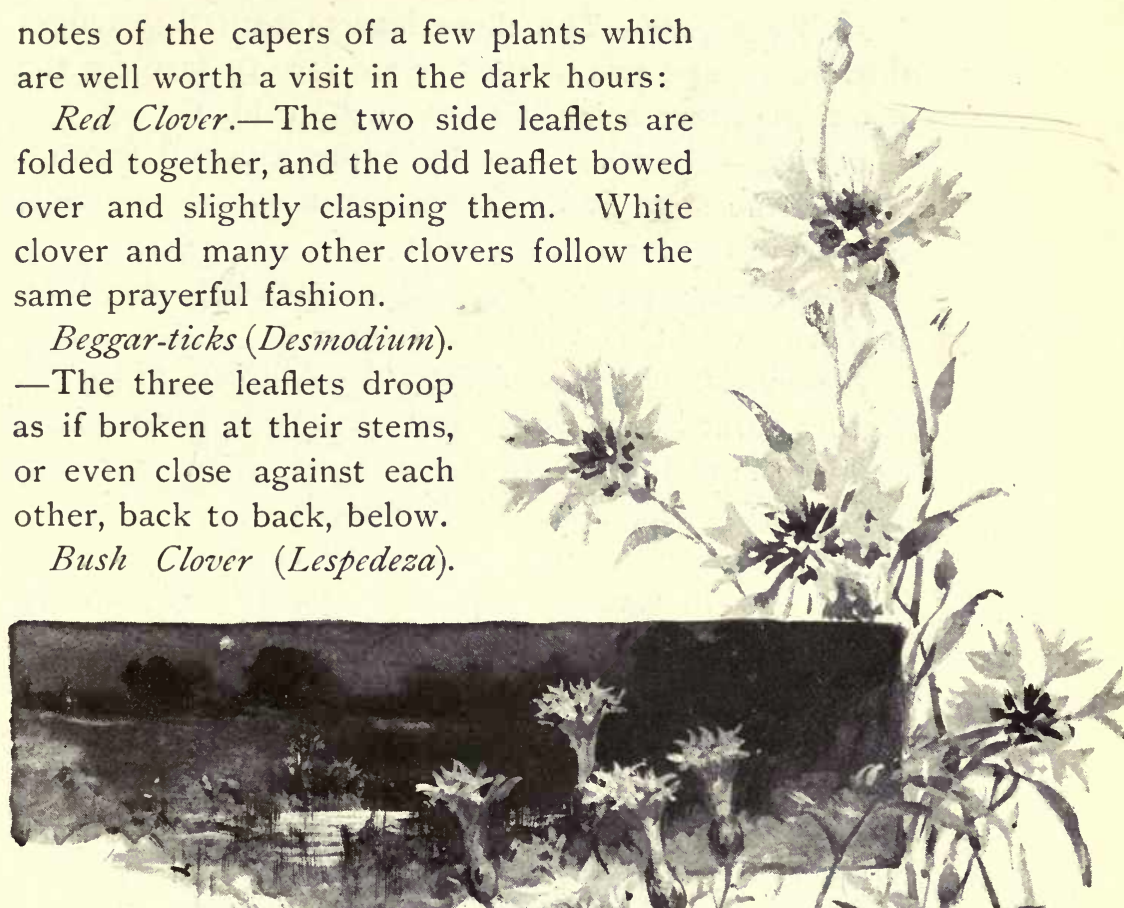

-Leaflets all turn upward, clasping the tall main stem from base to summit, a complete transformation from their daytime aspect.

Partridge-pea (Cassia).-Its feather-like leaves have turned all their leaflets edge uppermost, and, overlapping each other closely, have flattened themselves against their main stem, scarcely distinguishable from the pods. 
Melilot Clover.-The three leaflets turn their edges uppermost, and two of them close face to face for the night, the other being left out in the cold.

Lupine.-The wheel-like leaf either closes downward against the stem at its centre, like a closed umbrella, or rises in the form of a goblet.

Locust.-Leaflets all droop, even pressing each other back to back below the main stem.

Pig-weed (Amarantus hybridus).-All sorts of whims. Leaves turned edge uppermost by a twist in the stem, or hug the main-stalk of the plant.

Fringed Gentian.-Closes its fringes.

Wild Rose and Mullcin.-Flowers closed.

Asters. - In various species the purple rays curl up into all sorts of cuddles.

Cranesbill.-Flowers closed spirally.

Blue-bottles.-The pretty blue, purple, or white spreading stars of the daytime are now entirely gone; each stem holding aloft a perfect shuttlecock, the petals being raised.

The Ground-nut (Apios tuberosa) and Wild Bean are hardly to be recognized in their queer antics. The garden beans too play similar pranks. Those Lima bean poles of the garden hold a sleepy crowd.

The Catchfly (Silene nutans). - Its white blossoms, shown in my initial design, gleam in your lantern's rays in the garden beds. They are opening for the night moths, but you will hunt in vain for most of them in to-morrow's sunshine.

Pea.-The blossoms nod and partially close.

Marigold.-Many species close their yellow rays like a conical tent over the central disk.

Balsams.-Leaves all droop as if wilted. 
Poppies.-Flowers closed like two clam-shells; inner petals coiled.

Pusley.-This conspicuous spreading "mean" weed of the daytime is hard to find, all of its broad thick leaves being turned with edges upward as it spreads on the ground.

Wood-sorrel.- The three leaflets droop and close back to back against the stem.

There are, indeed, probably few plants which do not put on a night-cap of some sort were our eyes only sharp enough to detect it.

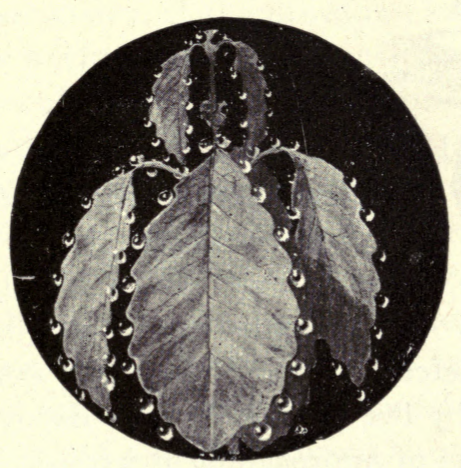



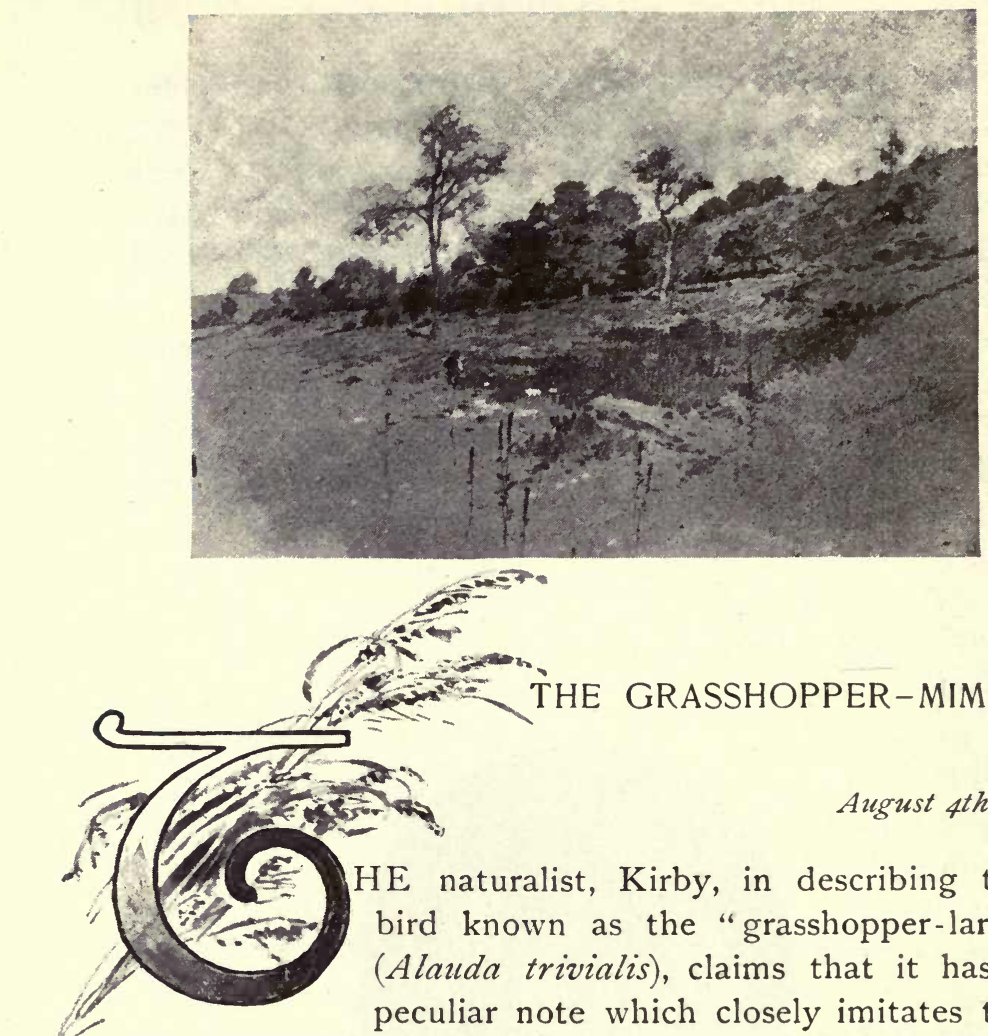
THE GRASSHOPPER-MIMIC August 4th

$\mathrm{HE}$ naturalist, Kirby, in describing the bird known as the "grasshopper-lark" (Alauda trivialis), claims that it has a peculiar note which closely imitates the songs of the grasshoppers or locusts upon which it feeds; the inference being that this vocal strain may be designed by the bird either as a decoy to the insect, or as a means of approaching it without exciting suspicion. This inference is commonly considered somewhat gratuitous, even though no better reason be assigned for the mimic song.

But we have in our own August fields a grasshoppermimic which leaves Kirby's bird far behind. So good a mimic, indeed, that little is known of its song except as it is credited to the common meadow grasshopper or 


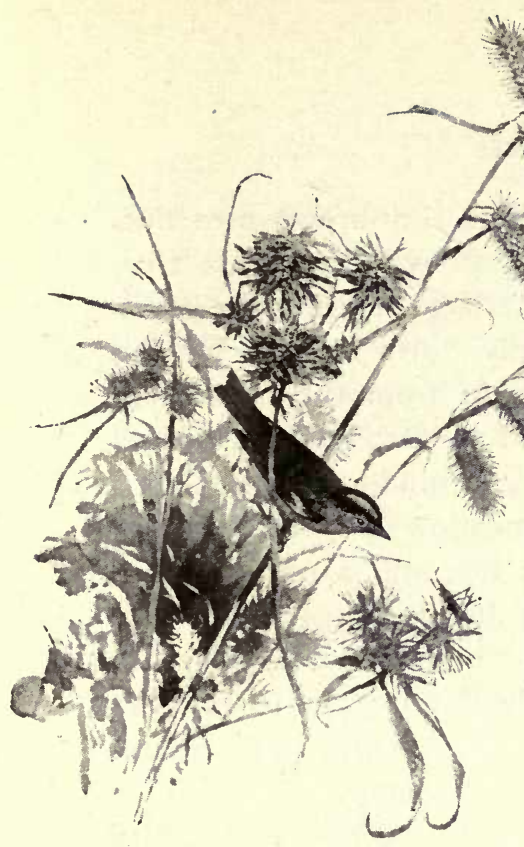

which takes possession of the meadows at this seasonthe bird-songs having now almost entirely ceased - that few listeners would ever imagine it to proceed from the throat of a bird.

We all know the song of the meadow grasshopper, even if we don't happen to know the formidable book name of the singer (Orchelimum vulgare). Our ears must be dull indeed not to have recognized the " $Z i p$;

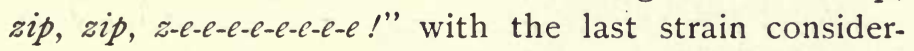
ably prolonged into a continual roundel sustained by thousands of tireless minstrels throughout the meadow. We may hear it anywhere in the fields almost any sunny summer day, but it is especially prevalent in the vegetation of the swamps. If we steal slyly upon its source, we may discern the green gauzy-winged minstrel head downward on the sedge, and with his shrilling taborets vibrating over his back.

Perhaps, however, as we approach the sound the 
song may suddenly cease, while a tiny brown bird flutters out close by, and skimming over the grass tips, disappears yonder among the herbage, whither the grasshopper seems to have suddenly flown unseen, for the buzzing song is now heard again from the immediate neighborhood of the bird. A few lessons like this will soon fix the mimic's song in our minds, and enable us to detect it even amid the meadow din, for although a most excellent imitation, it has still a peculiar bird quality which soon distinguishes it from the wing music of the "high-elbowed grigs" in the grass, especially if we learn to identify

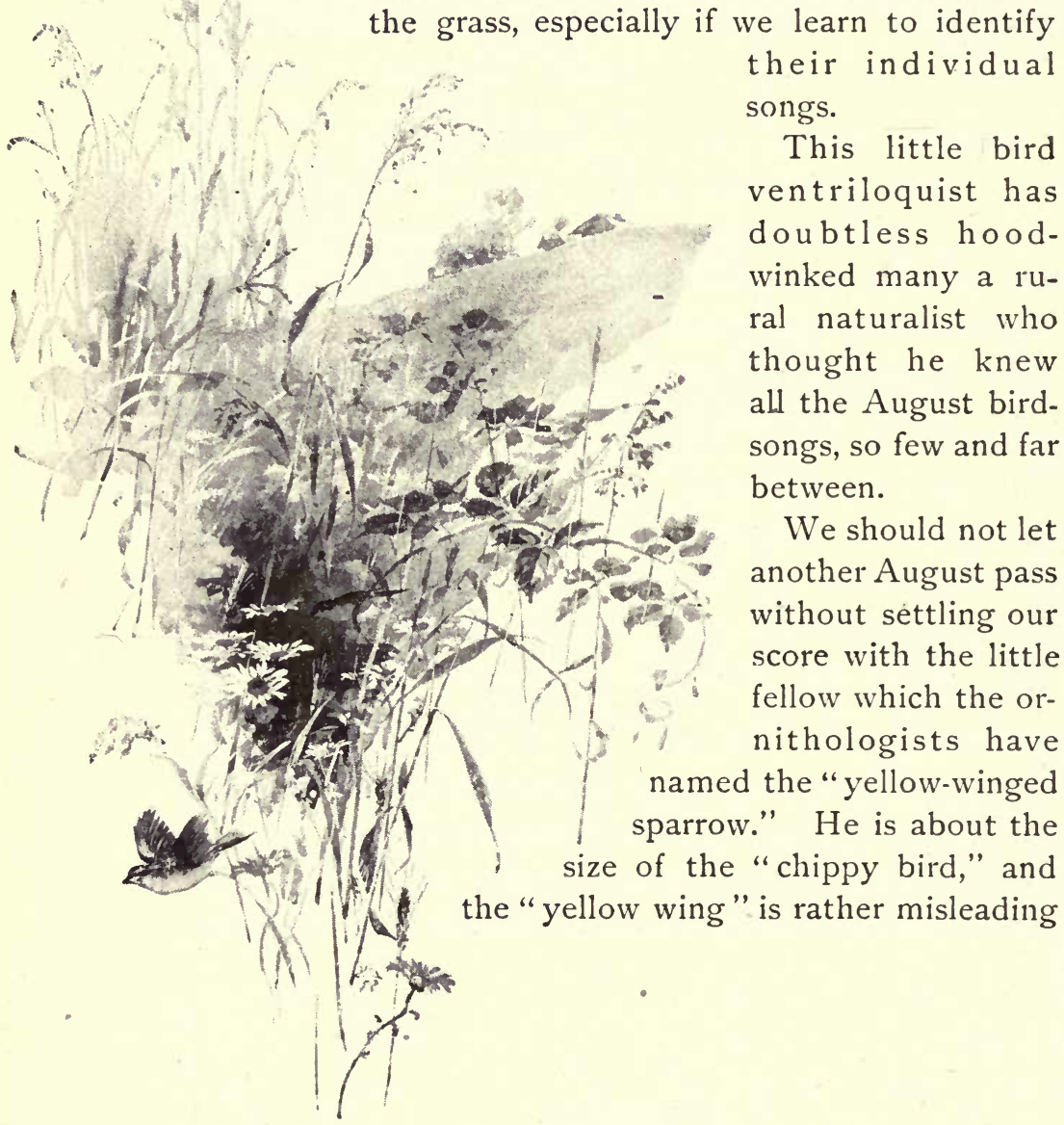


as a distinguishing feature, the yellow being confined to a small spot upon the shoulder. But, taken with its song and its brown and white striped head, our bird may be readily identified. Hunt him up; he will give you all the "hide-and-seek" that you will want on a warm August day.

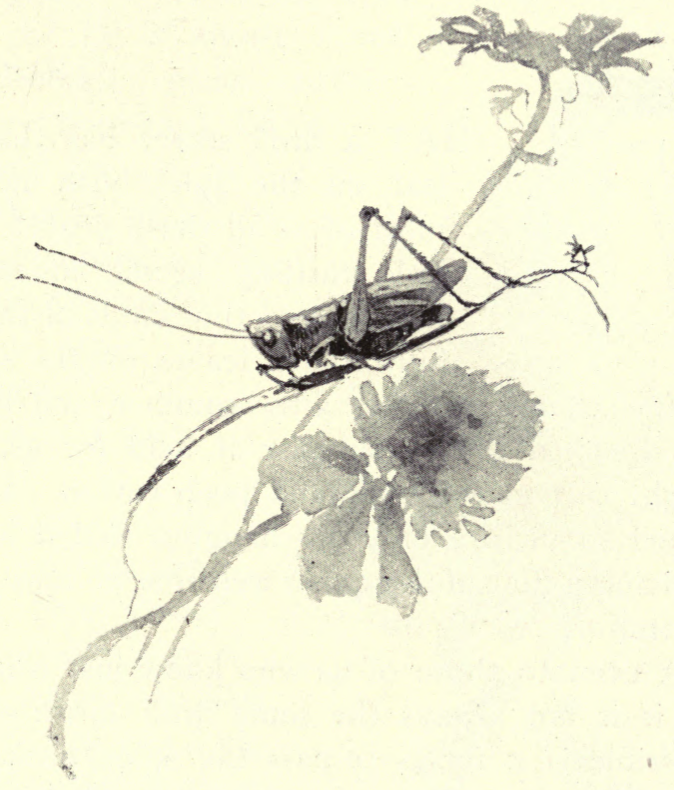




\section{THE SPICE-BUSH BUGABOO}

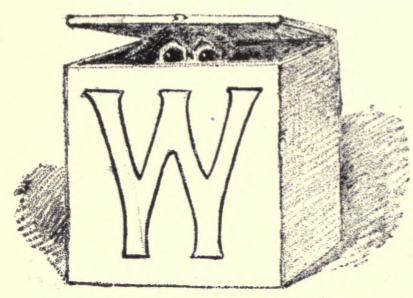

August IIth

HAT a droll secret has that curled leaf on the spice-bush held from most of us all these years! A comical, startling secret indeed. We have passed thousands of these carefully folded leaves on the spice and sassafras bushes summer after summer, and few of us have dreamed of the surprise it held for us, had we thought to part the folds and peep within. I am half inclined to picture only my hanging folded leaf, without giving a hint of the queer welcome we may get from the interior.

But even to those of us who know just what to expect, is it not always the same droll surprise? How impossible is it for us to pass the spice-bush without exchanging a greeting or two with its sly tenants!

I remember an incident in early boyhood which well illustrates the peculiar effect which a first discovery of the spice-bush bugaboo usually excites, and which proves also how complete is its concealment. I had gathered a number of the folded leaves from a spicebush growing near the front fence of a farm-house. 
The farmer, a venerable "old inhabitant," came from his door-way to see what I was after, well knowing from experience that I was looking for "bugs" of some sort. When he had approached close to my elbow I suddenly opened one of the leaves. Had it contained a viper he could hardly have appeared more excited. "Be conscience' sakes!" he exclaimed, starting backward with affright. "I never see sech a beast. Ef I'd 'a' known I hed sech wild-lookin', pizen critters around my door-yard, I'd 'a' been scar'd to go out o' nights. Wut be they?" he continued, pausing a safe distance up the path ; “a kind o' snake er grub, I s'pose."

"It is only a caterpillar."

"Waal, naow, wut 'll he make? I s'pose you know. I sh'd s'pect suthin' pertickler out o' critters thet start aout like thet. Like nuff you'll git an aowl er suthin' aout on't. Ugh!"

"Oh, there's nothing to get scared about," I replied, smoothing one of the caterpillars.

"Ugh! I wouldn't tech the

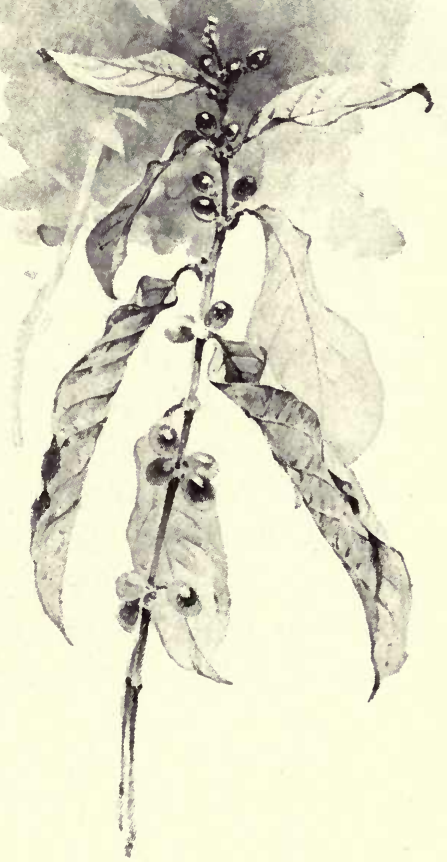


critter fer a nine-dollar bill !" he exclaimed, as he started with a shudder that fairly electrified his aged being, and almost ran back to his cottage door.

To the feminine entomologist the first introduction to the spice-bush caterpillar is usually quite as demoralizing. That blank, unwinking stare of the two big black eyes is quite threatening, until we discover that it is all a bugaboo-that they are mere freaks of ornament on the body of the caterpillar, and not actual eyes.

This caterpillar when full grown is nearly two inches

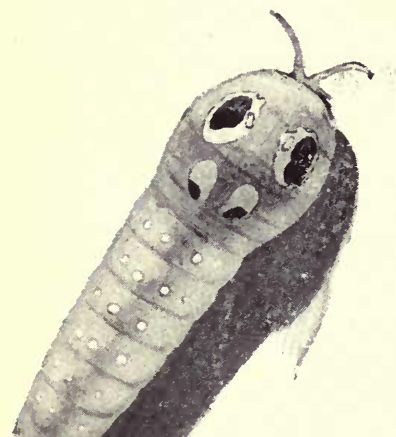
in length. Its body is of a bright green with small blue spots, and during the last week of its growth it changes to a rich yellow color. The eye spots are black surrounded with buff; and upon a little provocation the head becomes further ornamented with a pair of orange-colored horns, with the same malodorous peculiarities which we noted a few weeks ago in the "parsley caterpillar," to which this spicebush specimen is closely allied.

The "yellow" stage of the caterpillar indicates that its period of transformation is close at hand. Selecting a suitable situation, either horizontal or perpendicular, it spins a tiny tuft of silk, into which it entangles its hindmost pair of feet, after which it forms a V-shaped loop about the front portion of its body, and hangs thus suspended, soon changing to a chrysalis of a pale woodcolor. These chrysalides commonly survive the winter, and in the following June the beautiful "blue swallowtail" (Papilio Troilus) will emerge, and may be seen suggestively fluttering and poising about the spice and sassafras bushes. 


\section{THE EVENING PRIMROSE}

BY DAYLIGHT

\section{August IIth}

$\mathrm{AN}$ we really claim to know our evening primrose? Night after night, for weeks, its pale blooms have opened, and shed abroad their sweet perfume in the darkness in every glen and by every road-side; and yet how few of us have ever stopped to witness that beautiful impatience of the swelling bud, the eager bursting of its bounds, and the magic unfolding of the crinkly yellow petals?

But it is not to the primrose of the twilight, nor the opening bud nor fresh-perfumed flower, that I would now invite attention. The sunset primrose we all know; it speaks for itself; but how few of us have the slightest interest in those faded blooms of noon-day hanging like a chime of bells on the drooping stems! For twentyfour hours they may be seen hanging there, and perhaps for half that time who has guessed their pretty mystery? 


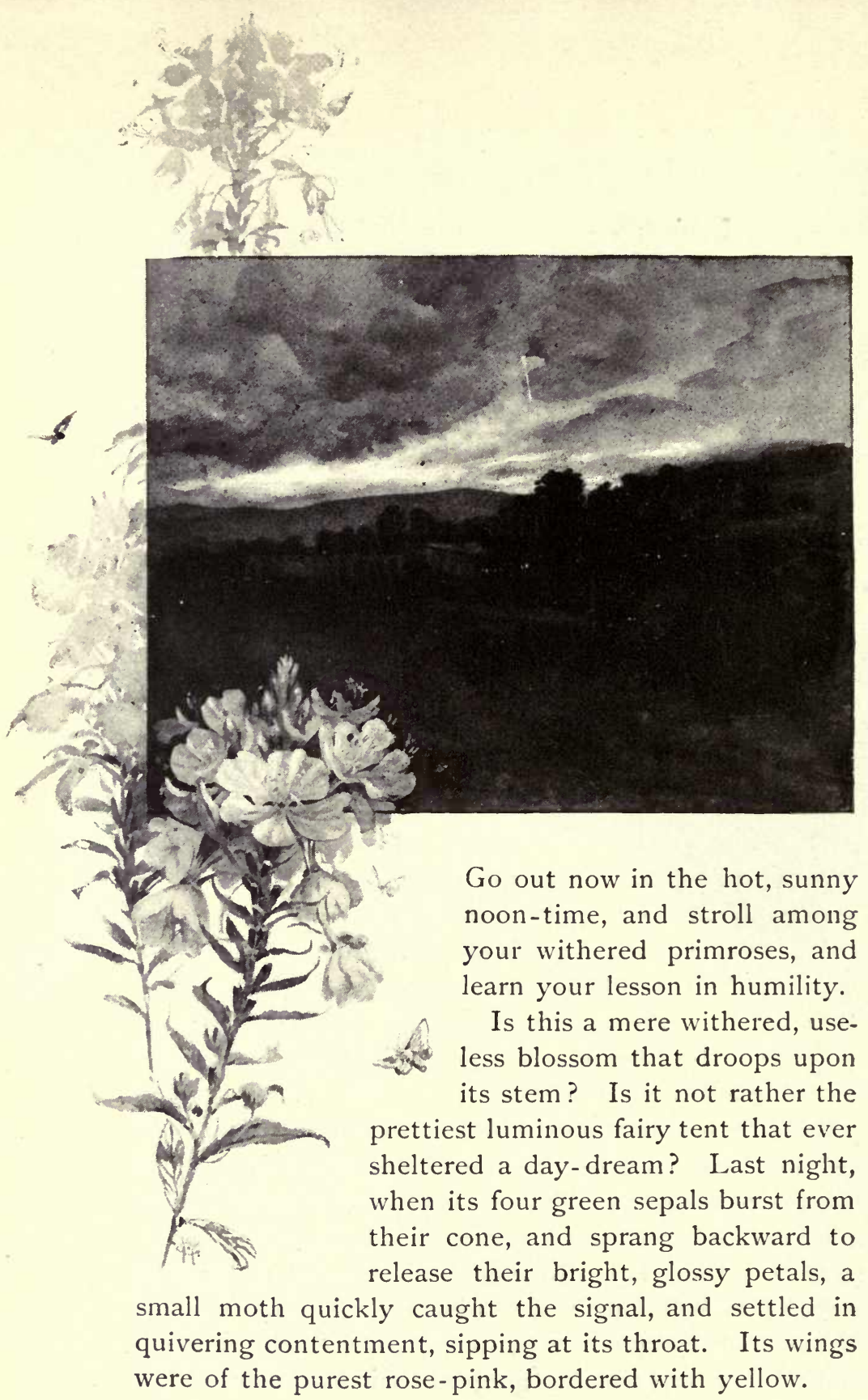


All through the night it fluttered among the fresh opening flowers, one of a countless host of feathery nocturnal moths and "millers." But as the sunrise has stolen upon these primroses, the fickle broods have all forgotten the flowers, and dispersed afar. "All," did I say? Oh no; not all. Let us turn to our withered blossoms, and, one by one, look within their bells. Here is one that falls even at our approach, plainly the blossom of night before last. We will turn our attention only to last night's flowers. Here is a bell that appears to have an extra petal folded within its throat; and upon opening the folds, we disclose our faithful nursling with pink and yellow wings; the earliest twilight sipper, that even on the approach of dawn is loth to leave the flower, and creeps into the wilting bloom, where it remains concealed through the following day, and doubtless occasionally falls with it to the ground.

In the color of its markings we find an outward expression of its beautiful sympathy, the yellow margins of the wings which protrude from the flower being quite primrose-like, and the pink being reflected in the rosy hue which the wilting primrose petals so often assume, especially at the throat.

These pretty moths are by no means rare. A carefui search is quite certain to disclose a number of them. I once found three upon the same plant. Look, then, to your daylight primrose.

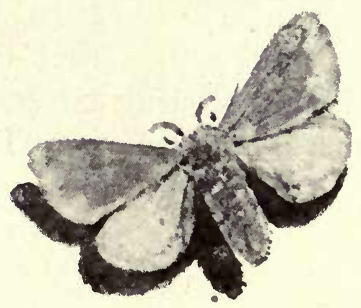




\section{BEETLE MUSICIANS}

\section{August I8th}

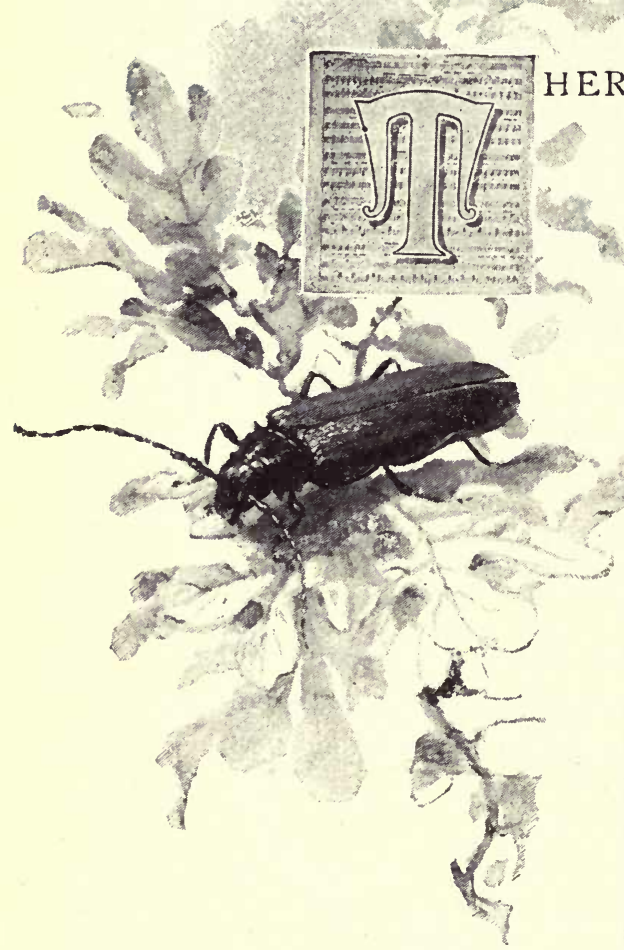

to be heard in the great symphony of insect sounds which fills the summer noon. We all know the cres. cendo of the cicada, or harvest-fly, whizzing its timbrel in the trees, and the buzzing "zip, zip, zip, zee-e-e-e" of the meadow grasshopper (Orchelimum vulgare) everywhere in the sunny fields, the "zip, zip, zip, zip, zip" of its companion, the comical cone-head grasshopper (Conocephalus ensiger), to say nothing of the great orchestra of "high-elbowed grigs" gently fiddiing with their long hind legs among the grass blades, their wing covers serving as strings and their thighs as fiddle bows. This individual fiddle of 
the locust (I refer to the flying locust of our fields, those "grasshoppers" so generous with their "molasses;" these are the true locusts, the insect usually called "locust" being the cicada) - this individual fiddle of the locust, then, is an inconspicuous instrument in itself, being barely distinguishable by the ear without effort, but in its myriadfold reenforcement it becomes an important element in the great meadow symphony.

But while the grasshopper and locust tribes are responsible for most of our meadow music, there are yet a few minor isolated musicians whose modest strains we seldom hear, though individually their solos may be superior to those of their recognized rivals.

In a previous paper I alluded to the mysterious music of the Antiopa butterfly, and the click-wheel rattle of the "Coral-wing;" and I now desire to introduce to the music-loving public a trio of instrumentalists whose claims are not sufficiently recognized. But on second thought, perhaps one of my performers is already familiar to most of my readers, if not as a musician, assuredly as a "horrible creature " and a "horrid bug," that brings terror and confusion to the peaceful family group assembled around the evening lamp. A low drone just outside the window announces the visitor, and in a moment more he is buzzing and bumping about the ceiling, and is soon master of the house, his formidable jaws insuring him a respectîlil distance and careful attention.

But if we forego formalities, and unceremoniously lift our intruder by the nape of his neck, we learn of an accomplishment which doubtless explains his overweening assurance. For, lo! is he not the "first fiddle" of all out-doors? "Squeak, squeak, squeak!" is his now incessant refrain. It is well for us if we are content to 


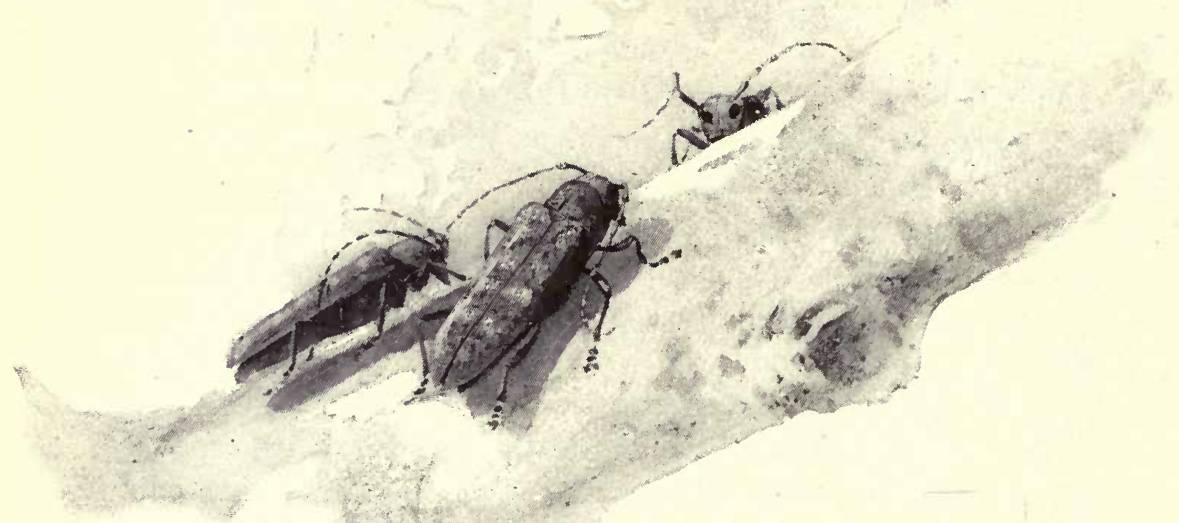

listen admiringly and not investigate, for if our doughty musician can once fasten his . teeth upon us, he will punish us severely for the indignity, even parting with his head, if need be, to prolong his chastisement.

This musical character will be recognized by a glance at his portrait on the oak-leaves. In the classic programme he is announced as Orthosoma unicolor. He is a mahogany-colored creature throughout, about an inch and a half long, and carries two violins and four fiddle bows, thus possessing within himself the resources for solo, duo, trio, or quartette, as his whim may dictate. Shall we then quarrel with his self - complacency?

His music is produced by the contact of the four 
hind legs, chiefly the last pair, with the edges of the wing covers. $\mathrm{He}$ is the "first fiddle" of all out-doors. The locust orchestra follow his lead and method, but none of them have inherited such a mahogany Stradivarius as he, and are thus left far behind.

If the Antiopa butterfly has deceived some observers into the belief that it has a "voice," what shall be said of this concert of quaint singers which I have pictured on the bough opposite, for singers they would certainly seem to be. There is no motion of the legs or wings observable in this group as they sit there quietly in the sun on the poplar branch. No fiddling here. And yet the faint trio of squeak music is plainly perceptible, as they nod continuously to each other in mutual approval. I have frequently come upon such a group, or an occasional isolated individual sunning itself upon the trunk of a poplar in the woods. The insect is about an inch and a quarter long, and in its decoration is a decided contrast to the 
fiddlers, being clothed in a nap of mottled gray and ochre yellow. Unlike most beetles, the head is set upon the body with the face looking directly in front, and the expression of that face, with its almond-shaped black eyes, as it peers around the edge of a twig with nodding accompaniment, lends a comic element to the musical performance. This is the Saperda calcarata. His musical instrument is unique in the insect orchestra. It is not a fiddle, nor a click-wheel, nor a drum, nor a timbrel. It is a musical collar, from which he literally grinds out the music with the back of his head, into which it sets as in a socket. At least such seems to be his method. If not, which of my boy readers will tell us more about this queer squeak of the Saperda? Now is the time to find him. Hunt among the poplar branches.

If we care to search among the golden - rod blossoms we may find many specimens of another similar musician, the Painted Clytus, a beautiful creature nearly an inch long, banded with yellow and sable, sipping among the blossoms, and squeaking contentedly at the feast.

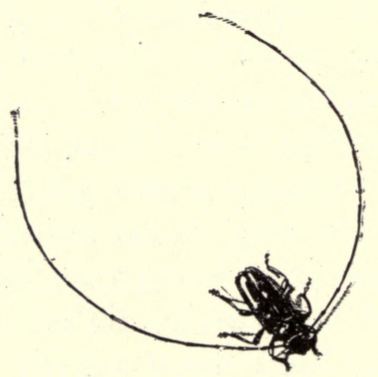




\section{AN ECCENTRIC PRECENTOR}

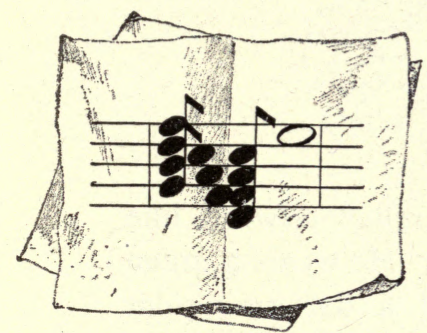

August I8th

ORCHESTRA is complete, of course, without its leader. Even the "first fiddle" must observe the baton. And as the insect world affords us a veritable fiddler and a harpist, as well as other instrumentalists, so too may we find our precentor close at hand, if our eyes are only sharp enough. This group of singing beetles upon the poplar branch, I wonder if they are watching him as they nod their squeaky trio? For he is close at hand. Even among these very leaves we are sure to find him with a little search. But if they are indeed observing him, he must be a decidedly confusing leader, for no two of the bobbing heads are keeping the same time. Ah, here he is! perched upon the mid-stem of an aspen leaf close by. You have seen him, perhaps, a hundred times, and all his pompous pride has been wasted on you, being doubtless mistaken for a part of a withered or curled leaf. Our precentor is about an inch and a quarter long. The forepart of his 


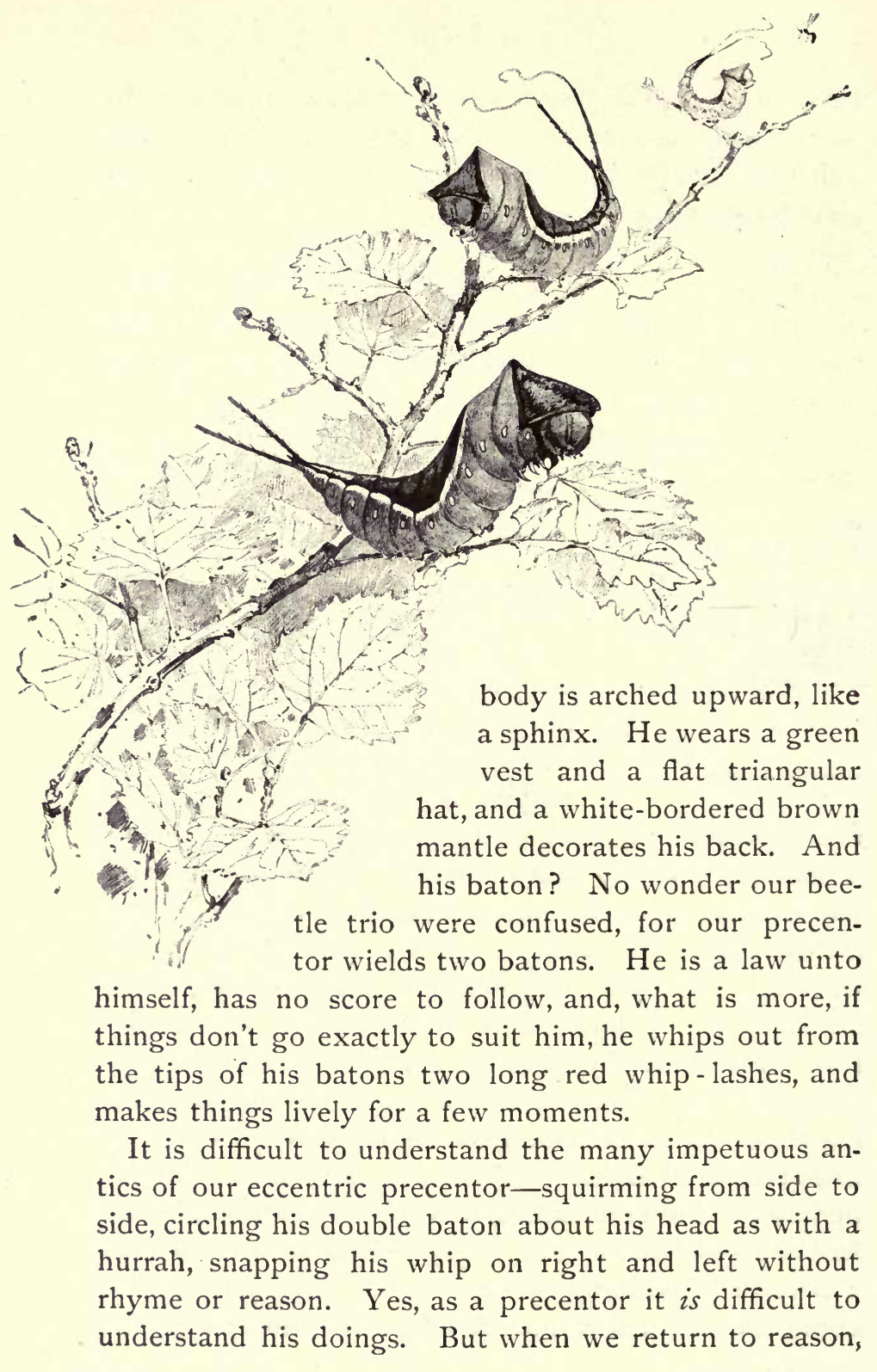


and remember that he is only an important puss-moth caterpillar, it is not half so mysterious. If we watch and wait for a moment or two we shall doubtless witness a return of that buzzing fly - a parasite, perhapsthat has just been tickling him.

The puss-moth caterpillar is quite common upon young aspens, and will be readily recognized from my portrait. It is an amusing insect, and, so far as I have seen, those peculiar rosy whip-lashes concealed within the forked tail, to be used when occasion demands, are not described in the popular works on natural history.

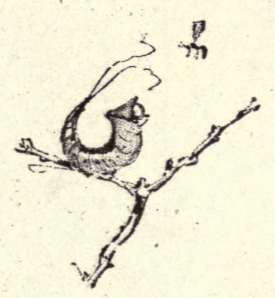




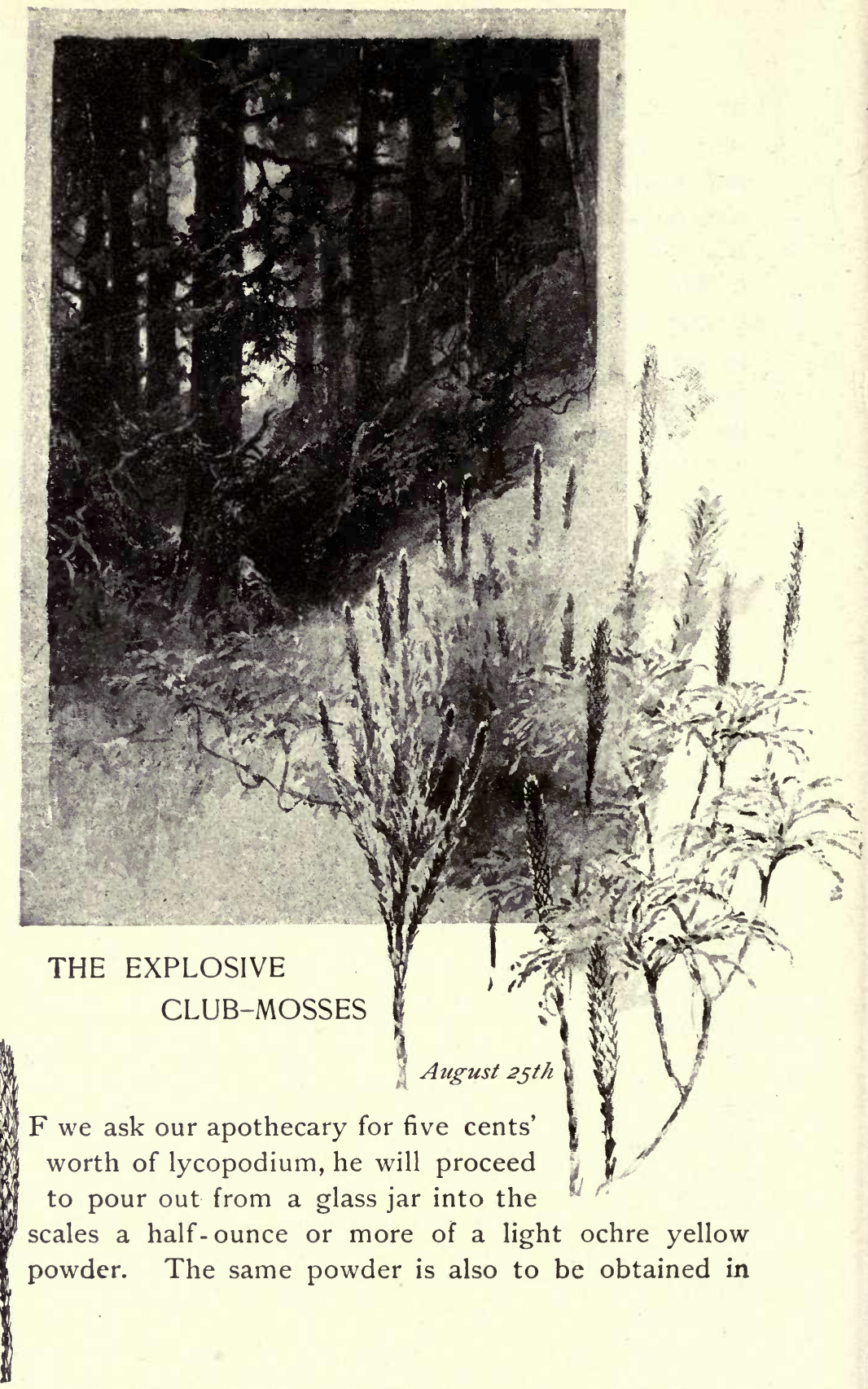


its tiny vial among the regular list of homœopathic remedies. Outside of the drug-store, however, few of us have ever seen it; rather, I should say, few of us have ever seen it to recognize it, even though we may have breathed it into our lungs in the woods, or brushed it from our clothing in clouds, under the impression that the dusty soil was alone responsible for our soiled garments.

"What do you use it for?" I recently asked an apothecary.

"We keep it to put in pill-boxes with the pills," was his reply; "that is all we use it for. Powdered licorice is also used for the same purpose, but the lycopodium is preferable."

But there is much of interest to be found in this yellow powder which is not generally known. Nor need we visit the druggist's to get our sample for experiment. What, then, is this drug, lycopodium? Our botany will enlighten us: "Lycopodium, a cryptogamous plant, commonly known as 'club-moss,' a low evergreen somewhat resembling a moss, its stems clothed with short pointed scaly leaves, the fruiting stems discharging their subtle spores in the form of a copious sulphur-colored inflammable powder."

So, in substance, says Dr. Gray, and though the combustible nature of this yellow cloud is published to the world in nearly all our botanies, it is a singular fact that comparatively few of those who know the plant in all its many varieties, who perhaps have named it with its Latin tag, and who have pressed it and mounted it in their herbarium, have known its singular explosive properties and the fiery tricks it is capable of performing. Country people everywhere, even though innocent of 


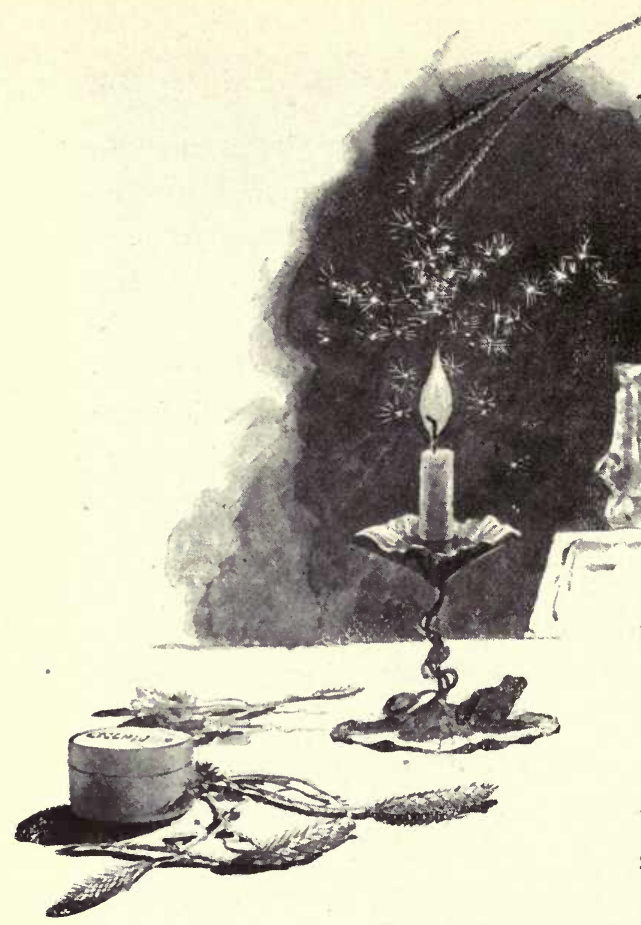

botany, will certainly recall the well-known "ground-pine," which carpets the winter woods in its fanshaped green foliage, and which is such a favorite for Christmas wreaths and decoration in general. This is the most familiar form of the lycopodium ( $L$. dendroideum), but there are others equally common in our woods, some assuming the form of miniature branching pine - trees, or trees resembling closely tufted mosses, but all, at one season or another, lifting their catkin-like fruiting spore fronds, and shedding in the breeze their smoky yellow clouds. Certain of these species are now fruiting in the woods, and we have only to find them to obtain our generous supply of this same yellow powder of the pharmacy.

Where the plant grows abundantly these spore stems rise in profusion among the leaves, and as we walk through them our shoes and nether garments are soon covered with the yellow dust. With a little care each 
separate catkin, by a gentle bend and shake, may be made to pour its dry grist into a box held beneath it, and several ounces of the powder may be thus gathered in a few moments. A little of this powder poured upon the flame of a match or candle will demonstrate its inflammable qualities, exploding with a brilliant lightninglike flash. A few of the stems picked when immature and allowed to dry in the house will produce the same flash when shaken above the flame.

In earlier times, and even to-day, for aught I know, this same powder was in great demand behind the scenes at the theatre, where, in association with the terrific din of the rolling balls and the crash of the enormous sheet of tin, it did brilliant duty in the mimic thunder-storm.

In their natural destiny these floating spores are carried to the ends of the earth by the winds, to say nothing of an occasional artificial journey towards the stars as they are borne aloft in the rocket, and light the zenith in their glare. I have discovered that the pollen of the pine blossoms has similar inflammable properties to the lycopodium.

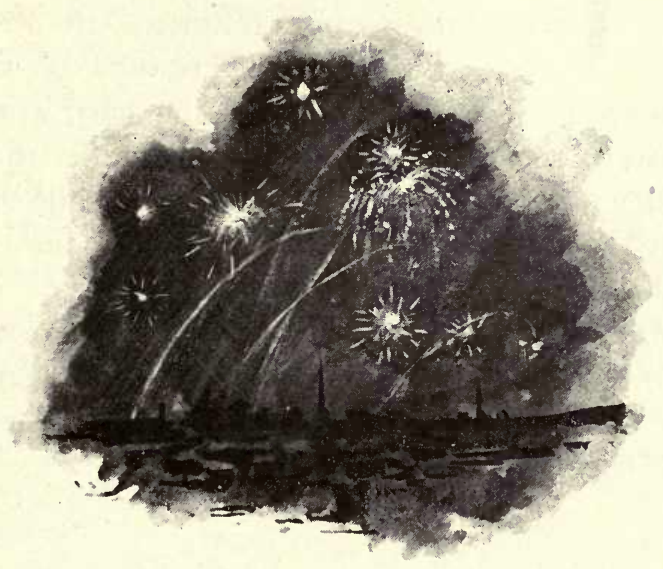




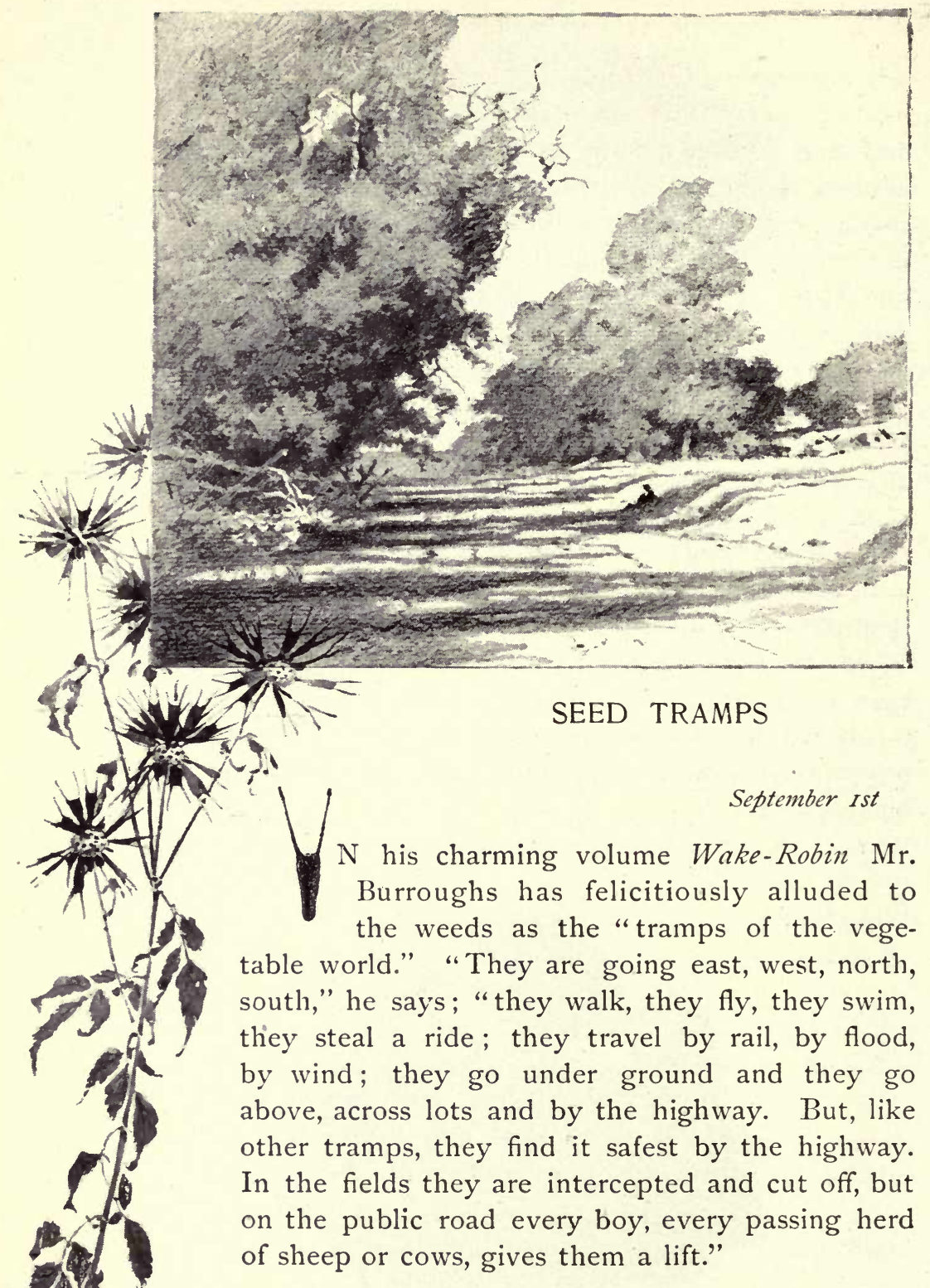


It is to this class of restless vagabonds that I would now direct attention, and what a precious lot of tramps they are! Foreign immigrants almost without exception, by hook and by crook, by fair means and foul, they have travelled from the ends of the earth, until now they are always and forever with us, lording it over every copse and wood. Do we seek our garden for a quiet evening stroll, they present their unwelcome compliments. Do we stoop to drink at the way-side water-trough, they thrust their cards upon us, and not content with a mere recognition, even plaster us with a whole pack of them.

But the woods are their stronghold. There they have us at their mercy - lay in wait for us, hedge us about, and intimidate us, until we return from our walk in helpless chagrin, decorated with their advertising tags from head to foot, champions against our will of their whole shady fraternity. What a representative rogues' gallery do we often bring home with us on our nether costume or even upon our coat-sleeve! Sly brigands, whose presence in the woods we had never suspected did we not here see their unimpeachable cartes de visite.

We may know little enough of botany, scarcely enough, perhaps, to serve us in giving a wide berth to the poisonous plants that have often made us suffer; but there is at least one interesting botanical family whose familiar forms we have been forced to study with patience - the burrs and beggar-ticks, the stick-seeds, Spanish-needles, and "pitchforks." We know them all, and recognize the same old persistent tokens from year to year, yet how few of us catch them in the act of assault!

One or two, like the group that flanks my highway 
on the left with a "qui va là !" yearning for a $\mathrm{jab}$ at the humble craft in the background, are familiar to us even in their haunts. But here is an odd assemblage upon the skirt of our coat, the hangers-on of every wood and copse, and many of them I am certain the "oldest inhabitant" has never seen except as he picks them from his

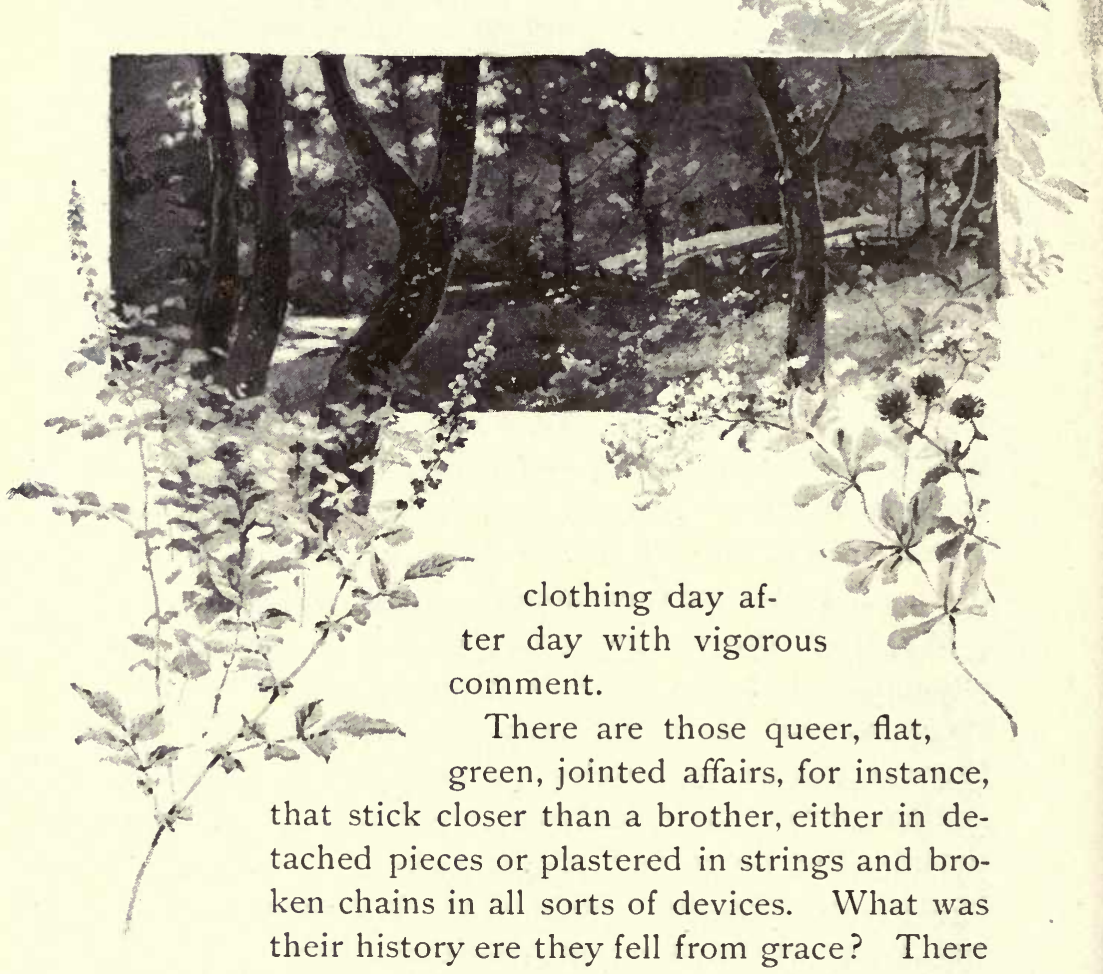

is a whole troop of them which are popularly stigmatized as "ticks," and commonly supposed to be members of the same chain-gang. But this is not so; there 
are at least a half-dozen different countenances to be found among them, and a little study will soon enable us to assort the several distinct types. I will not attempt to; they are all sinners, and mostly black sheep from promising and comely ancestors.

In the botany this group may be found under the title Desmodium, a name derived from a Greek word meaning a bond or chain, the seeds being arranged in links, as it were, each a tiny pod covered with minute hooks and containing a single seed. I have shown here four distinct forms of the pods, from either of which a botanist could readily bring to mind the pretty pink parent pea-blossomed flower of the woods. The lowest of them, rounded above and below, is the Desmodium Canadense. The jointed pair above, D. paniculatum, the single triangle, $D$. nudiflorum, and the upper trio, D. accuminatum. Turning our attention to the " pitchforks," Bidens (two-teethed), we have also a variety of styles, from the four-tined Bidens cernua at the right to the $B$. frondosa near it, and the slender Spanish-needle above, $B$. bipinnata, the three-pronged individual on the left being the seed of $B$. connata. Each of these groups belongs to an individual family - the first to the Bean family, the second to the Composite.

One of the most persistent and tenacious of all these wild "beggars" is shown in the upper part of the group. As we pick him out of the puckers he has gathered about himself in our garments he appears less than a fifth of an inch in diameter, unless, indeed, he has multiplied himself into four smaller sections, an odd trick which he generally resorts to. One of these sad-ironshaped pieces is shown below. It is armed, not with hooks like the many clinging seeds, but with veritable 


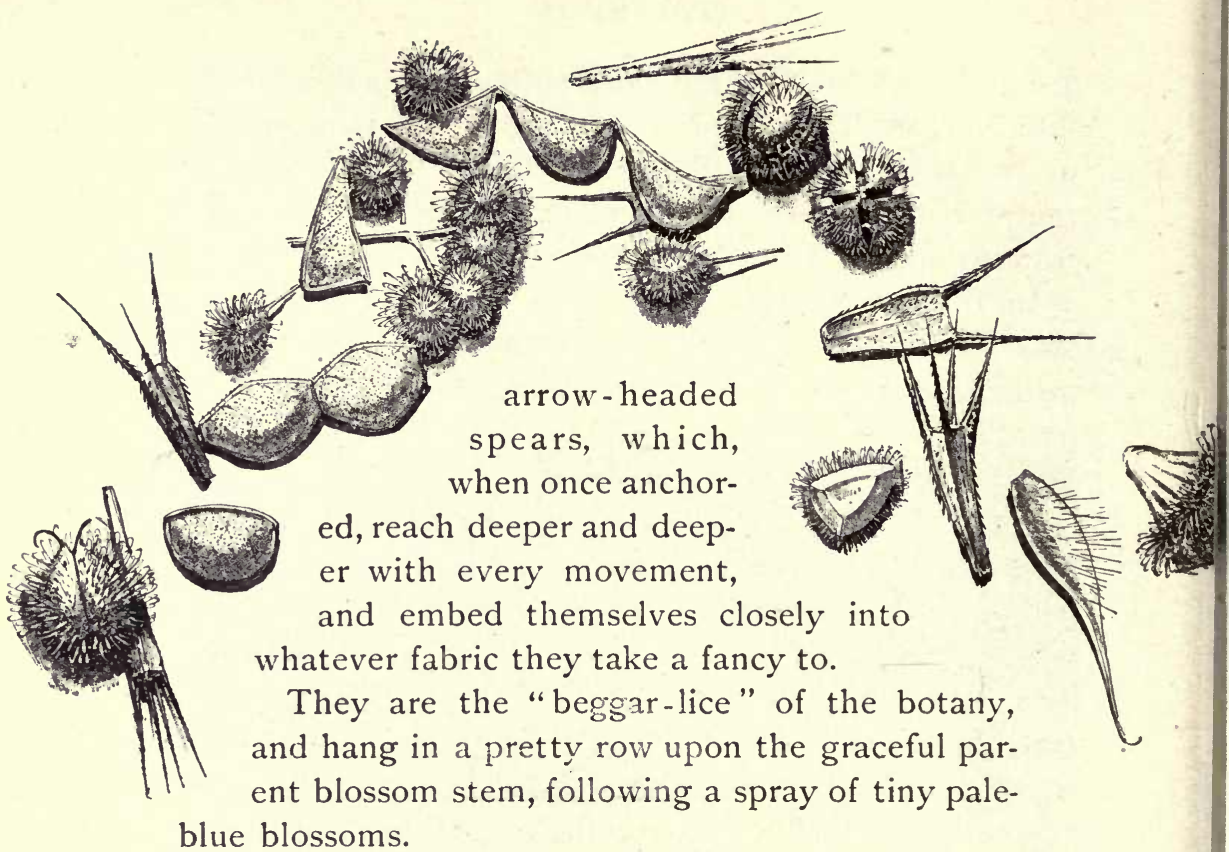
blue blossoms.

Another burr with a similar trick of multiplication is shown at the left below, splitting in half like two springbacked turtles with curved tails. This is the fruit of the Sanicle Marilandica, a common plant in open woods. A very frequent offender is the twin seed of the cleavers, or goose-grass, Galium, round and beset with slender hooks; there are a number of species, and if you occasionally chance upon a cluster of similar specimens among them, only of a distinct pear shape beneath the hooks, you may rest assured that you have visited the haunts of the enchanters night-shade as well as the cleavers. But the prettiest and most shapely of all the burrs upon our coat-sleeve is the nodding urn of the agrimony, its lower rim circled with a stiff array of hooks, and whose slender spires of green fruit may be 
seen all summer, tapered off at the summit with their bright golden blossoms.

We all know the tenacious burdock and the cockles and clot-burrs, the most formidable of their kind among our native burrs; and he who has come into contact with the enterprising barbed spines of the sly "hedgehog" caltrop-as he reclined for comfort on the sand of the sea-shore, has probably speedily arisen to express his full recognition of their prior right to the premises. One of these vile burrs is shown on page 274 , the singular fruit of the Cenchrus, an anomaly among the tribe of grasses.

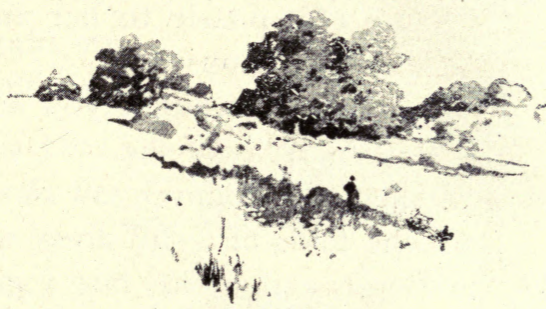




\section{A QUEER “SPIDER'S NEST"}

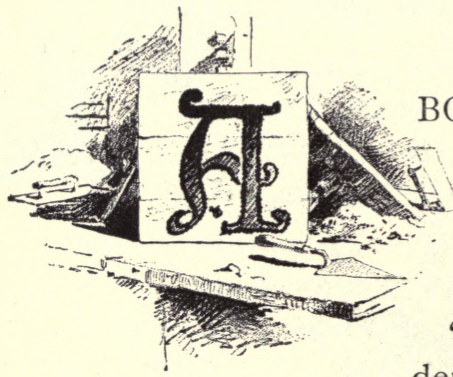

September 8th

BOUT two summers ago a lady brought me a natural history specimen which was something of a puzzle to her and the rest of her household.

"I have brought you a queer spider's nest," said she. "I suppose you have seen lots of them, but I never saw one like it before. It fell from the folds of a silk dress, which I was taking from the closet, and broke, but I gathered up the pieces and the spiders, which all seemed to have been killed by the fall, and here are the fragments."

I opened the handkerchief in which the nest was brought, and disclosed what appeared to be an irregular lump of mud. One side of it bore a perfect cast of the silk gros-grain fabric - a perfect mould, easily identified as from silk. The broken portion disclosed a smooth cavity with a few spiders, apparently dead, within it, and, with the number of others to be seen in the débris, showing that the cell had originally contained no less than sixteen spiders, varying in size, but all of the same 
species. The lump of mud contained two other cells, each of which was similarly packed with the spiders, one of them yielding seventeen individuals. All of them were in the same limp and lifeless condition.

But a closer examination of the mass revealed the secret of our queer spider nest. After a moment's search I brought to light in one of the cells a tiny egg, and in the second a small white grub in the act of finishing a meal from the mutilated remains of the spiders.

"It is perfectly plain, don't you see," said I, "that this plump larva, and not the spider, is the real lord of the manor, and that all the spider prisoners were to have been eaten."

"Yes," said my friend; "but how

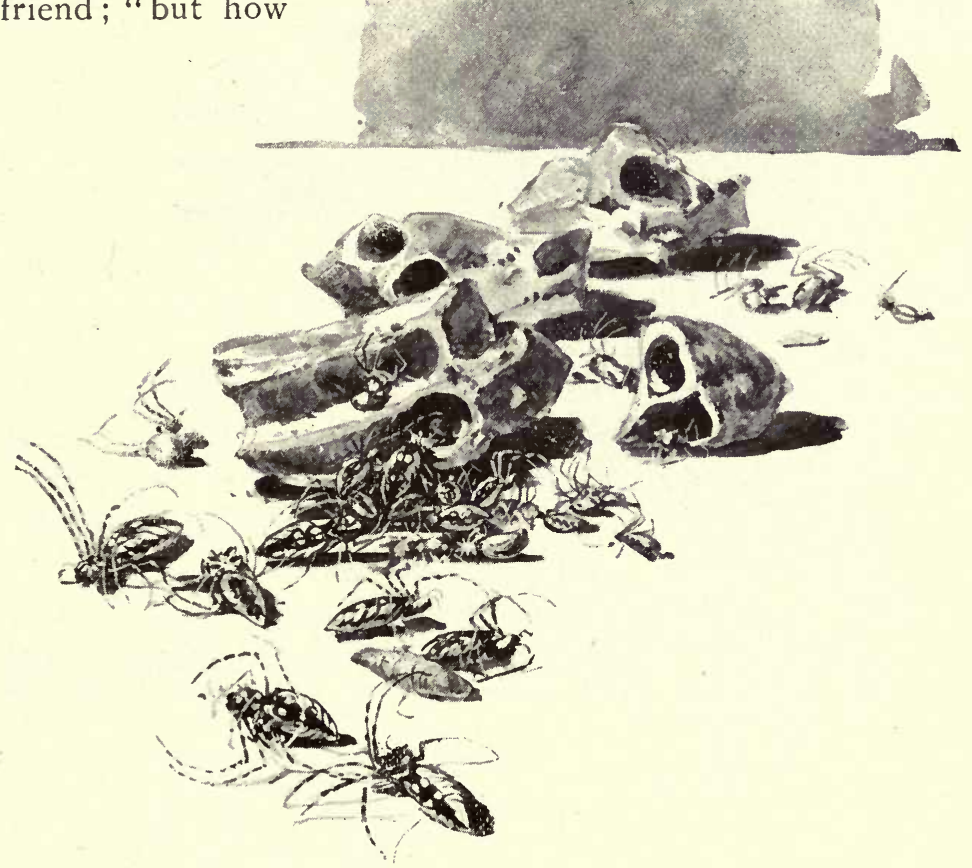


did the spiders get there? Have they deliberately packed themselves here in this old wasp nest to be eaten up?"

"Ah, then, you knew it was a wasp nest, did you?"

"Why, of course," she replied. "It didn't occur to me at first, but I have often seen the same sort of mud

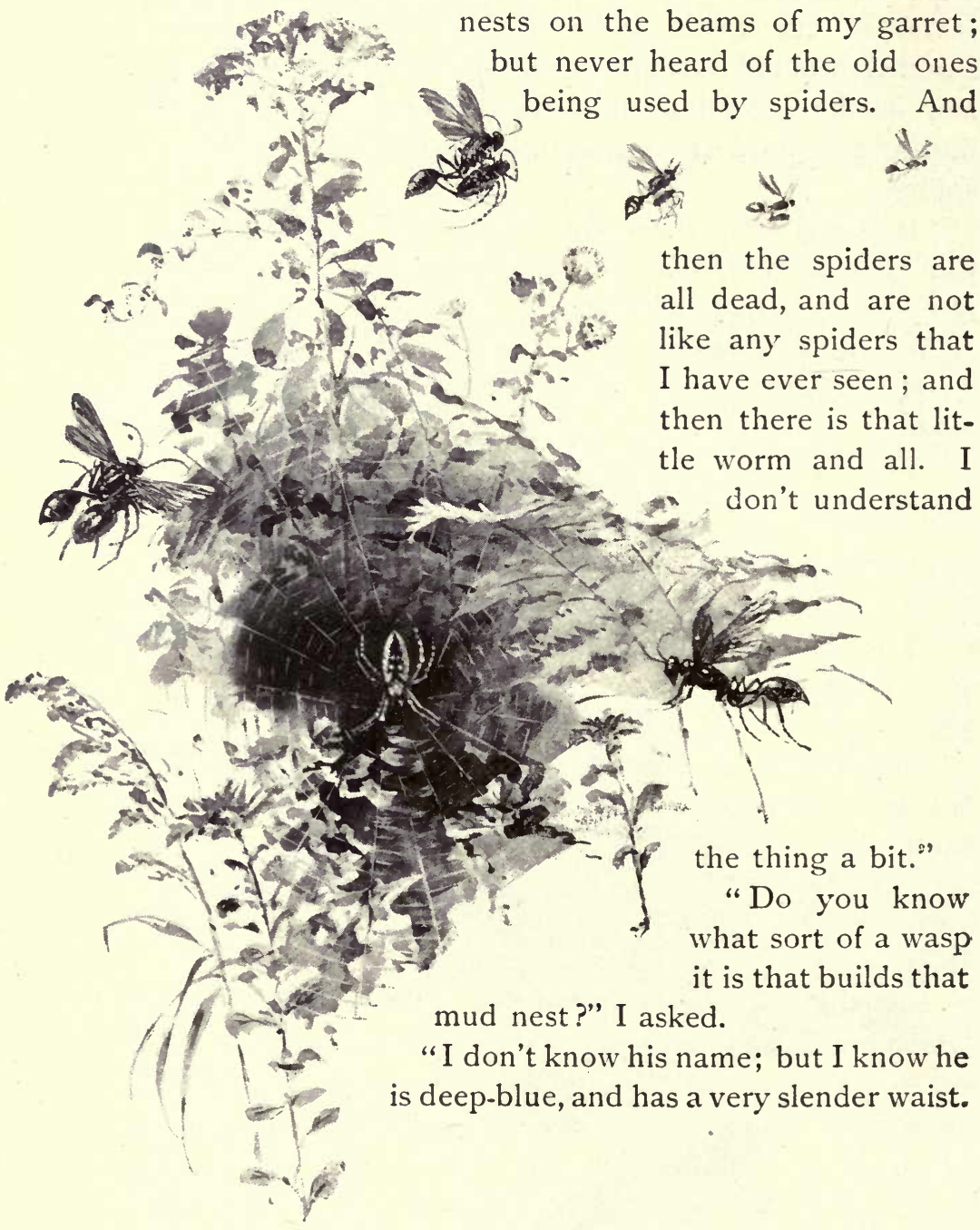




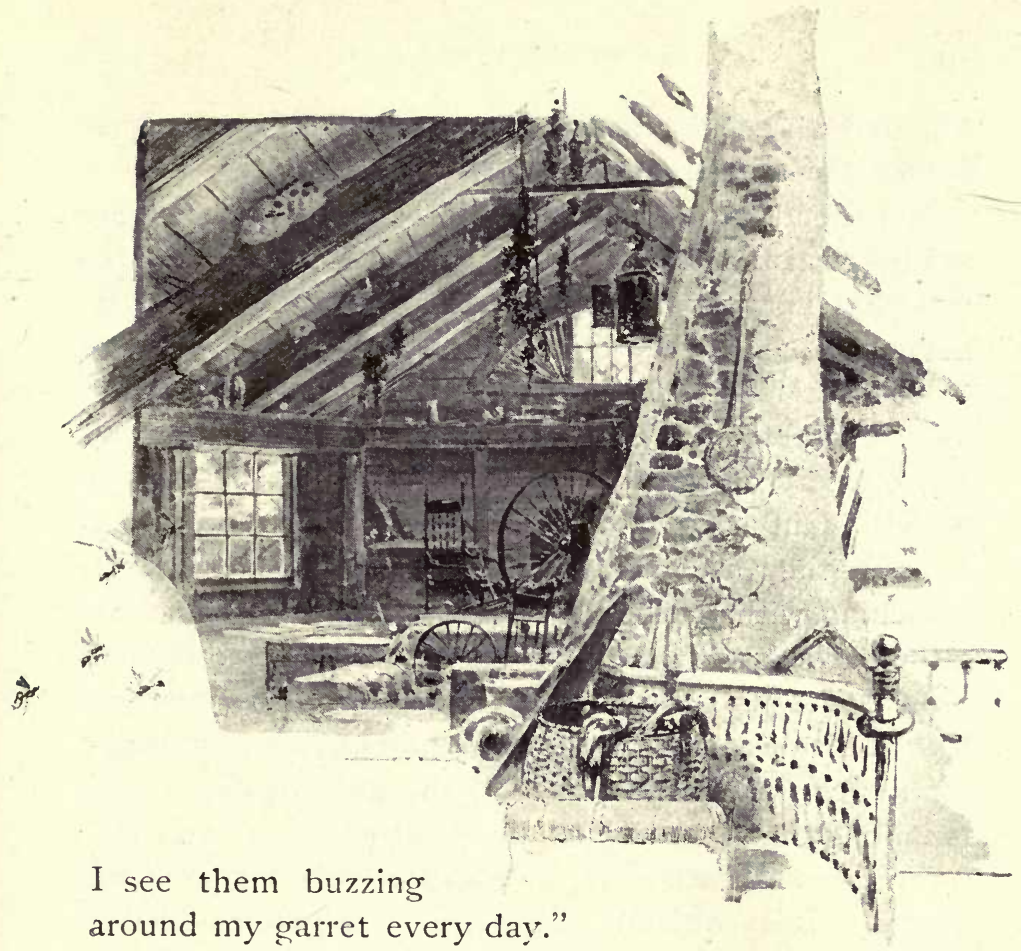
around my garret every day."

"And it has never occurred to you what that nest was built for?"

"Why, certainly," she replied; "the young wasps are raised in it. I understand all that; but it is those spiders that puzzle me, for this nest is all closed up tight with mud, and there is no sign of a wasp to be seen, and he could not get into it if he wanted to."

"And what do you imagine that blue wasp has been doing all these weeks while buzzing around your garret rafters?" I inquired.

"Feeding its young ones in the nest, I suppose."

"And where are the young ones?" I asked.

"They have probably grown up and flown away by this time. But what has that to do with these spiders? 
I understand about the wasps, but the spiders are what I want you to tell me about."

My friend knew the wasp-nest and the "deep-blue slender-waisted wasp" in her garret, but the trouble was that her acquaintance with the insect did not go beyond the garret window.

Had she followed our "mud-dauber" or mason wasp as it flew abroad in its busy mission for that clay nest the mystery of the spiders would soon have been revealed. Out across the road it flew, and was soon buzzing over the rowen-field near by, which at this season is glistening with the beautiful upright web wheels of the satin-backed Argiope, a pretty spider, now about half grown, with its body banded in stripes of gray and yellow. This nest, the doom of so many insects even large1 than itself, knows no terrors to the mud-dauber. In a twinkling the glistening spider is seized, even in its lair, or, frightened thither, captured after a hunt among the leaves. It is quickly stung into submission by the wasp, and thus drugged into a stupor, as it were, though otherwise unharmed, is carried straight to that garret mud nest.

Another and another trip is made to the rowen-field, with like results, until the mud cell is at length packed to the brim with the spiders. This done, the wasp lays an egg among them and immediately seals the opening with mud, and leaves the care of the prisoners to a deputy that is fully equal to the responsibility.

One by one they fall a victim to the growing grub within, their number having been nicely calculated as a' larder to carry him to his full growth. If we open one of these cells two months hence we shall find a few remnant spider legs as the only hint of the original 
"spider nest," while the cavity is now filled with a filmy brown cocoon, containing perhaps a plump white larva, perhaps a pupa, or maybe a steel-blue slender-waisted wasp just making its exit, and fully prepared to tell you all about spiders, if you will only listen to its hum with proper understanding.

So then our "dead spiders" are not dead after all. A very little provocation in the way of a rude touch or jostle of any one of them will cause a perceptible tremor of the legs even after weeks of confinement within the sealed mud chamber. A wonderful provision of nature is this potent sting of the parent wasp to insure a supply of fresh living food for its young until the completion of its growth.

Many varieties of spiders are packed within these nests through the season. The earlier nests are usually filled with the half-grown specimens of the beautiful black and yellow Argiope, which is the species shown in our illustration.

The common house-spider is a favorite prey in the summer months, while in the late autumn the banded Argiope seems to be the principal attraction. The September nests in this locality are usually packed full with this species.

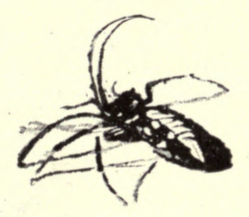




\section{THE TALKING FLYY}

\section{September 15th}

OT once but a half-dozen times has this comical-looking fly made game of me in my walks. It needs only a single glance at the specimen to see that something out of the ordinary run of things might be expected from him. The first time he experimented on me I well remember. I was sitting beneath a hazelbush in the shadow of a stone-wall, examining some flowers which I had just gathered. For a matter of five minutes while thus employed I was carelessly conscious of voices somewhere in the remote neighborhood on the other side of the wall. The tone suggested a masculine source, and at one moment seemed to take the form of a soliloquy, and then of an interrupted dialogue, now suggesting a long-drawn nasal exclamation which pictured to my mind a Coriolanus in the far distance "driving his oxen by sheer force of his lungs," "Ha-a-aw-w-w!" with a falling inflection, and again a yell across the 
meadow, "Sa-ay! Fra-a-ank! Waou!" or perhaps a brief nasai interchange of seasonable comment about crops or weather. All these pretty pastoral visions hovered in my fancy between my botany glass and my flowers, carelessly, as I have said, and would have vanished like a dream had not a little incident served to revive them, and forever frame them in my memory.

My flower identified, I prepared to resume my walk,
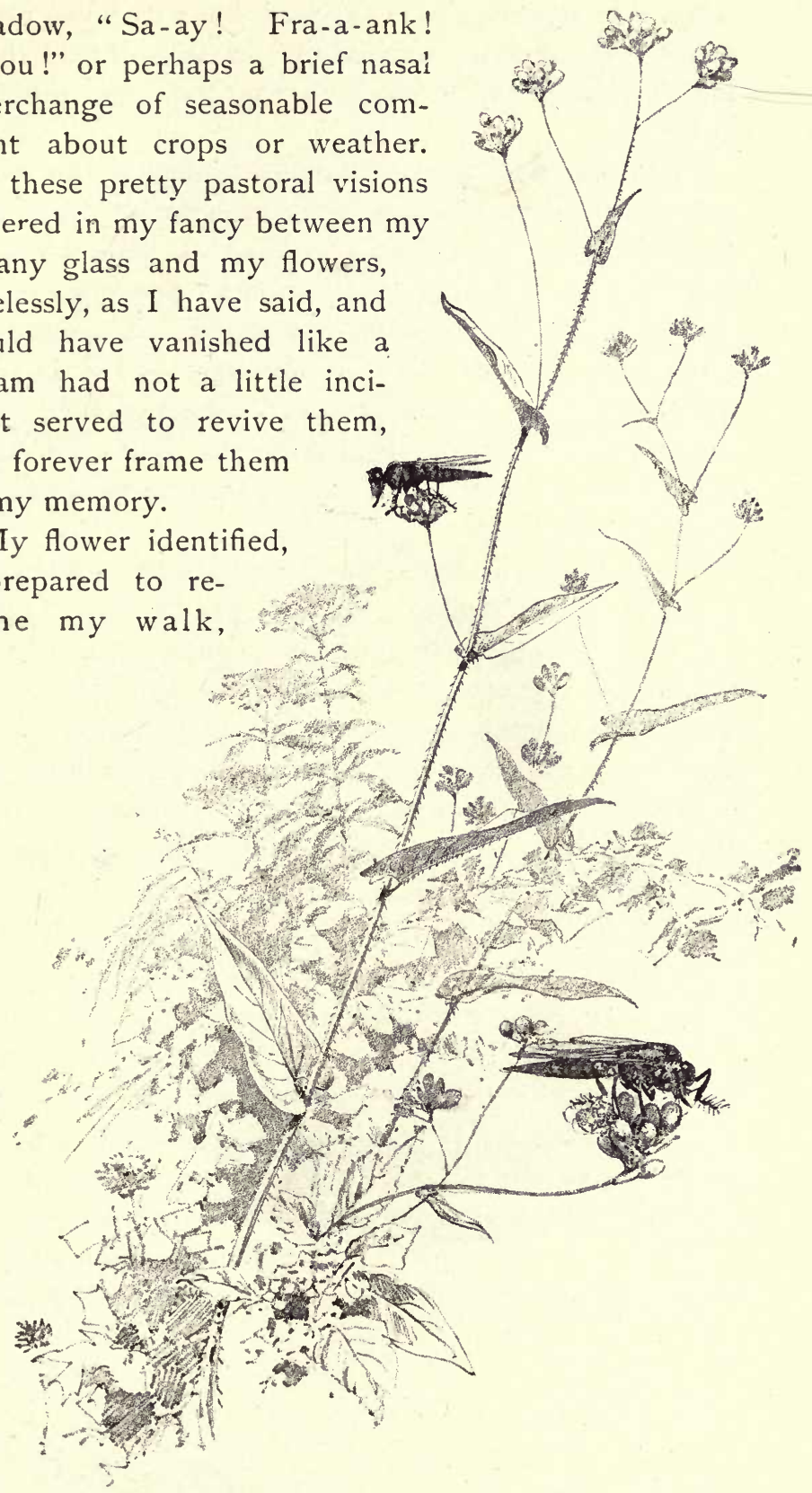
when my attention was claimed by a curious visitor, which had suddenly perched upon a head of tear-thumb blossoms close at my elbow, ogling me most mischievously.

I had seen portraits of this black-sheep in the rogues' gallery of insects, but was never brought into such close quarters with the original before. I soon identified him, and knowing that in my superior fighting weight I would be perfectly safe in tackling him, I prepared to catch him with a sweep of my hand, when away he went with a "Ba-a-a-a-a-a-a-a-a-a!" which seemed drawn out in a long nasal perspective to the limit of my hearing, and the inspiration of my pastoral visions was suddenly revealed.

On several occasions since I have been momentarily deceived by the twanging buzz of the big fly. It is impossible to suggest in type the peculiar quality of the sound, but a glance at my portrait of him will serve to identify the insect, and he may be heard tuning up any day now in our meadows, as indeed he might have been for several weeks past, and may be for several to come. $\mathrm{He}$ is closely related to the murderous mock bumblebee described in a later page.

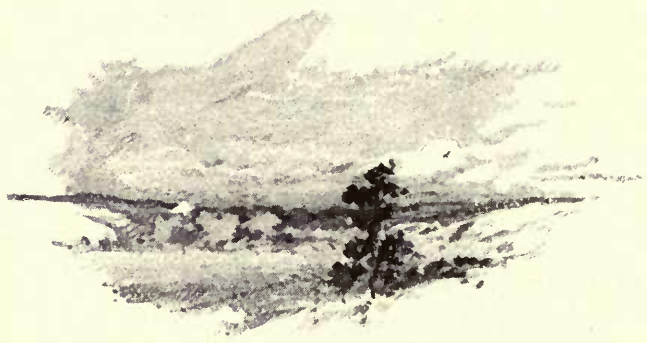




\section{AN UNDERGROUND FRUIT}

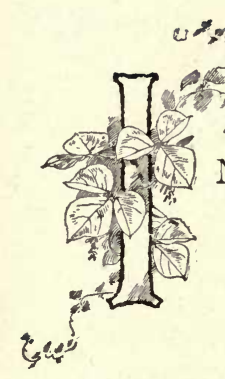

September 15 th

$\mathrm{N}$ a former botanical chapter I called attention to some common plants which have kept a few secrets from most of us. And there is still another which I forgot to mention, or perhaps concluded to postpone to its more appropriate season. We may see it now everywhere in our walks, clambering over fence and shrub, and lending its graceful foliage and drooping pinky-white blossoms to many a homely weed which ought to be glad enough for the borrowed adornment. Here is a nook in the woods where the ground is screened beneath its delicate threefold leaves, while an ascending spray has twined to the summit of a neighboring goldenrod, perhaps, with long tendril-like tips reaching out for new opportunities.

It is the delicate "wild bean;" and if the threefold leaf and long raceme of pale drooping blossoms do not at once suggest the name, a little further search will disclose the telltale cluster of flat pods, like tiny Limas hanging among the leaves.

But the botany, we find, has still another christening 
in store for the delicate vine- "the hog pea-nut" -an inelegant name of no possible significance, unless it be that the hog, from his well-known rooting propensities, is most likely to discover its secret.

The Greek scientific title is more

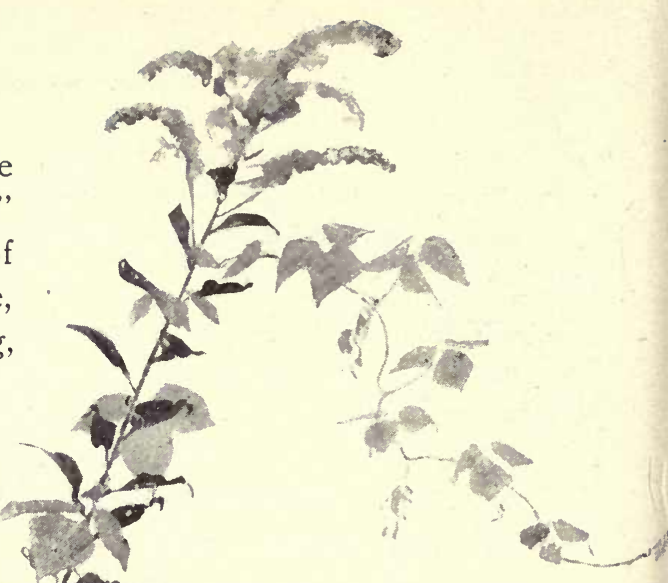
entific title is more
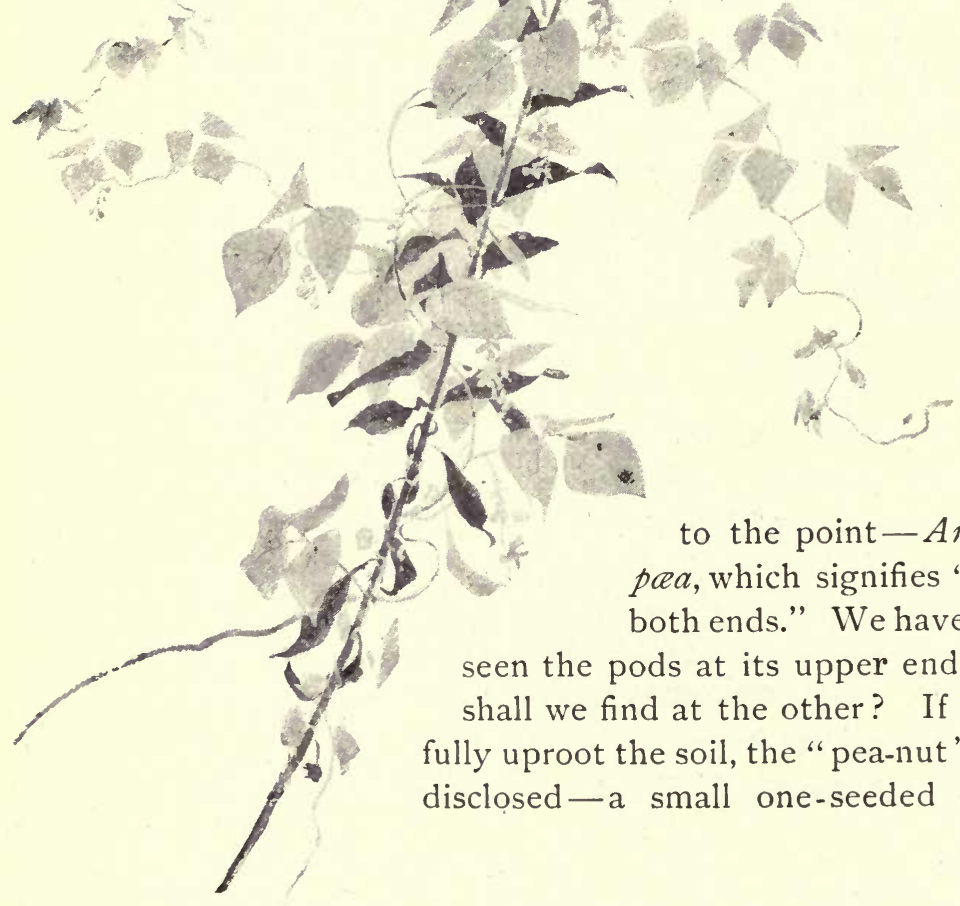

to the point-Amphicar paea, which signifies "seed at both ends." We have already seen the pods at its upper end. What shall we find at the other? If we carefully uproot the soil, the "pea-nut" is soon disclosed-a small one-seeded rounded 
pod, pallid, and beset with fine brown hairs, and which not one person in a thousand of those who know this common plant has ever seen. These are the seeds that plant the soil for next year's vines, and are the fruits of queer little underground blossoms, bearing no more resemblance to those at the "other end" than is seen in the pods.

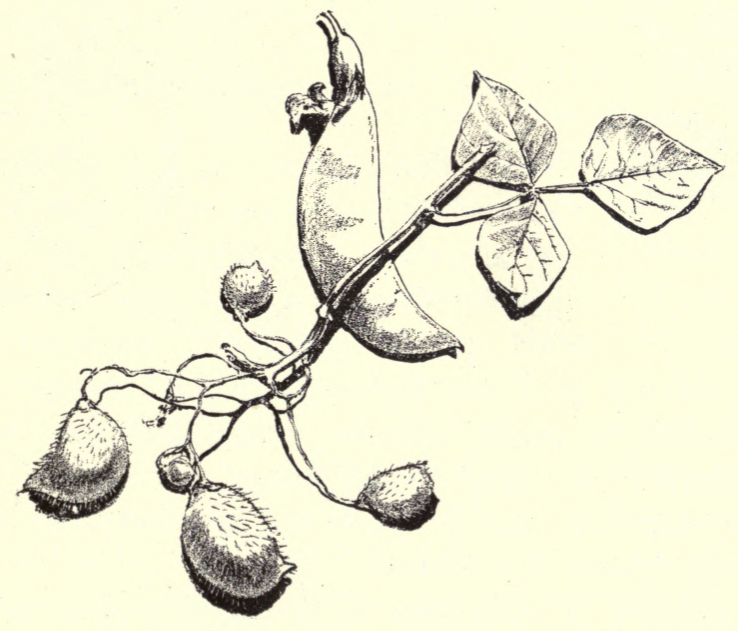




\section{A BUTTERFLY BOWER}

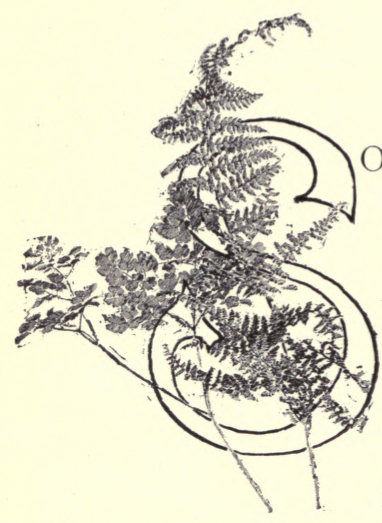

September 22d

OMEWHERE among my books a wistful poet sings,

"I'd be a butterfly born in a bower."

Now I don't know that it is the habit of butterflies in general to be born in bowers any more than anywhere else-under a cabbage-leaf, or a fence-rail, or stone, or dried leaf, for instance. But I am going to give my poet the fullest justice in assuming that he meant to imply that he would prefer to be the "Hunter's" butterfly to any other in creation; for in this insect we have in truth the one butterfly that is literally "born in a bower."

Its bower is composed of petals and other parts of flowers, and hangs among the blossoms of the common everlasting (Gnaphalium decurrens). It is occasionally almost concealed among the flowers, but may often be found quite conspicuously displayed, and three to four inches in length.

If we take a walk in the grassy road, in the pasture lot, or mountain path, we may now find dozens of them. 

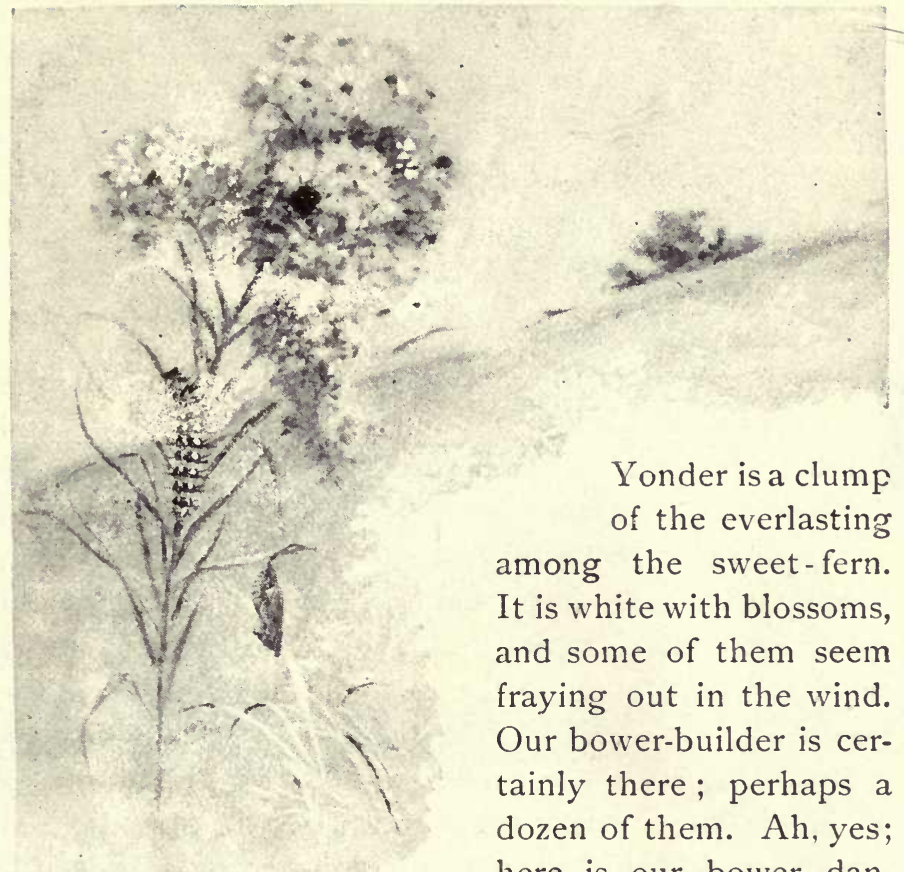

Yonder is a clump of the everlasting among the sweet-fern. It is white with blossoms, and some of them seem fraying out in the wind. Our bower-builder is certainly there; perhaps a dozen of them. Ah, yes; here is our bower dangling from the top of the stem, and blowing in the breeze. It is compactly woven with silk and petals, and within we find-what? Most probably a pretty maroon and yellow banded spiny caterpillar an inch and a half long, spotted boldly with white, and perhaps a wonderful pendent jewel of a chrysalis, apparently of green burnished bronze with rainbow films and golden reflections, or perhaps only a dull drab affair; but any one of them will give forth the same beautiful butterfly, with its orange and black and rose-colored wings. 
BALLOONING SEEDS

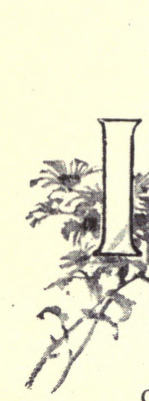

$\mathrm{N}$ a previous chapter I discussed the ways of the "vagabond" seeds, the burrs and "pitchforks," and the "beggars' ticks," with their singular devices for stealing their way around the world. In decided contrast to these ingenious waifs so dependent upon circumstance are their airy winged companions, and what an endless variety of these buoyant feathered seeds are now flying to the ends of the earth on every breeze!

Beginning with the plumy willow and poplar cotton of May that covered the surface of the streams and washed in downy drift - rows on the muddy banks, each successive month has sent its swarms of winged seeds upon their wanderings, and though most of these early broods have found their rest, and are even now, as in our willow, firmly rooted and established for the future, we may still see an occasional restless vernal specimen on its travels.

The dandelion balls followed the willows in the last of May and June, and launched their myriads of feathered parachutes, one of the prettiest of all their tribe.

We all know this common type of the winged seed, but how little do we know of the companions that 
it meets in its travels, some of which are even more beautiful in design.

Every cobweb will show us a few of them, and I have seen a single autumn gossamer that offered an assortment of eight distinct forms, mostly from the great order of Composita, the very children of the breeze. The thistle is a familiar example.
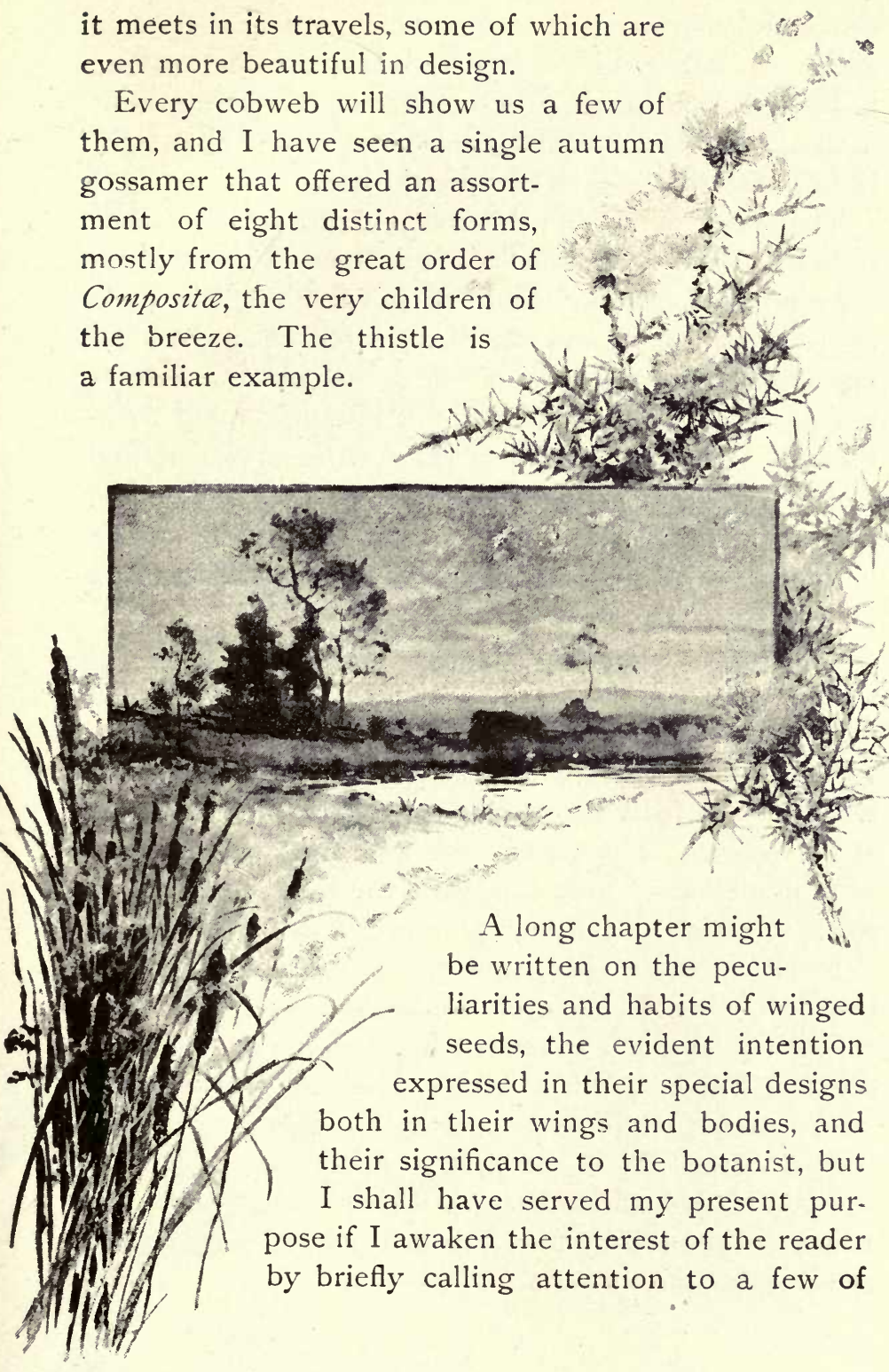
the more characteristic forms which are now floating about us with more or less frequency in our autumn walks. I have pictured a fanciful eddy wafting aloft such a winged swarm, and, considered simply as designs in the abstract, how interesting they are!

The lower member of the group might at first glance be taken for a dandelion seed, but if seen in its natural state no such mistake would be possible, for this parachute is the largest and one of the rarest of our ballooning seeds, being the fruit of the oyster-plant, a species having escaped from gardens, but now becoming naturalized. The total length of the seed is shown natural size, and it appears a giant by the side of the dandelion, its winged disk measuring an inch in diameter. The feathered rays, perfectly flat when at rest, suggest a diminutive spider web.

The form close behind this is the tiny shuttlecock of the Galinsoga, a weed which I have found more commonly in city yards than elsewhere, each seed being surmounted with a jagged silvery white star, so appearing when viewed from above, but in the wind assuming the shape shown. The milk-weed and the dandelion are seen immediately over this, with the long feathery tail of the clematis in the background.

In all of these specimens the flying apparatus has been of a simple character, the seeds contenting themselves with uniform plumes. But here we have an individual which sports a double assortment of wings, a ring of round white scales alternating with long needlepointed awns. It is the pretty star-shaped pappus of the dwarf dandelion (Krigia), whose small yellow flat flower is followed by a silvery ball of these seeds quite as pretty as the blossom. 
The purple iron-weed of the swamps ( $V e$ ronia) lets loose a downy fledgling with a row of teeth and a tuft of down for the breeze. The wild lettuce sends out its thousands of flat black tokens, each with a slender bristle tufted at the summit, while a similar plant, the blue lettuce, sees no advantage in this long appendage, but attaches its wings to a tiny disk at the summit of the fruit, a fact which the young botanist appreciates, for
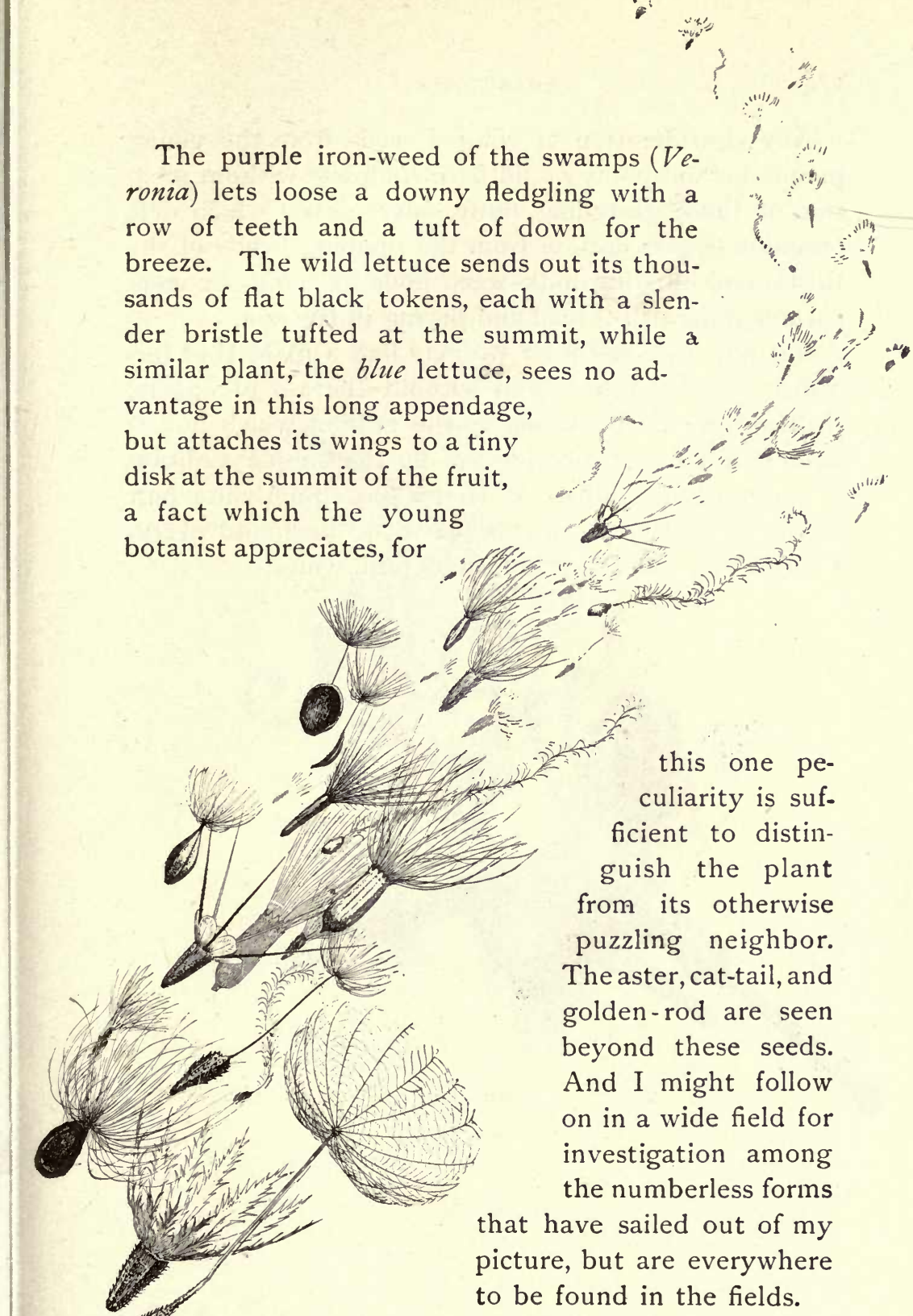
Any consideration of winged seeds from the young people's stand-point would be incomplete without mention of those glistening, fluffy, fairy globes which deft feminine fingers fashion from the ripening heads of the thistle and bursting milk-weed pods by tying the compact pappus with thread and drying in the sun.

But now in September we may find a plant that furnishes its fairy wares even without the aid of fingers, real brownie dust-brushes by the million, which household fairies find ready for use by the simple addition of a pin for a handle. It is the glistening white puff of the groundsel shrub (Baccharis), to be found everywhere along our coast from now until winter.

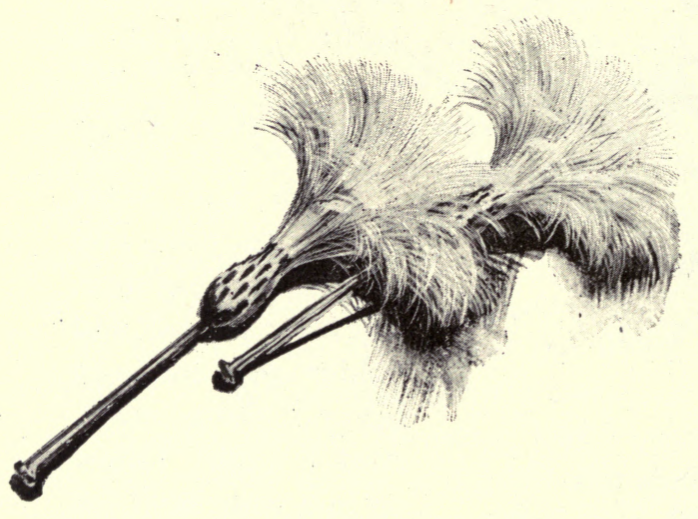




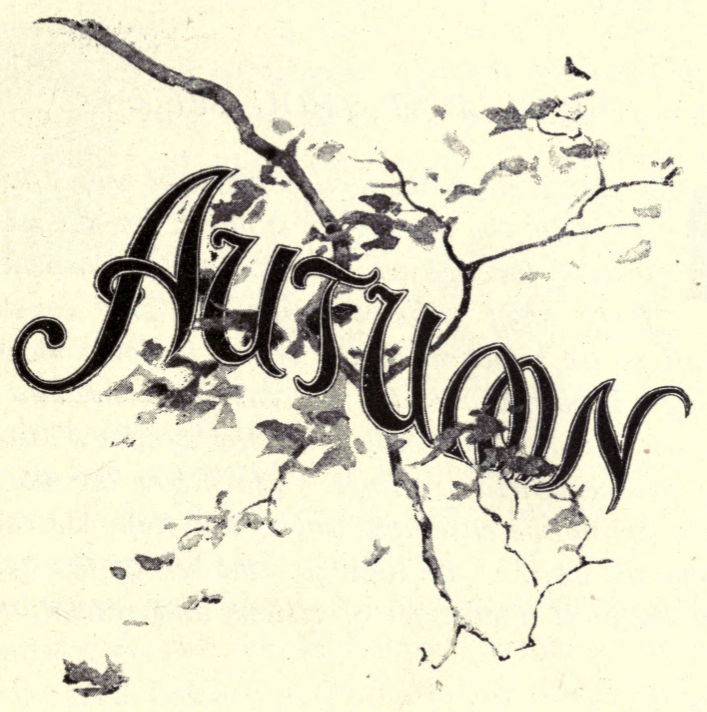




\section{WOULD'ST THOU SEE?}

"6 HE seeing eie is the soul's mysterie which no man

aivineth, the mortal eie sufficeth for the windowe thereof through which it looketh out. Neither is there sight without quietnesse and constancie.

Nor shall ye see bither while thy bearte is yon. Would'st thou see? Looke then to thy present concerne, and heede not distraction, for thus only shall thy windowe avail thee and thy prospect yield greetinge. Mark bow thy mortal eie doth give thy minde ensample, for is not thine ere constant to but one the while? Be thou so, and bebold thy windowe shall be the blest interpreter of visions and revelations." 


\section{THE FAIRY RING}

September 29th

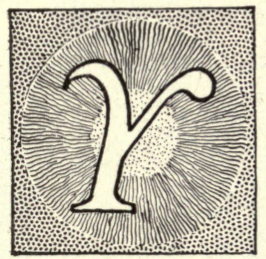

EAR after year, perhaps, we see the "fairy ring" of small fawn-colored mushrooms out upon our lawn. As we first remembered it, it was but a foot or so in diameter, and closely clustered, while with each successive crop it has spread into a more widely scattered circle, until it is now several feet in area. Who planted the seed in this fantastic form, and why does this particular species especially favor the circle or the crescent in its method of growth? These are questions which naturally occur to any one who has seen the singular phenomenon.

The freak well illustrates the peculiar conditions of vegetation of the whole fungous tribe. These plants have no seed, but are perpetuated by the aid of myriads of dust-like spores. This is well seen in the puff-ball, whose smoke-like puffs scatter their countless atoms to the ends of the earth. Though they may fall in a million places, no spore will vegetate into a plant unless the conditions which the puff-ball requires are present in the soil.

In the fairy-ring mushroom, as in all other mushrooms, the rule is the same; the spores are shed from beneath the cap, and many fall upon the ground. We 
will suppose a single spore to have been blown by the wind to the spot upon the lawn. A single mushroom or group is soon seen. Its spores are scattered beneath it. The earth immediately around the stem has been exhausted of the chemical necessities for new growth, and only such spores as have fallen in the outer edge of the circle will find the congenial conditions for vegetation, leaving the centre bare of growth. And thus the ring enlarges as the interior soil is exhausted, until it occasionally reaches the diameter of several feet in a more or less broken circle.

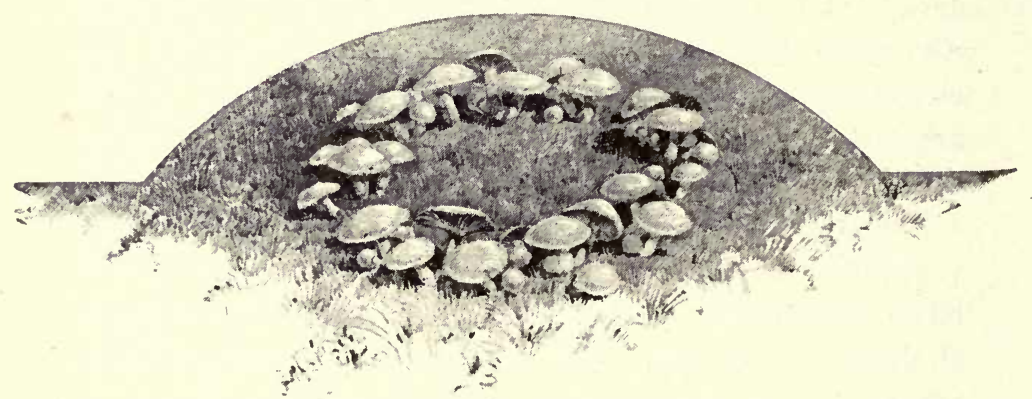




\section{A QUEER “BUMBLEBEE”}

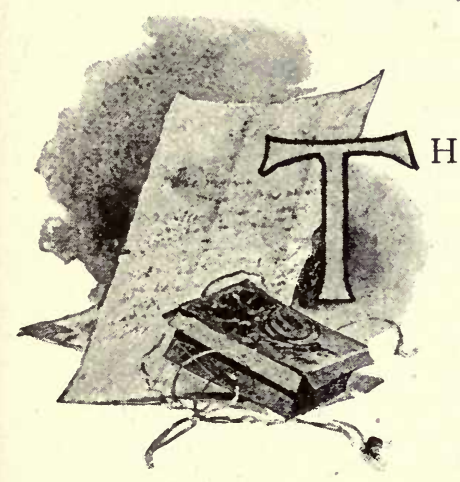

September $29 t^{\prime}$

$\mathrm{HE}$ following portion of a letter from a Connecticut farmer, village philosopher, oldest inhabitant, weather prophet, and phonetic expert, is reproduced by willing permission, and is herewith answered for the first time. It accompanied a package by mail containing the specimen in question.

"Mr. Gibson:

"SIR,-in the summer of — wen you was bordin with.me here at the farm you hed a gret laugh at me becuz I sed I seen a bumble bee ketch a hoss-fly and eat him up. . . . I haint fergot how you tuk on about it and I recoleck thet you sed I better make a note on't an swar to it before a notry cuz I wud never see the like agen in mi born days, and you sed thet you wud give me the first nine dollar bill you come acrost if I wud kill the critter in the ack next time and thet you would give me a gold plated goose-yoke and I dont kno what all and thet you wud give me a two dollar bill fer every bumble bee I wud send ye with a hossfly in his teeth. Likenuff you hev fergoten this last part but I haint. I sed be you in arnest and you sed you was. So here I be stickin to the letter on't and seein how ded sartin you was thet I was coddin, I am glad to be even with ye. 
"I hev been waitin a long while but luck hez give me another chance. I send by mail in a match box a bumble bee which I ketched last evening. I seen him buzzin around fer a spell while I was milkin and putty soon he pitched on to a fly on the barn door and took him to a catnip bush and wus eatin him wen I give him a rap with my hat and ketched him. The fly aint a hoss-fly, pleg on it, and so I spose youl back out of your bargin but it doos jest soot me pooty slick to think how youl hev to eat crow wen you see the bumble bee with the fly in his mouth killed in the ack as you sed. Larnin is a vallable thing no doubt but it aint got no slow agin experiens."

The "bumblebee" was received in good condition, and I have endeavored to picture the same in the act of pursuit of his prey, and as he appeared in his last serene moments when viewing the pastoral landscape from the catnip-bush, with my friend milking in the foreground. I thank my correspondent for the kind information contained in his letter, and assure him that I shall not let that little horse-fly technicality stand between him and his nine-dollar bill and gold-plated goose-yoke. I know his "bumblebee" very well. No doubt it captured the fly as described. But did it occur to my friend that he had possibly overlooked some important facts in his eagerness to get that goose-yoke? It is a strange thing, for instance, that when our bumblebee concludes to dine on horse-flies instead of honey, he should suddenly contrive to get rid of one pair of wings! We will say nothing of other lightning changes that must have taken place in the insect's being, for this one transformation is sufficient. If he will catch the next bumblebee he sees upon a red-clover blossom he will find that it has four wings, while this horse-fly specimen which he has sent has but two. No, I will 
not "back out" from my bargain, but, on the contrary, I am prepared to redouble my cash inducements for every normal two-winged bee of any kind that he or any one else will send me.

What, then, is our mock bumblebee? It is, in truth, no bee at all, but a rapacious robber fly, which nature for some reason has wonderfully disguised as a bumblebee. It hovers in the flowery haunts of bees, and, safe in its disguise, makes havoc among the unsuspecting small fry among the insects, or even among many nearly as large as itself, clutching them with its strong legs, and quickly finishing them with its strong blood-

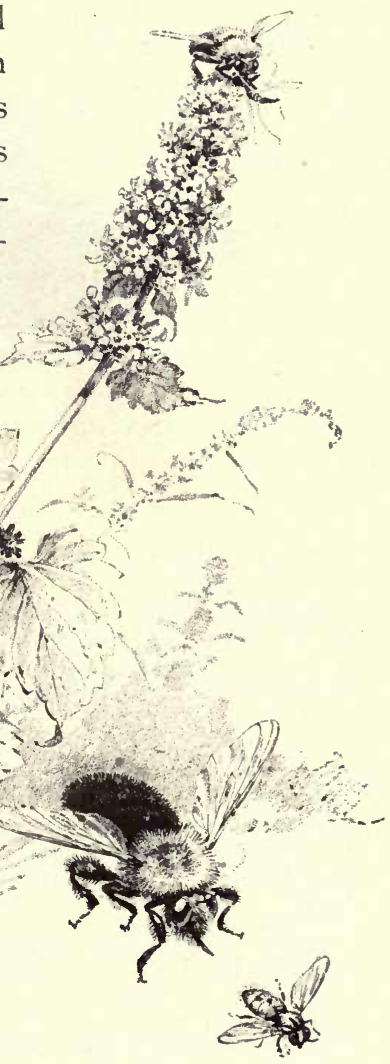


sucking proboscis. Only last summer, while sketching, I observed one of these murderous flies hovering about me, with a huge bot-fly impaled on its horny beak.

I beg to introduce to my Connecticut friend the Laphria fly, warranted to bring confusion to horse-flies and rural authorities in natural history.

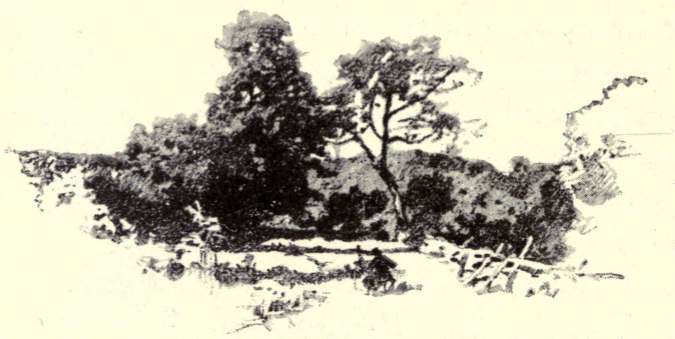


AT nerve you must have!" said a companion stroller to me recently, as I caught in my hand one common brown wasp after another and twirled it in my fingers; "what nerve! for I know, of course, that they must all have stung you, only you won't admit it.

"Could I do it?" he continued, in reply to my question. "Why, of course I could do it, only I am not such a fool!"

In vain I assured him that the insects were harmless; in vain urged him to clutch a small swarm which crawled upon the fence close by. But prejudice is a difficult obstacle, especially in matters of this kind, and I was obliged to caress my wasps alone.

"It is all in the way you do it," I observed, as I picked up two at once from the summit of a goldenrod, and rolled them into one waspy jumble between my fingers, and then let them loose upon the wing, none the worse bodily, even though somewhat richer in experience.

At length, after much persuasion, my friend's credu- 


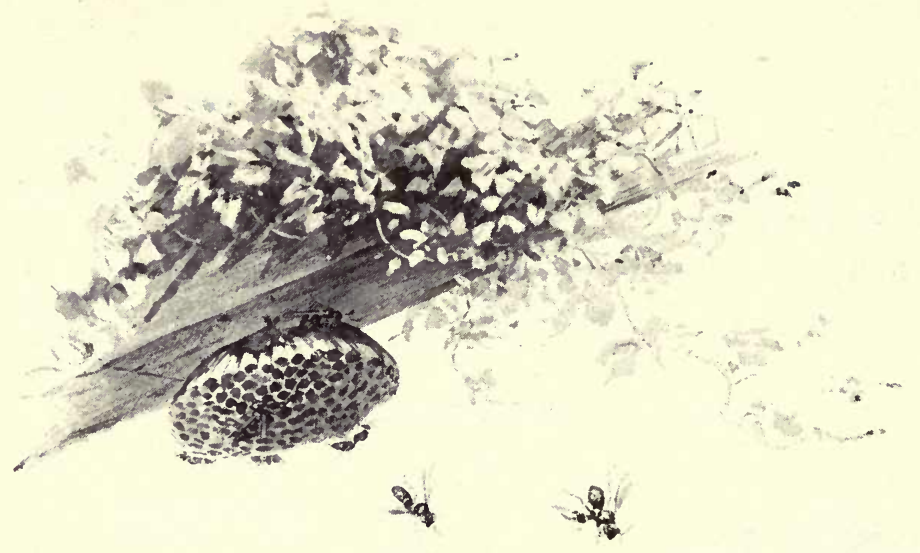

lity was overcome to the point of trial, and he grasped his wasp with true heroism, holding

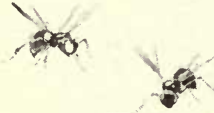
his breath meanwhile, and bringing all his hypnotic power, as he said, to bear upon the victim, and to this alone he attributed his escape from the insect's sting; for he handled it without the slightest harm.

"You are right," he said; "it is all in the way you do it."

But his next essay was not so conspicuous a success, and I express it but mildly when I say that he has done with this sort of amusement for all time.

There is, in truth, a right way and a wrong way in the handling of a wasp. I read a few winters ago what was considered a surprising statement, in a Boston newspaper, that a "boy caught a butterfly at South End yesterday, in midwinter;" in commenting upon which a New York natural-history editor sententiously remarked, "It may be all right to catch a butterfly at 'South End,' but when you grab a wasp it is safer to take him at the north end."

But this is not my secret. There is a knack about 
handling a wasp, I confess, but it can be mastered by any one, and I give the secret for the benefit of the tyro naturalist, who may not be on such intimate terms with his wasp neighbors. The safest season for experiment is in September. You are now certain to find your wasps in numbers upon the golden-rods just emerged from their paper cells beneath the eaves or fences. Creep up slyly, hold your open palm within a foot of the insect, and murmur to your inmost self the following brief sentiment,

"Polistes! Polistes! bifrons! proponito faciem!"

and wait until the insect turns towards you, which it is more or less certain to do; then, with a quick clutch, grasp your prize. It is not necessary to hold your breath or wet your fingers, as is commonly supposed; the above classic charm will work quite as well without. After holding the insect in the hollow of your hand for a moment, take him boldly between your fingers, roll him, pull him, squeeze him, and twirl him as you will; no amount of abuse will in
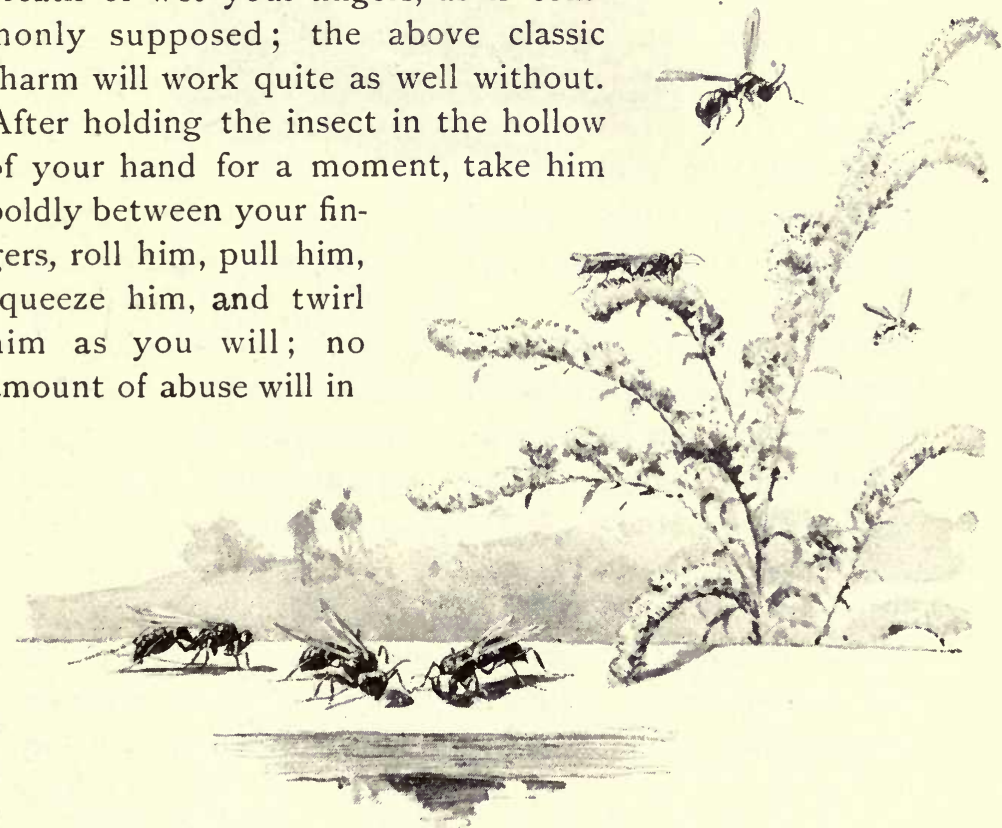
duce him to sting. Perfect faith in the above will enable any one to handle a wasp with impunity.

P. S.-I almost forgot to mention that it is always safest to experiment with white-faced wasps, as these are drones, and have no sting.

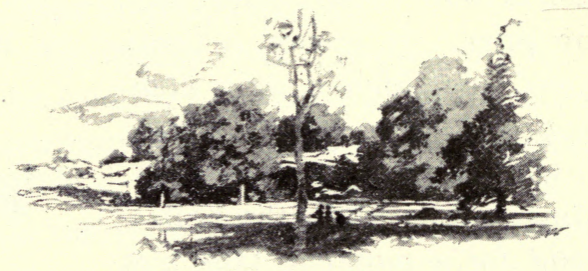




\section{THE WONDERFUL FUNGUS TRIBE}

\section{October bth}

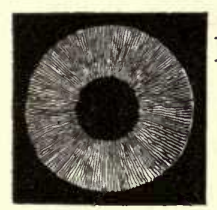

$\mathrm{NE}$ of the eminent authorities on fungi, Fries, has estimated that the spores in a single puff-ball may reach a total of ten millions. Under favorable conditions of growth their yield would cover an area of two square miles. Thousands upon thousands of puff-balls are sowing their brown spore smoke upon every autumn breeze, and millions of other fungous growths - toadstools, mushrooms, etc.-are also adding their myriads. Did the reader ever stop to think what infinite potentialities were borne in the cloud of dust that obscures the landscape just before a storm?

At first glance Nature would seem to be needlessly prodigal of her means towards the perpetuation of these singular and omnipresent plants. But her generosity is the result of deep design. She knows full well that not one in thousands of these floating atoms will ever vegetate. And yet they would seem to be common enough. A single short walk in the woods almost anywhere will show us a whole museum of them, for they are almost universal in their growth. Hardly a square foot of the leaf mould beneath our feet but what is threaded by 


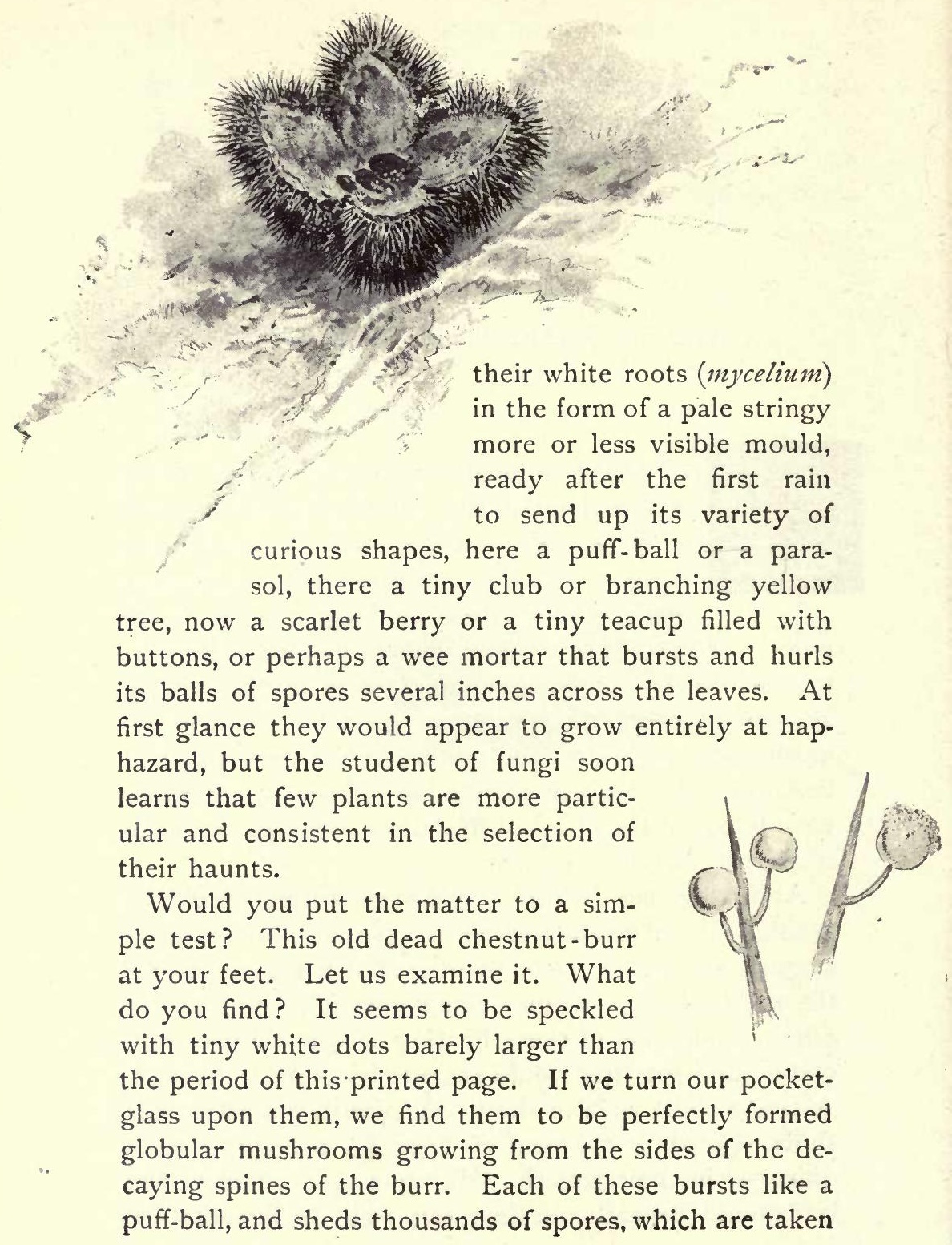


up by the wind and wafted where you will. They fall in every conceivable place, but it is only when they find their favorite dead chestnut-burr that they care to grow. They are never found elsewhere than among these decaying spines. It is a distinct species, named after the chestnut-burr, its only home.

Here upon the matted leaves we find a little colony. of small yellow parasols with long black stems. They appear to be growing through an oak-leaf; but if we carefully tear away the leaf we bring our parasols too, for they are true to the dead oak-leaf only. You may find other similar parasols upon the maple-leaf, but they are another species.

Once, while sitting in the woods by the edge of a stream, a young companion called my attention to an orange-colored cone about three-quarters of an inch in height protruding from a bed of green moss at my elbow. I discovered it to be the cap of a small mushroom, whose stem penetrated deep into the moss. With much care I succeeded in separating the moss, being curious to discover upon what the fungus had grown, and to my astonishment, when I drew it to the

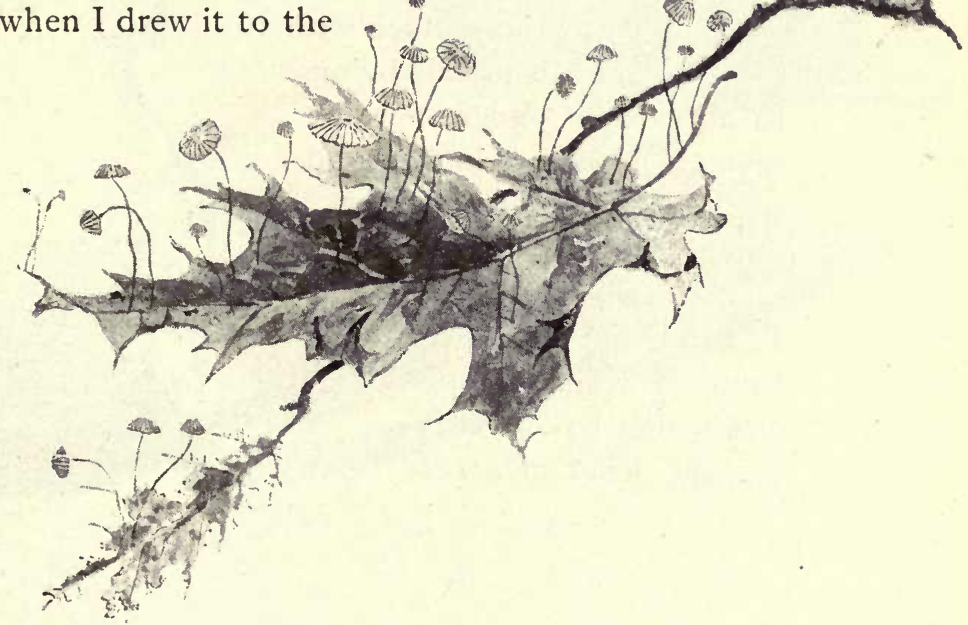




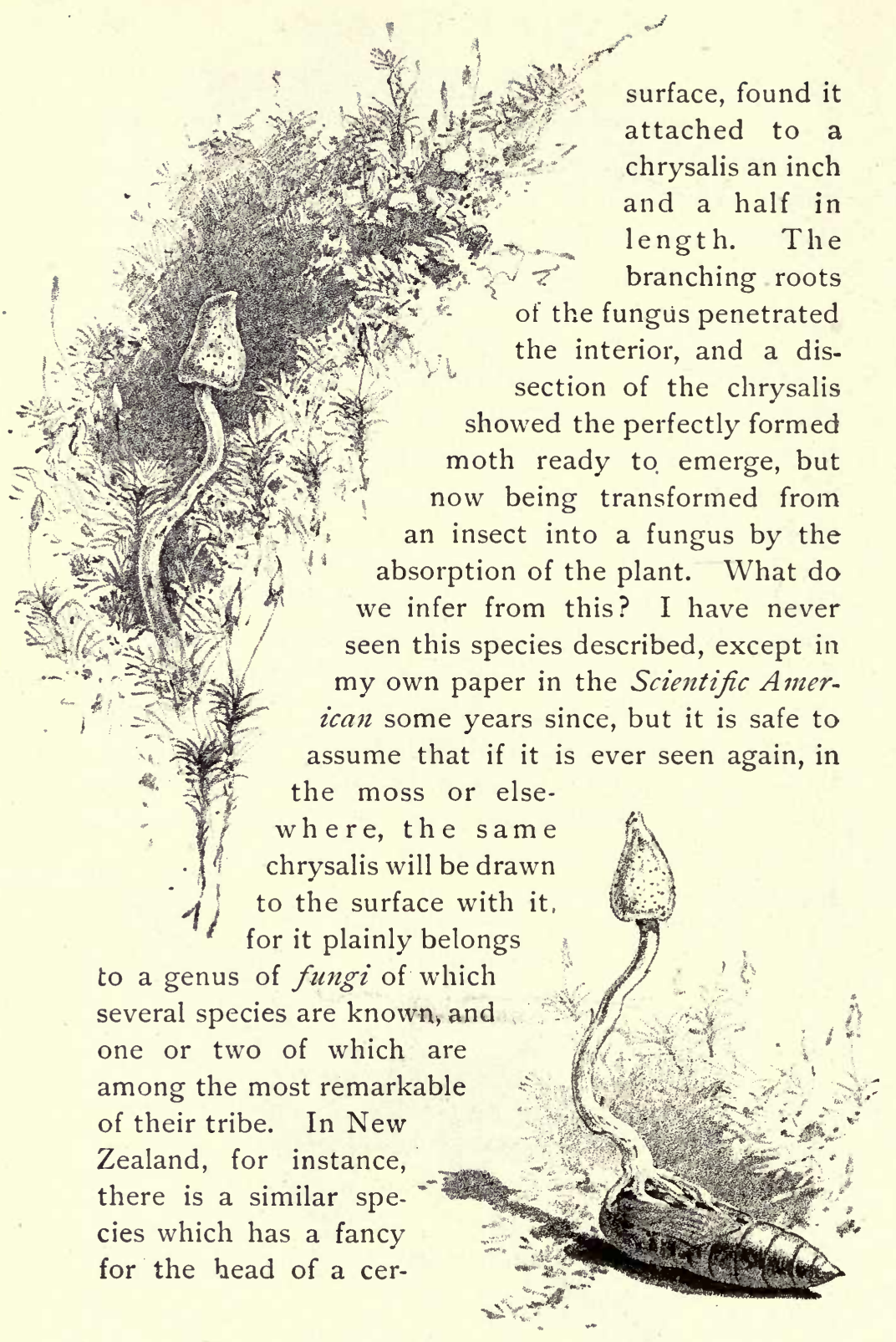


tain caterpillar. It grows rapidly to the length of several inches, gradually absorbing the body of the insect, and at length takes root in the ground and continues its growth.

In the Chinese apothecaries' shops we may obtain à queer bundle, like a small bunch of crooked dried fagots, about four inches in length. They are powdered and used as medicine by the innocent Celestials, and are a regular article in their pharmacopœia. It needs but a second glance to see that these dried sticks consist of a long-stemmed fungus attached to the head of a wrinkled dead caterpillar, a species known as the Sphaeria sinensis in the technical works.

These are only a few of the typical eccentricities of this wonderful tribe of fungous growths. Almost any half-hour's walk in the country will show us many equally curious. The instance of the chestnut-spine fungus is but one of many similar surprises in store for the amateur fungologist.

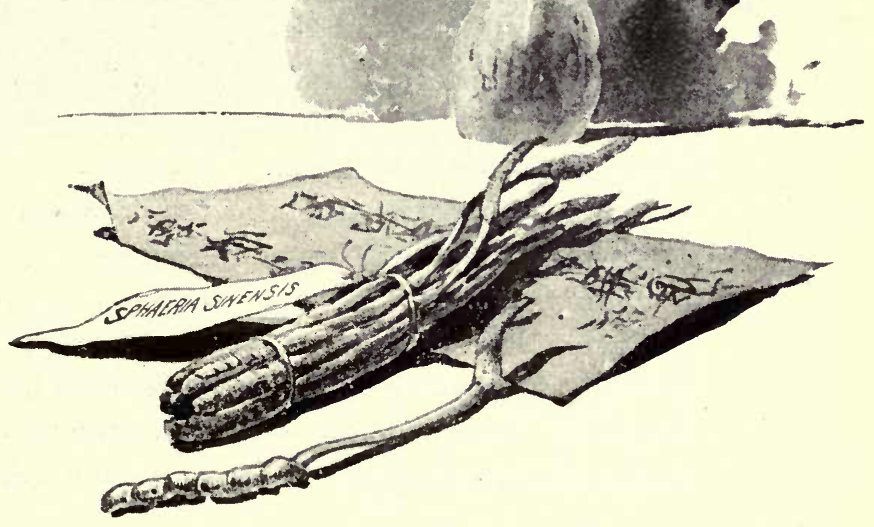



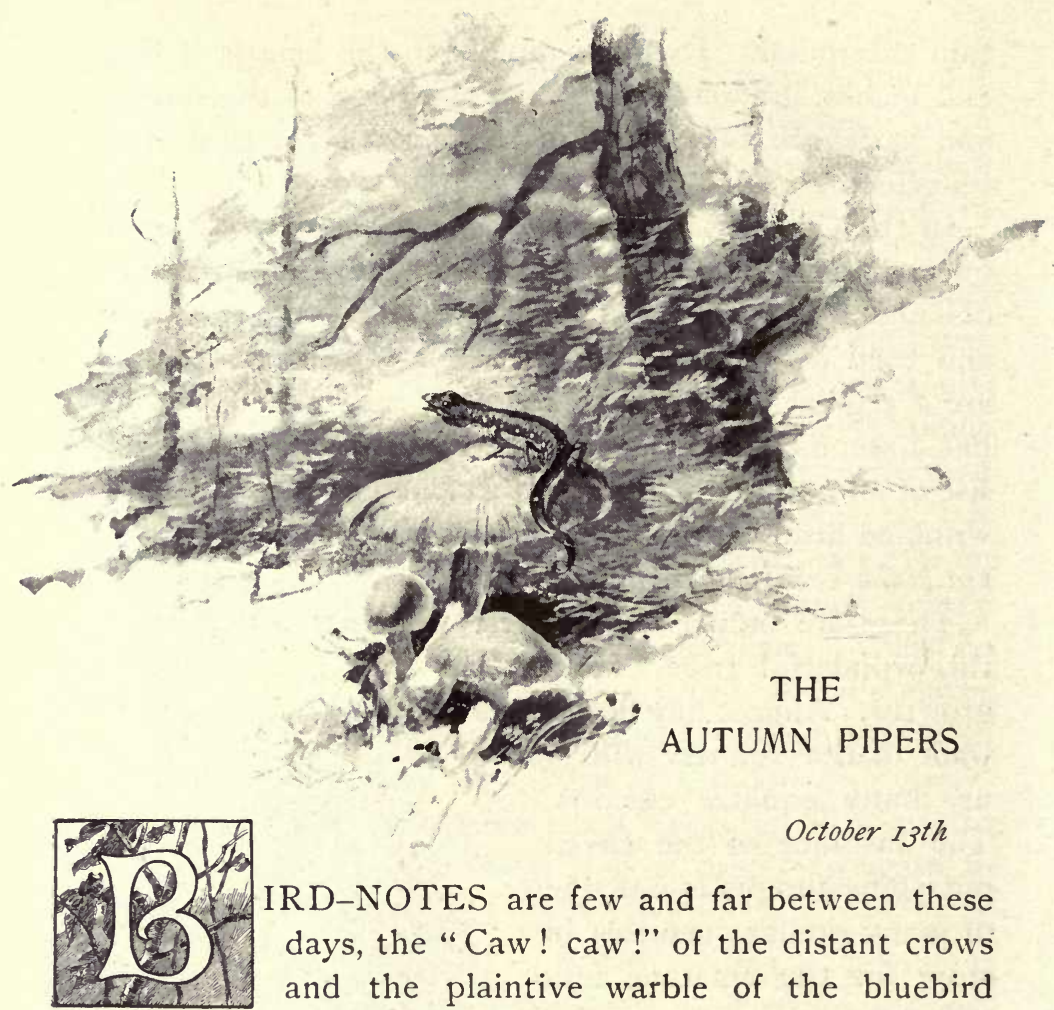

October 13 th

IRD-NOTES are few and far between these days, the "Caw! caw!" of the distant crows and the plaintive warble of the bluebird being perhaps the more notable exceptions. But a new order of music now follows on the programme to hold the diminuendo until the frosty days shall finally close the musical season.

There are a great number of sprightly autumn whistlers which now come upon the scene, either in solo or in chorus, among which a discriminating ear may detect a variety of distinct songs. We all know the impetuous "Tr-r-r-r-rdt!" of the tree-toad (Hyla versicolor), even though we know not where to look for its source, having perhaps rested our eyes upon the vocalist 


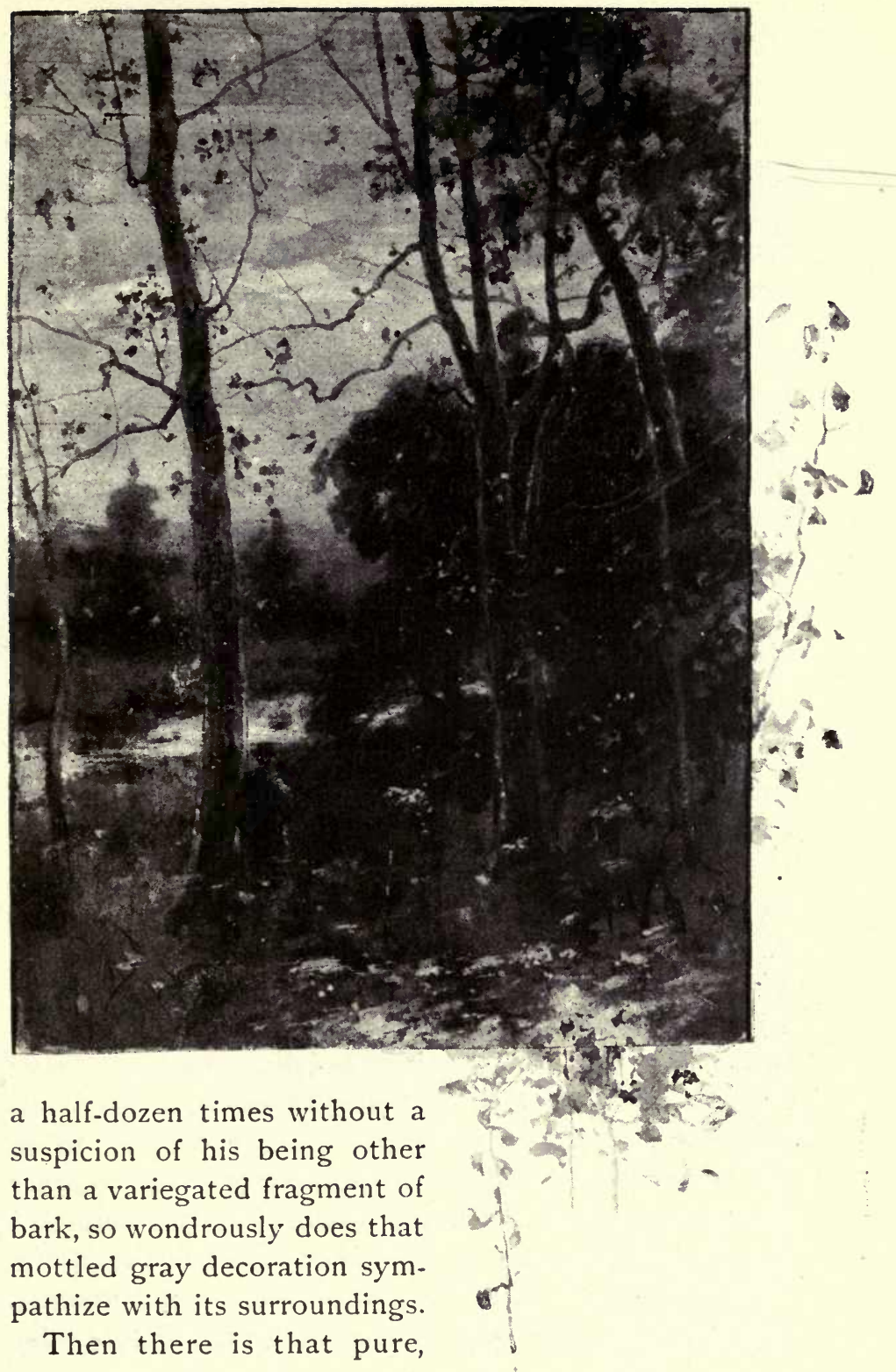


shrill pipe of finer quality, without quaver or trill, which is quite as much wrapt in mystery as to its source as that of the tree-toad, except that it proceeds somewhere from the boughs over our heads, a note that brings back the spring again. For this is the same shrill peep that ushers in the April from the ripples of the swamp - the Hylodes, now turned acrobat, as much at home here among the trees as we saw him in the bog last March. We hear his pipe, and occasionally catch a glimpse of the piper jumping across the brown dead leaves, himself as brown as they, but the piper and the pipe are rarely caught together.

The brown leaves also claim another protégé dressed to their liking, whose somewhat coarse clucking note occasionally joins the shrill peep of the Hylodes. We may see him jump, and might yet almost fail to find him again, so perfect is his disguise, were it not for that telltale black cheek which he wears-the wood-frog, another dweller of the spring swamp out for a few months' airing.

But the rarest and most mysterious of all these forest peepers yet remains to be described. Many of us have heard his sprightly plaint without knowing where to place the credit. Burroughs, I believe, is the first to have traced the music to its source, and caught the mu. sician in the act. He tells of his discovery as follows:

"For years I have beén trying to ascertain for a certainty the author of that fine plaintive peeping to be heard more or less frequently according to the weather in our summer and autumn woods. It is a note that much resembles that of our small marsh frogs in spring - the Hylodes. It is not quite so clear and assured, but otherwise much the same. Of a warm October day 


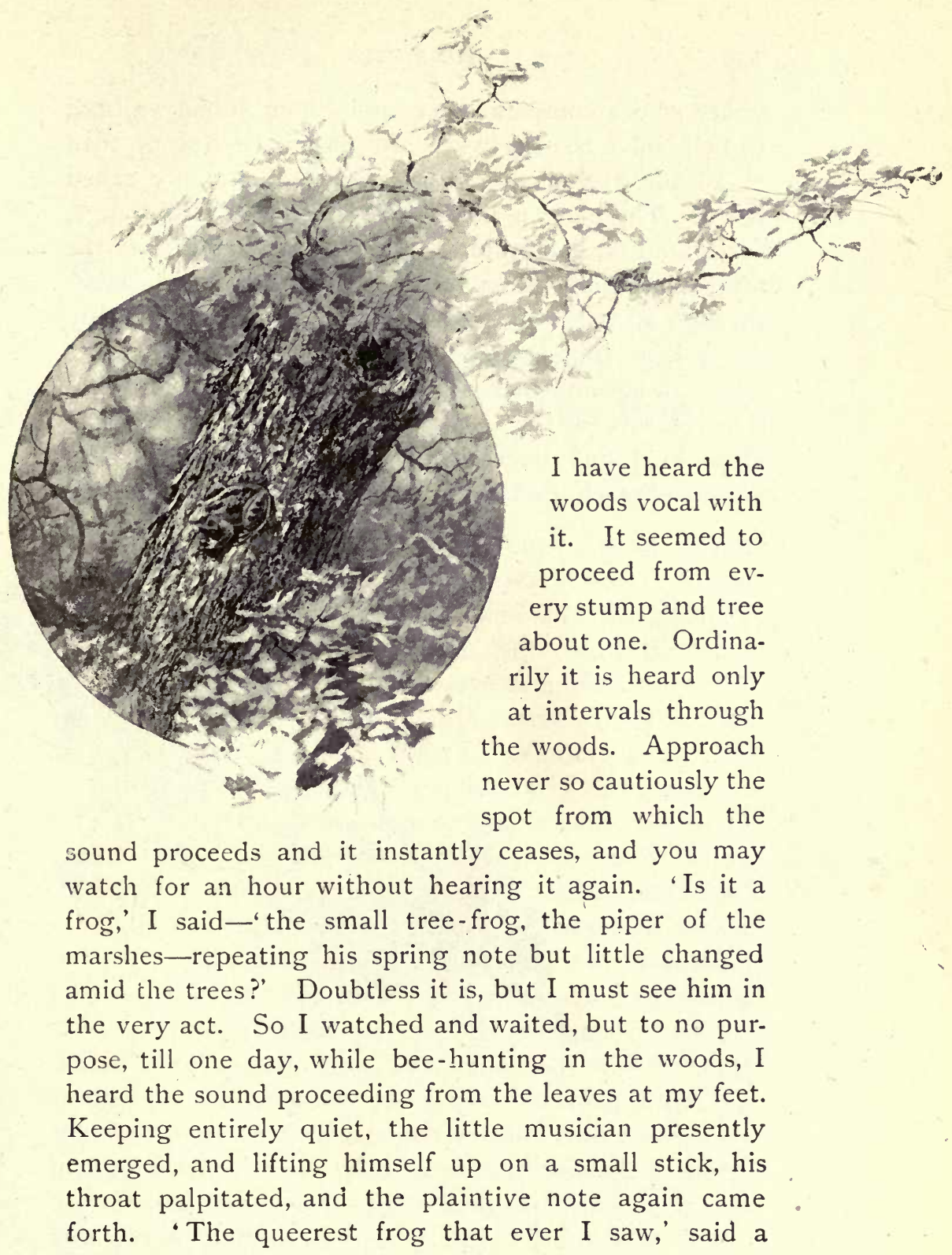


youth who accompanied me, and whom I had enlisted to help solve the mystery. No, it was no frog or toad at all, but the small red salamander commonly called lizard. The color is not strictly red, but a dull orange, variegated with minute specks or spots. This was the mysterious piper, then heard from May till November through all our woods, sometimes on trees, but usually on or near the ground. It makes more music in the woods in autumn than any bird. It is a pretty, inoffensive creature, walks as awkwardly as a baby, and may often be found beneath stones and old logs in the woods, where, buried in the mould, it passes the winter."

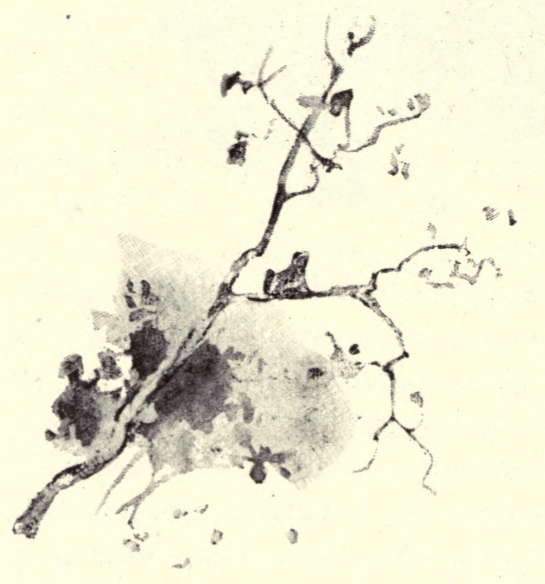


A BURDOCK

BIRD-TRAP

\section{October $13^{\text {th }}$}

$\mathrm{E}$ have indeed a most formidable device in the tenacious burr seed of the burdock. Beset with hooked-tipped spines, it lays firm hold on everything within reach, and is not easily removed, as many a rural lad can testify who has had a handful 12. of them rubbed into his hair by some playful school-mate. He soon learns, however, that pulling is useless, that each effort only increases the hopeless tangle, and that only by crunching and separating the seed can its hooks be removed, and leave him possessed of his full allowance of hair. These eager hooks have, of course, but one possible mission in the economy of nature - to steal a ride on the first craft that shall come within their reach. By making the most of their opportunities-dog, sheep, human, and otherwise - they have succeeded in travelling pretty extensively over the civilized globe. 
Several years since I met with an incident which showed this tenacious proclivity in a new light, and gave it a serious significance not before suspected--a trap for birds. In passing through a copse one autumn day I came upon a scene such as I have here pictured. The captive bird was a chickadee, long dead. It had apparently lit upon the cluster of burrs, and its feet becoming entangled, had fluttered violently to escape, only to have its wings pinioned securely on each side, in which position it died. I have never seen or heard of a similar instance. Are our small birds, then, ordinarily acquainted with the dangers of the burdock traps, and thus warned to avoid them? The experience of this chickadee would seem to be the certain fate of any small bird which should repeat its heedlessness.

The lesser hooked burrs, such as the stickseed, beggars ticks, sanicle, and agrimony doubtless occasionally come into contact with the plumage of birds, but in their diminutive size, though fully as tenacious, could scarce prove more than an inconvenience. 


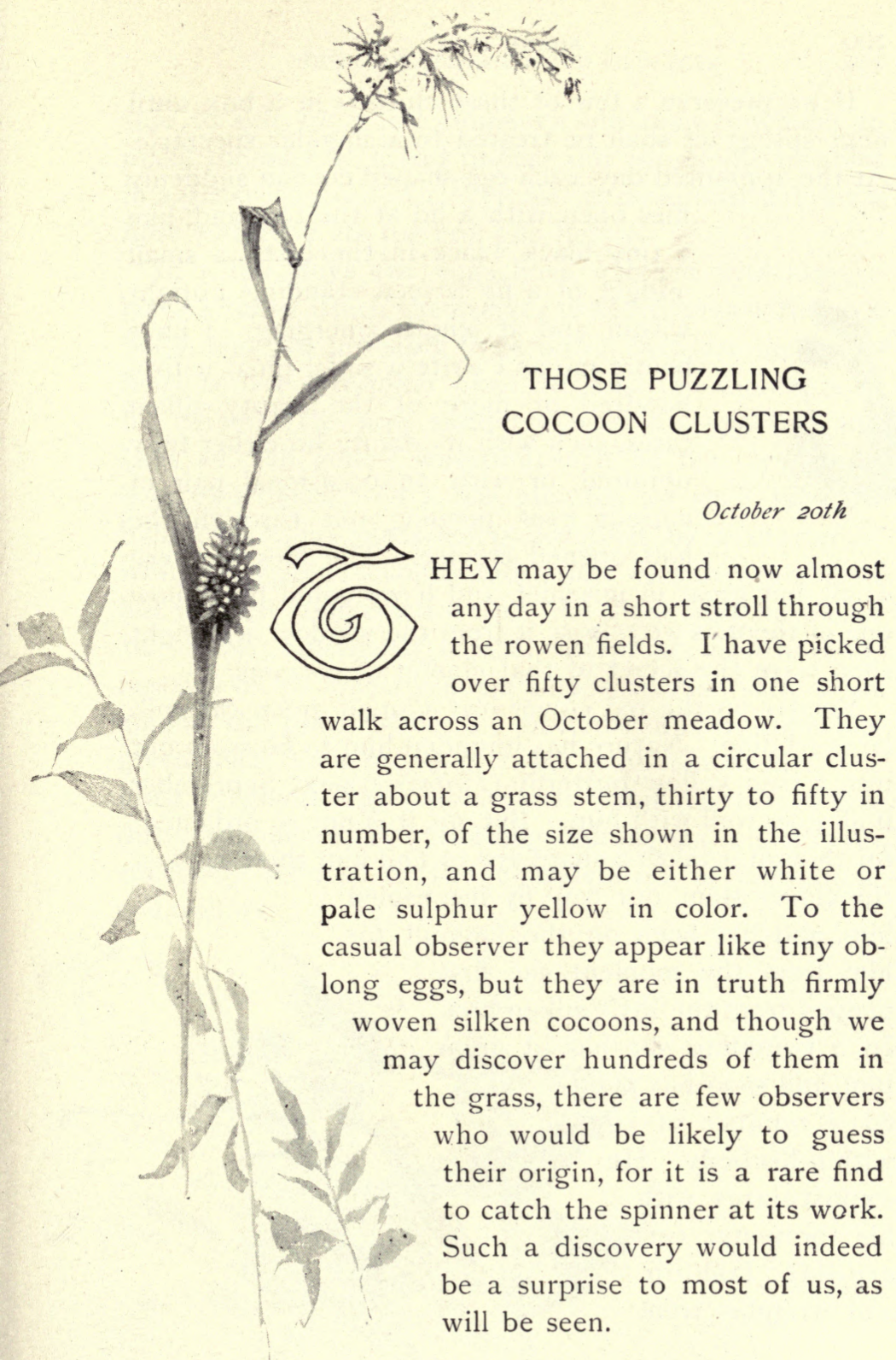


If we preserve a few of these clusters in a box until next spring we shall be treated to a singular spectacle. At the appointed day, each egg-shaped cocoon suddenly flies open, with a lid at the top, and, like

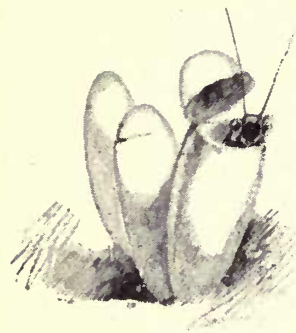
a tiny black " jack-in-the-box," a small midget of a fly is seen standing upright within, and at length emerging. I have before me as I write a small phial with a hundred or more of the empty silken cases, each with its dainty lid either fully upraised, or with an occasional pair of curious eyes peeping out through the half-opened crevice. The flies are very small, but great in mischief, and if we could but follow one of them as we release it from the window, we might soon learn the secret of that cluster of cocoons.

Yonder on the red clover leaf a small green caterpillar is feeding. Nature has intended him to blossom out into a pale yellow butterfly (Philodice) next September if all goes well with him. But, no, it is not so ordained; for though it takes a sharp eye to find him there against the clover stem, our tiny fly has espied him, and has been on the lookout for him from the moment she first peeped from the little silken box. In a twinkling she has lit upon him, and soon has planted a number of eggs within his body. $\mathrm{He}$ expostulates with his tormenter caterpillar fashion, and wriggles from

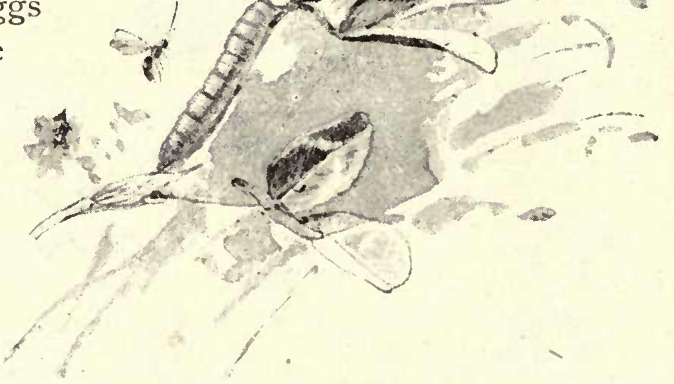


side to side for a few moments, and then concludes to make the best of a bad matter and forget his troubles in a generous meal of clover, for he now must eat for a host where he ate for but one before.

In a few days the eggs have hatched into minute larvæ; these attach themselves to the tissues within his body, and are probably little more than an inconvenience to our caterpillar until the final few moments of his career. He now suddenly loses his appetite, and feels an "all gone" sensation, such as few dyspeptics ever experience. In a few minutes we shall look for him in vain, his place being occupied by a cluster of white or yellow cocoons and a few whitish grubs half hid in their unfinished webs. An hour ago he was a full - grown, apparently normal caterpillar; now nothing remains of his identity but a thin, shrivelled skin down ameng the grass, while the butterfly of his hope has given place to a brood of black ichneumon-flies - a most pregnant illustration, drawn from real life, of the dire consequences of indwelling, abiding sin, which is respectfully referred to the consideration of our pulpit counsellors.

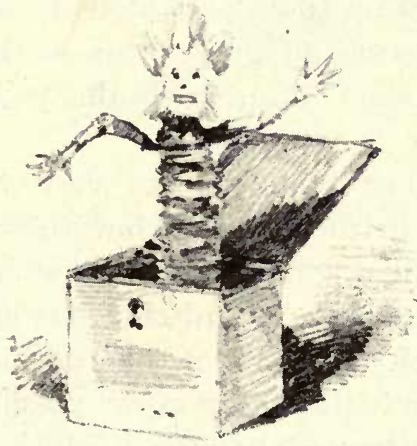




\section{THE WITCH-HAZEL BOMBARDMENT}

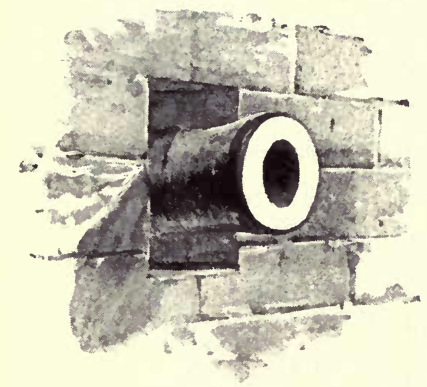

October 2oth

$\mathrm{NE}$ by one the lingering wild flowers have succumbed to the frosts; a few of the hardy asters being the only reminders of the regal glory of the October copses.

But though the blighting breath of the approaching winter is fast quenching even these remnants of bloom, there is one fresh blossom which shall abide to welcome "chill November," even as the dandelion welcomed May, and as the rose and the golden-rod welcomed June and September. The waving pennants of the witch-hazel, coiled for weeks within their patient buds, are now swung out from thousands of gray twigs in the copses, and the underwoods are lit up with the yellow halo from their myriads of fringy petals.

These luminous blossoms are very well known to most dwellers in the country, but there is something else going on there among the twigs which few observers have suspected. It is a mischievous haunt out there among the witch-hazels about this time. I shall never forget the caper it played upon me years ago.

I had been attracted by a bush which showed an un- 
usual profusion of bloom, and while standing close beside it in admiration I was suddenly stung on the cheek by some missile, and the next instant shot in the eye by another, the mysterious marksman having apparently let off both barrels of his little gun directly in my f́ace.

I soon discovered him-an army of them in fact, a saucy legion - all grinning with open mouths and

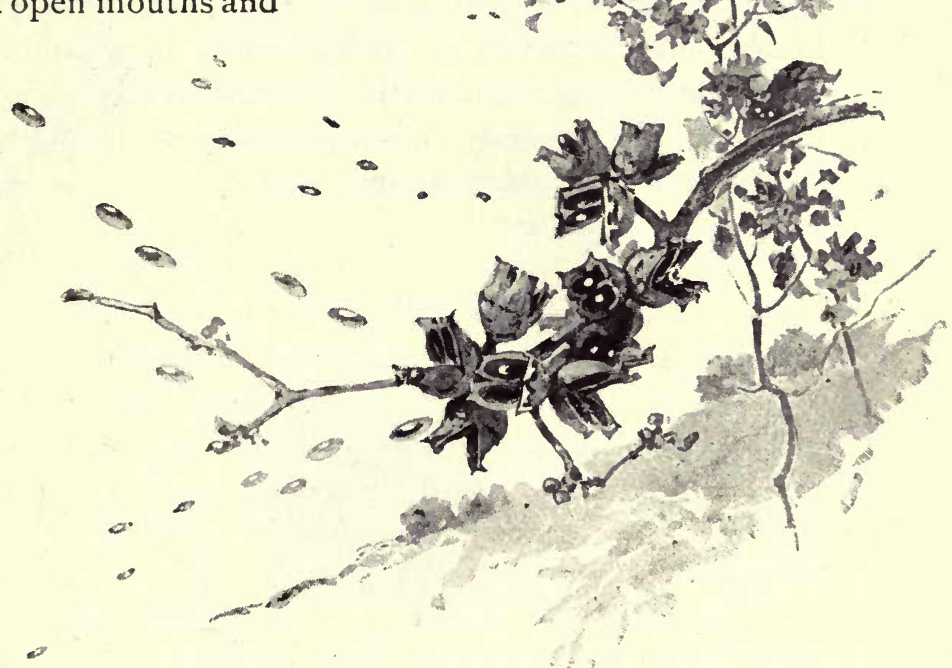

white teeth exposed, and their double-barrelled guns loaded to the muzzle, and ready to shoot whenever the whim should take them.

These little sharp-shooters I have shown in my illustration. They are the double-barrelled guns of the witch-hazel-the ripe pods of last year's flowers-now 
opening everywhere in the woods among the yeilow blossoms. Each pod contains two long black shining seeds of bony hardness. The pod splits in half, exposing the two white-tipped seeds. The edges of the horny cells contract against the sides of the seed, and finally expel it with surprising force, sometimes to the distance of over forty feet. If we sit quiet on a sunny day in a witch-hazel copse we may hear the dry leaves rattle with the continual bombardment. A branch of the unopened pods brought home and placed in the vase upon the mantel will afford considerable amusement as the seeds rattle about the room, singling out their whimsical targets, or, perhaps, carrom around from walls and ceiling, from the glass lamp-shade upon the table, or the evening newspaper of paterfamilias, or: possibly, the bald spot upon his head.

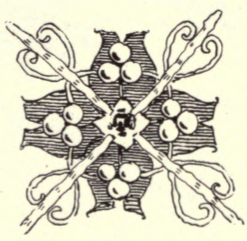




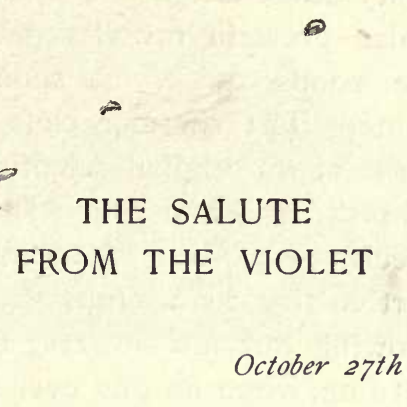

$\mathrm{HE}$ witch-hazel is not the only sharpshooter of the autumn woods. It has a tiny rival down there among the dried leaves, which, in proportion to its size, is quite as valiant - the blue spring violetand with which it doubtless exchanges an occasional salute.

"But the season of the violet was closed some six months ago," you remark. "What has November to do with violet seeds?"

Yes, the "blue violet" which the world knows closed its season in May; but having devoted a month or so to vanity, it has since been settling down to sober realities of life, and the cares of maternity-scattering its broods through the woods.

There are blossoms there among those seeds even now which the frost will probably kill-perfect blossoms. To be sure they have no petals, but all these shooting pods, that are pinching out their pear-shaped seeds a distance of ten feet upon the dried leaves, were preceded by just such blossoms, tiny, pointed affairs, 
which never even peep beyond their calyx. How few of our wild-flower hunters know their "blue violet?"

My illustration, the Viola cucullata, is a specimen which grew in my city garden, a plant brought from the woods and which soon made itself too much at home. The singular cleft form of the leaf was the cause of its original selection, a variety known as the "hand leaf," and which is a frequent "sport" of this species of violet. In its new quarters it devoces itself particularly to a rank growth of its peculiar foliage, showing but few flowers; but in the late summer and autumn, when no one ever thinks of a violet, the plant is prolific in bloom, invisible to the general observer, but easily seen on close examination of the soil at its root. Every sunny day, even until the middle of November, the three-cornered stars of the opening pods may be seen by hundreds, and all the neighboring grass-plot and borders are sown with violet seeds.

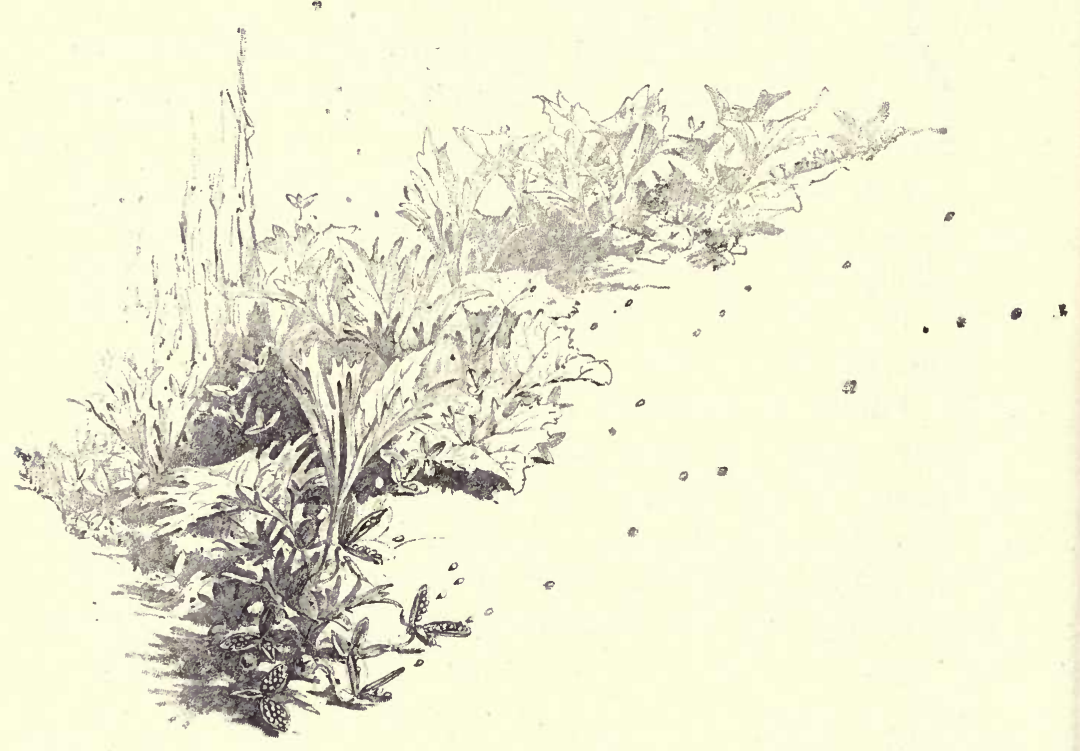




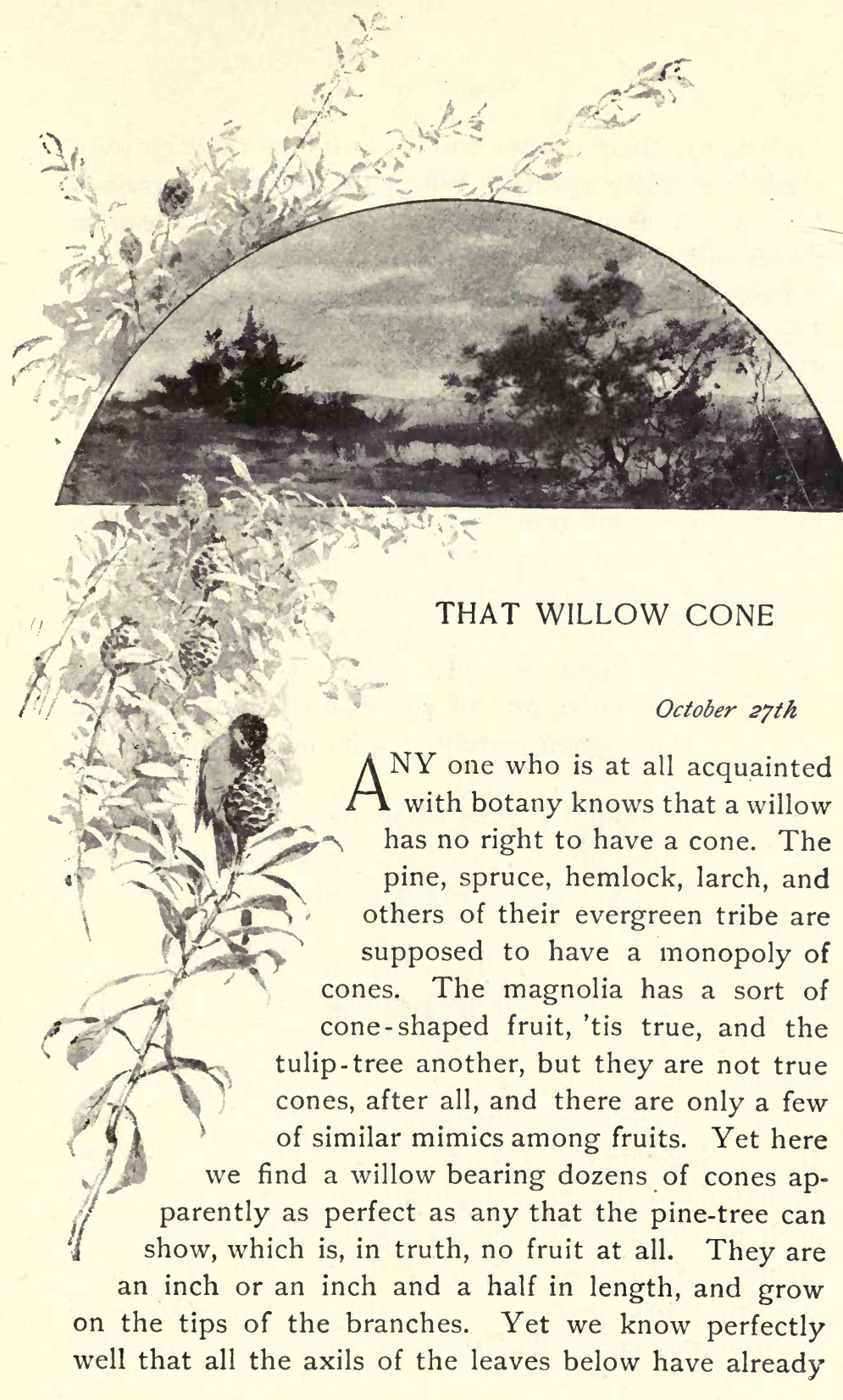


turned out their proper willow fruits in the "cottony seeds" of early spring. What, then, is this spurious fruit which we now see everywhere among the leafless dwarf willows?

Look! Yonder chickadee can tell us all about it. He knows the confusing botanist that would make a pine out of a willow. See! He alights upon a branch, and now inserts his bill at the apex of the cone, and probes the interior. Presently the probe is withdrawn, and with it the tiny expert who is responsible for this mischievous confusion-a small orange-colored grub, which has been sleeping and luxuriating for weeks within the hollow core of the growing cone. It is perfectly plain from an examination of a section of this cone, with its layer on layer of leafy scales, its hollow cavity at the centre, and of course no sign of any seed, that it was designed merely as a home for this plump larva.

And why, then, has this willow been so accommodating as to give up its own plans, and sprout this tiled domicile for a yellow grub to which it is under no obligation?

If we gather a few of the cones and keep them until next spring, we shall see the real magician who has voudooed the willow-a tiny fly (Cecidomyia strobiloides of the naturalists), that tampers with the willow buds of spring, and with some magical medicine humors it into thus taking care of its young ones. This cone is one of thousands of similar gall growths upon various plants, such as the rosy ball on the cinque-foil, the crimson sponge on the sweetbrier, or the swollen tumors on the high blackberry stems, with their hundreds of squirming tenants, all of the same origin, caused by the 
stings of tiny insects and the implanting of their eggs.

It must have escaped the notice of old Gerarde, the botanist of two centuries ago, else he had doubtless classed this species as the "cone-willow," even as. he actually classified another willow as a "rose" on account of a similar insect excrescence, in which the bud was transformed into a dense cluster of leaves somewhat suggesting a rose-a species which may frequently be found in company with our "cone."

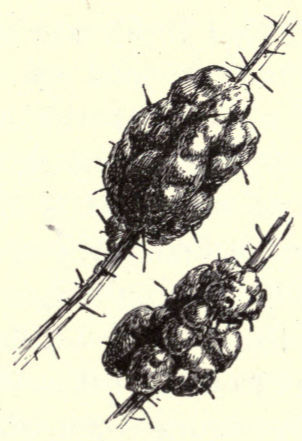




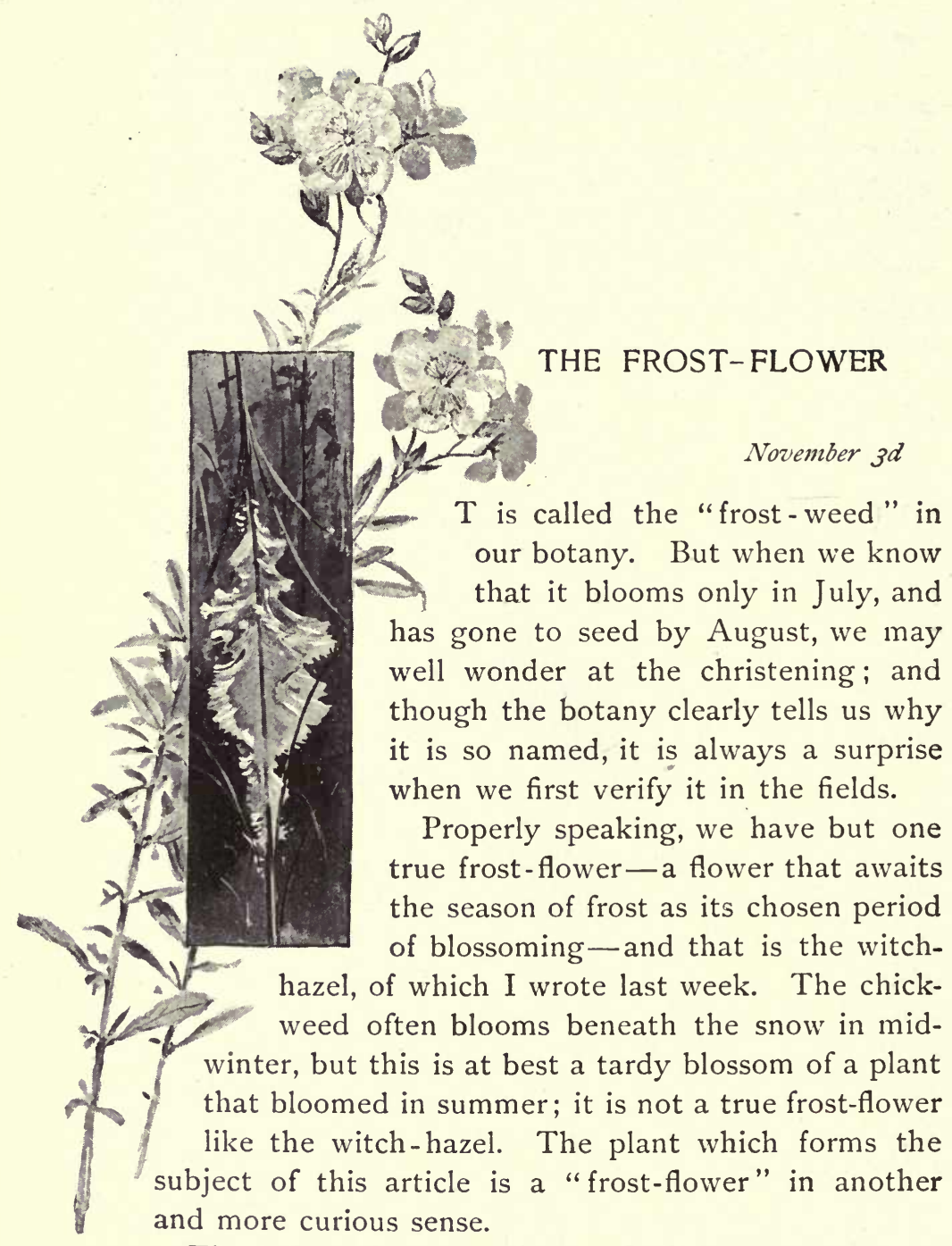

The botanical name of the plant is Helianthemum 
Canadense. It is richly endowed with blossoms - three sorts, in truth. One bright showy one of July, which soon withers, followed in August and September by thousands of others on each plant, though no one would guess it, so minute are they; and again, now in November, the third and quaintest blossom of them all.

The July blossom is indicated in my illustration. It is bright yellow, about an inch across, with its stamens flatly pressed against the petals, and two or three are occasionally in bloom at once. The November flower is also shown in my panel picture - the flower from which the plant is named, but which few people ever see. Almost any morning during the past week, after a severe frost, would have shown it to us among the stubble where the plants are known to grow, glistening like specks of white quartz down among the brown herbage close to the base of the stem.

It is a flower of ice crystal of purest white which shoots from the stem, bursting the bark asunder, and fashioned into all sorts of whimsical feathery curls and flanges and ridges. It is often quite small, but sometimes attains three inches in height and an inch or more in width. It is said to be a crystallization of the sap of the plant, but the size of the crystal is often out of all proportion to the possible amount of sap within the stem, and suggests the possibility that the stem may draw extra moisture from the soil for this special occasion. The frost-flower is well named. 


\section{INOVEMBER BIRDS}

\section{November $3 a$}

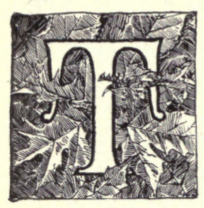

$\mathrm{HE}$ glow of the autumnal tints has now almost faded from the hill-side, and is smouldering beneath the ashen gray of naked twigs; for the sound of rustling leaves now follows us in our rambles in

the woods.

The wilds are almost desolate as to bird voices; the plaintive note of the bluebird is the sweetest note these days, and the jargon of the distant crows is November's own.

But the crows we have always with us, and their vocal strain is never much of a novelty. Most of the great choir of spring songsters are now on their migration to the South - the bobolinks (such as have escaped the shot-guns of New Jersey and Pennsylvania), song-sparrows, thrushes, orioles, vireos, etc.- - and those that now remain with us are mostly so shy and uncommunicative as to be scarcely recognizable by their friends.

But these November remnants of the spring and summer are not my "November birds." November, at least with us in New England, has its own especial birds, even as it has its flower. But they are ours for a few days or weeks only-brief visitors, birds of passage from the North, that touch and go, as it were, sampling our 
meadow crumbs in their leisurely journey to the South, and we should avail ourselves of the opportunities to make their acquaintance.

Prominent among the list of these rare visitors is the fox-sparrow, which may now be seen in flocks in the woods, in size suggesting a thrush, but whose stouter bill and foxy dress and compact build will readily identify him. Then there is quite a brood of tiny warblers which are now passing our way, either as the pioneers of those coming flocks, or loiterers of flocks already gone. The autumnal-streaked warbler, with its jetty head and white cheek and gray and black streaked back and breast (Dendroica striata), is a common straggler in our November woods; also the yellow-rumped warbler, with yellow crown, black cheek, and broad black stripe on the breast under the wing $(D$. coronata). The Cape May warbler is considered the rarest of these flying callers (D. tigrina). Its throat and breast are of a bright yellow, streaked with black. A yellow line over the eye and the tan-colored cheek, with melting tinge of the same color around the back of the head and upon the throat, will help to identify the species. Then there are yellow redpoll and black and yellow warblers, whose distinguishing features are well indicated in their names, though the latter has lost some of its black in its autumn plumage.

Among the most constant of these autumn birds is the snow-bird, with its black head and ashen-gray body. He has only just arrived with us, but inasmuch as he will abide with us all winter he is not properly one of my "November birds." The most conspicuous of all these November comers is the white bunting, or white snow-bird, which arrives with the first flying snow-flakes, 


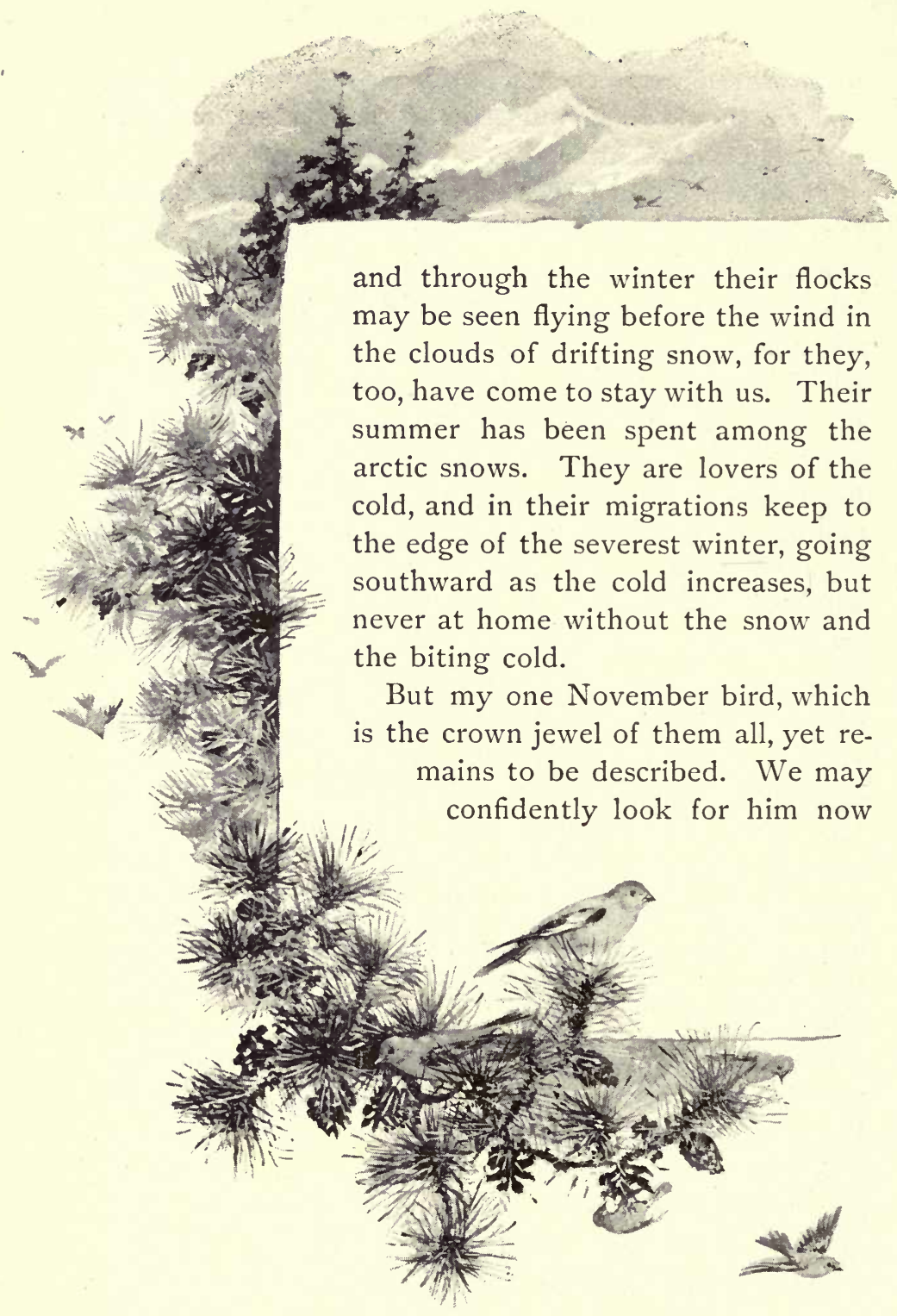


out in the orchard or border thicket of the woods. $\mathrm{He}$ passed us in his northward trip early last spring, but was lost in the throng. But now he is almost alone, and we should not let our November pass without paying our compliments to him, almost the tiniest of our native birds. His total length is only four and a half inches, his plumage generally of a dull olive-color, but he wears a crown of the brightest vermilion, which is his unique feature. You would hardly suspect it as you see him there, almost within touch of your hand, prying among the dead leaves upon the apple branch. Strangely enough, he seems especially careful to keep it concealed beneath the surrounding olive feathers. "Rubycrowned Kinglet," he is called-“kinglet," a little king. There are few crowned heads of larger size that wear a brighter coronet than the Regulus calendula. His is a needless lesson, for certainly none of his superiors in size has more reason to display the crown than he.

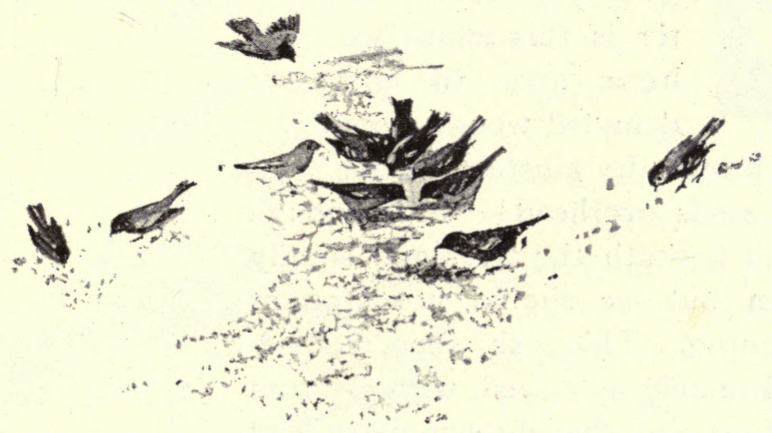




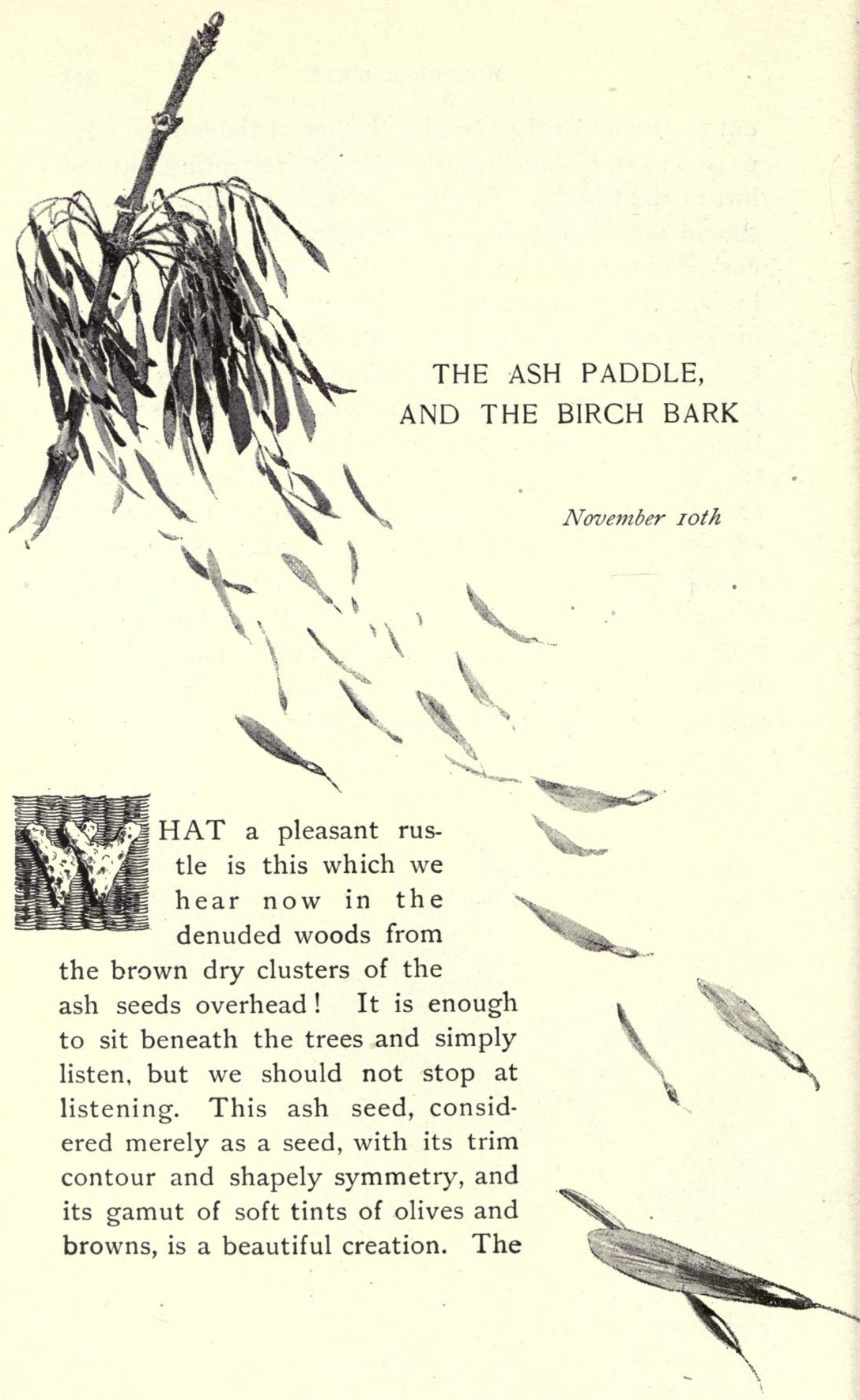


botany designates this particular form of seed as a samara, or winged fruit, of which the fluttering broods of the maple, the pine, tulip-tree, and $\mathrm{elm}$ are other familiar examples; but this rustling ash seed has a little more to say to us-that is, if the reader is of my way of thinking - than is found in the botany. Every now and then a stray seed flutters down in its dizzy whirling flight and settles lightly upon the dry leaves. Let us look at one closely, and as we look give freedom to our fancy.

Something in the design of this flat-bladed samara will surely set us thinking and irresistibly suggest a series of questions.

What is the favorite and most ancient timber from which the oar and paddle are made? The ash. Who, then, was the primeval wood-craftsman who first took

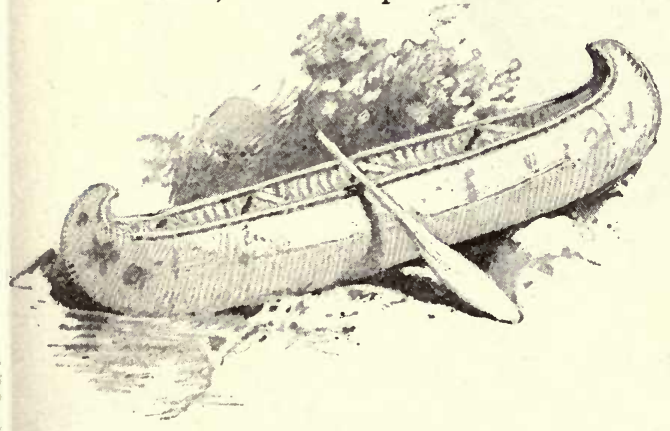
this unmistakable hint from this singular seed-for is it not a perfect model for the Indian paddle or the blade of the modern oar? How many 
centuries did these clusters of prophetic seeds rustle against the white bark of the birch, awaiting that ultimate association of utility in the Indian canoe and paddle?

Nor is this the only model which the ash bestows. There are half a dozen native species of this tree, each with its especial design of paddle-here a long tapering and there a broad and abrupt blade, each, no doubt, the faithful expression of its particular parent tree-of the grain and fibre of its being. Confusion, then, to the wood-craftsman who shall violate its precept and shape his red-ash paddle upon the blue-ash model!

The birch and the ash are further wedded in the trophies of the Indian. We have seen where he obtained his model for the paddle; who knows where he found his hint for the fashioning of the stone arrow-heads which he bound upon the ash shafts of his arrow?

"The birchen bough drops its bright spoil Like arrow-heads of gold,"

says Bryant, in his poem to "October," in allusion to the autumn foliage of the smaller white birch, whose leaf might well serve as a pattern for many an Indian arrow-head in the archæological collections.

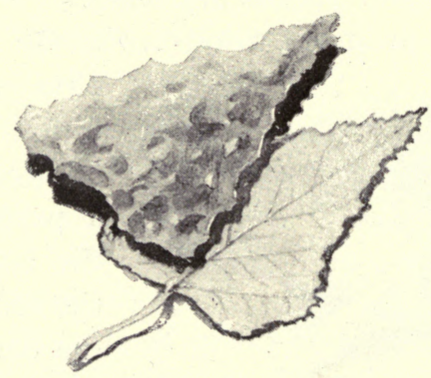




\section{BIRD-NEST MATERIALS}

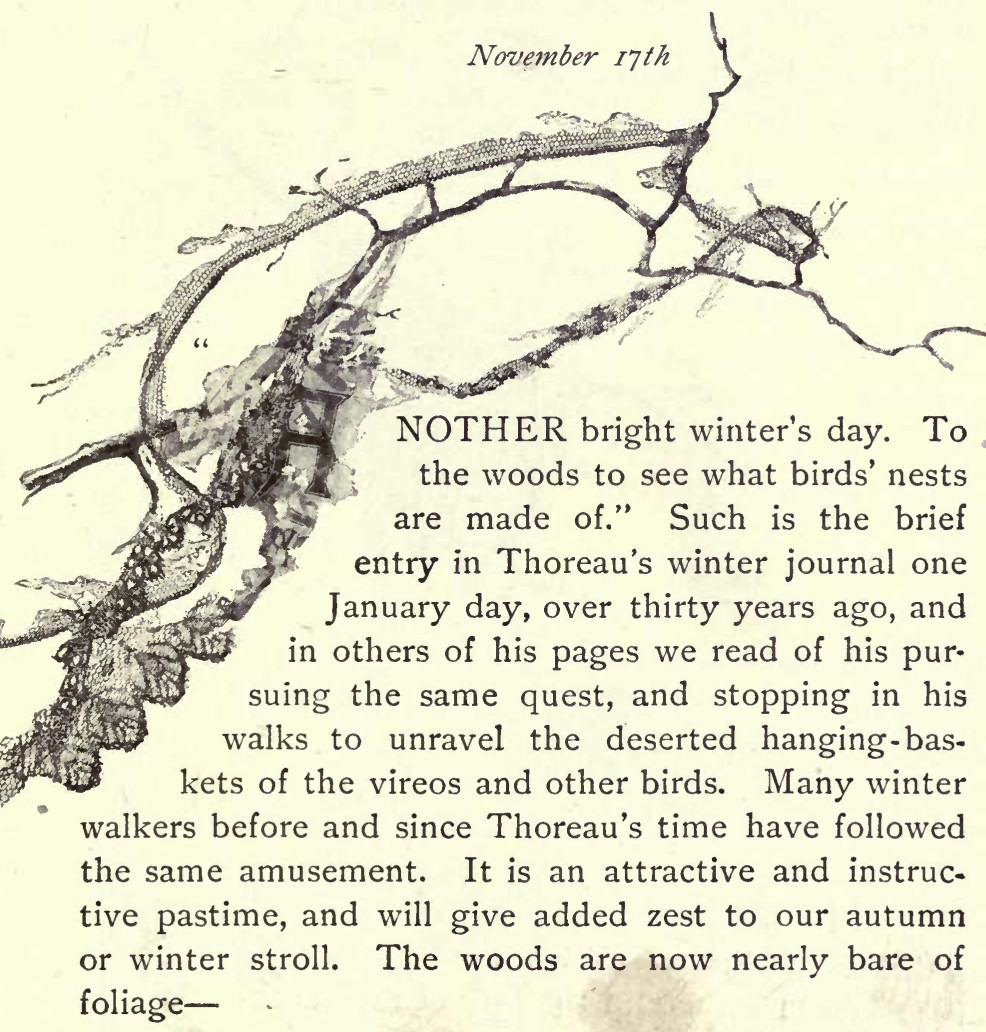

"Boughs are daily rifled By the gusty thieves, And the book of nature Getteth short of leaves "- 
and hundreds of nests which before were completely concealed are now disclosed on right and left. What a surprising list of materials have these feathered builders gathered in their gleaning!. What singular preferences and whimsical fancies are shown in almost any deserted nest you may meet!

Let us begin with this gray vireo's nest

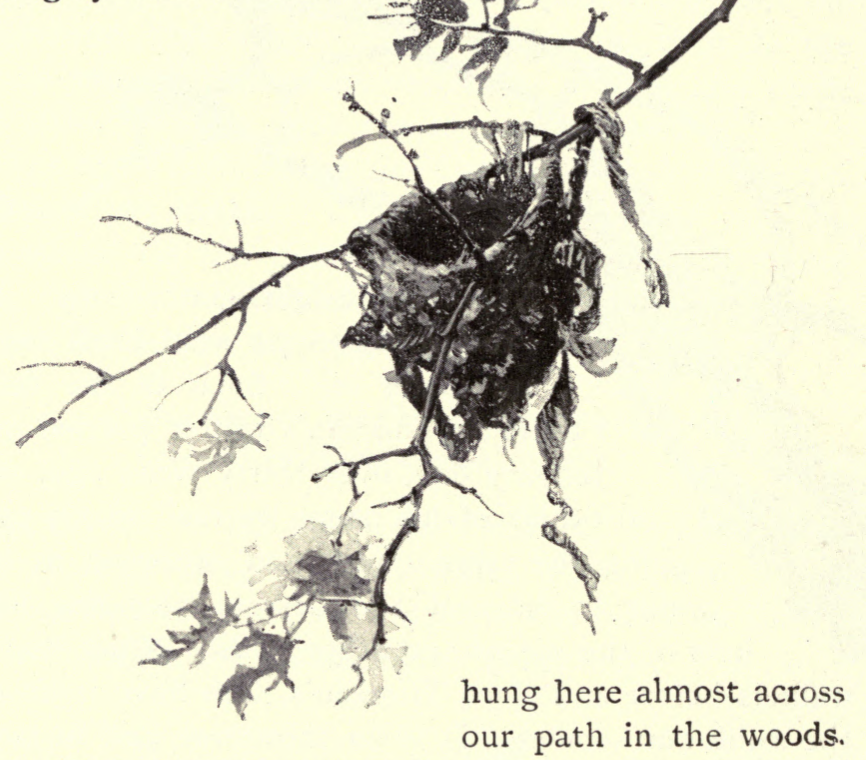

How little did we suspect its presence as we passed this way last June! What are the materials of this basket hanging here in the fork of the maple? Let us unravel it. It is already somewhat worn and weatherbeaten, but it will be many a month before these tough strands which enwrap the twig are loosened. Here we find the toughest material of the nest, our wise bird 
having selected fibres of inner bark, spider, and cocoon silk, and strips from the milk-weed stalk-strong as flax - to moor its cradle.

The compact body of the nest gives a singular variety; here are strips of white and yellow birch bark, aster calyxes, cobwebs, a blue-bottle fly, spider-egg silk tufts, slender roots, bits of pith, skeletonized leaves, pine-needles, old cocoons of the tussock-moth, grass, caterpillar-hairs, dandelion seeds, moss, and feathers. A broad piece of mottled gray paper-like substance forms the outside base of the nest. We might have been certain of finding this - a fragment of hornet'snest, one of the favorite fabrics of all the vireos. And what is this white weather-beaten fragment which crops out beneath it? A bit of newspaper! Further unravelling shows a number of similar pieces embedded in the fabric, and one or two are seen on the ground beneath the nest.

Such were the ingredients of a certain vireo's nest which I once found, and which I have selected as my present specimen. It was a nest of the red-eyed vireo, and though quite an average specimen of its kind, it proved in one respect a remarkable disclosure, as I will explain. Most of the fragments of the nest I threw away, but I found in the newspaper bits a revelation which led me to preserve them most carefully. Not that the newspaper element was an exceptional rarity, for all the vireos have a fancy for this peculiar material. Indeed, the white-eyed vireo was called the "politician" by an old ornithologist because of this very fondness for the newspaper. But why did I preserve these particular newspaper selections above others? As I have said, the nest was that of a red-eyed 
vireo. This bird has been called the "preacher" by Wilson Flagg, a close bird observer, who had noted the peculiar, continuous, deliberate song-sermon of the bird in the tree-top. Remembering this, I was led to scan with curiosity, as I had often done in previous. nests, the text of these weather-beaten waifs of news. There were about a dozen pieces in all. In most of them the print was worn and illegible, and in others so fragmentary as to be without sense. But at length I came upon the sentiment which I have here reproduced

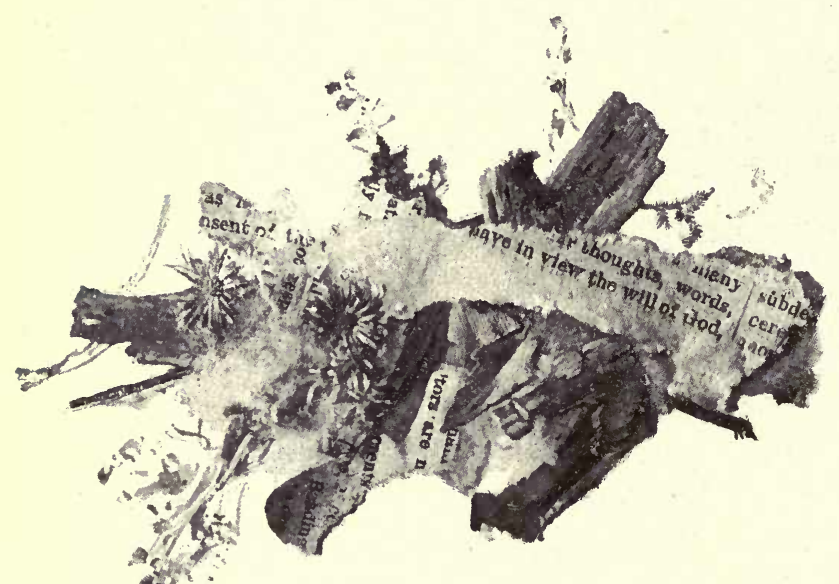
by photography, the only single perfect sentence to be found in all the printmy "preacher's" text - "have in viere the will of God."

But I have not begun to mention all the curious things that are woven into a vireo's fabric. These nests are the "samplers" of nature's nest textiles, and each one may have a new surprise for us. I once found one which was decorated with a hundred or more black spiny caterpillar-skins. Another showed the gauzy mitten of a toad. Another a half-yard of lace edging. And only last year I discovered the most singular specimen of all-a real novelty even for a vireo-a nest almost entirely composed of snake-skins. 


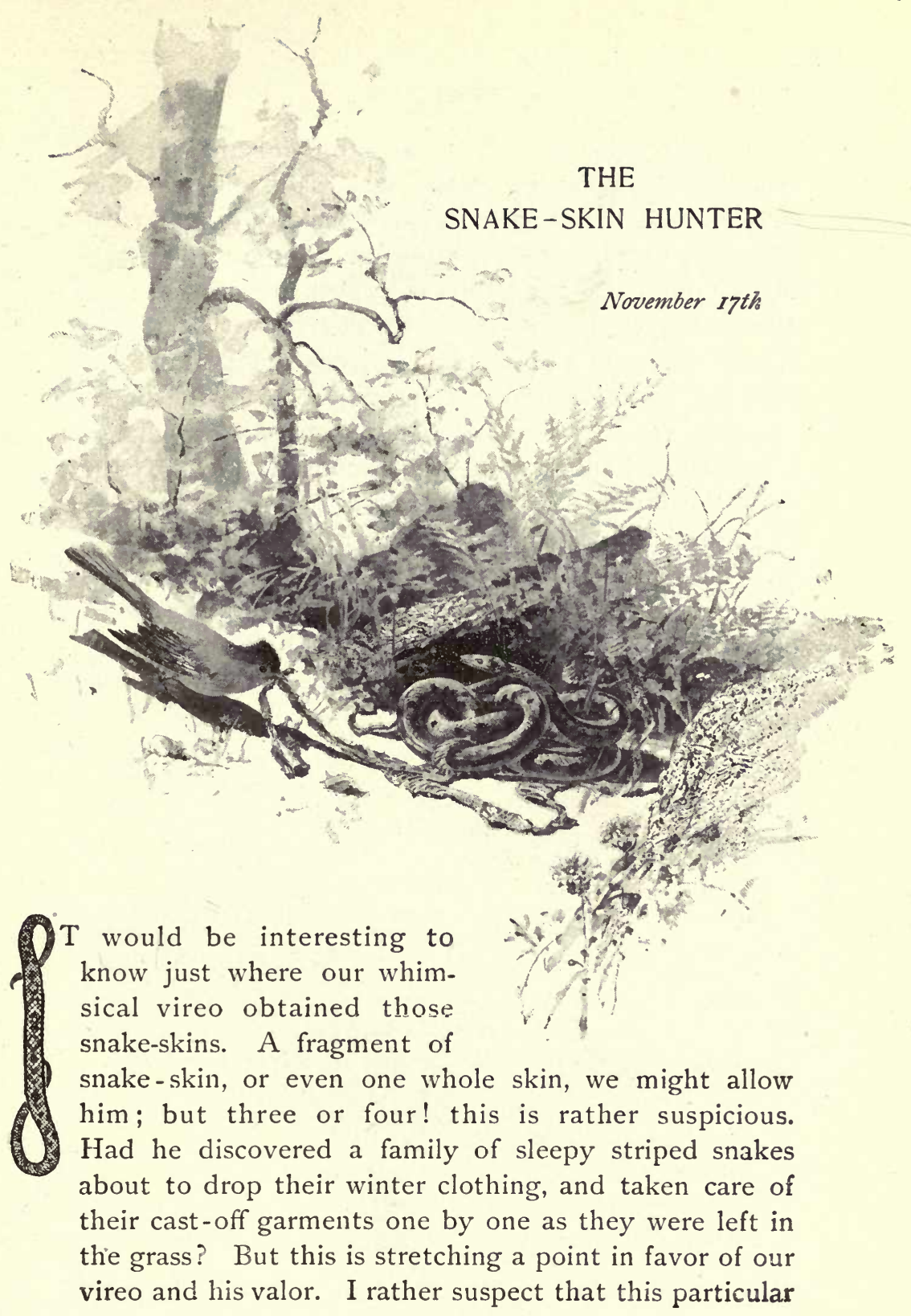


nest represented a raid on the stores of another bird noted for his partiality to the snake-skin. Once, when a boy, while investigating a woodpecker's den in a willow-tree, I pulled from the bottom a handful of snakeskins. Knowing the habits of snakes in the casting of their sloughs, and knowing, too, that the "racer," or black-snake, was a good climber, I concluded that I had intruded upon the private dressing-room of the snake, and not knowing how soon he might return to change his clothes, I quickly left the premises. A few years later the mystery was explained in my ornithology. I had found a deserted nest of the great crested fly-catcher. This bird is the snake specialist, and its nest in the deserted woodpecker's hole is seldom free from a generous lining of snake-skins of various kinds and sizes.

Here are a few of the eccentric specialties of other nest-builders :

\footnotetext{
Wren...............Feathers.

Chipping-sparrow....... Horse-hair and roots.

Solitary vireo .........Coon-hair, deer-hair.

Snow-bunting..........Fox-hair.

Worm-eating warbler... Hickory and chestnut catkins.

Ovenbird ............ Dried spore-stems of mosses.

Purple finch..........Hog-bristles and horse-hair.

Kentucky warbler........Pith of weeds.

Prairie warbler......... Cast-off caterpillar-skins.

Yellow warbler..........Feathery seeds.

Blue-gray gnat-catcher...Bud-scales, dried blossoms, and fern-down.

Humming-bird.........Fern-wool, red-oak leaf-down.

Baltimore oriole....... Milk-weed bark, horse-hair, and long moss.

Yellow-billed cuckoo.....Small sticks.

Robin............... Grass and mud.

Golden-crested wren.....Spanish-moss.

Chimney swift ......... Home-made glue (saliva) and sticks.
}

It will be seen that there is a wide variety of choice 
among the birds. No doubt, like other two-legged artists, they enjoy most spirited squabbles among themselves as to the comparative merits of hogs' bristles and badgerhair, or of this or that method of laying on the paper, hornet-nest, horse-hair, or caterpillar-skins. We must admit, of course, that there is some particular virtue in each of these ingredients, but we must draw the line somewhere. Here, for instance, we come upon a nest in the fork of a tree that is lined with cherry-pits and buckwheat-shells. But I will not dwell upon this now, for I shall have something more to say about it in another page.

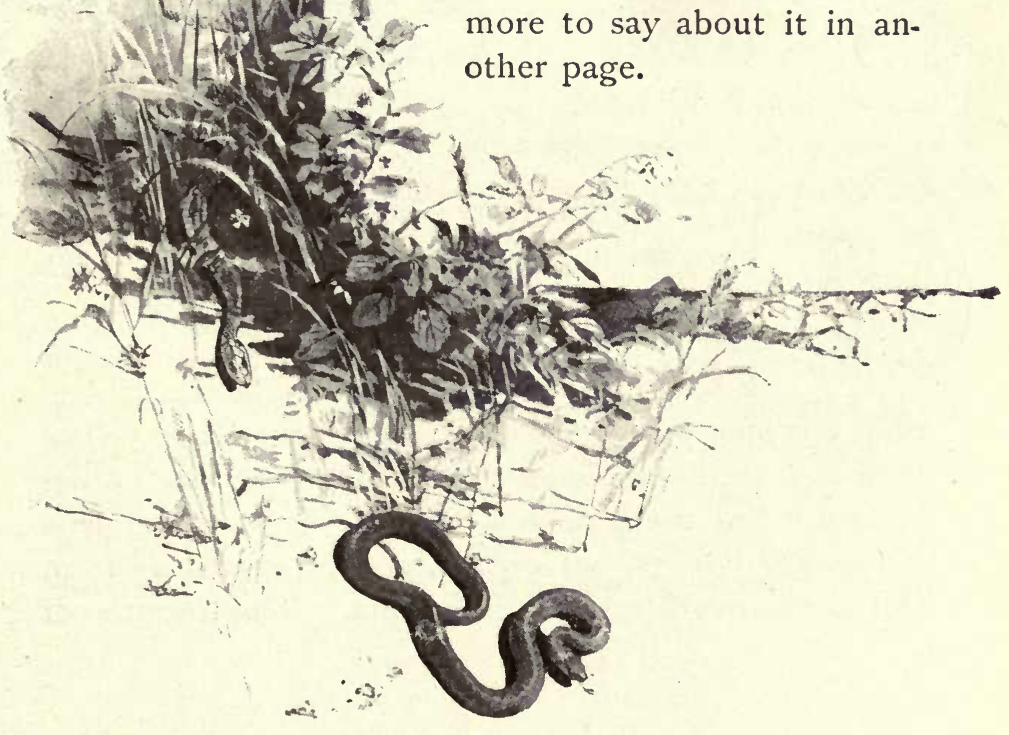




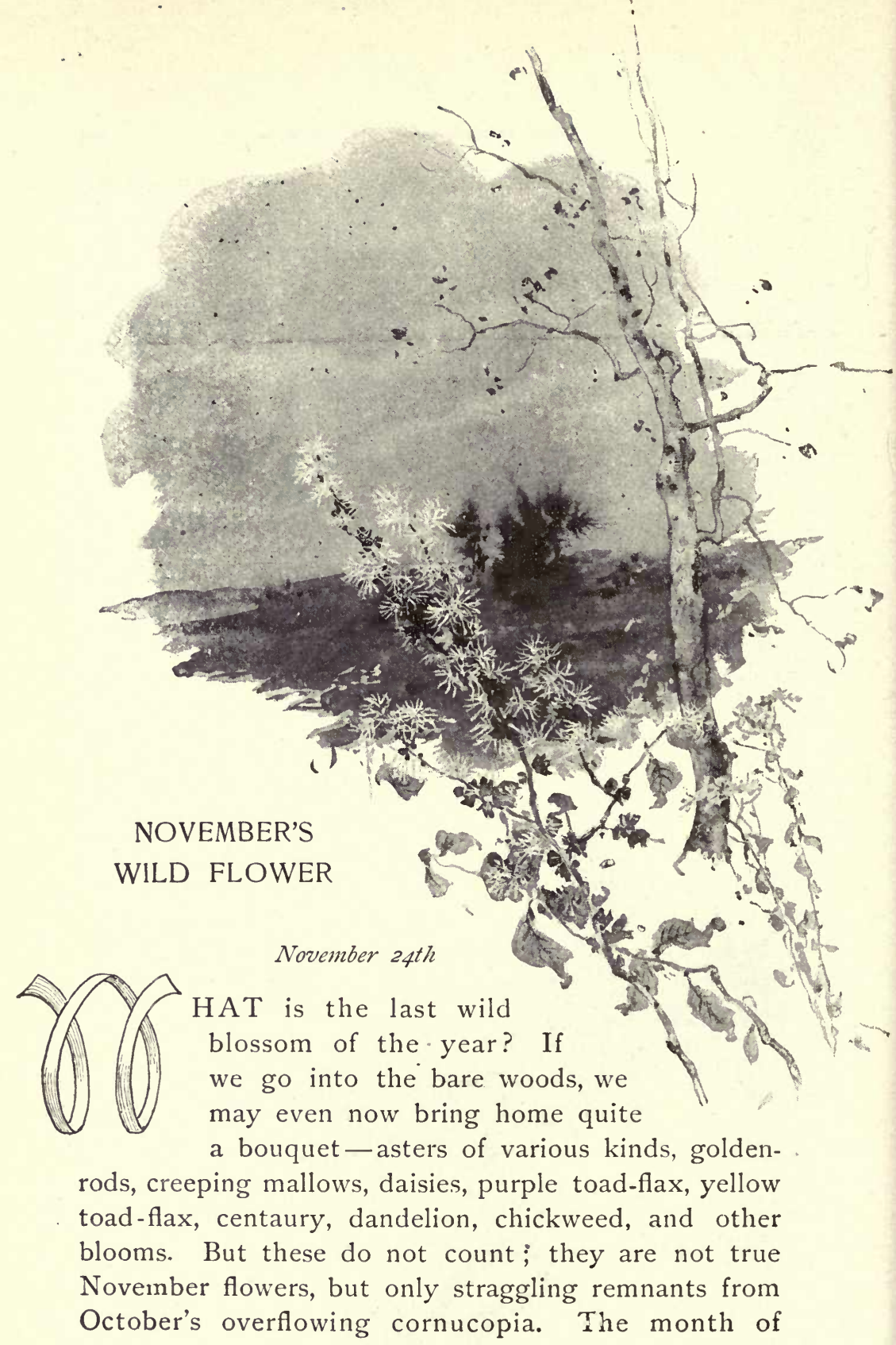


March has its own chosen prophet in the hooded hermit of the bog-the skunk-cabbage flower. What is the one floral emblem of November - New England November, at least? Before what flower may we now pause in the woods, with this greeting from the poet:

\footnotetext{
"Thou waitest late and com'st alone, When woods are bare and birds are flown, And frosts and shortening days portend The agèd year is at an end."
}

Thus sang Bryant to his "fringed gentian" long ago; but I will venture the assertion that the next time he went into the bare autumn woods he had to run the gauntlet of the bombardment from the witch-hazel guns, for it is to the witch-hazel blossom alone that such sentiments could be addressed with any justice or truth.

"The fringed gentian belongs to September," says Burroughs, commenting upon the above lapse of the poet, "and when the severer frosts keep away it runs over into October. But it does not comé alone, and the woods are not bare. The closed gentian comes at the same time, and the blue and purple asters are in all their glory. Golden-rod, turtle-head (chelone), and other fall flowers also abound. When the woods are bare, which does not occur in New England till in or near November, the fringed gentian has long been dead. It is, in fact, killed by the first considerable frost. No; if one were to go botanizing, and take Bryant's poem as a guide, he would not bring home any fringed gentians with him. The only flower he would find would be the witch-hazel." Burroughs evidently gave the cold shoulder to the remnant blooms already 
mentioned, his botanical quest referring only to the fresh new flower of the month, for the fringy blooms of the witch-hazel are the only flowers that "wait and come alone."

Elsewhere the poet welcomes the dandelion in his late autumn flowers, for this

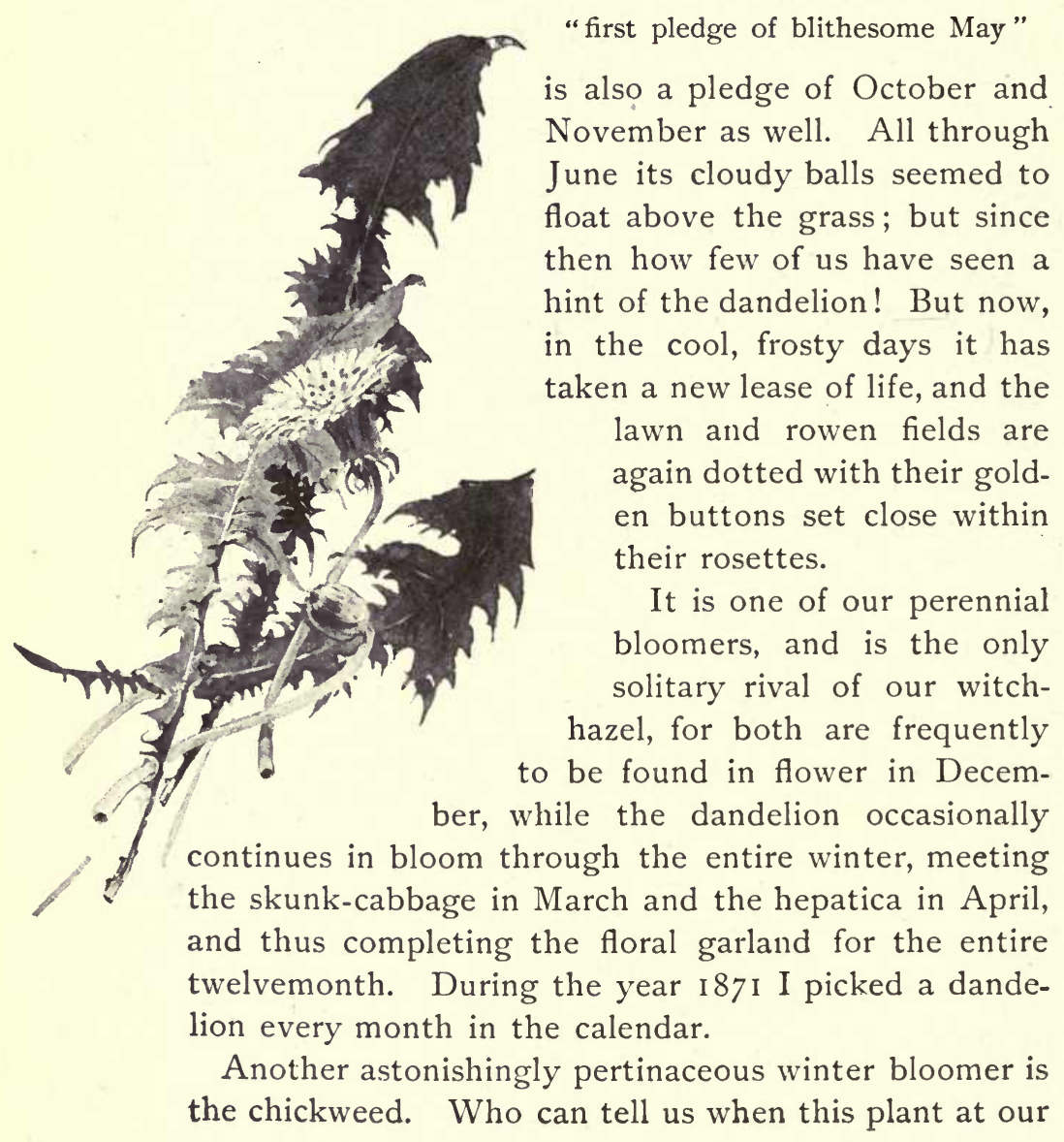


feet first began to bloom? It must indeed be a cold day when

$$
\text { " "the chickweed's eye is closed." }
$$

You are always sure of it. Even in midwinter, if you know its haunt in some sunny nook, you may dig away the snow, and pick its white, starry blossoms, larger and fuller now than those of summer. I recall a beautiful episode from one of my winter walks long ago, in which the lowly chickweed won my gratitude. I was skirting the borders of a swamp where every hollow between mound and tussock was roofed with thin, glassy ice left high and dry by the receding of the water beneath, and had approached within a few feet of the remnants of an old farm hot-bed, which stood at the foot of a steep southern slope. Its foundation was rimmed with the mimic glass as though in consolation, and, in further sympathy, at one portion the clear crystal roof disclosed a lush growth of the chickweed beneath, its starry blossoms rivalling the surrounding snow in whiteness. A mimic conservatory-no, not a mimic, rather say the model, the "cold-frame" which nursed its winter blossoms eons before the modern infringement of the florist was conceived of, or the florist himself an entity.

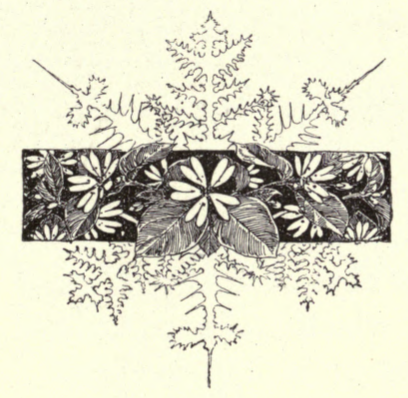




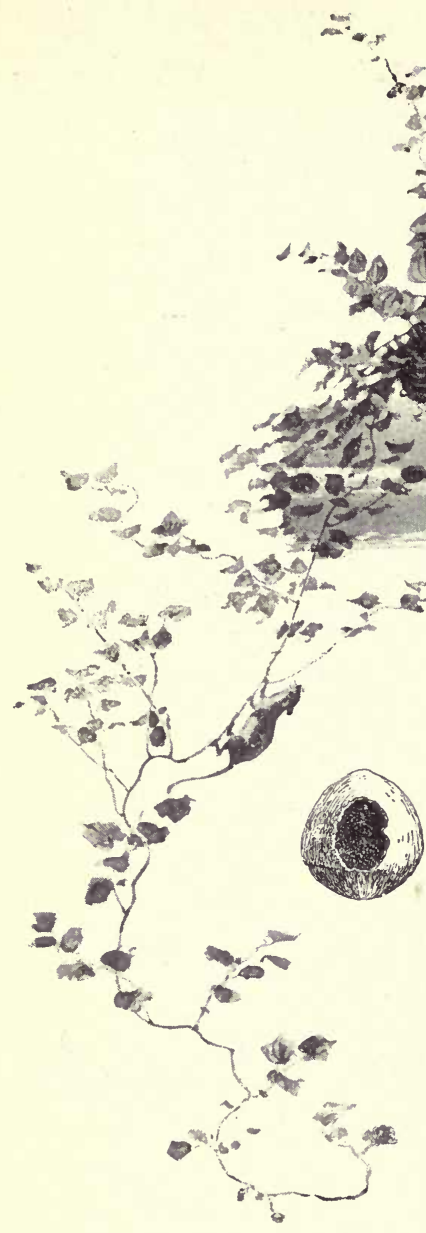

A WINTER BIRD'S-NEST

December Ist

UR birds'-nest hunter at this season may learn much of the constructive arts of the birds. As I showed in a former chapter, the unravelling of these abandoned nests reveals a surprising variety of textiles and linings and decorative materials.

But if we suppose that we are the only birds'-nest hunters in the woods, we are greatly mistaken. We will say nothing of the owls, the cow-bird, the jays, the fish-crow, the black-snake, and the red squirrel, which have all had their turn at the bird cradles, with more or less murderous success. If we continue our search long enough, we are certain to come upon the most novel nest of all-one which has been found before us, and which has been packed as full of innocent mischief as a "jack-in-the-box." 
I remember once in a winter walk discovering what I supposed to be an abandoned nest of the chipping-sparrow in a small spruce about seven feet from the ground. I reached for it, and had barely touched it when I felt a commotion within its interior, and in another instant two black, beady eyes were staring down at me over the edge of the nest. But only for a moment, for, with a squeak and a spring-like a gray streak-to the ground, the mysterious tenant was soon lost in the grass. I carefully removed the nest. It proved to be, as I had supposed, that of the chipping-sparrow, but so many liberties had been taken with it that but for the horse-hair lining I should hardly have recognized it. A domed roof of interwoven grasses

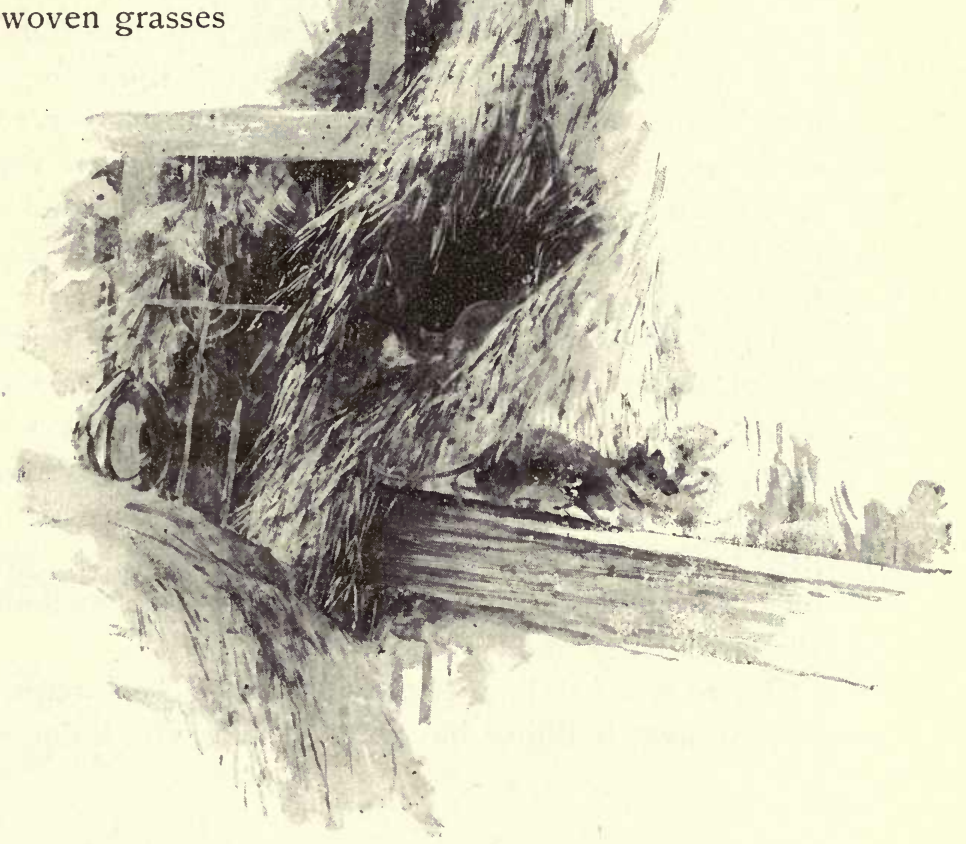




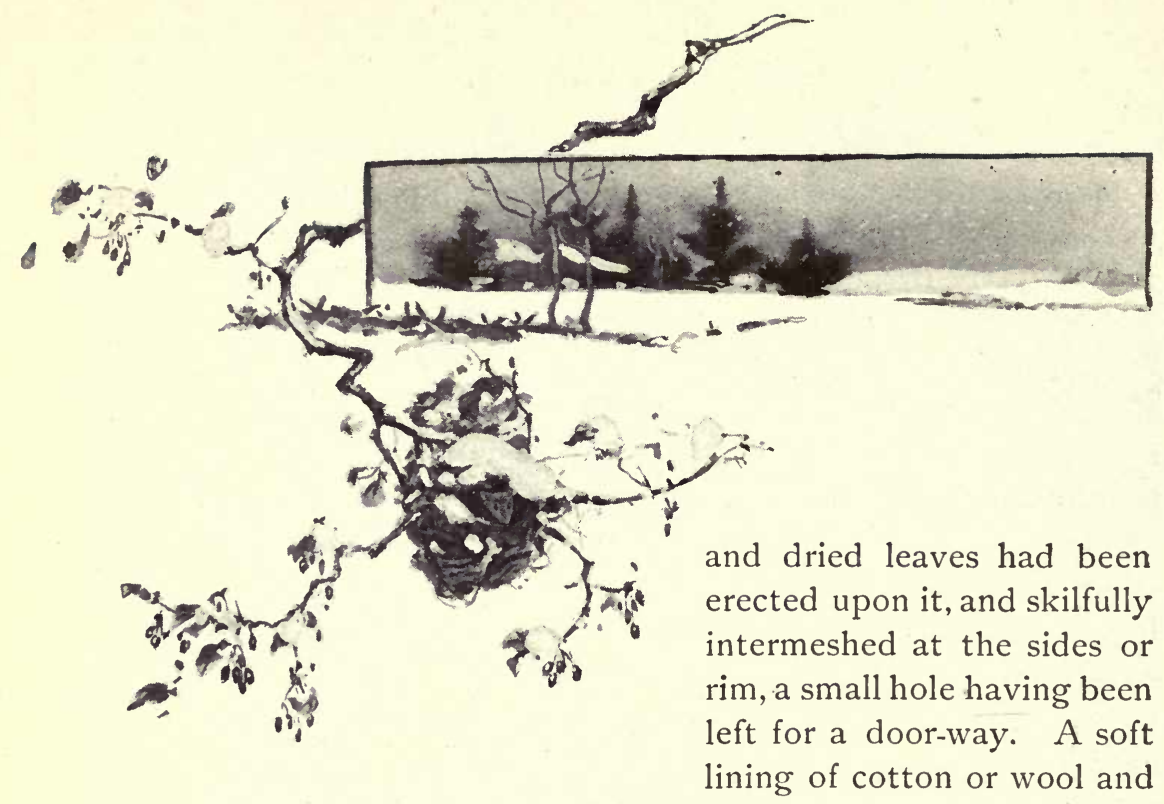

feathers almost filled the interior.

I carefully replaced the snuggery, and doubtless had I thought to visit it occasionally during the subsequent months a half-dozen whiskered, furry, bead-eyed infants would have crowded at that little door-way to give me a squeaky reception. For I had intruded upon the winter retreat of the field-mouse, destined soon to be a well-packed nursery.

The field-mice are the natural successors and heirs to the bird domicile, and their evidences are to be seen in many a disintegrating nest in the woods. On several occasions I have discovered the nests of vireos and the hair-bird lined with a variety of litter for which the bird builders could hardly be held responsible-chaff of oats, Indian-corn with the eyes cut out, buckwheatshells, and the like.

There is no telling what whims the vireo might not take in nest building, but when we find the lining of its 
nest composed of cherry-pits and hazel-nuts-even though the nest be several feet above the ground, and far out upon a slender twig, as I have found it - we must look elsewhere for our bird, especially when we find all the nuts to have been emptied through small round holes in their sides, and the tiny grooves of sharp teeth marking the edges of the shells.

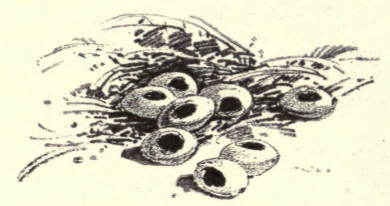




\section{THE MOST MARVELLOUS DRILL IN THE WORLD}

December 8 th

HE season of animated insect life is long past, and the "bug-hunter's" attention is now mostly confined to the winter harvest of cocoons everywhere disclosed among the denuded twigs. True, there's the black-and-tan "woolly bear" every now and then to be seen crawling across the snow, the caddis-nests in the brook, the water-beetles at the edge of the ice, and those winter butterflies and snow-fleas, all of which I shall describe in a later page. But there are two curiosities more remarkable than any of these yet awaiting us in the woods, if our eyes are only sharp enough to find them; one of which, in certain respects, is the most wonderful insect which any insect cabinet can show.

It is true that we might have looked for our strange insect several months ago; but then there was so much else to choose from through the summer months, and we knew that our secret would keep, and that the winter would show us our prize. And here it is, clinging to the bark of a maple-tree in the woods, all ready and waiting for its collector-a perfect specimen, with legs and wings firm and nicely spread and set, and, what is more, mounted to the bark with its own pin!

A "big black wasp," you think? Yes, it does look 
like a wasp; but I can readily imagine an ordinary wasp turning green with envy at a sight of the sting which this specimen carries; the hornet's dagger is an insignificant affair beside it.

Let us examine the insect closely. It seems to be standing on tiptoe on the bark, with wings upraised; its body is bent in an upward arch, and seems entangled in a double-twisted loop of horse-hair. And thereby hangs a tail, for it is this singular loop that has won the insect its well-deserved name as the most wonderful borer on record.

If I were to exhibit to the reader a piece of black horse-hair about five inches in length, and claim that it was a wonderful new kind of gimlet which was capable of boring a hole four inches deep into solid wood, would I be taken seriously? And if so, how astounding would seem the assertion! And yet to all appearances such is the instrument and such the actual feat accomplished by this black wasp-like in- 


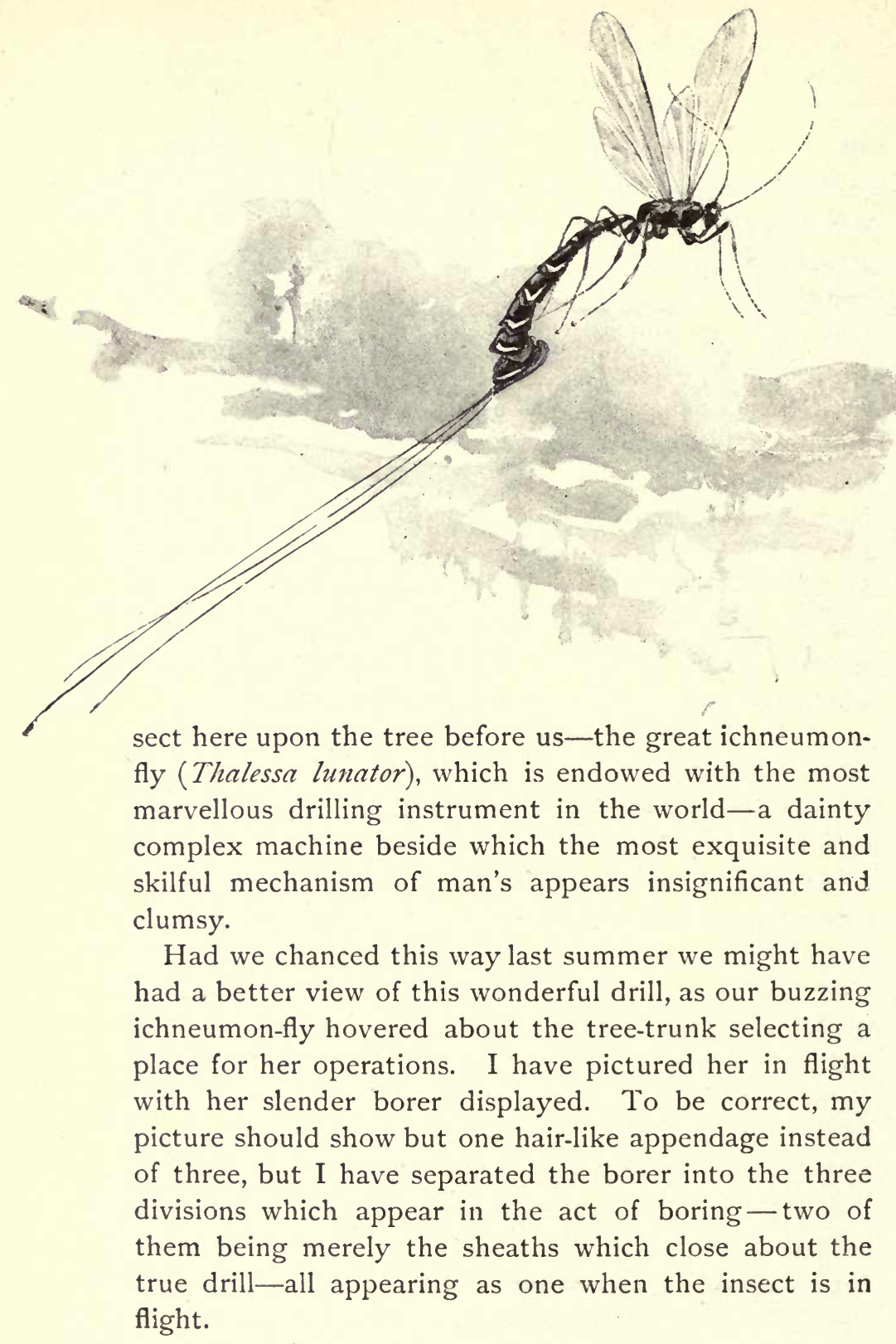


The variety of her positions assumed during the boring process I will not attempt to describe, nor can I, in a brief popular paper, enter upon the very strange muscular and anatomical action which accompanies the process. But I have shown my ichneumon as she appeared after the drilling was well under way; the large disk at the extremity of the body being a contractile tissue distended by the loop of the drill within, and by which the pressure is communicated to the straight shaft below. By a muscular wriggling motion, continued with patience for hours sometimes, the horse-hair gimlet has sunk three inches into the wood, bringing up to the surface a continual pouring of fine sawdust. The membranous disk has disappeared by gradual contraction, and the body at length assumed the position which we now see in our dead specimen on the tree, with the two loops of the sheathing parts separated and meeting around the drill where it enters the wood below, this short section of about half an inch beneath the tip of the body being all that is now to be seen of the original four-inch bore. But this last effort was evidently too much for the insect. It exhausted her strength, and she died without being able to withdraw the shaft.

And what is it all about? What fun can there be in such laborious work, and in such hot August weather too? The intention of this ichneumon is no less astonishing than her mechanical skill. She knows very well

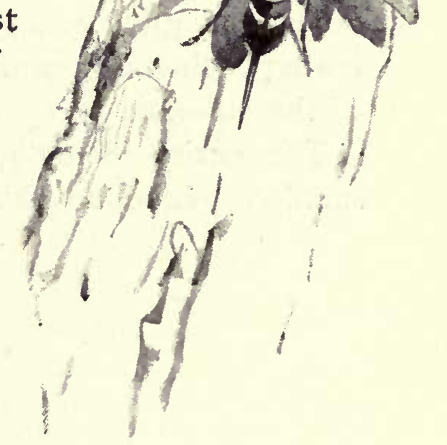


what she is drilling for. There is a rival drill in the insect field which she is evidently determined to exterminate. I have shown her in the act of pouncing upon another wasp-like insect upon the tree-trunk. These two insects are linked in a most strange fashion in the divine plan of Nature. The second insect is the pigeon Tremex (Tremex columba), a borer of no mean accomplishments, though her drill is less than an inch in length. We may see her almost any day in August, sometimes half a dozen together working upon a single tree. Sooner or later our ichneumon finds this same tree and searches out her enemy; for the Tremex has laid its eggs within the tree, and its young larvæ are now driving their tunnels through the wood. It is these that the ichneumon is after. She knows that they are within, and her drill is something more than a mere drill, for when once in place she lays an egg through it, and the little grub which hatches from it immediately takes the hint given by its mother. It searches among the burrows within the tree until it finds the Tremex larva, upon which it fastens itself, living upon it as a parasite, and ultimately destroying it. It is an ichneumon-fly instead of a Tremex which emerges from the aperture in the tree bark next summer.

The mechanism of this ichneumon instrument is too complex for adequate description here. It is composed of three long pieces, which are dovetailed one with another, and glide easily through their entire length, the boring being accomplished by the alternate gouging: of the chiselled tips.

The entire diameter of this shaft is less than the smallest period on this page, and though constructed 
of three pieces, there is room to spare for a soit channel through its centre, by which the egg is conducted to the depths of the burrow.

I have somewhere read that this particular boring tool of the Thalessa has been infringed upon by a recent human device, in which the same drilling mechanism has been employed without so much as a "thank you" to the ichneumon. How many others of the implements and devices and commodities and processes in daily use by man - the fruit, it is claimed, of his "superior intelligence," all duly protected by letters-patenthave had their first working model in nature ages before the human era? Who is he that assumes to be the first paper-maker, weaver, plasterer, potter, or mason? The world is overrun with impostors who would claim the invention of saw, file, chisel, and gouge ; of the first gun, or diving-bell, or lathe, to say nothing of propellers, water-proof cement, log-cabins, javelins, scissors, and even-pincers!

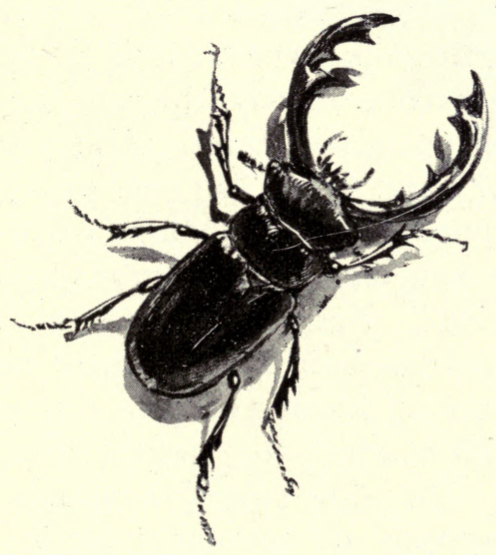




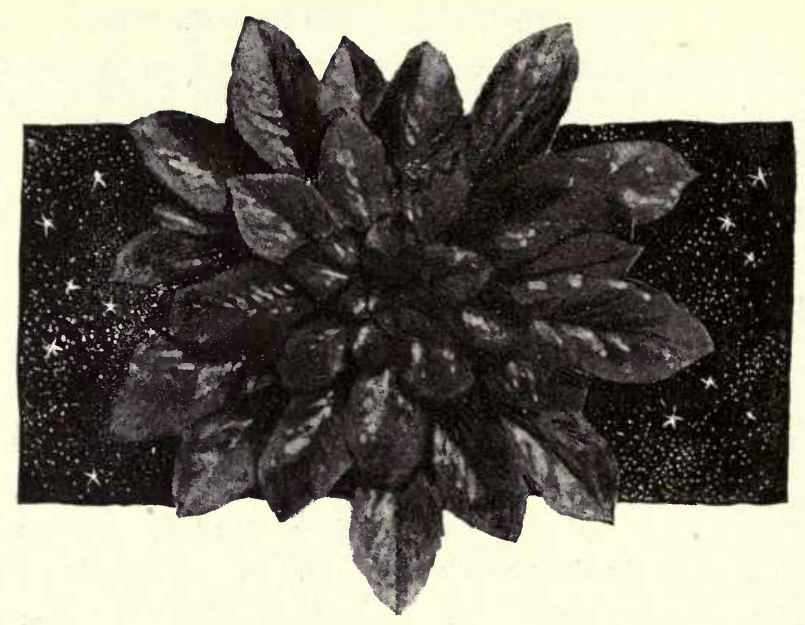

WINTER'S ROSETTES

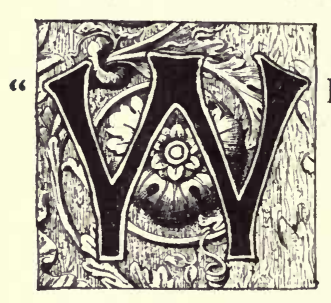

December rsth

E are going to have an early spring," said a rural philosopher to me one late February day, pointing, as proof of his assertion, to the numerous clusters of lush green leaves disclosed everywhere in his garden upon the melting of the snows. "The weeds are starting already," he says, pulling up a close clump of peppergrass leaves. And yonder is a flat starry tuft of sorrel leaves as green as April grass, and near by a hundred-pointed starry rosette of the evening primrose hugging the frozen ground-all proofs of an "early spring." Yes, the spring is in the hearts of all of them, and has been abiding there for several months. How few of them ever get the credit for the hope and faith of which they are the perennial eloquent symbols! The snow covers thousands of them. Not all our evergreens are accounted for in our bot- 
any. We find no adequate mention of these quiet resolute rosettes which are everywhere disclosed in spring upon the melting of the snow, but which might have been found as early as the previous September. Many a dried stalk or withered seed-pod protruding above the snow will point the way to them. This wiry spire of the pretty moth-mullein beset with its globular pods; these brown catkins of the rib-grass plantain; this feathery sprig of peppergrass -we may readily guess what a pretty tufted carpet is that which covers the bare earth about their feet. This brown spiny mockery of last summer's thistle reminds us of the most beautiful of all these winter decorations, the symmetrical compound star of acanthus-like leaves, guarding the root beneath, and waiting in patience for the first opportunity of sending up its stalk of bloom.

The evening primrose shows us one of the most perfectly symmetrical of all these leaf clusters-a beautiful complex spiral star, geometrical in its arrangement, and a perfect pattern for the modeller, sculptor, decorator, or wood-carver. The willow-herb, or fire-weed (Epilobium), is almost equally perfect; and, indeed, our artworker may find a wide choice of ornamental types, 
without recourse to "design"- - to those accustomed liberties with leaves and blossoms in the "conventionalized" rosettes so prevalent in decoration.

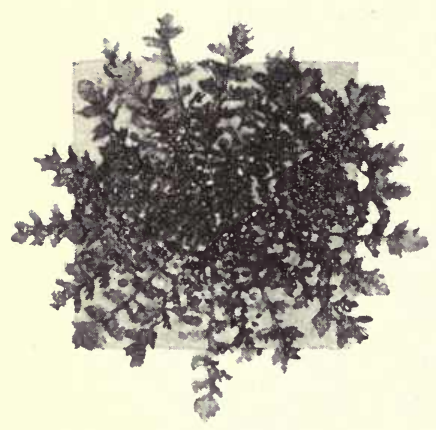

To the botanist this beautiful symmetry tells an interesting story, giving, as it does, a key to the entire spiral arrangement of the leaves in the mature plant, the stem being but a prolongation of the axis upon which the same progression of the rosette is repeated. In the evening primrose, for instance, we may count nine leaves up the stem before we reach one directly over the first, or starting-point. A careful examination of the rosette discloses the same arrangement. If we imagine the stem of the plant to consist of an elastic cord at full tension, then our rosette would represent the resultant of its contraction to the ground.

In the instances of the mothmullein, thistle, and evening primrose, we see typical biennials, or plants which spend one year in making a rosette, one year to blossom, and die the next. The plantain rosette is perennial, renewed from year to

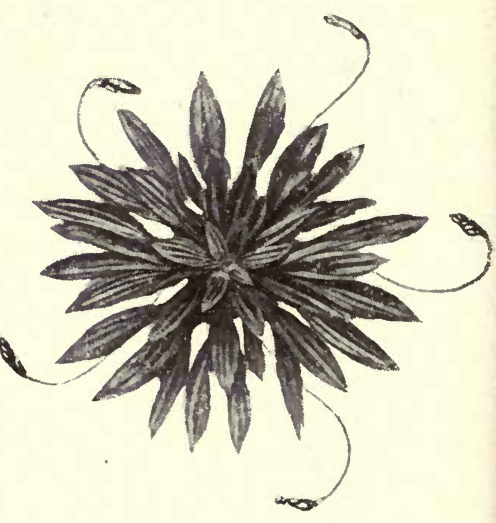
year from the same root. The peppergrass, with its deeply-cut leaves shown above, is classed as an annual by all botanists, though its millions of rosettes prove it to be biennial as well, for many of them abide the winter awaiting the spring for bloom. 
The examples which are here pictured are not drawings, but are reproduced from actual photographs from the plants themselves, all gathered in a few moments from a vacant city lot not five minutes' walk from my Brooklyn home. Almost any good-sized spot of bare earth will show many other forms equally interesting, and occasionally so profuse as to carpet the ground. The plantain and peppergrass are thus frequently prevalent.

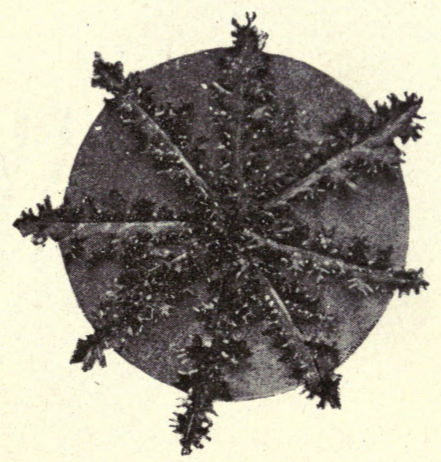





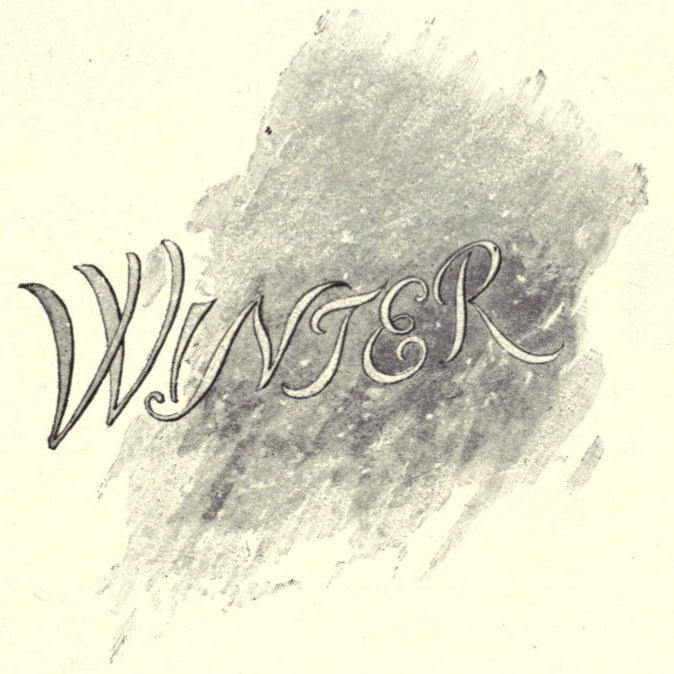


" $T$ seems as if the day was not wholly profane in which we have given beed to some natural ob1. ject... He who knows the most, be who knows what sweets and virtues are in the ground, the waters, the plants, the beavens, and bow to come at these enchantments, is the rich and royal man.' -EMERSON. 


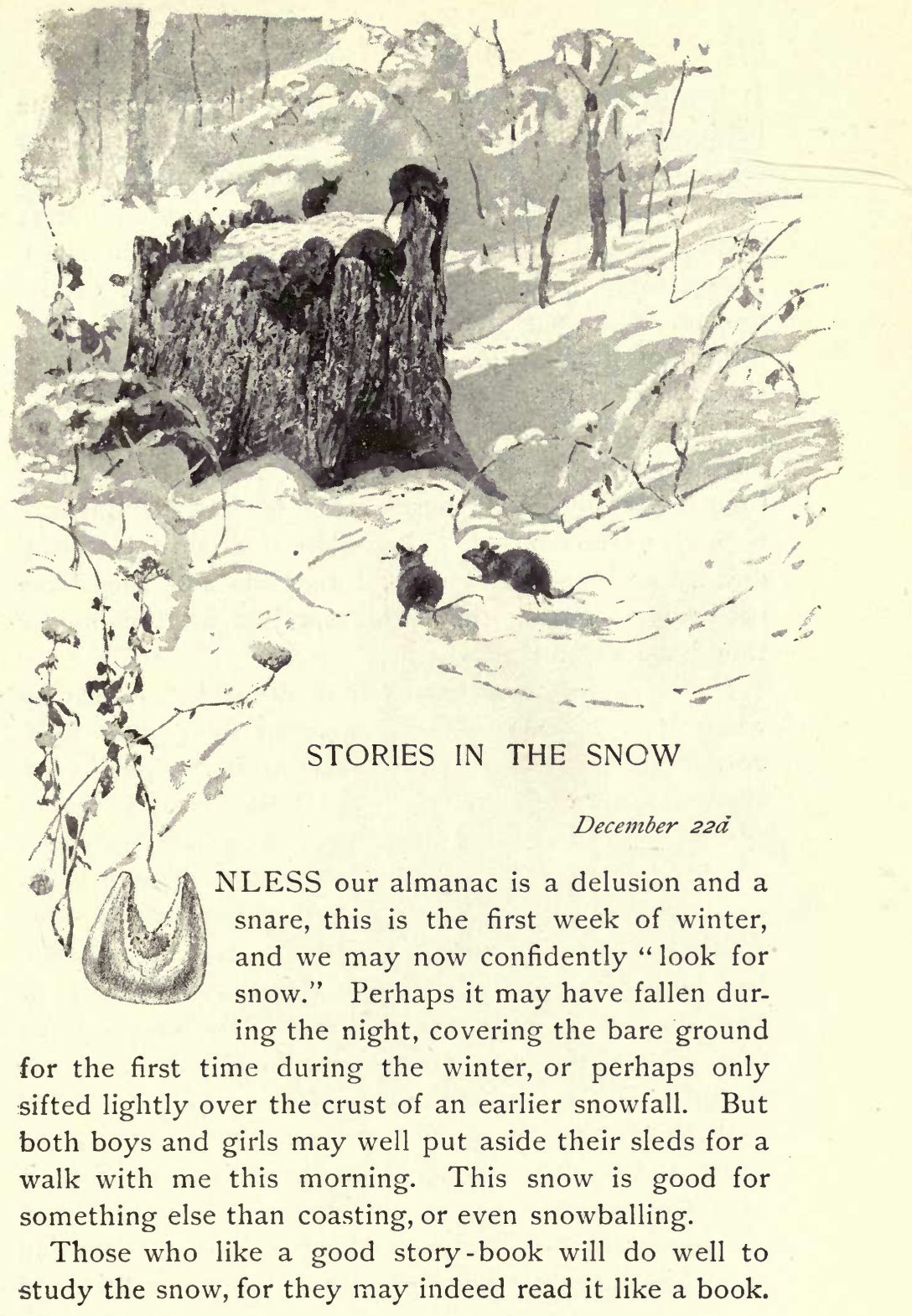


It is a great white page storied with the doings of the little wild folk which few of us ever see. Who ever sees a deer-mouse, or even a common field-mouse? The summer meadows are full of them, but we should never suspect it, did we not occasionally surprise one scampering away with a squeak before the scythe of the mower, or perhaps jumping like a gray streak from a forkful of new-made hay, or from beneath the cornshock as it is raised to the cart.

Their doings down deep among the summer grass no one ever sees, but it is not so now. From the moment their little whiskered noses peep from their burrows their acts are recorded. They write their autobiography day by day. We can see all the mischief they have been up to during the night, and just what company they have kept.

Here is a well-worn track to a pile of brush near by where the snow is all cut up with footprints-a favorite rendezvous, evidently; doubtless the gossip exchange of all the wild bead-eyed folk. Here is a spot among the weeds where four little birds have danced a quadrille or minuet-balance corners, forward and backward, chassez, and all hands round. Close by, the snow appears as if sewed with tiny stitches, and here we see two long jumping trails circling about a stump. How alive they seem! telling plainly of a lively race between two mice, both tracks terminating in a hole beneath a stump. The snow on the top of the stump is ruffled with the feet of the furry populace who witnessed the sport, and doubtless cheered on their favorites in their sprightly race.

I remember one winter catching sight of a retreating tail whisking into a hole beneath a stump like this, and 
I shall not forget the eager pull with which I dislodged a piece of the rotten timber, nor the jumping mouse that sped out across the drift, nor the pocketful of hazelnuts and beechnuts which rolled out upon the snow. There were acorns and chestnuts, too, and kernels of corn with their "eyes" nibbled out, and in a cozy alcove within I discovered a snug nest of grass and cottony substance - the winter home and larder of the deer-mouse, or white-footed mouse.

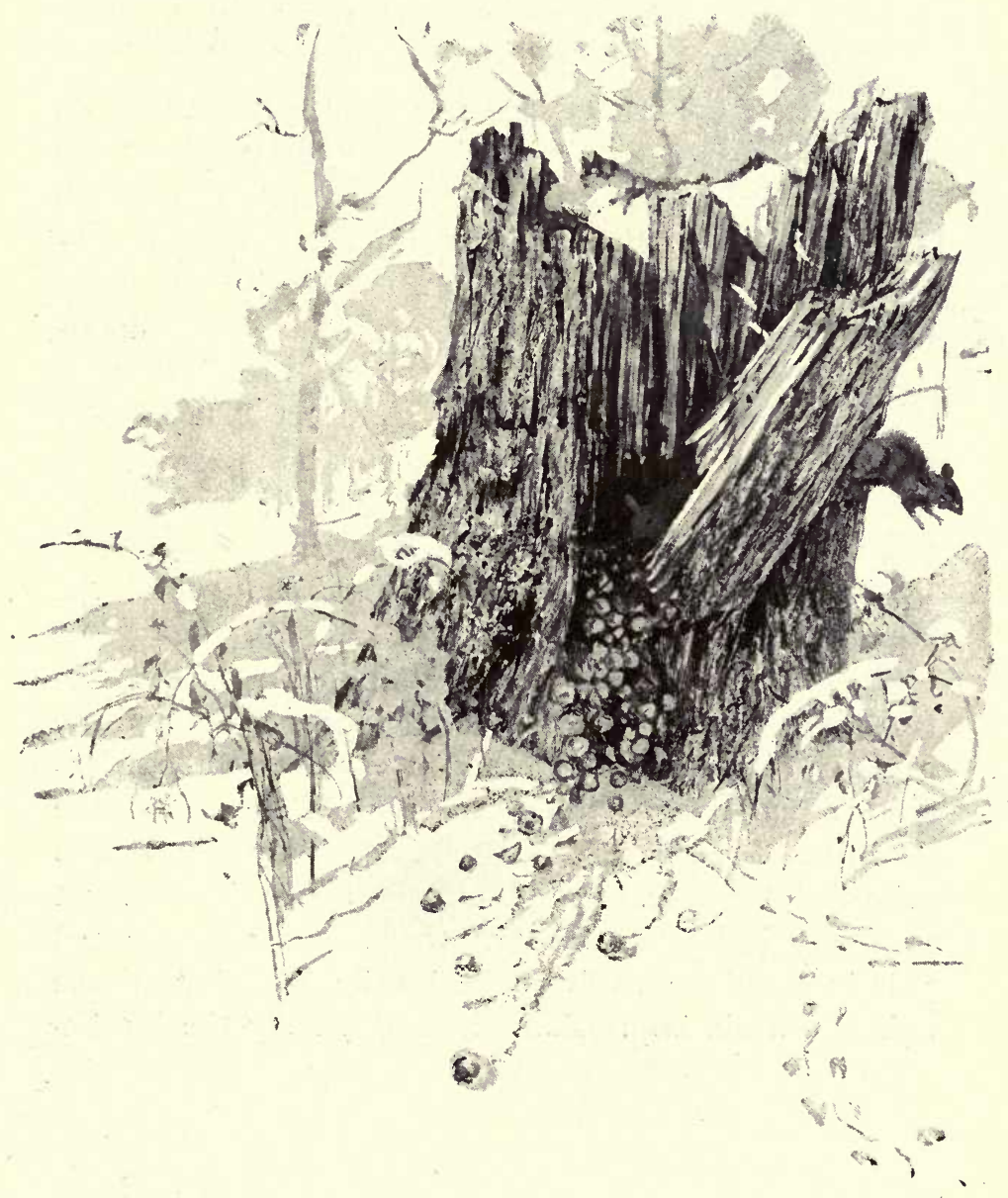


HOW BUNNY WRITES HIS AUTOGRAPH

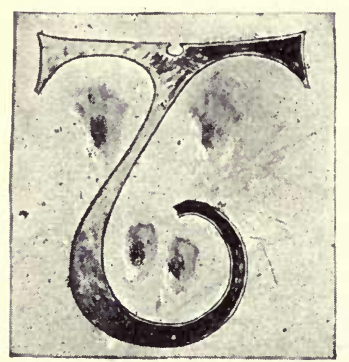

\section{December 22d}

HERE are few country boys who do not know those footprints about the box-traps in the woods, and all through the thickets everywherefour in a set. Yes; we all know them; they are the unmistakable seal or signature of the little gray rabbit, or, more properly, hare. And yet I have never met an individual who knew just how bunny writes his autograph. Even though we see him in the act, he writes it so fast that we cannot follow him. It is only by examining it very closely that we can get at the secret.

These footprints are always four in a set; the two front impressions being about six inches apart, and the other pair quite close together, or even united occasionally, or placed one directly in front of the other; the direction of the hare's course being plainly seen by the prints of the toes. But it will be a surprise to most people to find on examination that the widely-separated pair in front are really made by the hind-feet of the animal, certain impressions showing plainly the full im- 
print of the long hind shank even to its heel, or elbow, as this joint of the leg is incorrectly called.

Where the animal has progressed by slow, short jumps - "when the hare limps awkward"-the marks of the long soles are frequently to be seen; but in the more rapid leaps, clearing from one to two yards, only the tips of the feet have touched the snow.

The instantaneous photographs of Mr. Muybridge have shown us some very surprising disclosures in the various positions of the running horse and other animals. I should like to see a rabbit caught on the fly in the same way; I am sure we should get some comical revelations.

A careful examination of his fourfold autograph indicates the method of its technique. The short fore-paws are planted near together, the hind-feet then pass outside and some inches beyond

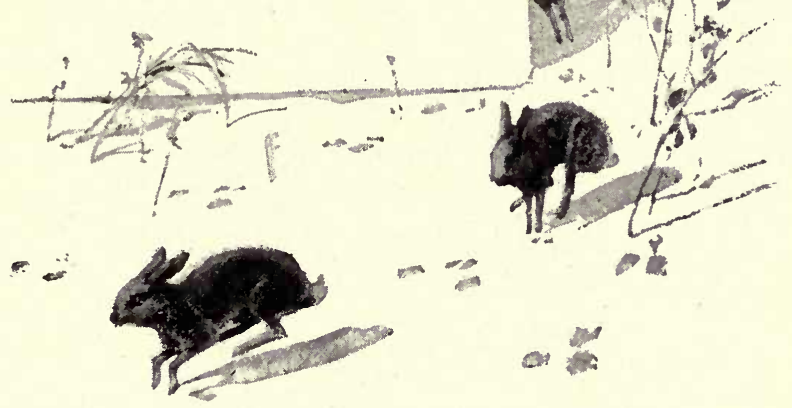


them, and then follows a jump which may vary from two to ten feet.

It is quite possible that bunny may really lift his fore-paws by a spring before the hind-legs overtake them, as shown in my foreground hare, but I fancy that the photograph may yet show us some such transitory attitude as we see in the one behind him. 


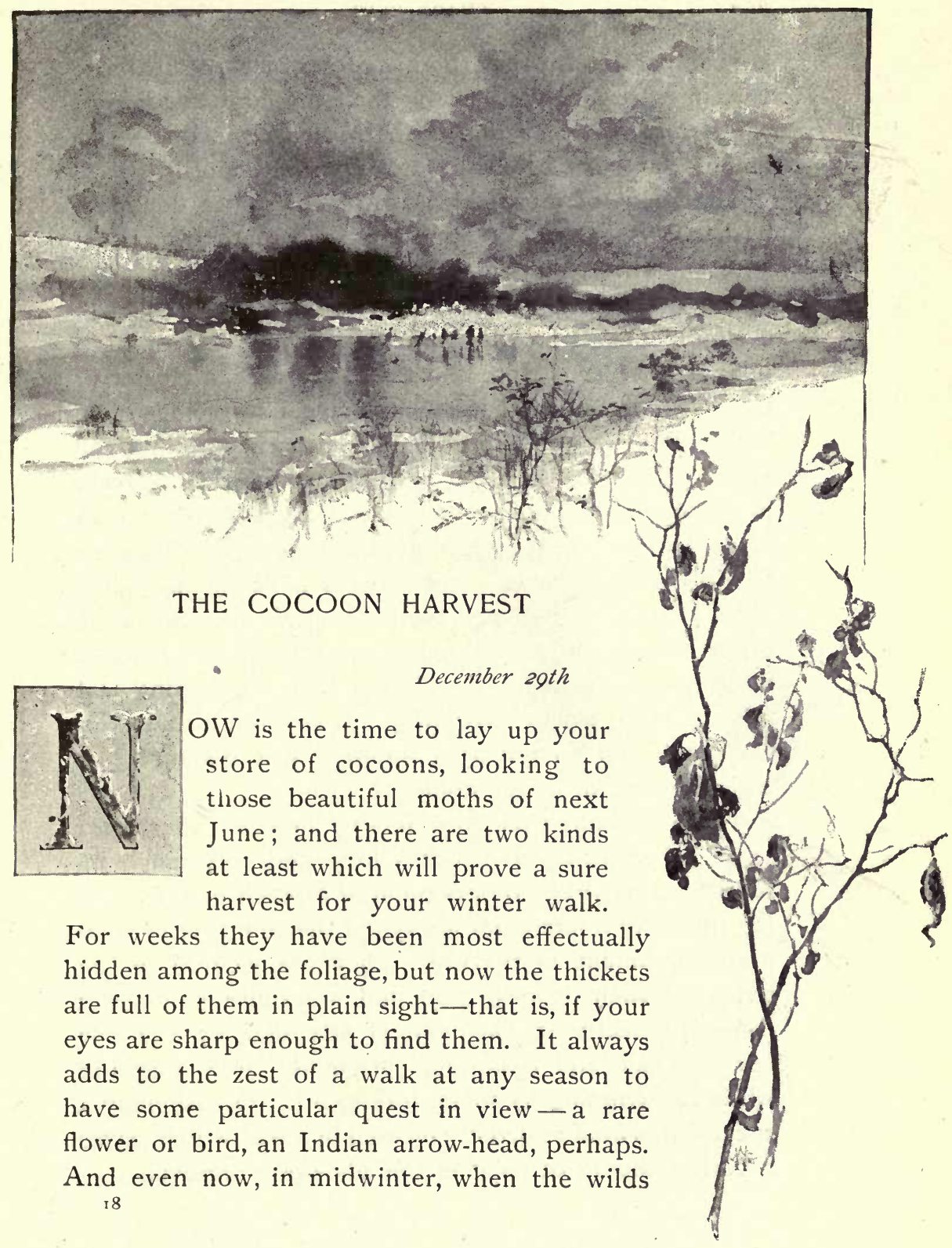


are comparatively drear, there are few objects of life more certain to reward your search than the large cocoons of the Attacus Cecropia and the Attacus Prometheus - two among our most beautiful and important moths.

The twigs of most thickets are now quite denuded, with only what might appear a stray determined leaf here and there. Often this leaf is precisely what it appears to be, clinging by its stem, or perhaps tangled in a tiny spider's web which the winds have as yet been unable to sever. Here and there, however, a cluster of two or three will be found which have a suspicious look, and a closer examination discloses that they are but the artful disguise of a living secret within - the Cecropia in its warm double cocoon. But there is a great deal of hocus-pocus, too, among these deceptive leaves. The bunch of leaves often proves a delusion. They are a continual challenge to the analytic eye; a puzzle often only to be settled by so small a factor as their degree of firmness in the wind, a light, beckoning leaf seldom being worth answering. It is often a matter of no small skill to tell at a hundred feet distance just which cluster of leaves holds its cocoon.

These cocoons vary considerably in size and shape; some being nearly five inches long and very much inflated and bag-like; others pointed at each end and being more contracted, but always of the toughest of silky gray parchment in texture. They are secured to the twigs by their longest side, and are quite commonly (especially early in the winter) attended by the few leaves which the caterpillar originally drew together while constructing its silken framework. Occasionally a specimen is found partially incased in a leaf, which leaves a perfect mould of itself in the silk upon removal. 
With these another cocoon is commonly found, and it is an interesting study of insect sagacity for those who are unfamiliar with it. In this case the deception is quite pronounced, and doubtless hundreds of the cocoons have been passed by and noted simply as dangling leaves- "the last leaf upon the tree in the spring," perhaps. This is the hammock of the Attacus Prometheus.

Unlike the Cecropia caterpillars, the Prometheus adopts a distinct preconcerted plan in the construction of its cocoon, by which it provides a safe anchorage for the winter. A suitable leaf is first selected, generally upon a wild cherry, sassafras, spicewood, or buttonbush; the stem of the leaf is then completely incased in silk, and carefully secured to the twig for several inches by the same means; after which the leaf is contracted about the caterpillar, and forms the mould for its winter hammock. The wind and weather at length loosen the withered leaf, but nothing short of a vigorous pull will dislodge the cocoon, which often suffers the branch to break, or calls the pocket-knife into use before it will release its hold.

Among the most pleasant winter memories of my boyhood was the quest for these cocoons. Whether on foot through the

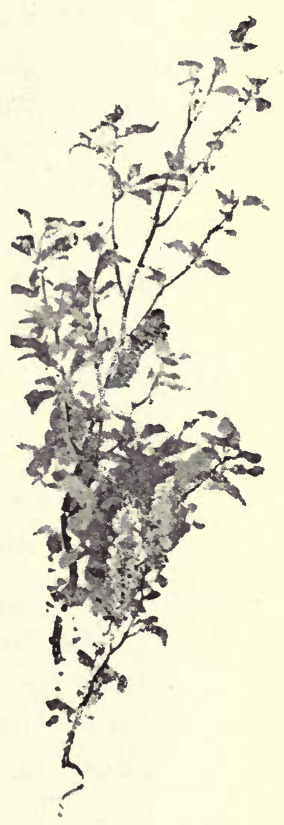
woods, or on frozen lake or river, skating around among the flaky ice of the sedgy border swamps and coves among the button-bushes and alders, submerged in summer, but now revealing those empty nests of the "conkaree," which so tantalized me a few months before-here I filled my pockets with a daily harvest 
of cocoons that was the envy of my lessfavored entomological companions.

Nor has the fever left me; even to-day I cannot pass a cocoon and leave it alone. I find my steps turning involuntarily towards every thicket I meet in my winter walk.

Only last week, from one small copse in the suburbs of the city, I brought home a bouquet of twigs bearing one hundred and forty odd of the cocoons of these two moths, mostly of the Cecropia; also one small branch with a dangling accompaniment of twenty-three cocoons of the beautiful ailantus moth, which, added to the stock gathered in previous recent walks, ran the total number up to nearly four hundred.

What will I do with them? I shall take the greatest pleasure in dividing them around among my friends, to most of whom they will prove a real curiosity and rarity, and who, when June comes again, will thank me most earnestly, as so many have done already, for

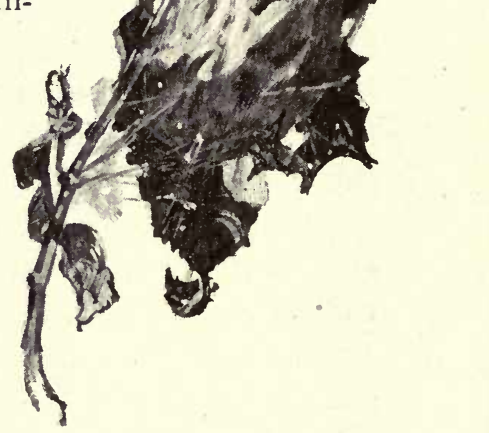
affording them a glimpse of that wondrous revelation of the emerging moth.

Gather the cocoons, then, my young friends. Gather all you can, and distribute them among your neighbors. It is good missionary work. There is a winged sermon in every one of them. 


\section{AMONG THE WINTER TWIGS}

\section{Jamuary 5 th}
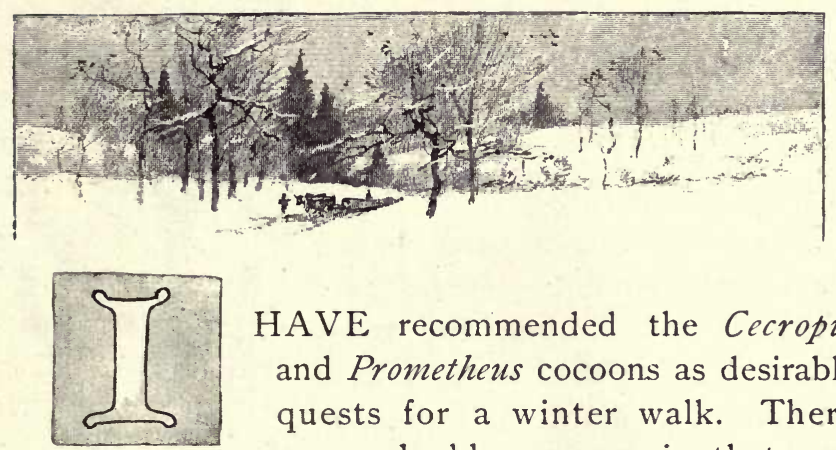

HAVE recommended the Cecropia and Prometheus cocoons as desirable quests for a winter walk. There was a double purpose in that recommendation; for, even though we get no cocoons, we are led into wild haunts where various other interesting things are to be seen. There is much besides cocoons to tempt our search among the denuded twigs of the woods. The fallen leaves have laid bare many of the pranks of insect life that are completely concealed in the summer foliage. What a variety of interesting galls are now to be found that had escaped us when last we walked this way! There is that bulbystemmed golden-rod. We see them on all sides now against the snow. It is worth our while to gather a few of them to keep till spring, when we may witness the little winged tenant emerging through a tiny hole, which is even now to be found beneath the bark if our 


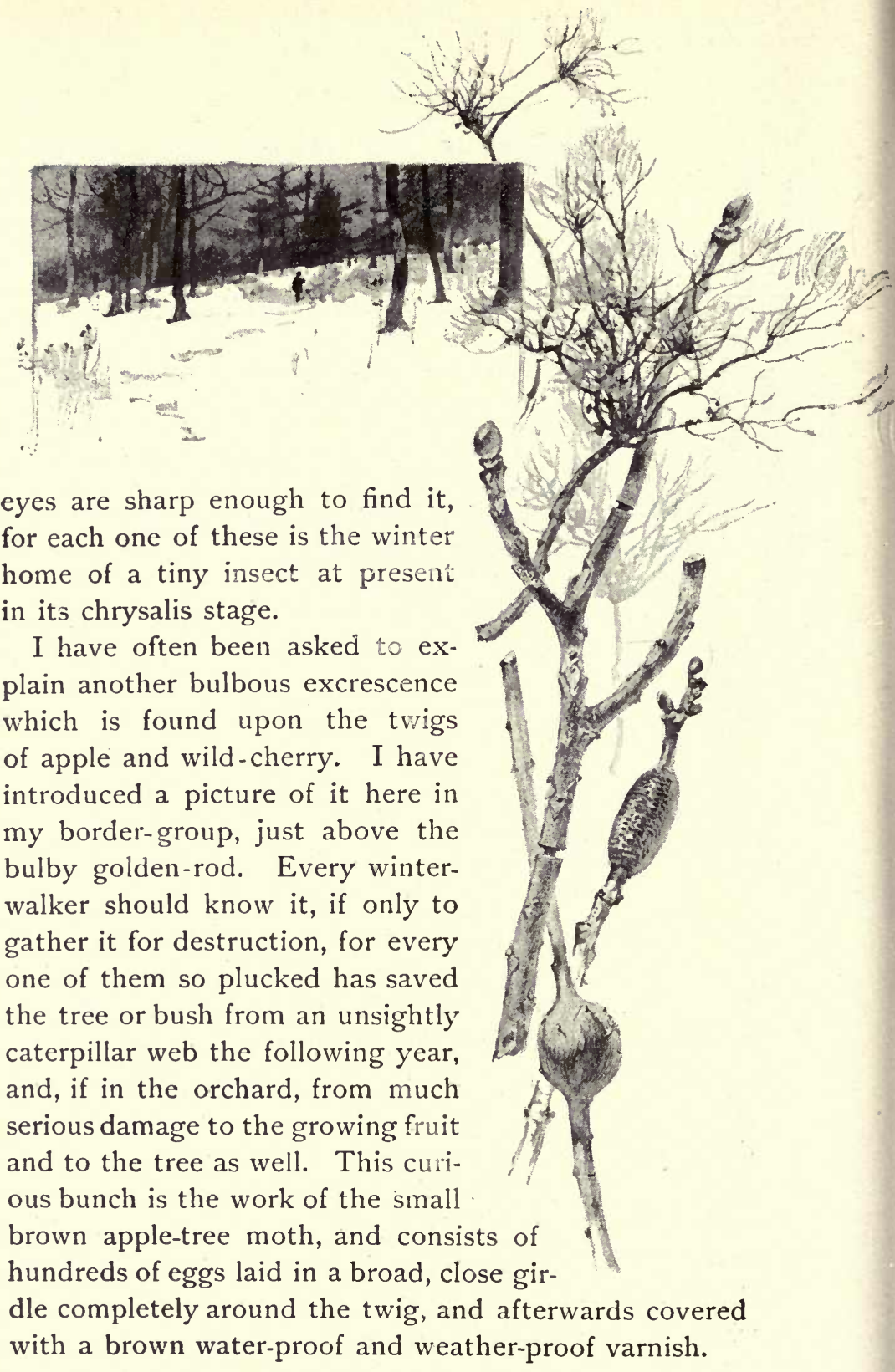


One of the most noticeable freaks to be seen among the bare branches are those eccentric clusters of twigs in the birch and sugar-berry trees; all the branches running into brooms, as though getting ready for the spring house-cleaning. But this is no natural expression of the tree. It has been bewitched by a tiny mite, whose broods live year after year in the crowded twigs, and are the cause of the diseased growth. In early times these bunches were known as "witches' brooms," and all sorts of weird stories were connected with them. But the true "witch" has since been caught riding the broom; and inasmuch as she is not readily discovered without a magnifying glass, we need hardly worry much about her.

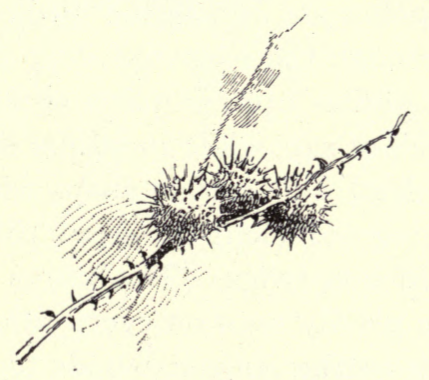




\section{THE GIRDLER BEETLE}

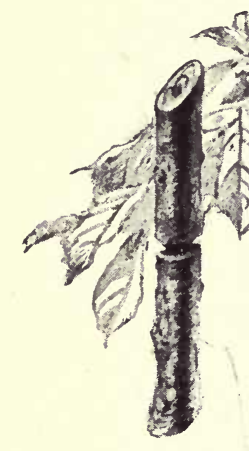

January 5th

F we search beneath the hickory-trees we may gather an interesting handful of twigs. The snow is sometimes strewn with short branch tips, their ends appearing to have been cut off as with a file. Some artful fagot-cutter has been at work here, surely! If we examine the lowhanging branches of the trees, we shall find better proof of his clever work, as shown in the pictured twig. The branches are seen to be girdled with a deep groove, sunk through the bark and deep into the wood. Many of these girdles appear quite recent, the branch beyond being full of sap, while in others this part of the twig is plainly dead, and readily snaps when handled, a strong wind being sufficient to strew the surrounding snow with the lifeless twigs. The works of the mysterious pruner are plainly seen on every side, but we shall have to go back to the August woods to solve the riddle of his identity. Here we shall find the artful "girdler" trimming the trees to its fancy, or, as I should say, to her fancy; and how many are the misshapen hickorytrees that can be laid to her effective industry?

I have pictured the pruner at its work; and now 
that I have disclosed it in its haunt, and shown it to be a prosaic beetle, I must be true to scientific fact, and that fact is that this is a mother beetle, working solely in the interest of her offspring. It must be admitted that she takes a curious mode of providing for her children; but she is doubtless doing the best she knows, and the plan seems to have worked very well, or else we would not see her following the hereditary example of her long line of foremothers. This is the way she insures her posterity. First she finds a twig that suits

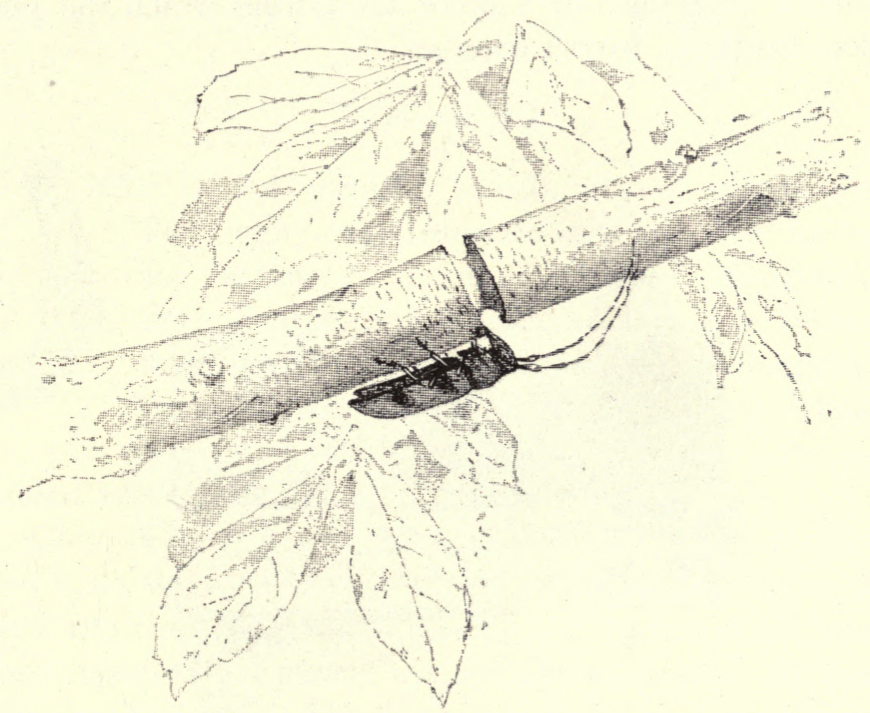

her fancy - and her fancy is easily satisfied. After gnawing around on the bark for a while, as though to find a suitable place to begin operations, she at length starts her groove, travelling round and round the twig, sideways, sinking the girdle deeper at every turn until satisfactorily completed. After this-sometimes before, 
it is said-she travels along the branch tip beyond, and lays an egg in the soft bark, beneath one or more buds of the twig, depositing each in a puncture well beneath the surface. She now commends the branch to destiny, and repeats the operation on another twig. Briefly told, the sequel is as follows: the eggs soon hatch into minute grubs, which penetrate beneath the bark, and later devour the wood, which is more or less alive with sap during the first season. The grub is believed to live within the twig nearly three years, reducing it at last to a mere shell, from which the perfect bettle at length emerges.

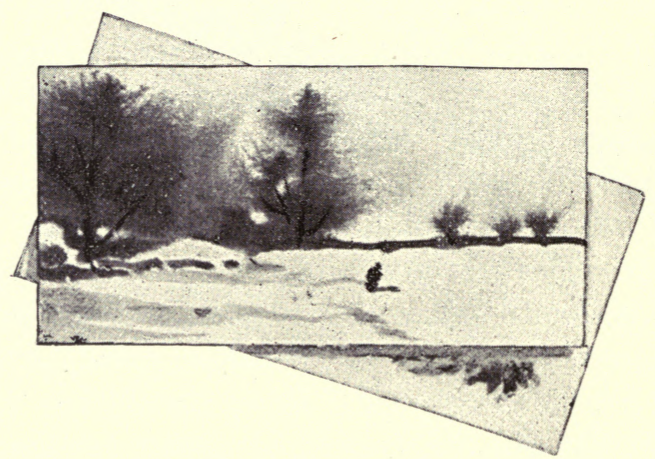



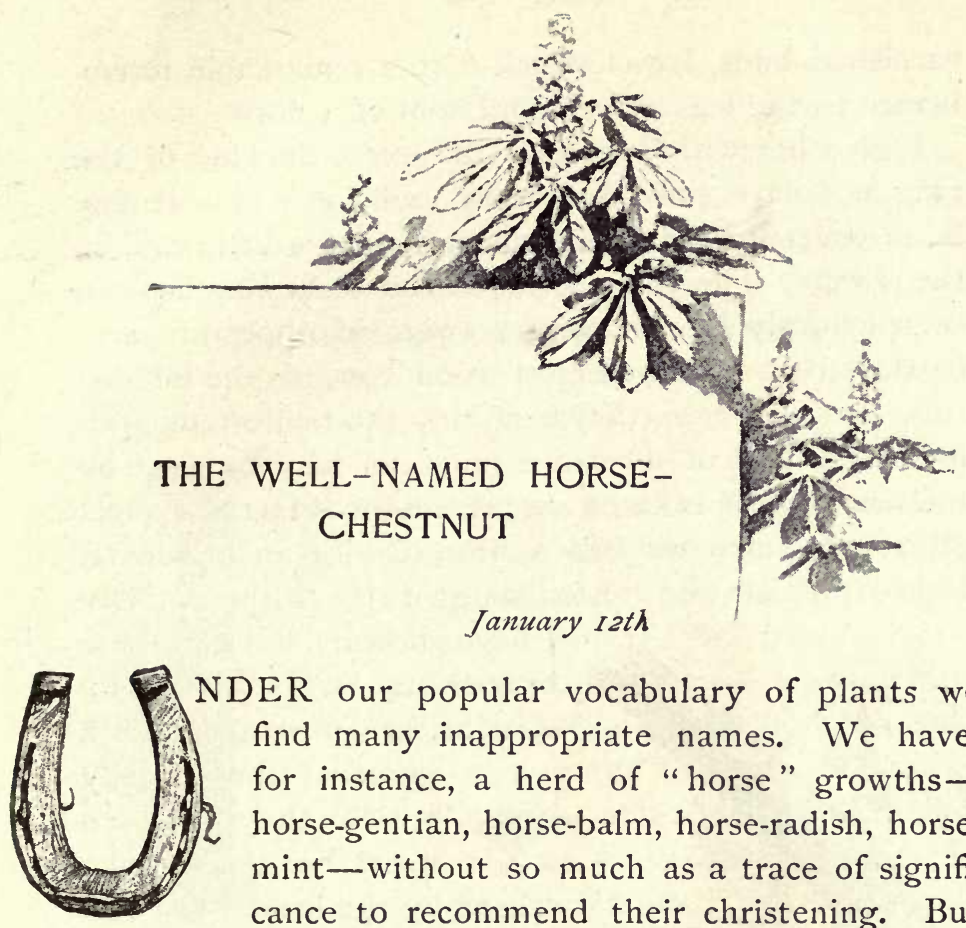

NDER our popular vocabulary of plants we find many inappropriate names. We have, for instance, a herd of "horse" growthshorse-gentian, horse-balm, horse-radish, horsemint-without so much as a trace of significance to recommend their christening. But the horse-chestnut need no longer be included among the common herd.

A few years ago a friend called my attention to certain scars upon the twigs of this tree, which he claimed were the reason of its christening. I had noticed the scars repeatedly without seeing any suggestion of the "horseshoe" which he discerned there; and the scars themselves were not very different from those on the hickory and ailantus, and various other compoundleaved trees, which leave similar sunken marks upon the twigs after the leaf-stalk has fallen. But one winter's day, while carefully examining the branches of the horse-chestnut, mainly with a view to its interesting 
varnished buds, I was struck with a remarkable resemblance to the leg, fetlock, and hoof of a horse.

I give herewith a careful and exact drawing of the twig as I have since repeatedly found it, and as it may be discovered by any one who will take a little care in the search. The three-cornered leaf scars may be seen conspicuously on the winter twigs in opposite pairs, particularly on the youngest wood, towards the budded tips. In themselves they bear only the faintest suggestion of the foot or shoe of a horse, as may be seen by reference to the isolated scar represented in the sketch. It is only when we find a branch with an accidental forked tip that the conditions give rise to the mimicry

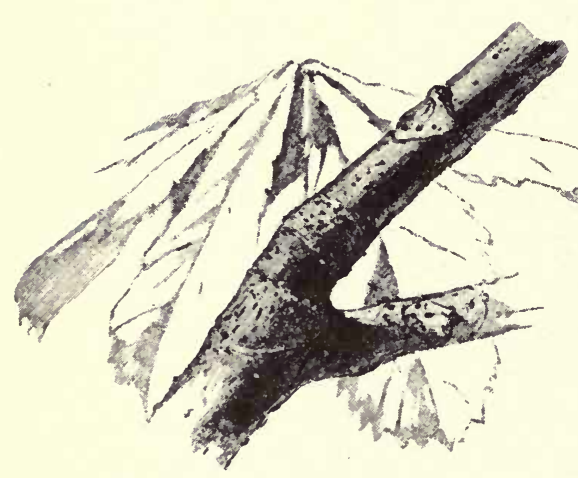

I have shown. Each of these branching twigs, naturally straight, has now acquired a curve at the fork, by which they seek to neutralize the vacancy caused by the loss of the terminal shoot. This curve answers to the fetlock joint of a horse's foot; while the distorted scar, with its row of seven raised dots around its edge, takes its place with striking significance. If with a sharp knife we now cut off the twig, trimming the wood close to the edge of the mimic hoof, the resemblance is still further enhanced, while the surface beneath discloses other markings which seem almost patterned after the sole, or "frog," of a hoof. Here we have the leg, hoof, fetlock, frog, seven nails, and all. It is certainly a curious freak, and well worth a hunt among the winter twigs. 


\section{THE GROUSE ON SNOW-SHOES}

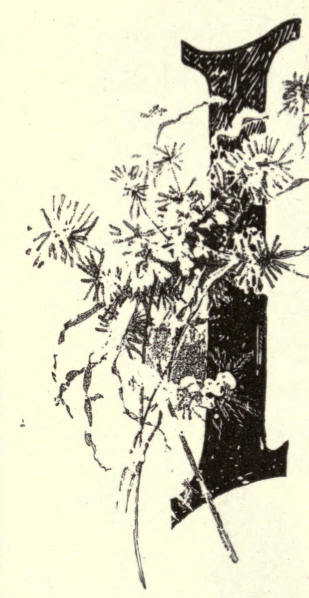

January' I2th

$\mathrm{N}$ a previous chapter I have touched upon the sprightly record of the birds and mice upon the fresh-fallen snow. I omitted to mention one very interesting snow-track which we may frequently meet with, leading us over the tops of snow-drifts and circling among the alders and sedges of the swamps, where the snow is suggestively littered with bud-scales and dirt. It is the track of a large bird; and from what we know of the habits of our winter game, is plainly that of the ruffed grouse, or "partridge," as he is commonly called.

But how is this? This is not the clean, trim imprint which the bird makes in the mud or wet sand of summer. Here is something worth looking into, surely. The snow gives us the tracks of the tiniest mice with perfect modelling, tail mark and all; yet while the foot of the grouse is slender and dainty, here we find a blurred and jagged track, with each toe apparently a third of an inch in width. It is worth your while, my city youth, to stop at the market or butcher's shop on 
your way to school this morning, and look at the feet of the grouse. Nature has not asked this bird to walk the snows for its living without providing it with proper means of locomotion. With its slender summer foot it would sink in the soft drift at every step, while now it walks with perfect ease on the lightest snow, for eash foot is provided with a snow-shoe.

Every autumn the shoe begins to grow, a stiff fringe of horny bristles spreading around the sole and on both sides of each toe, until, by the time

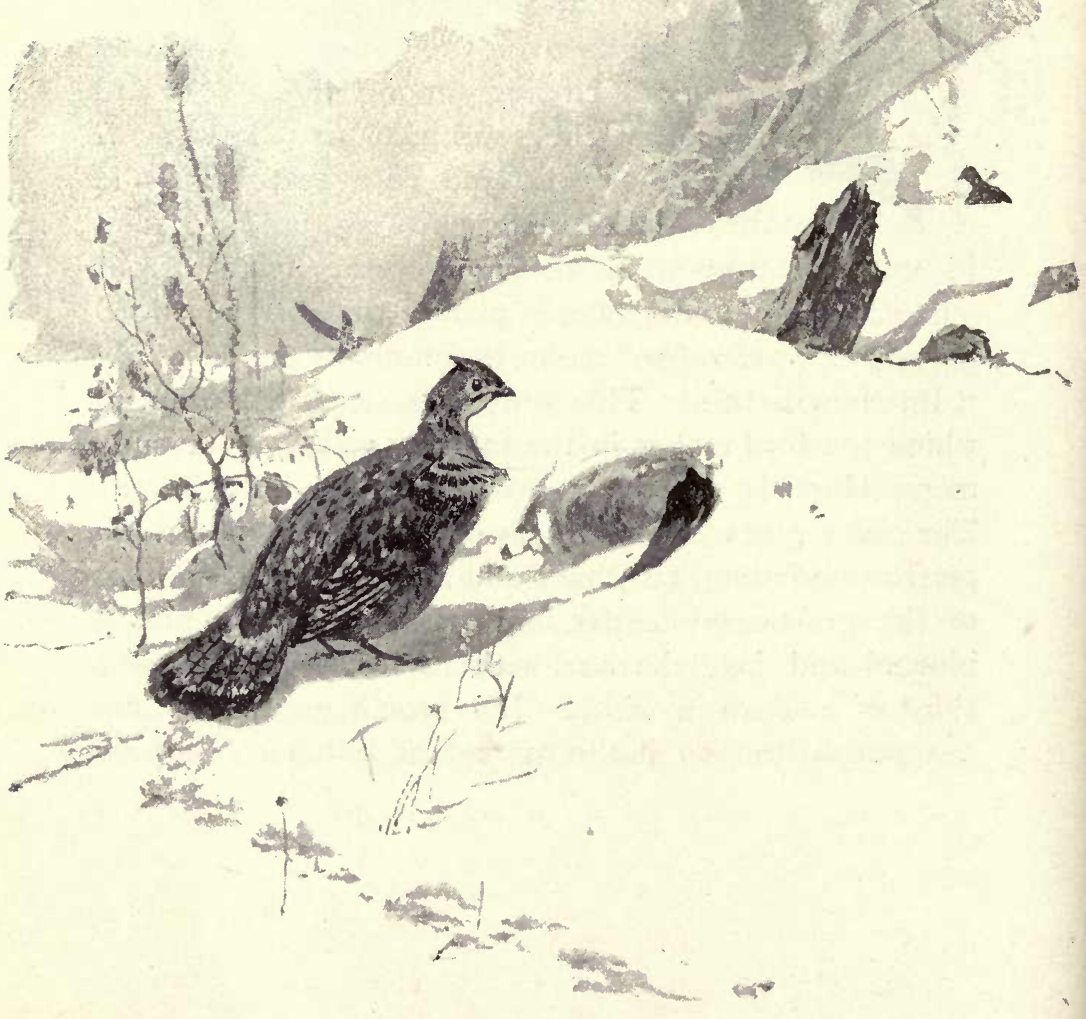


the blizzard arrives, the bird is ready to walk on the highest drifts. I have made a drawing of the foot with and without its shoe.

The intention of this bristly growth is perfectly plain, for in April, when the snows have melted, you may look in vain for the snow-shoe; the grouse has kicked it off as a thing that has served its purpose. And yet, unless I am much mistaken, you will find no mention of this singular fact in any of our natural histories. The curious pectinated (comb-toothed) feet of the grouse are noted as a special feature of this family of birds, but the peculiar annual growth and adaptation are, I believe, not generally known. The difference between the summer and winter tracks first drew my attention and awakened my suspicion, but that observant naturalist, Mr. Ernest Thompson, was the first to record the snow-shoe of the grouse.

This accommodating foot is common to all the grouse family, and the prairie-hen is even more generously equipped in winter than the ruffed grouse. The latter bird uses his broad foot for burrowing, and the winter walker, after a fresh snow-fall or during a very cold stress of weather, may often find their snow tunnels running for several feet beneath the drifts.

I once knew a boy who surprised a grouse in the act of excavating one of these burrows; but the bird, in spite of the most extreme caution on the boy's part, left nothing but its tail in his hand to show for his adventure when he reached home. 


\section{THE "FAIRY RING" \\ AND THE FAIRY}

January I2th

$\mathrm{HE}$ rabbits, mice, and birds all leave their own peculiar and unmistakable autographs -their "hands and seals"-in the snow, but they are not responsible for all the singular hieroglyphics to be seen on this great white page. The wind often takes a hand, and after a light, fresh snow-fall plays pretty pranks with the drooping stems of some of the withered grasses; a single grass-blade under the influence of varying playful breezes tracing a puzzling variety of inscriptions.

Various degrees of proficiency are exhibited by these queer writings; some being clusters of eccentric touches, cutting the snow in odd lines, like stenographic notes, as it were, made by our artist on the spot, as though quickly jotting down some racy incident of furry life which was passing at the moment. I have seen these queer inscriptions on the fresh-fallen snow when I was utterly at a loss to explain their origin, until the thought of the wind suggested a clew, and by bending down the tip of a long neighboring grass-blade I was enabled to add to the written score so perfectly that I doubt if either old Boreas or gentle zephyr, whichever may have been the writing-master, would have been 
able to tell where he left off and I began. Here and there we see a beautiful bow sharply drawn in the snow, a perfect arc or section of a circle, the work of this wiry sedge blade when the wind guided its hand. If we care to continue the search, we may find an arc extended to a semicircle, a spiral, or even to a complete ring, almost as true as if struck with a compass, and with the telltale drooping or broken grass-blade still at work with every stir of the breeze. "Fairy rings," the children used to call them. I have pictured both the ring and the fairy.

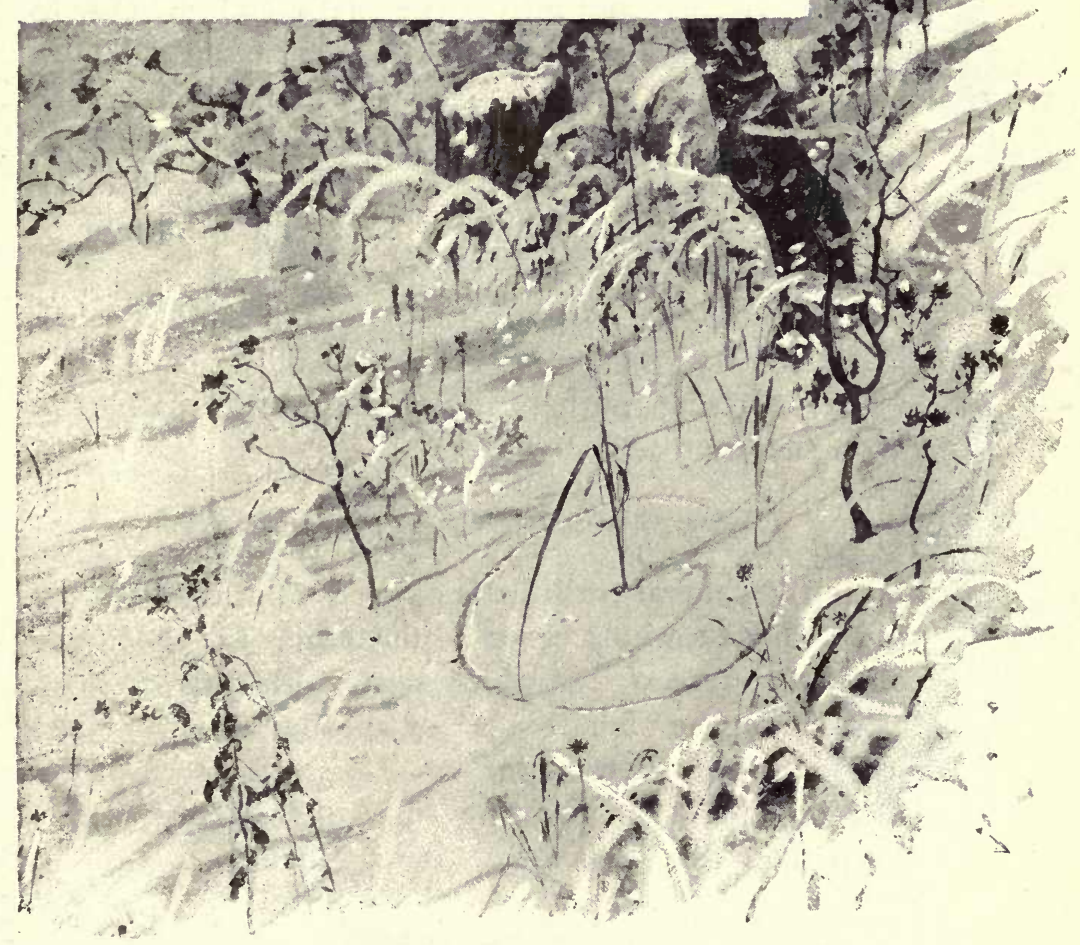




\section{THE THAW BUTTERFLIES}

Jamuary roth

HE "January thaw" does not always arrive or. schedule time. 'It may come in late December, or not until February. Even though there are no icicles to melt and drip at the eaves, and no snow to slide in mimic avalanche from the steaming roofs, we may know of the thaw's impending arrival by the appearance of its butterfly heralds. Nor is it necessary that the thaw should be a general condition of the weather. I have known a sunny, sheltered nook on the south side of the barn to have a little thaw all by itself.

The poet sings pathetically of the fate of the butterfly on the approach of winter:

"Dying when fair things are fading away;"

and in the general truth he is correct. But did he know that we have a whole brood of butterflies for which the cold has no terrors, and which always tide over the winter to enjoy the "fair things" of another spring? The well-known "yellow edge," or Antiopa butterfly, elsewhere alluded to in these pages, is of this hardy tribe, and perhaps the best known among them. 
Then there are the "Comma," the "Semicolon," and the Atlanta, or the Red Admiral, so familiar to all our young butterfly collectors-all members of the same sturdy group known as the "angle-wings." As late as the middle of October, when most caterpillars, like the Cecropia and Prometheus, have tucked themselves away in their snug silken winter-quarters, you may still find the last caterpillar broods of these butterflies either transformed to chrysalids, or feeding upon their various food plants. But their gilded chrysalids are rarely content so to remain for more than two weeks, the severe frosts of late October only seeming to hasten their eagerness to be on the wing. It is true there is little invitation in the way of blossoms for honey-sippers now; but the cider-presses are running, and the whole family of angle-wings, it must be confessed, would disdain acres of bloom for one good sip of applejack. Go to the pomace heap at the cider-press, and you may pick them up in your fingers perfectly passive in contentment. In the orchard, the brown,

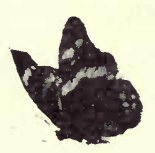
frozen apples offer a similar bait; and in the wood-pile the fermented juice of the exuding sap from the freshly-cut logs tempts the same appetite-a "nightcap," possiblythe necessity for which is foreseen by the butterfly in view of that long, cold sleep which it has chosen to take in its winged state rather than in the chrysalis, which is the choice of most of its kind.

When the biting chill of November ushers in the winter, you will look in vain for your angle-wings; that is, unless you look
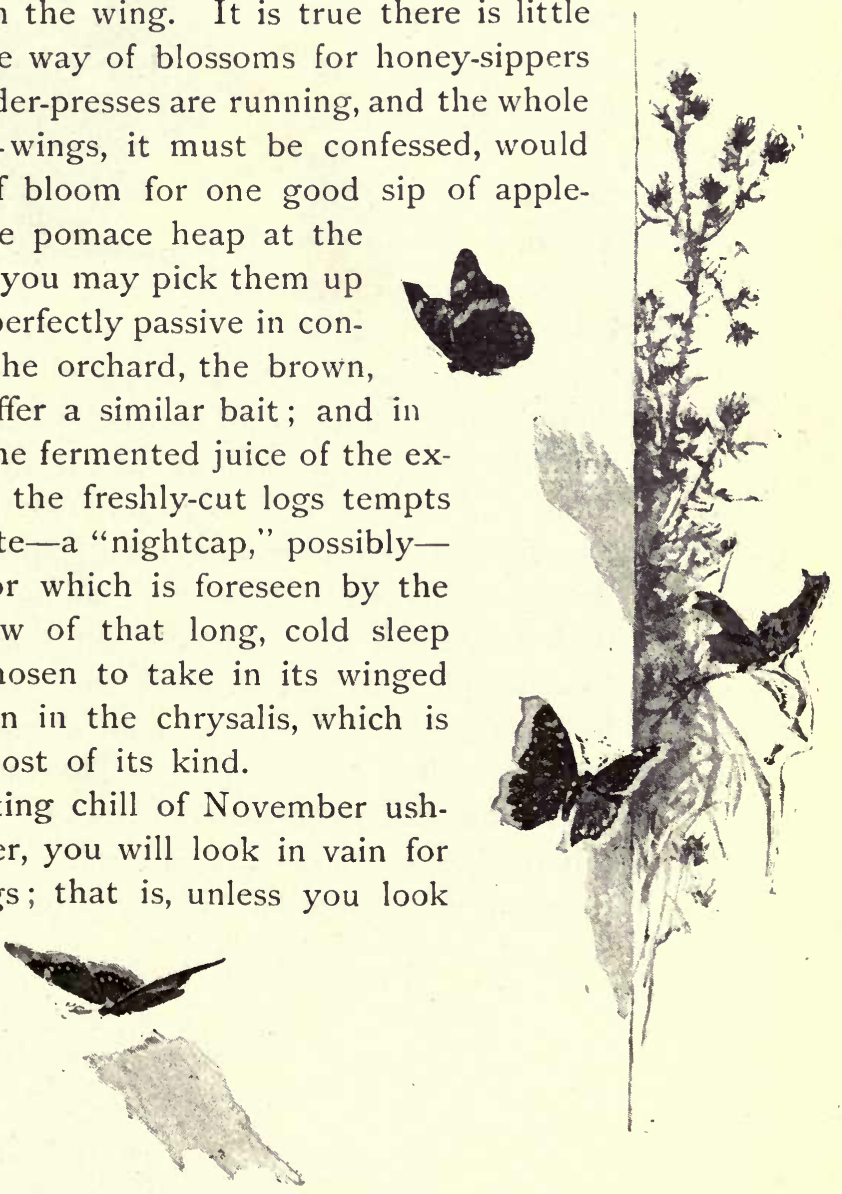


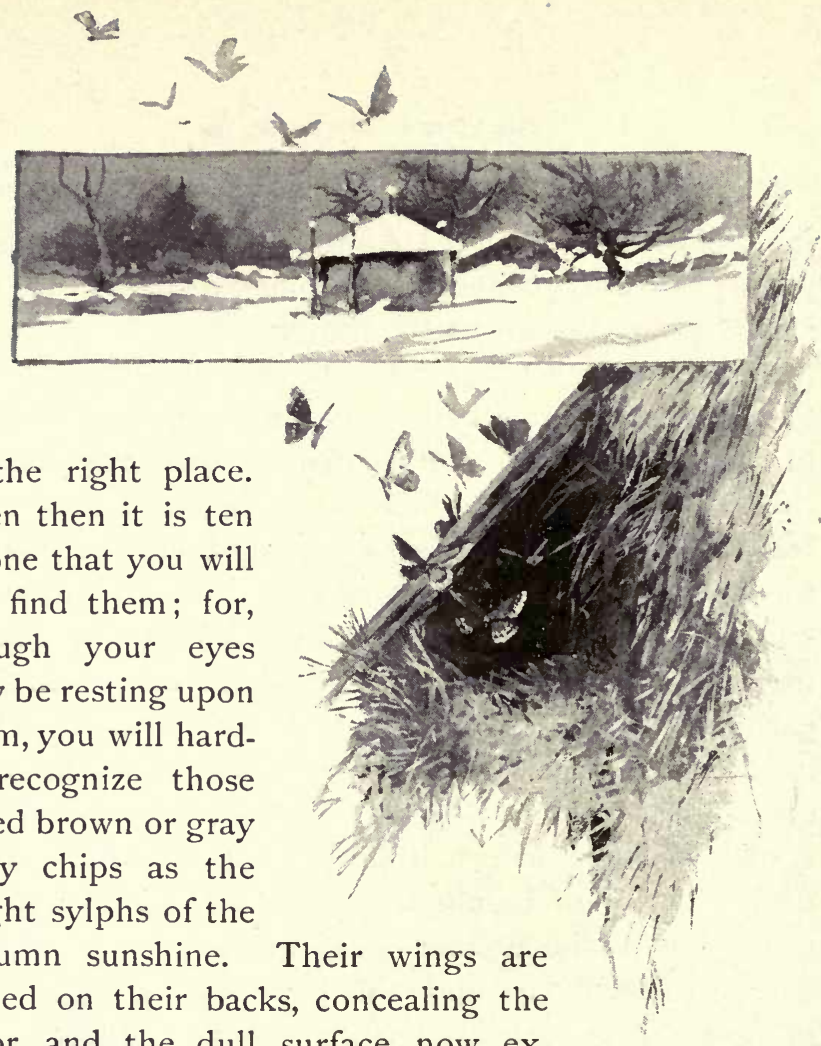

in the right place.

Even then it is ten to one that you will not find them; for, though your eyes may be resting upon them, you will hardly recognize those faded brown or gray scaly chips as the bright sylphs of the autumn sunshine. Their wings are folded on their backs, concealing the color, and the dull surface now ex-

posed is in such perfect harmony with their present dingy surroundings as to conceal all suggestion of their animate existence. Where, then, shall we look for them? A butterfly hunt in midwinter! Hundreds of the Antiopa have been found hanging in a single crevice between the boards of a shed, falling to the earth like bark scales when dislodged. They are found beneath loose clapboards and shingles, and the crannies in the hay-barracks beneath the conical roof are a favorite haunt for their hibernation. I have seen a small brood of them sunning themselves around an opening in such a barrack-mow; and once, in tearing away a slab of bark from an old stump, two or three of this same "yellow 
edge" tribe fell out upon the snow, like so many inanimate scales of bark.

Any one of these angle-wing butterflies may be kept in domestication through the winter months, becoming very tame and familiar, and forming a pretty feature of the conservatory, or even the window-garden.

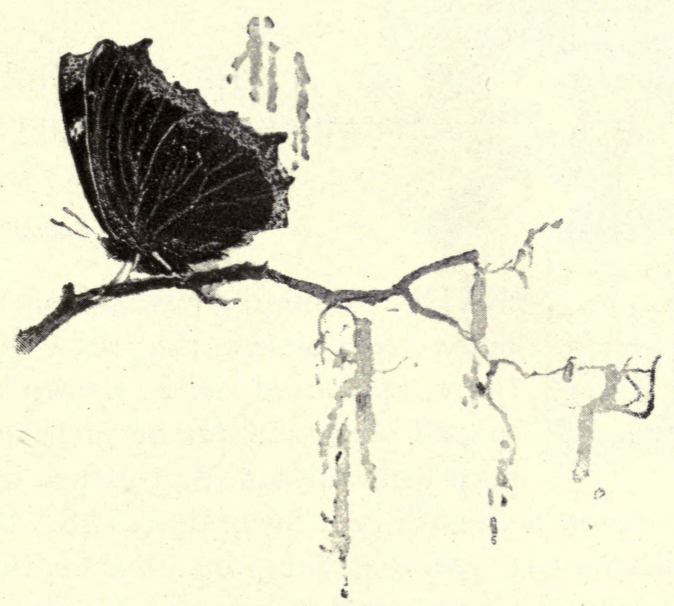



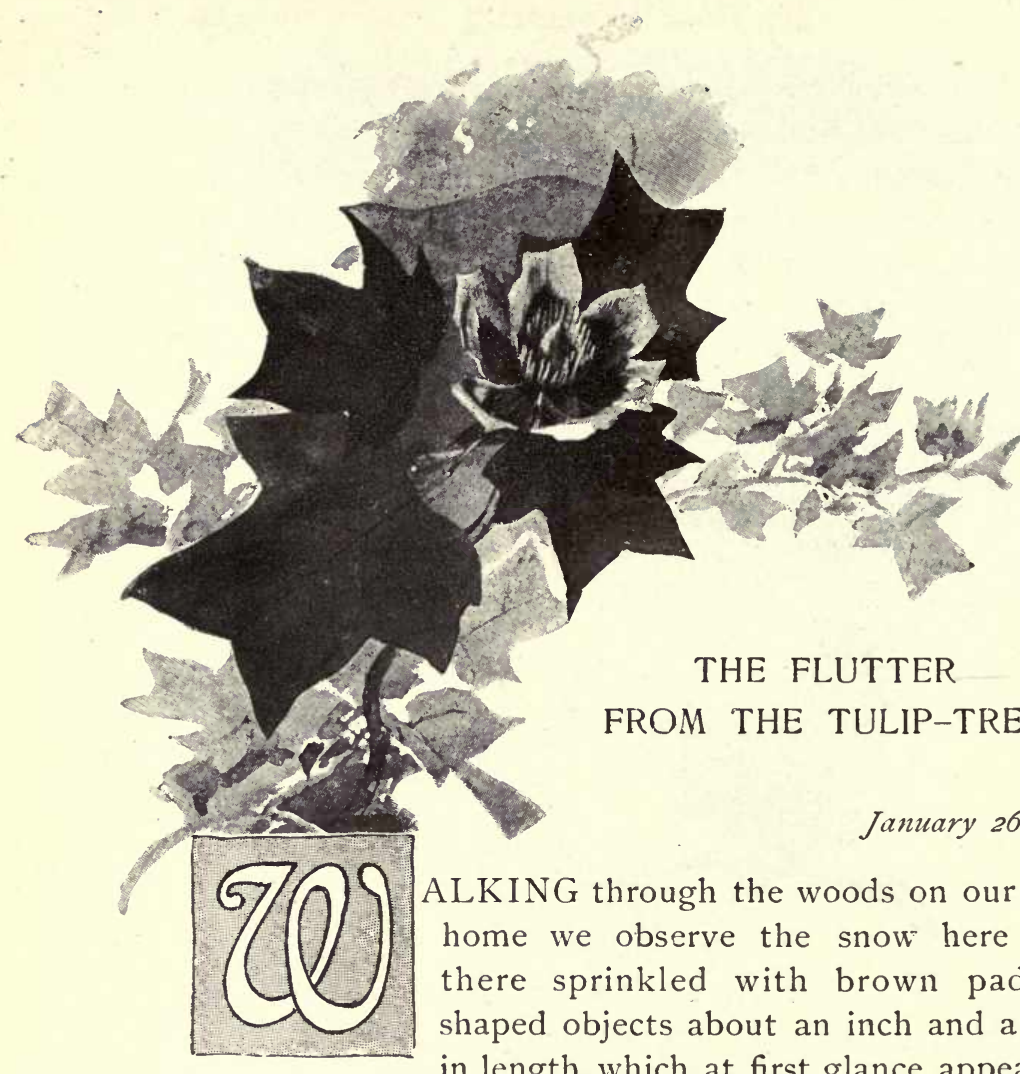

THE FLUTTER

FROM THE TULIP-TREE

January $26 t h$

be the seeds of the ash previously described. But upon examination we see that they are of an entirely new model, having a heavy and blunt curved extremity.

One of them is to be seen in my windrow of seeds on page 282. To one familiar with the woods these paddle seeds offer a temptation not to be withstood. Somewhere near by we may confidently look for the lofty tulip-tree, where the remnant seed-broods are still nestling by the thousands in their mimic cup or coneshaped clusters at the tips of the branches, each bringing 
to mind the orange-spotted yellow magnolia-tulips of last July. One glimpse of them is enough for me-a challenge which I never permit to pass unhonored. The nearest club or stick or stone is soon flying up among the branch-tips, and what a mazy, whirling, dizzy, dancing response is mine in the flying cloud which follows!

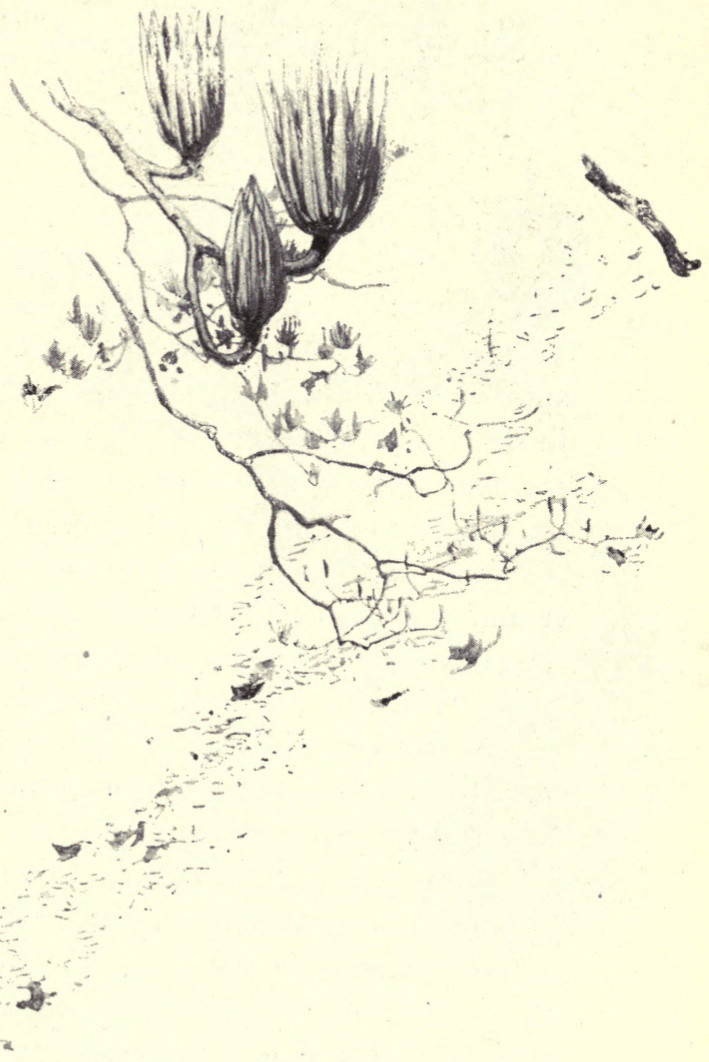




\section{SNOW-QUAKES AND THE SNOW-QUAKER}

January 26 th

$\mathrm{NE}$ of the most welcome occasional companions of the winter walker is the gray squirrel. On almost any genial day we are sure of him if our eyes are sharp enough, and our manners sufficiently decorous. His eccentric doings are written in his footprints everywhere upon the new-fallen snow, connecting tree with tree, and keeping one's eyes ever on the lookout for the whisking tail.

At our approach he has leaped upon a convenient trunk, and suspended himself head downward, unwinking and motionless, with brush laid flat against the bark. But not for long. If we wait with sufficient patience, the nervous loop of that tell-tail will soon show us his whereabouts, and in a moment more we see him bounding with graceful curves across the snow, every subtle motion of his beautiful body accentuated as never before, in its contrast against the white carpet.

His summer companion, the chickaree, or red squirrel, is still curled up in its semi-hibernating sleep, or perhaps has taken a peep at the white world without from its hole in the tree, or a nibble from its convenient frozen apple or nut in the crotch above. But we rarely 
see him in those winter days when the gray species is quite generally abroad.

We can hardly suppose that our gray rover is out freezing his toes merely for enjoyment. If we observe his doings closely, we may soon discover that a more urgent mission animates his being.
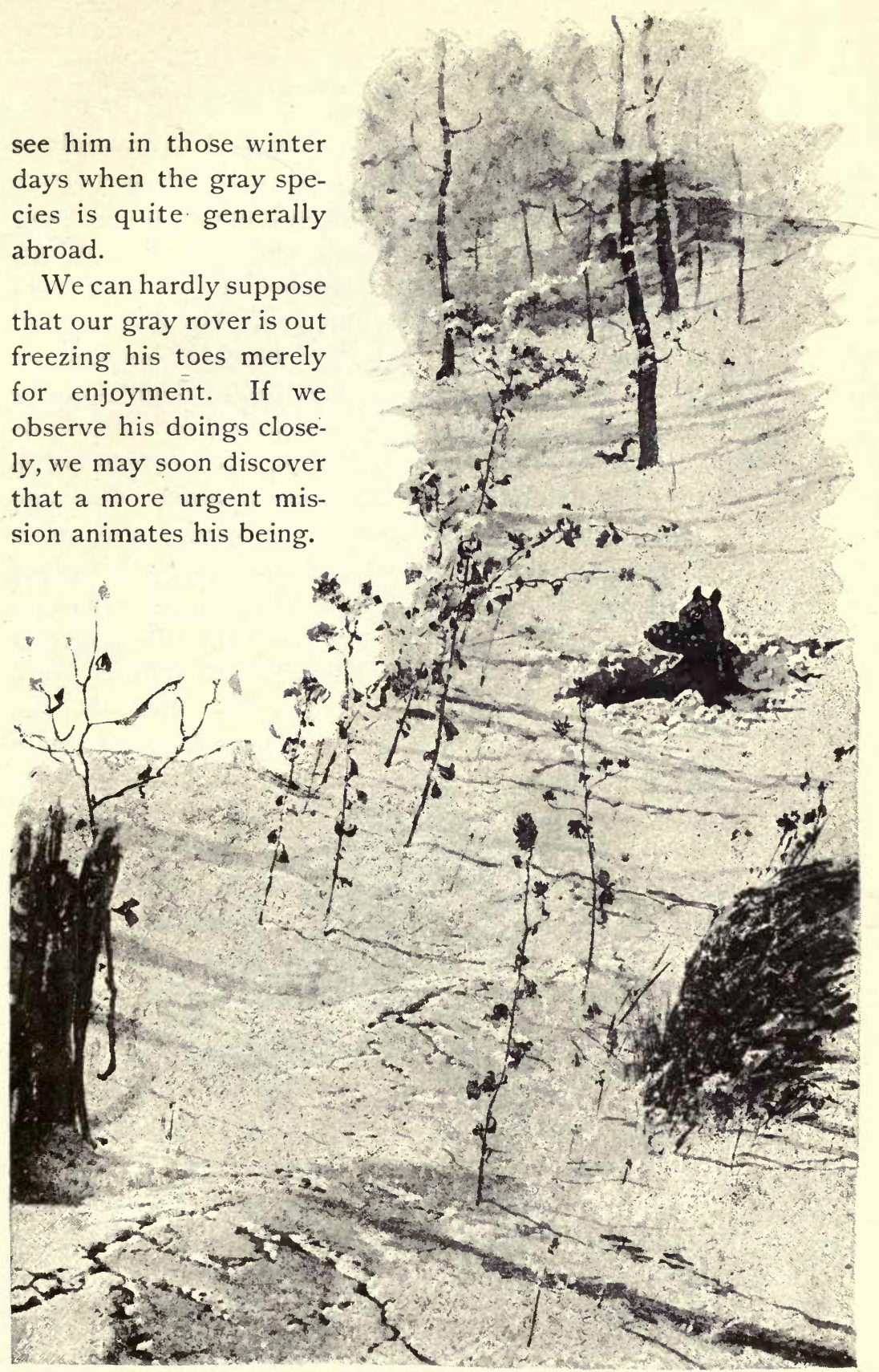
The red squirrel, aloft in his den, sets an example of providence which his bigger gray neighbor has persistently ignored. Every day last autumn he might have been seen packing away his provender of nuts, apples, etc., into secret chinks and crannies high above ground against the coming snow-bound days. The gray squirrel has doubtless had the benefit of much of his wisdom, but it is doubtful whether he has taken his hint even to the extent of a hazel-nut. These winter outings, therefore, are not primarily for pleasure, but for dire necessity. Let us observe our squirrel carefully. There he goes in graceful bounds across the snow, his sensitive plumy tail in every movement expressive of its homage to the line of beauty. Now he pauses and seems to scent the snow-flakes, and in a moment more, evidently satisfied with his bearings, he begins to burrow like a woodchuck, and is soon lost to sight. Now he reappears at the mouth of the burrow with a pine-cone in his teeth, and in the tree-top near by he quickly extracts its seeds while the cone scales litter the snow beneath.

"Wonderful sagacity this! How did he spot that cone so accurately through six inches or a foot of snow?" So exclaims the ordinary observer. So exclaimed the present writer on more than one occasion, until at last the true significance of the episode was revealed.

My squirrel on this occasion, which I can hardly consider exceptional, had already brought one cone from the hole and devoured its seeds. He then descended from his tree, and procured another. But did he discover it through the snow, and dig as above described? Not at all. He entered the burrow, and soon appeared with his second cone. Were there then two cones at 
this one spot? I queried; and those suggestive scales yonder, from perhaps a dozen cones, which strewed the snow, had these, too, all chanced to fall at this particular place beneath the snow? Drawing closer to the scene of action, the mystery of this "wonderful sagacity" was solved, the opening of the burrow being but a convenient door-way to a system of snow burrows extending for several feet on all sides, the crust upheaved and cracked here and there in broken mounds, each of which probably marked the scene of discovery and struggle with a cone.

Whatever may be said of the comparative provident sagacity of the red and the gray squirrels, it must be admitted that the snow-quaker fairly earns his Christ. mas dinner.

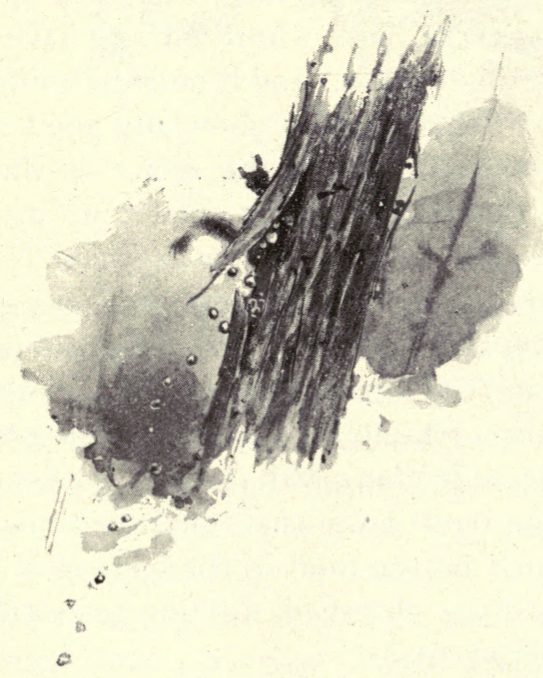




\section{WINTER GRIST FOR THE BIRDS}

February 2d

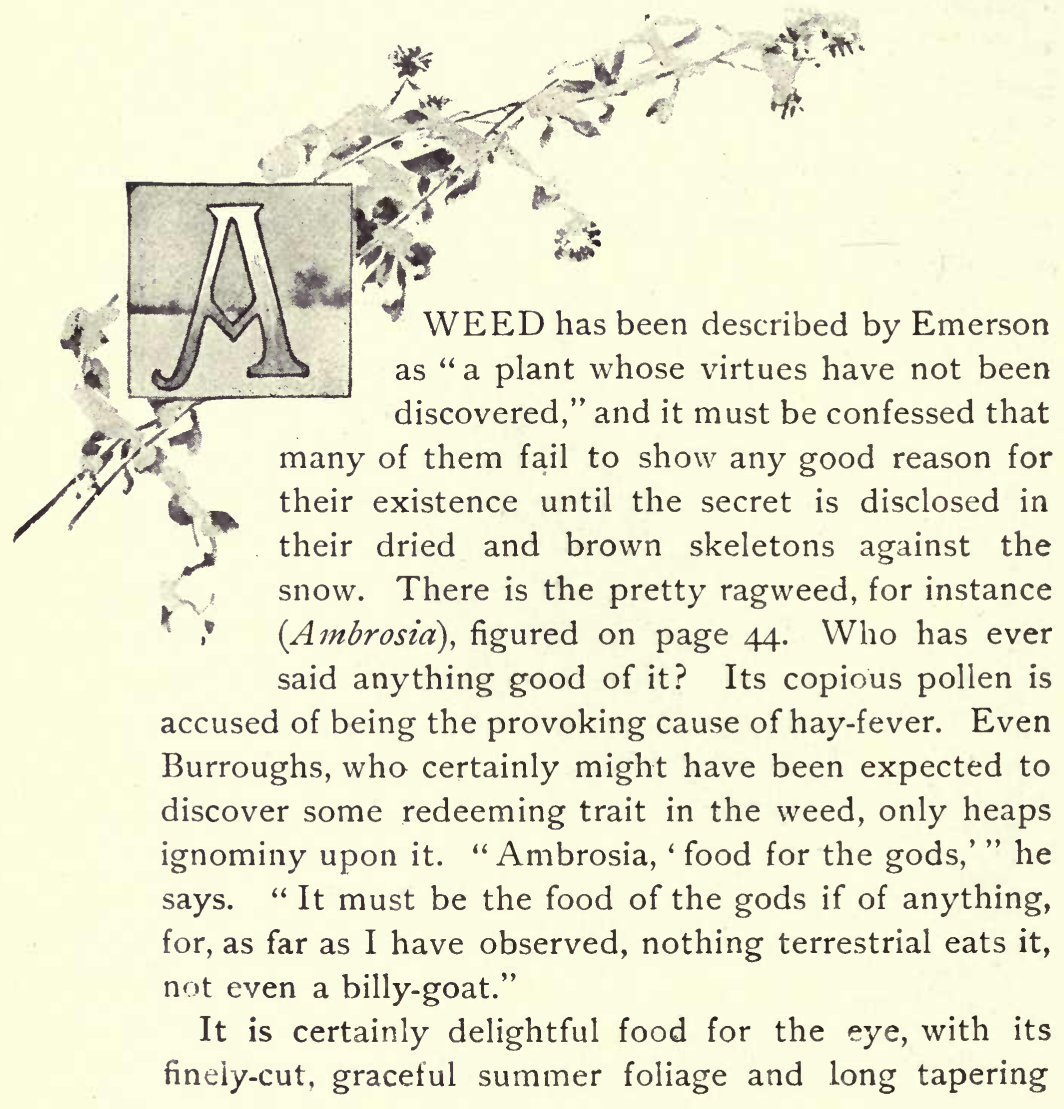




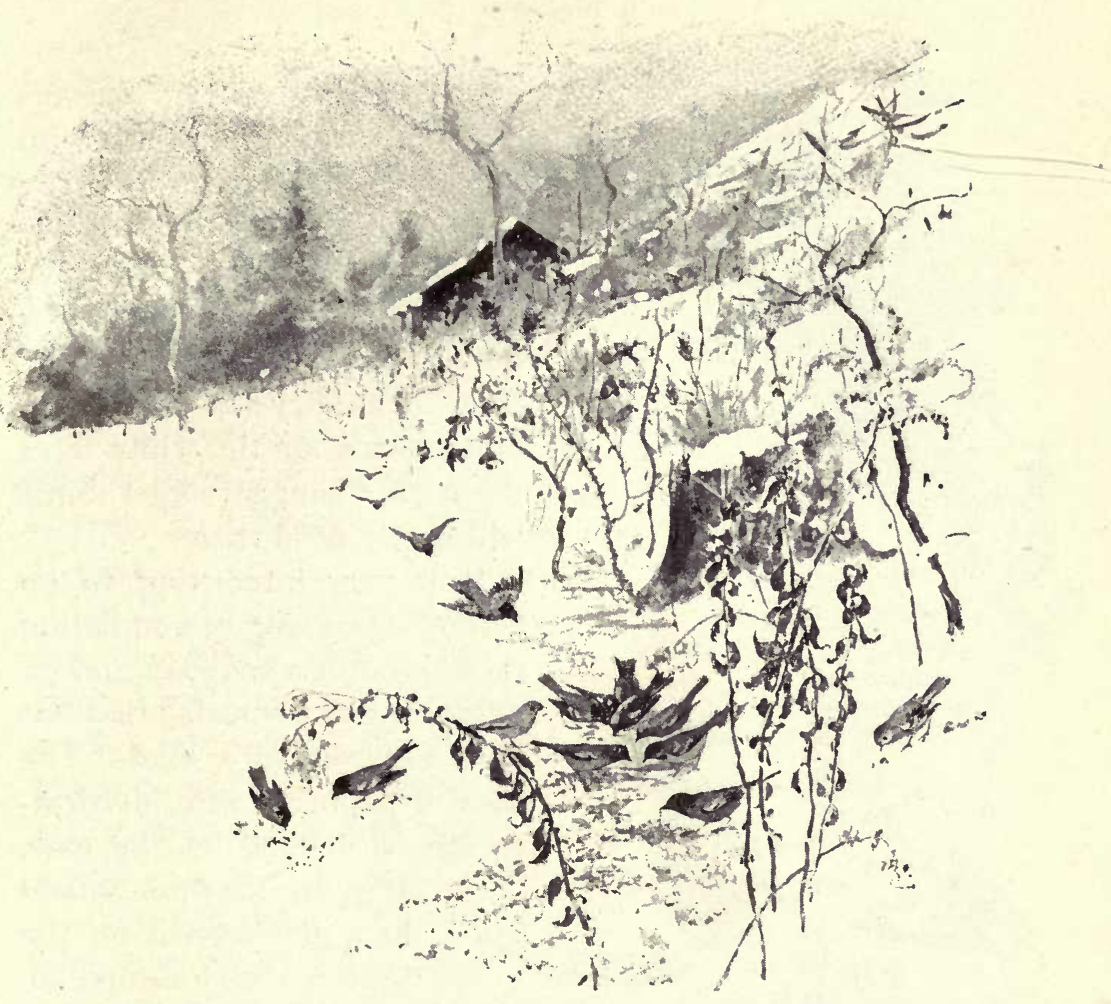

spires of greenish bloom ; but it is in the dried and leafless winter stalks of this and a number of other weeds that we find the best reason for their being. What could the birds tell is? How would the winter buntings, sparrows, finches, and snow-birds bridge over the snow-bound days were it not for this garner of seeds which the weeds hold above the snow?

Generally speaking, the seeds of a plant are supposed to be released upon maturity. We all know how speedily the wind takes care of the dandelion and thistle seeds when the plant has completed their education. 


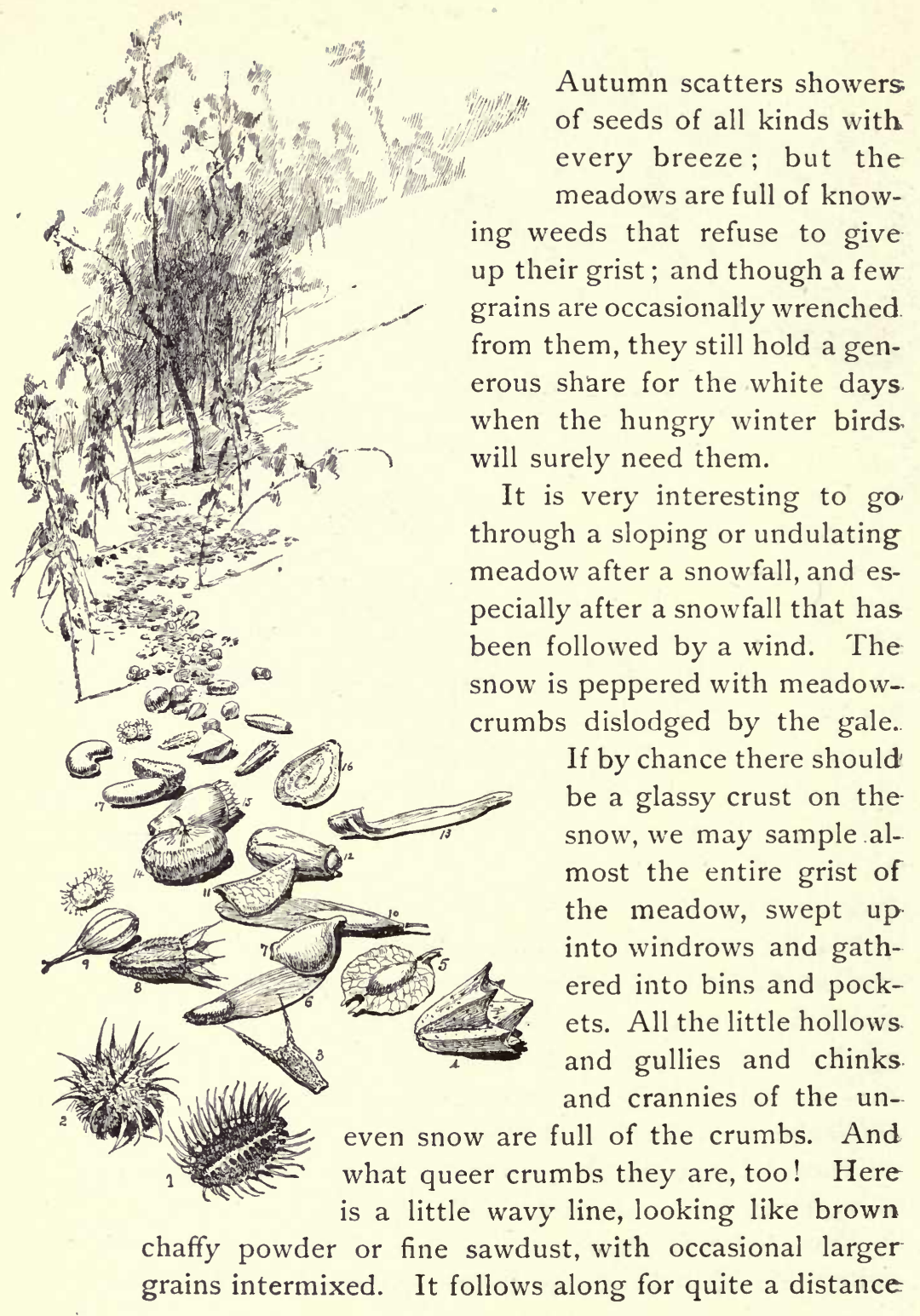


on the snow at the foot of the steep, white, weedy slope. It is well worth our while to study it closely. Each handful of the powder swept up at random will have a surprise in store for us. Darwin it was, I believe, who coaxed quite a number of foreign plants from the dirt scraped from the foot of a migrating wildduck. What_a garden might we not get next year from a pinch of this meadow snuff, or from a ball of mud rolled in it for only a moment! Not a foreign garden, it is true, but perhaps a beautiful one, nevertheless.

Let us see what we might expect, for we can tell pretty nearly what it would be, though we may be sure that it would include a fair number of plants which only the birds care anything about. I have shown a few of these crumbs which the windrow would give us - some of them only occasionally, and others in great quantity. I am sure that few of my younger readers will remember ever having seen such queer-looking things on the snow or anywhere else, but I can assure them that these are but a few of the precious packages which may be found in the winter fields, and each one of them is as good as a whole plant to the eye of a botanist. There is no mistaking where they come from.

Let us turn our powerful magnifying-glass upon each in turn as it may be necessary. Here is No. I, a turtleshaped seed beset with bristles. This is from the wild 
carrot, that manages to hold a generous remnant of seeds in its withered nest all winter. No. 2 needs no magnifying-glass, being a large hairy burr, nearly the size of a hazel-nut, and armed with cruel thorns, a seed of the hedgehog grass, and not a pleasant thing to handle. No. 3 we all recognize as the same two-pronged "beggar-tick" that is so fond of our clothes in the late summer. No. 4 is the urn-shaped kernel of the ragweed. No. 5 , the large samara of the elm, though you will find few of them in the winter. No. 6, a pine seed. No. 7, a buttercup seed. No. 8, with its rough conical body and fine-toothed crown, is the pretty seed of the sneezeweed, which certainly deserves a place among our meadow snuff. No. 9 has come from a sedge. No. IO was blown from the ash-tree, perhaps half a mile away. No. I I will be remembered as another of those friendly "beggar-ticks." No. 12 was once in the centre of a may-weed blossom. No. 13 is one of that fluttering swarm from the seed cone of the tulip-tree. In No. I4 we have the dainty packet which holds the seed treasure of the pig-weed. The tooth-crowned fruit of cichory is shown at I5; a wingless milk-weed seed at I6; that of the smart-weed at I7. And we leave the reader to guess at the long line of other representatives from grasses and sedges and other sources; and, like my little flock of birds, to take his pick among them.

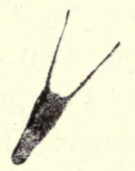



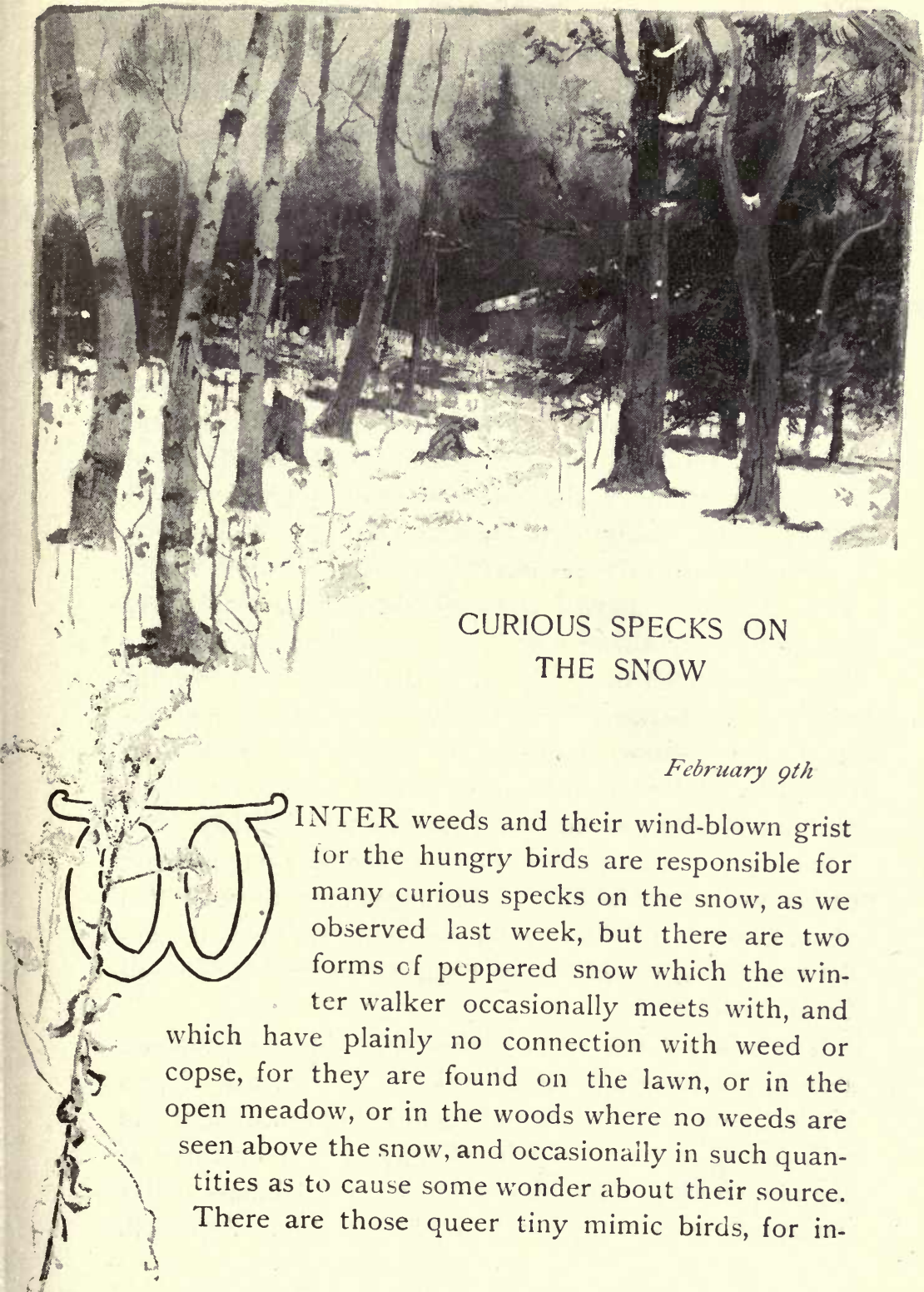
stance. Go where you will in the snowy woods, especially after a wind, and their flocks would seem to follow you, though without the snow to serve as their background no one ever sees them.

In an open winter their existence would never be suspected; but now we see their myriad flocks soaring over the drifts, with their tiny wings fully spread and tail expanded like diminutive hawks, floating above the white field.

I have said that they are everywhere to be seen, and this is really quite among the possibilities, for the wind is a most thorough sower; but it must be confessed that when we find the snow literally peppered with them, we may know that there is a birch-tree close by, for the birches are responsible for this winged brood. More than once have I been asked to identify this tiny mimic bird by those who need only have reached the drooping branch of the birch in the woods to have put a million of them to flight towards the snow. So constant and pronounced a feature of the winter are they that it is impossible for me to think of the snowy woods without recalling them, and I do so now to satisfy what I know must have been a frequent wonder on the part of many a winter walker who shall chance to read this page, and also to direct attention to those curious pendent nests where they have been so snugly brooded all these months.

The white-birch-trees during the winter season are seen to be hanging full of catkins. These are of two kinds, the more numerous of them being quite large and full, the others confined in groups of two or three at the branch tips. The latter are the true catkins-winter parcels done up ready for the coming spring. April will 


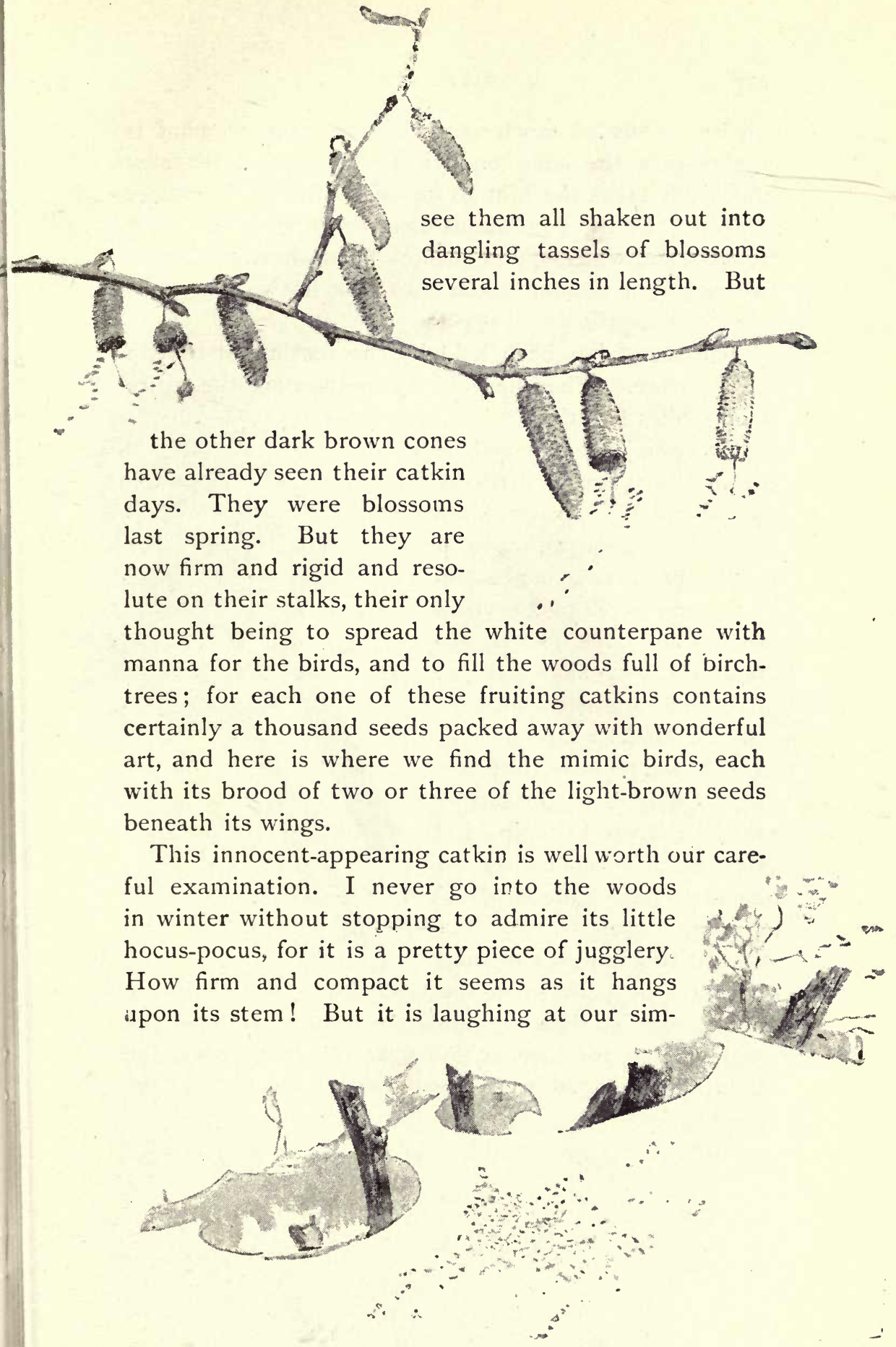


plicity. Only as much as shake the twig, or, what is better, give the cone a pinch at its tip, and see how quickly it takes the hint to be off. Firm and compact indeed! In the continuous disintegrating shower that follows, and which leaves nothing but a short, stiff stem, we may well wonder at the trick that has so long kept the cone together.

The secret has been held by the sentinel at the tip of the cone. When he once opens the door the entire troop takes flight.

On examination it will be seen that these birdlike scales and light-brown, filmy seeds have been arranged in circles and tiers around a central stem or core to which they were once joined. In ripening they have become free, and are then held in their compact shape only by contact and pressure, the whole elastic mass being locked by the hard scale at the tip. Let this or any other part become dislodged, the structure crumbles away.

And this is how the snow

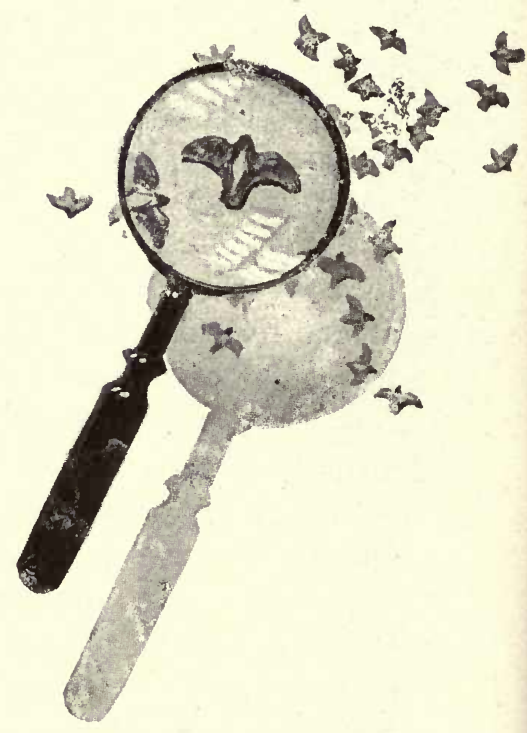
becomes peppered with the tiny birds. But these are not the seeds; these we rarely see, even in winter. The scales being the heavier, fall near the trees, while the light, filmy-winged seeds are blown to the ends of the earth. 


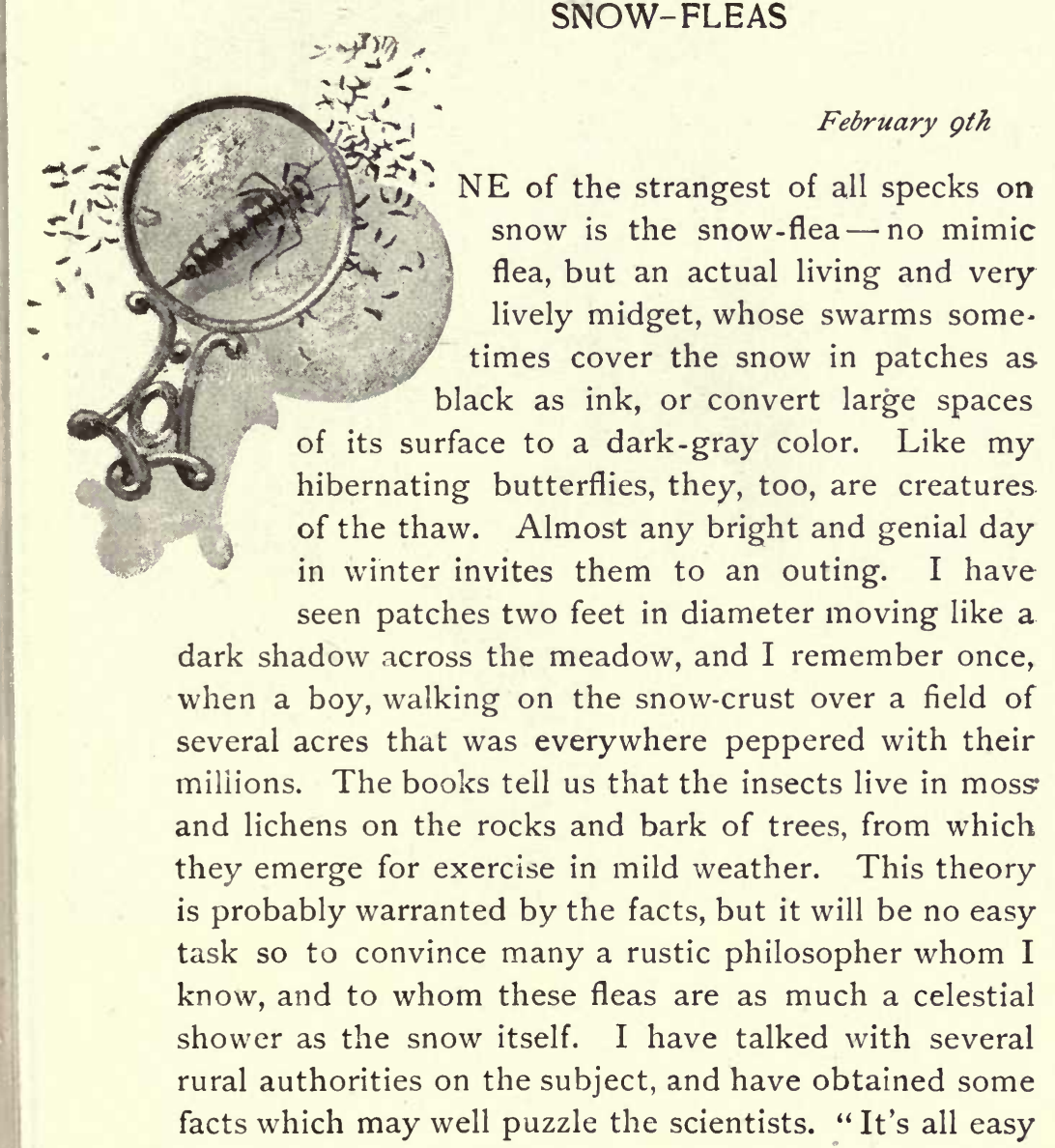


enough to say they come from the trees and rocks," says Enoch, "but thar's my five-acre meddy yonder, it's un-

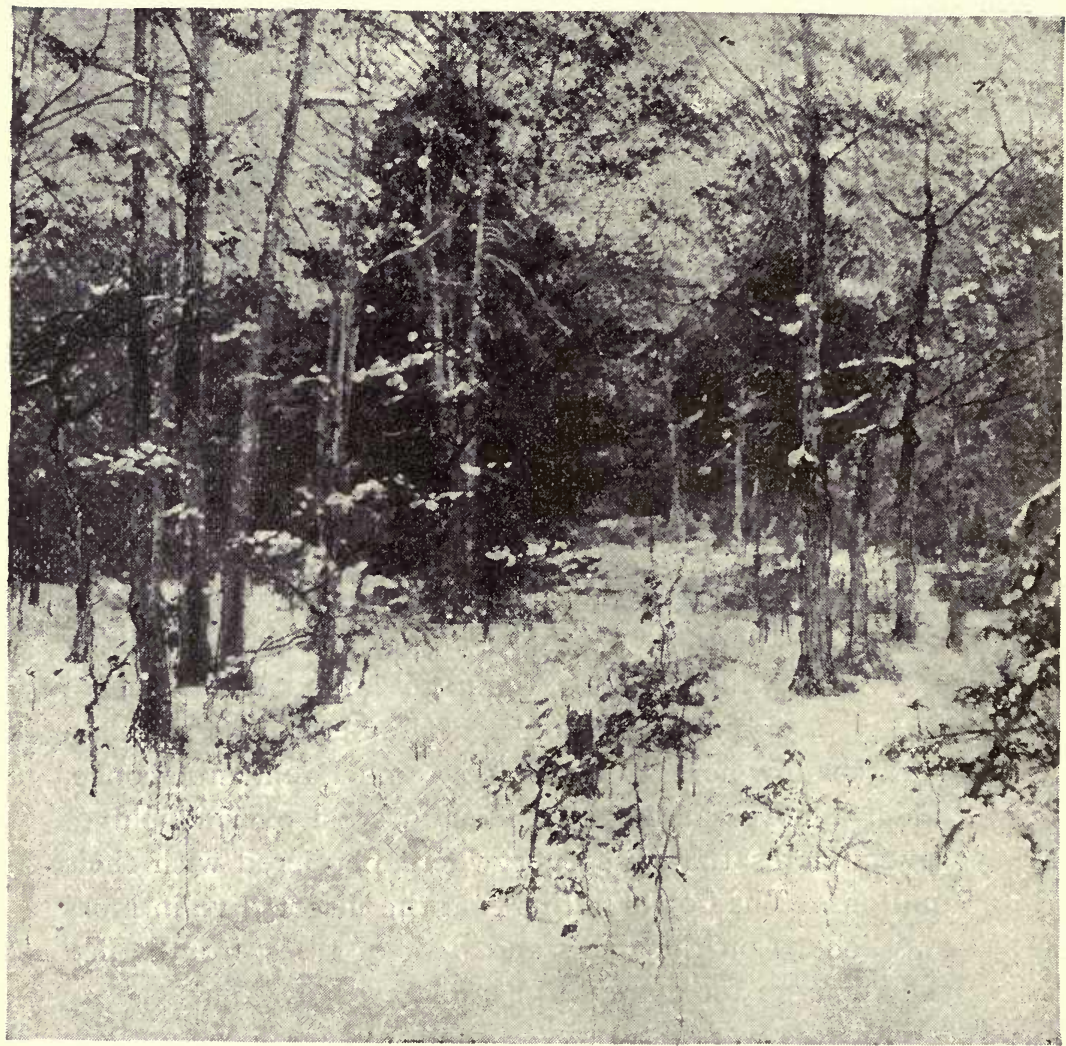

der two feet of snow, and they ain't a rock or a tree on it, ner in a half-mile on't, and yet it's all alive with 'em. I tell ye, them as sez they come from trees and rocks 
don't know wut they are talkin' about. Why, I've seen 'em cum down a-ridin' on the snow-flakes!"

I am sorry that I cannot give an accurate picture of the mysterious flea. Once, when a boy, I made a drawing from one by the aid of a magnifying-glass, but it was lost, and I can only give a suggestion of it from memory. 


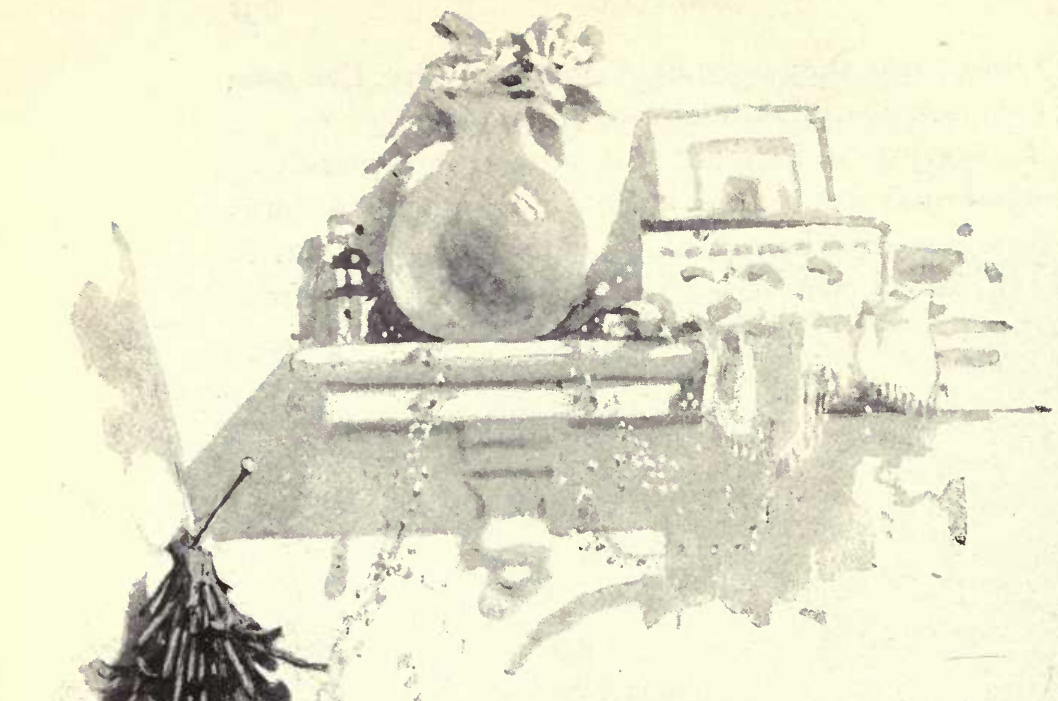

THE CURIOUS BASKET-CARRIERS

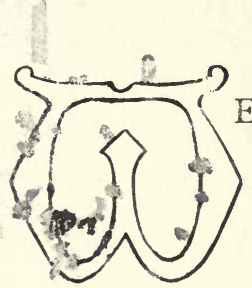

February ibth

\section{(1)}

must not let the winter pass without gathering a few of the cocoons of the basket-carriers, or bag-worms. There are many kinds of cocoons to be found in winter, and all sorts - of beautiful moths come out of them, but there are

a few such queer specimens as this of the bag-worm, with its array of sticks and leaves and thatch of vari\% ous sorts; and you may be sure it has a surprise in store for you next spring, if you have not yet learned its secret. It is only necessary to gather a dozen or so, and place them in a box and await further developments.

I shall never forget my first experience with them. It was one winter early in my boyhood. A larch-tree in front of my city home was dangling full of the stick- 
covered baskets, then seen by me for the first time, and a rarity in these parts. I gathered a hundred or more, and coveted all the rest that huns beyond my reach. I placed them in a box, and no one but myself knows how I longed for spring to come, in anticipation of that wonderful moth that was to have the place of honor in my collection. Surely, I thought, something extraordinary must come from such a very queer cocoon; and my suspicions were more than verified, for it was in truth a singular progeny that greeted me one morning in June, when I went to take my daily look at the box of cocoons.

All over the cover and sides of the box, the mantelpiece on which it rested, the walls, and the ceiling, were thousands and thousands of little parti-colored specks, wriggling and turning all sorts of queer antics in puzzling confusion, and hanging and squirming in webby festoons on all sides.

As soon as my surprise was over I began to investigate the matter a little more closely. The animated specks consisted of cases or baskets about an eighth of an inch in length, each of which was occupied by a lively little tenant, which, on being pulled out of its house, showed itself to be a tiny black caterpillar, with a very intellectual head, this portion being about one-fourth the size of the entire creature. On opening the box, its interior was found to be literally alive with the little fellows; and as I examined them closely, I noticed a

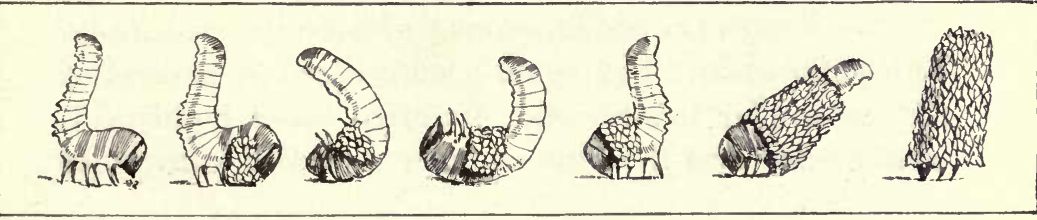


marked difference in the color of their diminutive cases. Some were pure white, others were buff-colored; some were bright blue, others variously tinted; and one was red, white, and blue. This little individual appealed to my patriotic sentiment, and I took him to the window to get a closer look at his domicile. Until that moment it had not occurred to me to examine the material of their tiny baskets. I went back to the box. I had previously noticed a mottled appearance in its interior, but it had not especially interested me. It now became a matter of more significance.

The box was made of common straw board covered with white paper, and at its upper edge, inside, were attached two loose pieces of blue paper, which formerly had covered the articles packed within-candles, I believe. The white paper had been worn through in spots by the myriad pairs of little teeth, and with the bits of fibre thus obtained, and by the aid of the silk web, of which the caterpillars seemed to have an inexhaustible supply, a countless number of baskets had been made. The mottled effect of the interior of the box was caused by the yellow straw board appearing in spots where the covering paper had been gnawed away. This yellow board had again been utilized by several of the caterpillar babies, who preferred more highly colored homes, and the blue paper was riddled with holes 
by the immense demand made upon it for building-material. Near by, on the mantel, was a pile of books, including one old leather-covered volume, from which a fragment of rea blotting-paper protruded. Both the leather and the blotter had been largely utilized in the baskets, the soft quality of the red paper having made it very popular among the little architects, many of which occupied conspicuously gaudy apartments. It was from this blotting-paper that the patriotic specimen above alluded to obtained the red material which surrounded his door-way - the white and blue bands having been built within the box.

Nor were these all the materials which the builders had laid under tribute. A green worsted mat, a red napkin, the black paper of a passe partout frame, had all furnished their share in the motley acrobatic procession that moved about the apartment.

A repetition of this singular show is within the reach of any one who cares to witness it, and there is no end to the experiments that may be tried as to building-materials, for the industrious little builders will make use of anything within their reach in their haste to begin house-keeping. Almost the moment they crawl from the cocoon they begin to erect their houses; and when we consider how little experience they must have had, their skill and dexterity are indeed surprising. Singularly enough, like true architects, the arch would seem to have especial attractions, as a foundation, but further than this their methods are their own. Professor C. V. Riley, our Government entomologist, has carefully described the process which follows, and I have taken the liberty of copying his little panorama, which illustrates the knack of the tiny builder and the growth of its case, 
for every one of these thousands of bag-worm babes have followed the same plans and specifications. The tiny inverted arch is first built. When this has reached nearly to the height of its body, the caterpillar grasps it with its feet and turns a somersault, thus bringing the arch uppermost. The builder then carefully turns beneath it, and upon regaining its feet proceeds to add to the structure on the lower edges until a complete ring is formed around its body, when, by adding tier on tier of chips, the bag is soon completed. My swarm above described, showed thousands of the houses in all these stages of progress.

But where was my moth? I waited for it in vain. And no wonder; for upon dissecting the cocoons, I could find no chrysalis from which I could expect a moth. Many of the cocoons were entirely empty, and the others contained only a chrysalis shell filled with eggs and a peculiar fuzz. This will be found to be the contents of the cocoons which we may now gather from the trees. But there is a moth-not such as we might select as the prize of our collection, it is true-a small, black-bodied, clear-winged, buzzing, bumblebee affair, whose only ambition in life would seem to be to bump its head against everything in its reach. This is the male moth. It was years before I could ever find the female, partly because I had gathered the cocoons at the wrong season, and partly because my powers of observation had not been sufficiently trained. Lest other youthful entomologists may become puzzled like myself over this very singular insect, I may mention that both sexes of the moth are to be found in the cocoons gathered in September. At this time the full-grown caterpillars suspend their baskets, and are transformed into 
chrysalides. The male chrysalis works its way out at the lower end of the cocoon, and its shell falls out after the escape of the moth. The female moth never leaves the cocoon-she is hardly entitled to the name of moth, being both wingless and legless; and after having deposited several hundred eggs within her pupa case, few would recognize in the inconspicuous remnant of herself which remains any likeness to an insect.

Few of our common insects have been such a theme for discussion and controversy among naturalists as the bag. worm; and there is much of interest in the life of the insect which it is impossible to touch upon in this brief paper.

The basket-carrie never leaves its case. It carries its house about in its travels, enlarging and decorating it with sticks and leaves as its whim directs, and always keeping it safely moored to the branches. A collection of the cases from different food trees makes a singular exhibition, for they are thatched with locust, hemlock, spruce, arbor-vitæ, or long pine-needles, according to the plant on which each is found. In the South, we are told, these basket-carriers are looked upon with much superstition by the colored natives, the nature of which is illustrated in the incident narrated by 
Dr. McCook of a darky laborer's refusal to burn a lot of the cocoons, with which his master's trees had been infested: "I can't do it, sah! I done got conscience agin it. Dem's what we call 'firewood billies,' an' dey is nuffin mo' nur less dan human critters what's a-bin punished fer stealin' wood wen dey wuz alive an' in de. body,"

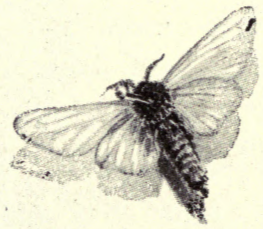




\section{HOUSE-CARRIERS UNDER WATER}

\section{February 23d}

AST week we made the acquaintance of those queer house-carriers of the trees, the bag-worms, with their thatched and ornamented cocoons now firmly swung among the winter twigs. But there is another house-builder that few of us ever see in its home-the caddis. He lives on the pebbly bottom of the stream or the shallows of the pond. Even as we stood upon the black ice at the edge of the dam, gathering our bag-worms last week, we need only have lain down upon the ice and looked beneath to have seen our caddis crawling upon the bottom, leisurely lugging its stone cottage or log-cabin around with him. But who would ever think of going "bug-hunting" in winter? This stream, locked fast and muffled in ice, or bubbling beneath the snow-drift, its overhanging icy border fringe crowding close upon the ripples in the intense cold, would hardly invite the entomologist as a likely field for specimens. The city naturalist who happens to keep an aquarium knows with what difficulty he can keep it stocked in the winter months if he would depend alone upon the dealers in aquarium supplies. A few lizards, polliwogs, and gold- 
fish are almost their only stock in trade at this season, with perhaps a fine show of green moss in bunches, picked in the woods, which "looks pretty" under water. "But I want some plants, snails, water-beetles, and crawfish," I said to such a dealer recently. "Oh, you can't get anything of that kind now, you know," he replied. "They're all dead or froze up. We'll have plenty of 'em in the spring."

Nevertheless, the film of ice over the pond or stream need be no barrier to the winter naturalist. The mud at the borders of the bank holds a lively harvest, and does not seem to care a snap for the seasons. One good scoop with a strong net will sometimes bring up a veritable summer haul of specimens-fish, frogs, water-beetles, lizards, water-boatmen, dragon larvæ, and occasionally a dainty case of the caddis, resembling one of the group which I have here picked from
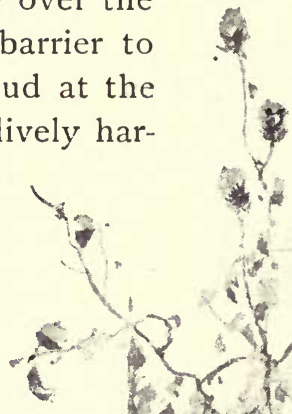
yonder pool and laid upon the snow. I have a number of these cases before me as I write, and they are really beautiful works of insect art. As a rule, each species of caddis is true to some particular whim in building or in the choice of materials for its domicile. Here are two individuals that seem to have taken a hint from the bag-worm, and think there is nothing to compare with sticks and leaves. Their cases are about an inch and a half long. Another has carefully selected tubular pieces of floating grass stems or straws, enlarging the tube, as its growth requires by slitting up the side and fitting in

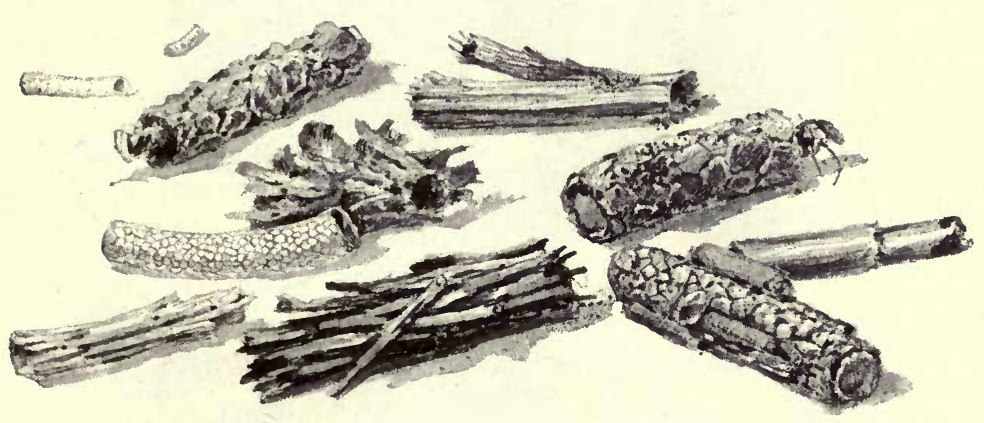

a strip of new material; afterwards, perhaps, decorating the exterior with a few stray chips or pebbles.

But the most interesting of all are the dwellings of the stone-builders, actual mosaic tubes of carefullyselected pebbles, all joined edge to edge, and neatly closed at the rear opening by a nicely-fitted pebble of larger size. And one there is, the glassy abode of the smaller caddis, a perfect marvel of mosaic art. A small, slightly curved tube about three-quarters of an inch in length (shown directly above the stick case in 
the illustration), the crystal palace of the most exquisite and gifted artist among all the caddis fraternity. The tube is composed of minute, glassy, flat pebbles, joined:

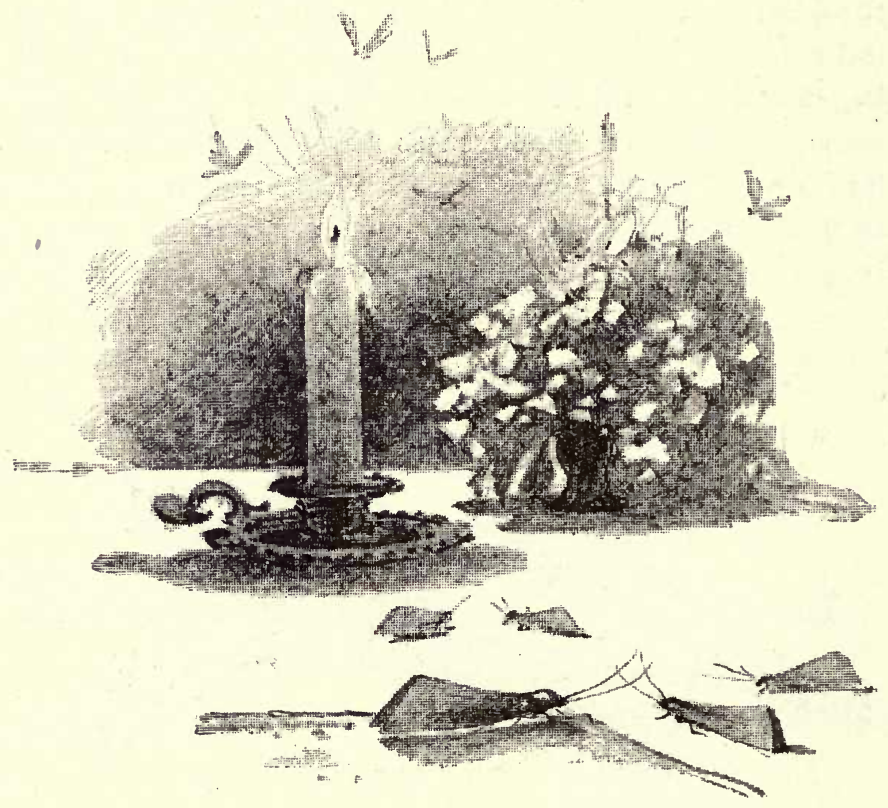

edge to edge with the most skilful exactness, and is often so transparent that when wet the form of the dweller may be seen through its wall. Here may the human worker in stained-glass find his matchless model. An artist, too, that accomplishes his task without resort to metal frame or solder, the edges of his glass being joined by some insoluble cement of which he holds the secret.

The art of the bag-worm appears almost commonplace. 
by the side of this rare product. With its ready reserve of silk it is an easy matter for the bag-worm to weave a mere pouch, while the further attachment of the sticks and leaves is mere pastime; but what shall we say of the intelligence that gleans among the pebbles beneath the water, constructing a mosaic tube about its body, even in the current of the stream? This is what the caddis larva does. As in the bag-worm, this case of the caddis serves as a protection against its enemies; and while the basket-carriers in the trees are keeping an eye out for the birds, dodging into their case and literally "pulling the hole in after them," or drawing it close against a twig, on the approach of the enemy, the caddis is continually on the alert for hungry prowling fish that know a tidbit when they see it. The number of empty shells to be found in every caddis pool would seem to show that the fish know all about caddis. I was once greatly amused at the sly arts of a tiny rockfish in my aquarium that soon left nothing but empty shells to show for my caddis and my snails. His plan of operation was to steal up from behind as the unsuspecting victim was regaling itself in the water, and with a sudden dash grasp the head of his prey, when, after a vigorous shake and determined grip, the shell was released, and the victorious fish retired to its corner among the pondweed to think which of the two yonder - snail or caddis-it would rather have for supper.

I have said that few of us ever see the caddis in its home. And yet he is an old acquaintance with most of us. There are few summer evenings when he does not make himself perfectly at home around our "evening lamp" in the country, that brown, circling, moth-like insect, with steep-sloping wings, and such a powerfully 
strong odor, being in truth the perfected product of these tube-cases beneath the water.

A collection of caddis cases makes a very interesting exhibit. I have shown a group of six foreign species, but it is possible that any one of them may yet reward our search in our native pools. I have found three specimens that closely resemble some of them.

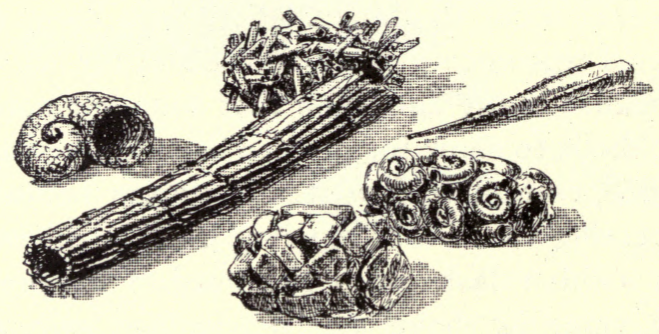




\section{THE WHIRLIGIG WATER-BEETLE}

\section{March $2 d$}

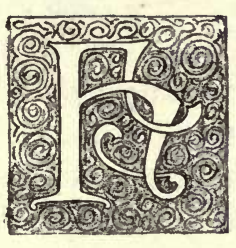

IBERNATION is the law among the insects which survive the winter; but, there is a notable exception, they are not all asleep. Indeed, if I were asked to name the sprightliest bit of life to be found in all the winter landscape, I think my choice would have to be, not the mouse, nor chickadee, nor even the hare, but a little dweller in the pond or brook, one of the lively brood that we brought up in our net last week as we dredged in the mud for our aquariumthe little black whirligig-beetle known as the Gyrinus. Had we approached the bank more cautiously, we need only have skimmed the surface of the water to have captured a whole family of them.

It is apparently summer all the year round to the Gyrinus. They take little account of the changes in the calendar, and I fancy their idea of the seasons must be summed up simply as "green summer" and "white summer." The caterpillars and thaw butterflies, grasshoppers, and other insects which we find in the freezing winter days are numb and stiff with the cold, but there is no numbness nor stiffness known to these little black bodies that whirl in their maze of ripples in many an opening in the ice along the edge of the pond. 


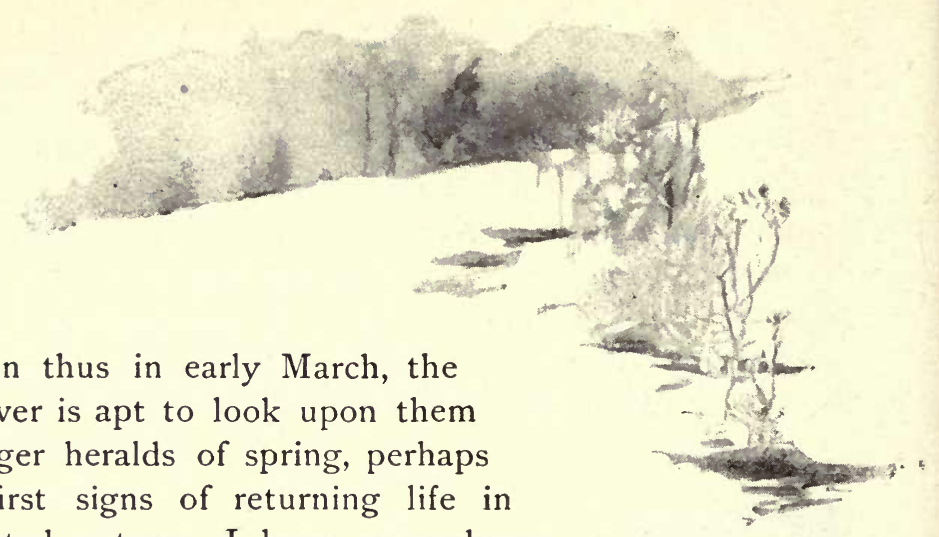

Seen thus in early March, the observer is apt to look upon them as eager heralds of spring, perhaps the first signs of returning life in animated nature. I have somewhere read of the early appearance of the Gyrinus being instanced as a sign of an advanced spring, but the inference is gratuitous. We may look for him almost any moderate winter's day; certainly, at least, any genial day that could tempt us out-of-doors has seen him there before us. Their whirling swarms have surprised many a winter walker-even Thoreau, who has

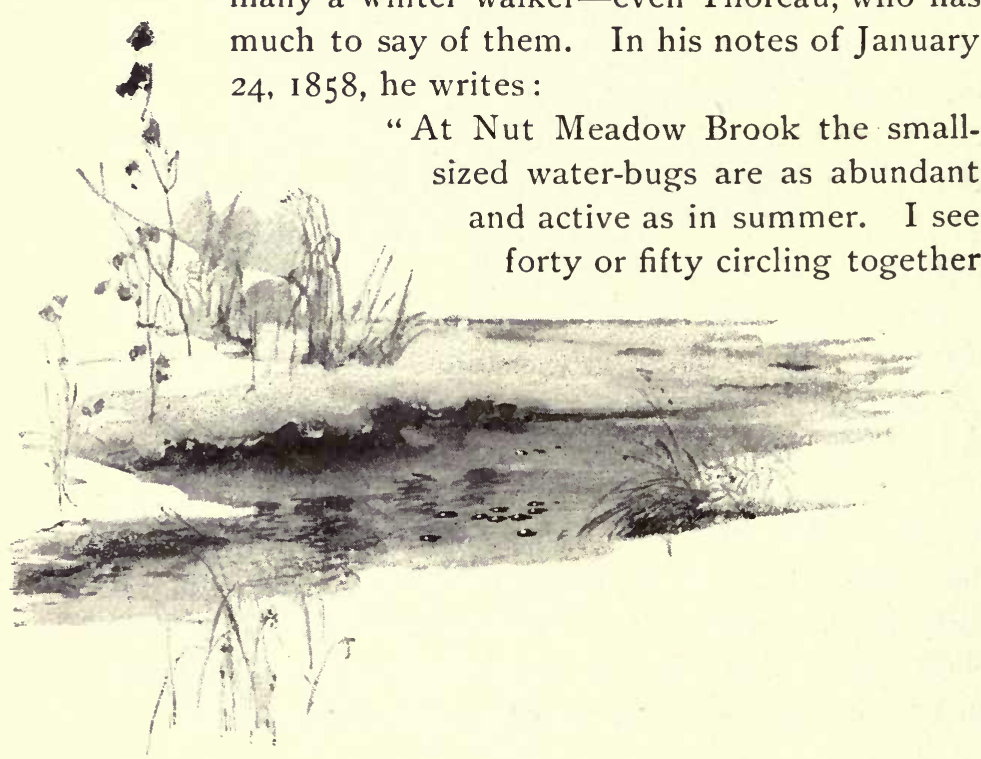


in the smooth and sunny bays all along the brook. This is something new to me. They seem to be more ready than usual to dive to the bottom when disturbed. At night, of course, they dive to the bottom and bury themselves, and if in the morning they perceive no curtain of ice drawn over their sky, and the pleasant weather continues, they gladly rise again and resume their gyrations. I think I never noticed them more numerous. What a funny way they have of going to bed! They do not take a light and go up-stairs; they go below. Suddenly it is heels up and heads down, and they go to their muddy bed, and let the unresting stream flow over them in their dreams.

"Sometimes they seem to have a little difficulty in making the plunge. Maybe they are too dry to slip under. Suppose you were to trace the course of one for a day, what kind of a figure would it make? I see one chasing a mote, and the wave the creature makes always causes the mote to float away from it. I would like to know what it is they communicate to one another; they, who appear to value each other's society so much. How many water-bugs make a quorum? Where did they get their backs polished so?"

It is true, as Thoreau says, that they do not take a candle and go up-stairs to bed as some bigger folks do; but if he supposed that they went to bed without a light, he little knew the bug he describes, for they carry a brilliant lantern that goes gleaming like a silver streak down into the depths; for when those little "heels go up" a bubble of air is caught beneath the tips of the black wing-covers, and a diamond of pure sunlight accompanies their course down among the weeds until they once more ascend to the surface. Indeed, this 


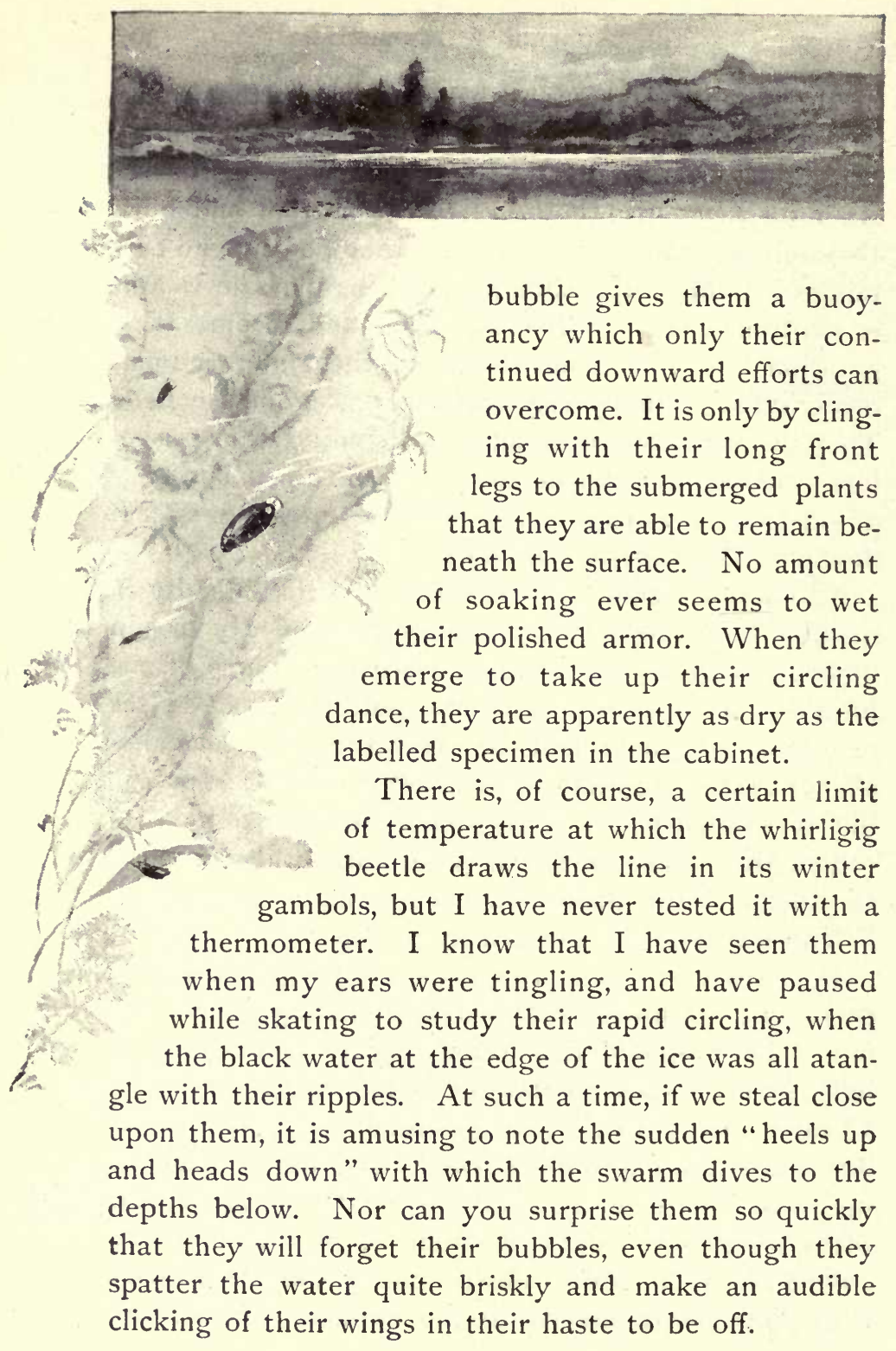


These insects are not "bugs," as Thoreau inadvertently implies, but true beetles, and, moreover, beetles endowed with resources far above the average of their kind. Most beetles are content with existence in one element, but the Gyrinus is equally at home in air or water as the whim takes him. His hard polished back conceals two gauzy wings which can be spread in a twinkling, giving him all the agility of a fly upon the wing, and which occasionally bring him in among the buzzing throng around "our evening lamp," while his peculiar equipment in the paddle-shaped feet of the two nether pairs of legs gives him the lead in the race among all the insect swimmers under the water. This remarkable adaptability to a dual mode of existence is further strikingly emphasized in the peculiar endowment of vision. The whirligig-beetle has two distinct sets of eyes; one large pair of goggles beneath its head, with which it commands a continual view of its lacustrine haunts while floating or circling on the surface of the water; and another pair on the lookout above-how keenly alert we all know, who have seen the whirling swarm dive with their bubbles at our cautious approach.

Indeed, were I to search my insect cabinet for the most appropriate emblem with which to close my pages, I could scarce find a happier exponent of "Sharp Eyes" all around the calendar than in our wide-awake, perennial little Gyrinus.

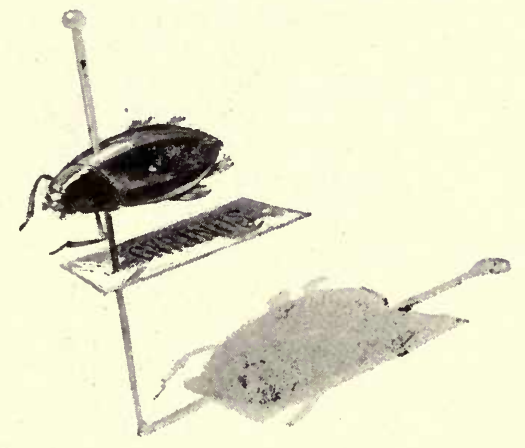





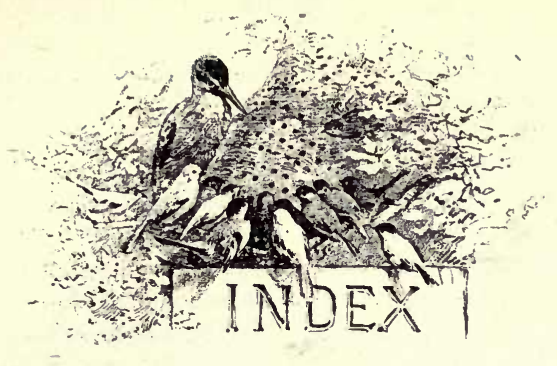

Аввотт, C. C., quoted. Claytonias, 23. Autumnal streaked warbler, 2 13.

Acorn, germinating, 29.

Azalea (A. viscosa), 57 .

Agrimony (Agrimonia eupatoria), hooked seeds of, 154 .

Ailantus moth (Samia Cynthia) cocoon, 256.

Alder, leaf-rolling beetle of, I04-Io6.

Ampelopsis. See Virginia-creeper.

Anemone ( $A$. nemorosa), wind-flower, 21.

Angle-wing butterflies, $27 \mathrm{I}$.

Animals in motion, photographs of, $25 \mathrm{I}$. Antiopa butterfly. See Butterfly.

Ants, II9.

Aphides, or plant-lice, II9.

Aphis-galls, 60.

Aphis-lion (Hemorobida), II9.

Apples, May, of Azalea riscosa and Podophyllum peltatum, 57 ; false, of $A$ ndromeda, 6o; various so-called apples - cedar, custard, ground, love, oak, pine, prairie, of Sodom, 57.

Apple-tree moth, egg-band of, 258.

April and April birds, 38.

Aquarium supplies, 299.

Arbutus, trailing (Epigea repens), 22.

Ash, seeds of, 2 I6, 284.

Asters, seeds of, I73; flowers of, at night, I26; various, 227.

Audubon, on the "drum" of the grouse, 42.

Autumn:-Calendar, 177-243; flowers of, 202 ; piping toads, frogs, and salamanders; bird-notes, 192.

BACHELoR's-BUtTons, or Blue-bottles (Centaurea), $\mathbf{1 2 6 .}$

"Bagpipe" of the toad, 54.

Bag-worm. See Basket-carriers.

Balsams, garden, leaves at night, r26. See Jewel-weed.

Baltimore oriole (Icterus Baltimore), 224.

Basella flower, pollen of, II 5.

Basket-carrying caterpillars (Psyche), 292-298 ; Southern superstition connected with, 298.

Basswood. See Linden.

Bean, various leaves of, at night, 126; bean family, clinging seeds of, I53; wildbean, underground pods of, 165-167.

Bed straw.-Cleavers, I54.

Bee bread, pollen ingredients of : queer fruits from the bee's basket, I I2-II6.

Beech-nuts, sprouting of, 29.

Bee, honey ; abroad in March, I-3, I9 ; its dual motives in visiting flowers, I I 2 ; entrapped by milk-weed blossom, II6; nest of solitary, 74; leaf-cutting, II 9.

Beeswax, I 12.

Beetles:- Bombardier (Brachinus fumans), 73; Brazilian, 99; clytus, music of, I42 ; crusader, II 8 ; eye-spotted spring (Elater oculatus), vi; fiddling, 140; girdler (Oncideres cingulatus), 260; golden cassida (Cassida auri- 
chalcea), 99; "green dandy" of the dog-bane (Eumolpus auratus), IO2, I I9; identification of beetles, 79 ; ladybirds (Coccinelli), I I9; leaf-rolling. weevils of hazel and alder (Attelabus), 104-106 ; rove (Staphylinus), 77 ; useful tail of, 78, I I9; Saperda, music of, I42, I43; other musical species, 33, 138-142; scavenger, 78 ; snapping (Eluter), vi, II9; stag (Lucanus), iv, 239 ; Thoreau on, 306 ; water (Gyrinus), 305; remarkable double vision of, 309 ; "going to bed" with a bubble, 307.

“Beggar-lice." See Hound'stongue.

"Beggar-ticks" (Desmodium), I50-155, I70, 284; night attitude of leaves, 125 ; flowers and seeds of, 153 .

Benzoin. See Spice-bush.

Bidens, I50-I 54 .

Bind-weed (Calystegea sepium), gold beetle of, 100.

Birch, white, bark in nest, 220 ; sugary sap of, enticing bees, 2 ; curious seed catkins of, 286-288; seed-scales on snow, 285-288 ; birch and ash associated, 217 ; leaf and Indian arrow-head, 217; broom gall of, 259 .

Bird entrapped by a burdock, I97.

Birds :-Of April, 38 ; in winter, food of, 280-284; of November, 212.

Bird's-nests, materials of, 219-225: vireo, 220; cherry-pits, buckwheat shells in, 225; hazel-nuts in, 223; deserted, used as winter resorts, 230.

Bird-songs, imitative of insect songs, I 28-I3I ; in words, 40.

Bitterweed. See Ragweed, Small.

Black and yellow warbler, 2 I 3.

Blackbird :-Grackles, $4 \mathrm{I}$; redwinged, song of, 40.

Black snake as a nest hunter, 230.

Black swallow-tail butterfly. See Butterfly.
Bloodroot (Sanguinaria Canadensis), 2 I. Bluebird, 39 ; song of, 40 ; in autumn, 2 I 2.

Blue-bottles (Centaurea cyanus), transformation of flowers at night, 126.

Blue lettuce (Mulgedium), seed of, 173 .

Blue mud-wasp (Pelopaus), I 56.

Blue swallow-tail. See Butterfly.

Bobolinks, migration of, 212.

Bombardier-beetle (Brachinus), 73.

Botany :- Teachers of, among butterflies, 8o-86; lesson from a squirrel, I7; practical, 93, I5I; in a cobweb, I 7 I.

Bower-building caterpillar, $\mathbf{I} 68$.

Brewer, the ornithologist, on the "drum" of the grouse, 42.

Bryant, W. C., quoted. Hepatica, 22; " painted-cup," 61,62 ; drum of the “partridge," 42 ; fringed gentian, 227 ; yellow violet, 20, $2 \mathrm{I}$; trailing arbutus, 22 ; birch leaves, 2 I 8.

Buckwheat shells in bird's-nest, 225.

Buds, opening, 48 ; various tints of, in landscape; leaf arrangement in; linden and tulip-tree, 49 ; hickory, horsechestnut, 50 ; winter, of dogwood, 49 , 50.

Bumblebee, a mock, 179 .

Bunting, white, 213; nest materials of, 224.

Burdock (Lappa major), dew on leaf, I 22; seed of, I55; a trap for birds, I97.

Burr-grass (Cenchrus), I 55, 274.

Burroughs, John, quoted. "A April," 38 ; Robin, 39 ; drum of the grouse, 42 ; fringed gentian, 227; peeping frogs, 6 ; early spring flowers, 22, 23 ; ragweed, 280; weeds, I50; whistling salamander, I94.

Burrs, I 20, I50-I55, I97.

Bush clover (Lespedeza), night attitude of leaves, $\mathbf{1} 25$.

Buttercup, seed of, 284. 
Butterflies:-Antiopa (Vanessa Anti$o p a), 34,270$ : rustling wing of, 32 ; hibernation of, 270 ; wing - music of, 30-33, I4I ; caterpillars of, 33: Archippus (Danais), 84 ; black swallowtail (Asterias), 80; caterpillar and chrysalis of, 82 ; blue swallow-tail (Troilus), curious-eyed caterpillar of, I32-I34 ; comma, 34, 84, 271 ; Hunter's, petal bower of, I68; red admiral (Pyrameis Atalanta), 34, 270; semicolon (Grapta interrogationis), 34, 84, 27 ; yellow (Philodice), 84 ; ichneumon parasites of, 200 ;-Butterflies as botany teachers, 80-86; tipsy, 27I; winter, 34, I84, 270; winter pets, 273.

Butterfly-net as a companion to a walk, II 7 .

Button-wood, leaf socket of, 45 .

CABbage, dew on leaf of, r22.

Caddis, larva of, 299-304; fine mosaic tenement of, 301 ; its water-proof cement, 302 ; enemies of, 303; caddis-fly, 303; foreign specimens, 304.

Calico-bush. See Mountain-laurel.

Calla (Calla Ethiopica), a relative of skunk-cabbage, 3 .

Camberwell beauty. See Butterfly (Anti$o p a)$.

Cape May warbler. See Warblers.

Cardinal-flower (Lobelia cardinalis), brilliancy of, 62 .

Carnivorous fly, I62, I79-182.

Carrot (Daucus carota), seed of wild, 284.

Cassia. See Partridge-pea.

Catchfly (Silene mutans) flowers at night, 126.

Caterpillars:-Apple-tree web or tent, 258; Vanessa Antiopa, 33; skins of, in bird's-nest, 221 : basket-carrying (Psyche ephemeraformis), 292-298; of black swallow-tail butterfly (Papilio Asterias), 82; of blue swallow-tail
(Papilio Troilus), 132; bower-builders, I68, I69; burrowing, 97 ; fungus growing upon a, I9I; ichneumon parasites of, 67-72, I99; oak (Dryocampa), 97 ; puss-moth, with whiplashes, I44; span-worm, II8.

Cat-tail (Typha latifolia), seed-down of, 173.

Cecropia (Platysamia), cocoon of, 253 ; moth, 256; parasites of, 71 .

Cedar-apple, 57 .

Centaury, 226.

Champignon. See Fairy-ring Fungus.

Chemical experiment with scouring-rush, III.

Cherry-pits in a bird's-nest, 225.

Chestnut-burr, fungus growing upon, 188 .

Chickadee and willow-cone gall, 208.

Chickaree, 276.

Chickweed, 226; blossoms under snow, $210,227$.

Chimney swift, nest materials of, 224 .

Chipping-sparrow, nest materials of, 224; nest of, as a winter nursery, 23I.

Chrysalis (Dryocampa) emerging from ground, 96; of Antiopa butterfly, 33; of blue swallow-tail, 134 ; of Hunter's butterfly, I69; of milk-weed butterfly (Archippus), 84; fungus growing upon, I90.

Cicada, or harvest-fly ("locust"), drum of, 33,138 ; cicada and "locust" distinguished, I39.

Cichory (Cichorium), seed of, 284; pollen of, $\mathrm{II}_{5}$.

Claytonia. See Spring Beauty.

Cleavers (Galium), clinging seeds of, $\mathrm{I}_{54}$.

Clematis (C.Virginiana), seed of, 172.

Clotbur seeds, I 55 .

Clover (Trifolium), various night attitudes of leaves, I25, I26; sprouting seeds of, 29.

Club mosses (Lycopodium), explosive spores of, I46-I49. 
Cobweb, botany lesson from, I7I; in dew, 124; in birds'-nests, $22 \mathrm{I}$.

Cockle-seeds, 155 .

Cocoons, Platysamia Cecropia and Prometheus, 253; winter harvest of, $\mathrm{Ce}$ cropia, Polyphemus and Prometheus, parasitic broods from, $67-72$; ailantus (Cynthia), 256; of bag-worm, 292; of tussock-moth in bird's-nest, 22I; cocoon clusters on grass-stems, 199.

Colt's-foot. See Wild-ginger.

Comma butterfly. See Butterfly.

Compositæ, winged seeds of, I 7 I ; clinging barbed seeds of, 153 .

Cone-gall of willow, 207.

Cones, 207; pine (see Pine-cones), spurious, 207.

Convolvulus. See Morning - glory and Bind-weed.

Coon-hair in bird's-nest, 224 .

Coral-winged locust (CEdipoda corallina), 34.

Corn in a bird's-nest, 232.

Cotyledons in seeds, design of, 29.

Cow-bird, 230.

Cranesbill (Geranium maculatum), flowers at night, I26.

Creeping mallow (Malva rotundifolia), 226.

Cricket, white tree (Ecanthus niveus), I I9.

Crow in autumn, 212.

Cuckoo, yellow-billed, nest material of, 224.

Cucumber, star (Sicyos angulatus), pollen of, II 5 .

Custard-apple. See Papaw.

DAISIES, 226.

Dandelion, $38,202,226$; in autumn and winter, 227; feathered seed-balls of, I70; seed, I7I ; seeds in bird's-nest, 221; dwarf (Krigia), beautiful seed of, 172 .
Darwin, allusion to, 282.

Deer-hair in bird's-nest, 224.

Deer-mouse (Hesperomy's leucopus), nest of, 248.

Desmodium, various species, flowers, and clinging seeds of, 153 .

“Devil's coach-horse," 77 .

Dew, singular freaks of, on various plants, $122,124$.

Dicentra (Cucullaria), $2 \mathrm{I}$.

Dog-bane (Apocynum androsamifoli$u \mathrm{~m})$ and milk-weed, resemblance between, 85; brilliant beetle of, IO2, II 9 .

Dog-wood, flowering (Cornus florida), 49 ; expansion of bud to bloom, 50; the "corn signal," 39.

Dog-wood, poison. See Sumach $(R$. venenata.)

Draba. See Whitlow-grass.

Dutchman's-breeches (Dicentra cucullaria), 2 I.

EGGS of apple-tree moth, 258.

Elder, poison. See Sumach (R. venenata.)

Elm, seed of, 284.

Emerson, R. W., quoted. April's bird, 39 ; weeds, 280 ; Nature study, 246.

Enchanter's nightshade (Circaa luteti$a n a)$, pollen of, $\mathrm{II}_{4}$; clinging seeds. of, I54.

English plantain. See Plantain.

Equisetum, I07-III. See Scouringrush.

Evening primrose (Enothera biennis), winter leaf rosettes of, 240, 24I; pollen of, II4; opening of ; daylight moth tenant of, 135 .

Everlasting, dwarf (Antennaria plantaginifolia), 21, 22 ; Gnaphalium, caterpillar bower of, I68.

Eye, the seeing, 176 .

"FAIRY-RING" mushroom, I77; snow circles, 269. 
False winter-green. See Polygala.

Fennel-worm. See Butterfly (Asterias).

Field-mouse, tracks of, in snow, 248 ; wintering in a bird's-nest, 232.

Finch, purple, nest materials of, 224 .

Fire-weed (Epilobium angustifolium), winter rosettes of, $24 \mathrm{I}$.

Fire-works from club-mosses in the woods, I49.

Fish-crow as a nest-liunter, 230.

Flagg, Wilson, quoted. "Drum" of grouse, 42 ; vireo, $22 \mathrm{I}$.

Flicker, or golden-winged woodpecker, 40.

Flowering dog-wood. See Dog-wood.

Flowering winter-green, or Fringed polygala, 63 .

Flowerless plants (Acrogens), type of, 107.

Flowers, earliest, I-3, I9-24; underground, of polygala, 63,64 , and wildbean, I65; of autumn, 202; flowers which are not flowers--painted-cup, 62 ; dog-wood, 50; flowers without petals never opening (Cleistogamic), 205; variots, at night, ז20-I28. See Wild Flowers.

Fly, a talking, I62-I64; blue-bottle, in bird's-nest, 22I ; carnivorous ( $A$ silus), I64-I79; mimic lumblebee (Laphria), I79-182; various, in sweep-net, II9.

Fly-catcher, great-crested, snake-skin nest of, 224.

Flying seeds, I7O-I74.

Fox-hair in bird's-nest, 224.

Fox-sparrow (Passerella iliaca), 2 I3.

Fragrant sumach (Rhus aromatica), 90, 94.

Fries, the fungologist, on puff-ball, I77, I 87.

Fringed gentian (G. Crinita), flowers at night, I26; Bryant's allusion to, 227.

Fringed polygala ( $P$. paucifolia) 63 .

Frog music, 52, 53 ; European, 6; Southcrn, 55 .
Frogs, clucking, 52; Savannah cricket (Acris crepitans), 8, so; peeping ( $H_{y} y$ lodes Pickeringi),6-12; song of, 8; in autumn, 9, I94; tree, 9; wood, 52, I94; toy decoy ("locust") for mimicry of, 52 ; mimicry of song, 9, 52, I94.

Frost-weed (Helianthemum), 2 Io.

Fruit, an underground, 165-167.

Fungus:-Cedar-apple, 57; fairy ring, I77; growing on insects, I9O, I9I ; various species of, I87-I9I; myriad spores of, $187 ;$ method of vegetation, I77.

GALINSOGA, beautiful seed of, I72.

Galls :-Aphis, 60 ; cone, of willow, 207; rose, of willow, 209; of golden-rod, 257; oak-appie, 57; various, 208, 257; witch-brooms, 259 (see also Mayapple, $5^{8}$; and false May-apple, 60.)

Garlic flower, pollen of, II5.

Gentian, fringed (Gentiana crinita), I26, 227 ; closed (G. Andrewsii), 228.

Geranium, wild, or Cranesbill, I26.

Gerarde and his "rose-willow," 209.

Germination :-Maple, 4, 5, 25-29; oak, clover, and beech, 25-29.

Ginger, wild (Asarum Canadensis), 2 I.

Ginseng, dwarf (A ralia trifolia), 65 .

Girdler-beetle (Oncideres), 260.

Gnat-catcher, blue-gray, nest materials of, 224.

Gnats in sweep-net, II 9.

Golden-beetle (Cassida aurichalcea), 99.

Golden-crested thrush. See Oven-birci.

Golden-crested wren, nest materials of, 224.

Golden-rod (Solidago), 202, 226; bulbous, gall of, 257 ; musical beetles of, I 42 ; seeds of, I73.

Goose-grass. See Cleavers.

Gossamers and dew, I24.

Grackles, 4I.

Grass, blades of, marking on snow, 268. Grasshopper :- Meadow (Orchelinum. 
iulgare), song of, 129,138 ; a bird-mimic of song. I28-I3I; cone-head (Conocephalus ensiger), song of, 138; Grasshopper music, 33; "Grasshopper," cicada, and "locust" distinguished, I 39; Grasshoppers captured in sweep-net, II8; parasites of, Irg.

Grasshopper-lark (Alauda trivialis), 128.

Grass-seed, extraordinary, 155 .

Gray, Dr. Asa, quoted. “"May-apples,” 59; ragweed, 44; germinating seeds, 27.

Great-crested fly-catcher, snake-skin nest of, 223.

Green dandy Beetle (Eumolpus auratus), ro8, II9.

Ground-apples, 57.

Ground-nut (Aralia trifolia), $65 ;$ Apios tuberosa, night attitude of leaves, I26.

Ground-pine. See Club-moss.

Groundsel shrub (Baccharis halmifolia), beautiful seed-tuft of, I74.

Grouse, ruffed, "drum" of, $4 \mathrm{I}$; theories of the mysterious sound from various authorities, 42 ; snow-shoes of, 265 ; snow burrows of, 267 .

HAIR-BIRD. See Chipping-sparrow.

Hare, footprints of, in snow, 250.

Harvest-fly, or Cicada, 33, 138 .

Hay-fever and ragweed pollen, 280.

Hazel, leaf-roller of (Attelabus), I04; witch, see Witch-hazel.

Hazel-nuts in a bird's-nest, 233.

Hedgehog - grass (Cenchrus), burr-seed of, $155,284$.

Hepatica. See Liverwort.

Hibernation among insects, 305.

Hickory, opening buds of, 50; beetlepruner of, 260.

"Highhole" woodpecker. See Flicker.

Hog peanut (Amphicarpea), leaves of, at night, 126; underground flowers and pods of, 165-167.
Hogweed. See Ragweed, Small.

Holmes, O. W., quoted, xxii.

Honeysuckle, wild (Azalea viscosa), 58.

Hood, Thomas, quoted, 219.

Hornet's-nest fragments in bird's-nest, $22 \mathrm{r}$.

Horse-chestnut :- Buds of, 48 , 50; remarkable leaf-scar of, 263.

Horse-hair in birds'-nests, 224.

Horse - tail (Equisetum), beautiful dew decoration of, 122. See also Scouringrush.

Hound'stongue (Cynoglossum Morisoni), " beggar-lice," I54.

Human inventions and their prehistoric models, 239.

Humblebee, "honey-bags and red hips" of, $\mathrm{I}$ i 2 .

Humming-bird, nest materials of, 224 .

Hylodes. See Frogs, Peeping.

ICE conservatory, 228.

Ichneumon flies :-A remarkable woodboring (Thalessa lunator), 234-239; construction and object of drill; the victim of the ichneumon, 238; " wasps" from caterpillar cocoons, 68$72,199$.

Indian paddle and ash seed, 216.

Indian turnip (Psoralea esculenta), 57.

Insects :-Entrapped by milk-weed blossom, I16; for aquarium, 300 ; gall-producing, $57,60,257-259$; in the grass, 77, II7; harvest of sweep-net, II 7I 20 ; hibernation of, 305 ; music of, 30 , 33, 34, 133 ; imitated by birds, 128r3 r of winter, $34,234,270,289,292$, 299, 305; under stones, 74 ; wood-borers, 34, 234-239;-Insect magicians, 208, 257; parasites on, 67-72, I I9, I45199. See also Beetles, Butterflies, Caterpillars, Chrysalis, Cocoons, Moths.

Iron-weed (Veronia), seeds of, 173.

Ivy, "five-leaved." See Virginia-creeper. 
Ivy, poison, or " three - leaved." Sumach ( $R$. toxicodendron).

JAYS as nest-hunters, 230 .

Jewel-weed (Impatiens), night attitude and beautiful dewy revelation of, 124 .

June-berry or Shad-blow (Amelanchier Canadensis), 49.

KENTUCKY warbler, nest material of, 224.

Kinglet, ruby-crowned (Regulus calendula), 2 I 5

Kirby, the naturalist, quoted, I 28

LACE in bird's-nest, 222.

Lace-wing fly (Chry'sopa Oculata), in8.

Lady-birds (Coccinella), I19.

Lark, meadow, 40.

Laurel (Kalmia latifolia), jumping stamens and pollen of, II4.

Leaf-cutting bee, I I9.

Leaf - hoppers (Helochara) caught in sweep-net, I 18 .

Leaf-roller of the hazel and the alder, 104-106; the process described, I05.

Leaf-rosettes under snow, 240-243.

Leaves masquerading as flowers, 50-62; night attitudes of, 123-127.

Leguminous plants classified by butterfly, 84 .

Lettuce, wild. See Wild Lettuce.

Linden ( Tilia Americana) opening buds of, 49.

Liverwort (Hepatica triloba), 22-24, 227; Bryant on, 22, 23 ; under snow, 24.

Lizard. See Salamander.

Locust and grasshopper, 34 ; the right and wrong of "locust," 139; coralwinged (CEdipoda corallina), 34, เ 39 ; green, 35 ; " "fiddling" of, 33, I39 (see Cicada);-“"Locust," toy, 52.

Locust (Robinia Pseudacacia), night attitudes of leaves, 96 .
Love-apples, 57.

Lowell, J. R., quoted, on opening buds, 48 ; dandelion, 38,227 , spring blackbirds, $4 \mathrm{I}$.

Lupines, various night attitudes of leaves, 126

Lycopodium, club-moss spores, inflam. mable nature of, 146-149.

McCooK, A. G., quoted, 298.

Magnifying-glass, pocket, 117 .

Mallow, creeping (Malva rotundifolia), 226.

Mandrake (Podophyllum peltatum), $5^{8}$. 59.

Maple :-Buds of, 48, caterpillars of, 98; silver, blossoms of, 22, sugar, and bees, 2 ;-maple-seed revels, 4 , sprouting samaras, 5, masquerading seeds, 25-28

Marigold, night aspect of flowers, I26.

Mason-wasps. See Wasp, Mud-dauber, and Vase-maker.

May-apples, 57; of Azalea viscosa, 58; of Podophyllum peltatum, 58, 59; Dr. Gray's allusion to, 59 ; false May - ap. ples, 58.

May-flower. See Trailing Arbutus.

May-weed (Maruta), seed of, 284.

Meadow-lark, 40.

Meadow-lily, pollen of, I I4.

Melilot clover, night aspect of leaves, I26.

Melon flower, explosive pollen of, II5.

Microscope, pocket, II7; interesting specimens for; Equisetum spores, I08; Equisetum skeleton, III; polien, II4.

Midnight, plants by, I2I-127.

Milk-weed (Asclepias cornuti) :-Seed of, I72, 284; blossom of, entrapping insects, II6; pompons made from seeds, I74; stalk fibres used in birds'-nests, 220; family, classified by butterfly, 85 : butterfly, see Butterfly (Archippus). 
Mocking-thrush. See Thrush.

Morning-glory, gold beetles on, ror.

Mosses, club. See Club Mosses.

Moth, feather-winged, II9; Bull's-eye (Saturnia Io), xvi; evening primrose, I35; rosy, 98; sack - bearer (Psyche), 298 (see Apple-tree Moth, Cecropia, Polyphemus, Prometheus, Dryocampa, 96 ; also Chrysalis and Cocoon).

Mountain-laurel (Kalmia latifolia), jumping stamens and pollen of, II4.

Mourning cloak. See Butterfly (Anti$o p a)$.

Mouse, field; nest of, 74; tracks of, in snow, 248; winter nursery of, in a bird's-nest, 232 ; white-footed or deer-

' mouse (Leucopus), 247.

Mullein (Verbascum thapsus) flowers at night, I26; Moth mullein $(V$. blattaria), winter rosettes of, $24 \mathrm{I}$.

Mushroom, fairy-ring, I77; various, 187I9I.

Music of insects, $30,33,34,128-131$, I38.

Musk flower, pollen of, II 5.

Muybridge, instantaneous photographs by, $25 \mathrm{I}$.

Nasturtium (Tropaolum), night attitude of, and dewy sheen, I22.

Nests and nest-building. See Birds'nests.

Nettle family distinguished by butterfly, 84 .

Nettle-tree (Celtis), sugar-berry gall on, 259.

Newspaper fragments in bird's-nest, 221 . 222.

New Zealand caterpillar fungus, I9I.

Night, plants by, I 21-127.

Night-flowering catchfly, 126.

Nightshade, enchanter's (Circaa lutetiana), pollen of, II4; clinging seeds of, 154 .
November birds, 2 I 2.

November wild flowers, 2 I0, 226.

OAK:-Buds of, 48 ; clinging leaves, 45 : fungus growing upon, I89; acorn sprouting, 29; caterpillar of (Dryocampa), 97.

Oak, poison. See Sumach $(R$. toxicoden dron).

Oriole, Baltimore, nest ingredients of,224.

Oven-bird, nest materials of, 224.

Owls, 230.

Oyster - plant ( Tragopogon porrifolius), beautiful seed of, I 72 .

PaInTED-Cup (Castilleia coccinea), 6r.

Papaw (Asimina triloba), 57.

Parasites, insect, 67-72, II9, I45, I99.

Partridge. See Grouse, Ruffed.

Partridge-pea (Cassia chamacrista), night transformation of, $\mathbf{1 2 5}$.

Pea blossoms at night, I26.

Peanut, young plant in kernel, 28; hog, see Hog-peanut.

Peepers. See Frog.

Peppergrass (Lepidium Virginicum), rosettes of in winter, 240-242.

Phœbe-bird, 40.

Photographs, instantaneous, of Muybridge, $25 \mathrm{I}$.

Phillotaxy, 242.

Pickering's frog. See Frog.

Pigeon Tremex (Tremex columba), a victim to the drilling ichneumon fly, 238 .

Pignut. See Ground-nut Ginseng.

Pig - weed (Chenopodium album), seed packet of, 284; (Amarantus hybridus), night attitude of leaves, 126.

Pineapple, 57.

Pine, pollen of, II 5 ; explosive properties of pollen, I49.

Pine-cones :-Clicking of, in March, I3 ; gray squirrel burrowing for, 278 ; hygrometric properties of, I5; queer 
motions of, I4; spiral arrangement of scales in, I7; the squirrel unlocking cone, 17 ; seed of pine, $217,284$.

Pith in bird's-nest, 221.

"Pitchforks," I5I. See Beggar-ticks. Plantain (Plantago major), dew on, I22; English ( $P$. lanceolata), rosettes of, in winter, 24I, 242.

Plants, classified by-butterflies, $80-86$; dew on, I2 I-I24; night aspect or sleep of, I24-127.

Pod, underground, of the wild bean, I65167.

Poison-dogwood, poison-elder, poisonsumach. See Sumach (R. venenata). Poison-ivy, poison-oak. See Sumach ( $R$. toxicodendron).

Poisonous “May-apples," 60.

Pollen, various forms of, II2-II6; of milk-weed, insects encumbered by, I 16 ; of slunk-cabbage, and bees, 2 ; explosive, of pine, I49.

Polygala, fringed (Polygala paucifolia), underground flowers of, 63,64 .

Polyphemus moth (Telea Polyphemus), cocoons and parasites of, 67-72.

Pomme-Blanche, or prairie-apple, 57.

Poplar-seeds, cotton of, I 70.

Poppy (Papaver), night-closing of flowers, 127.

Prairie-apple, 57.

Prairie-hen, foot of, 267.

Prairie-warbler, nest materials of, 224.

Primrose. See Evening Primrose.

Prometheus moth, cocoon of, 255.

Puff-ball fungus, I 77, I87.

Purple finch, nest materials of, 224.

Purslane, or Pusley (Portulaca oleracea), night attitude of leaves, 127 .

Puss-moth caterpillar (Cerura borealis), singular features of, I44.

Rabbit. See Hare.

Ragweed, great (Ambrosia trifida), stat- ure and pith of, 43 ; pollen of, as a cause of hay-fever, 280 ; seed of, 284 ; seeds of, as food for birds, 280 ; small (A. artimisifolia), 44.

IRed-eyed vireo, remarkable nest of, $22 \mathrm{I}$.

Redwing blackbird, 40.

Reed mace. See Cat-tail.

Rib-grass plantain ( $P$. lanceolata), 24I, 242.

Riley, C. V., on the bag-worm, 296.

Robin, 38, 224.

Rock flower (Saxifraga Virginiensis), 2I, 22.

Roman wormwood. See Ragweed,Small.

Rosettes of leaves in winter; evening primrose, thistle, peppergrass, plantain, 240-243.

Rose, wild, 202 ; at night, I 26.

"Rose willow," 209.

Rove beetles. See Beetles.

Ruby-crowned kinglet, 2 I 5 .

Rue Anemone (Thalictrum anemonoides), $2 \mathrm{I}$.

Ruffed grouse. See Grouse.

SAlamander, 74 ; a whistling, 'I94.

Salsify, or oyster-plant, I 72.

Sanicle, clinging seeds of, $\mathrm{r}_{54}$.

Sassafras, eyed caterpillar of, 132 .

Savannah cricket. See Frog.

Saxifrage, early. See Rock Flower.

Scarlet painted-cup, 6I.

Scotch pinè, clicking cones of, I 3 .

Scouring-rush (Equisetum hyemale), 107III, I22 ; use by early settlers, IO7IIO; antiquity of, I22; fruit and squirming spores of, Io8 stone skeleton of, disclosed by a chemical experiment, II I.

Sea-groundsel (Baccharis), I 74.

Sedge, seed of, 284.

Seeds:-Curious shapes of, illustrated. 282 ; dissemination of, I5O; agrimony, I54; ash, 2I6; aster, I73; bedstraw, 
I50 ; birch, 288 ; blue lettuce (Mulge dium), I73; burdock, I55; burdockseeds and birds, 197 ; burrs and stickseed, I50-I55, I97; cat-tail (7'ypha), I73 ; clematis, 172 ; enchanter's nightshade (Circcea), I54; galinsoga, I 72 ; galium, I 50 ; golden-rod, I73 ; goosegrass (Chenopodium), 154 ; groundseltree (Baccharis), I 74; hedgehog grass, I55, 284 ; hound'stongue, 154 ; maple, 4, 5, 25-27; milk-weed, I 72-1 74; pine, 13-18; poison-ivy, 93; salsify, or oyster-plant, I 72 ; sanicle, I 54 ; shooting, 203, 205 ; thistle, I 7 I-I 74 ; tuliptree, 274, 284; weed-seeds, I80-184; wild lettuce, I 73; willow, I 70; winged, I70-I 74; witch-hazel, 203.

Seeds, germination of, 24-29; cotyledons, designs of, 29.

Semicolon butterfly. See Butterfly.

Service-berry. See Shad-blow.

Shad-blow (Amelanchier Canadensis), 49.

Shakespeare, quoted. "Pignut," 66; "red-hipped humblebee" and his " "honey-bags," II 2.

Shave grass. See Scouring-rush.

Shooting seeds, 203, 205.

Shrimp, fairy (Branchippus vernalis), 36 .

Silk-weed. See Milk-weed.

Silver maple. See Maple.

Skunk-cabbage (Symplocarpus fatidus), pioneer blossom of, 3, 19, 23, 24, 226, 227.

Sleep of plants, 124-127.

Smart-weed (Polygonum), seed of, 284.

Snake, black, as a nest hunter, 230.

Snake-head. See Turtle-head.

Snake-root, black. See Sanicle.

Snake-skins in vireo nest, 222; bird collector of, 223.

Snapping-beetle, great eye-spotted (Elateroculatus), vi, II9; under stone, 74.

Sneeze-weed (Helenium auiumnale), seed of, 284 .
Snow - bird, 213 ; snow - bunting (Junco hyemalis), 21 3 ; nest materials of, 224. Snow-burrowers :-Grouse, 267 ; squirrel, 276.

Snow :-Curions specks on, 285 ; stories in, 247; rings and other devices of wind-blown grasses in, 268; snowtracks of grouse, 264 ; of mice, 248 ; of rabbit. 250 .

Snow-fleas (Podura), 289.

Soldier-bugs in sweep-net, IIg.

Solitary vireo, nest materials of, 224.

Sorrel-sheep (Rumex acetosella), rosettes of, in winter, 240.

Sorrel, wood, (Oxalis), night aspect of leaves, 127.

Spanish needles, I $_{5} \mathrm{I}$.

Spanworm, I 8.

Sparrow:-Chipping, nest materials of, 224; winter tenant of nest, 23I ; fox, $2 \mathrm{i} 3$; song, 40, 212 ; yellow-winged, insect-like song of, I30.

Spice-bush caterpillar (Papilio Troilus), 132.

Spider prisoners in a wasp-net, $156,161$. Spiders, various, I I9, I6r.

Spider-web:-Botany lesson from a, I 7 I; in the dew, $\mathbf{1 2 4}$; in bird's-nest, 221.

Spores, squirming, of scouring-grass; inflammable, of club mosses; of Fungi, $177,187$.

Spring beauty (Claytonia Virginica), 21, 22, 23.

Spring calendar, $\mathrm{I}-86$.

Spring flowers, $\mathrm{I}-3,20-24$.

Spring foliage, tender tints of, 48,49 .

Squirrel:-As a bird's-nest hunter, 230; gray, as a snow-burrower; in winter, 276 ; red, a botany lesson from, 17 ; providence of, 278 .

Squirrel-cups. See Liverwort.

Stag-beetle (Lucanus), 2 29.

Star cucumber (Sicyos angulatus), pollen of, II 5 . 
Starling. See Blackbird, Red-winged.

Stick-seeds, I 50-155.

Stones, life under, 73.

Stony skeleton of the scouring-rush shown by a chemical experiment, IIO.

Sugar-berry tree (Celtis), gall of, 259.

Sugar-maple and early bees, 2.

Succory. See Cichory.

Sumach, fragrant (Rhus aromatica), 90, 94 ; poison, 89 ; distinguishing characters and identification of, 92-94; confounded with the harmless Virginiacreeper, 92-95; Rhus radicans, 9I; Rhus toxicodendron and its various disguises, 90-92; Rhus venenata, 90.

Summer calendar, 89-174.

Swallow-tail butterfly. See Butterfly.

Swamp-cabbage. See Skunk-cabbage.

Swamp pinks (Azalea viscosa), 57.

Sweep-net, curious insect harvest from, II 7-I 20.

Sivift, chimney, nest of, 224.

ThOMPSON, ERNEST, reference, 267.

Thoreau, H. D., quoted. Birds' - nests, $2: 9$; "drum" of the grouse, 42 ; entomology, 88 ; midnight, I2I ; poisonsumach, 90; squirrel and cone, 17; water-beetle, 306 .

Thistle (Cirsium lanceolatum), rosette of, in winter, 24I; feathered seed of, I $7 \mathrm{I}$.

Thistle-seed pompons, I 74 .

Thrasher, brown. See Thrush.

Three-leaved ivy. See Sumach (R. toxicodendron).

Thrush, migration of, 212 ; mocking or feruginous, or brown-thrasher, 39; golden-crowned (see oven-bird); robin, 38 ; song of, 39 ; nest materials of, 224 .

"Tick" seeds. I 50-I 55.

Toad (Bufo Americanus):-Song of ; dual tone of song, 54 ; analysis of the "bagpipe" drone; imitation of its song, 55 ; singular vocal technique, 55,56 ; decoying the : Japanese mimic whistle of song, 56 ; mitten of, in a bird's nest, 222; tree-toad (Hyla versicolor) :-Spring song of, 52 ; autumn song of, I92; mimetic decoration of, I93; Hylodes, 9 ; in autumn, I94.

Toad-flax (Linaria), purple and yellow, 226.

Tracks in snow, 247, 25.0, 265.

Trailing arbutus (Epigea repens), 20 ; in February, 22; Bryant on, 21.

Trap, a burdock, 197.

Tree-cricket (Ecanthus niveus), I I9.

Tree-toad. See Toad.

Tremex. See Pigeon Tremex.

Trowbridge, J. T., quoted. The partridge, $4 \mathrm{I}$.

Tulip-tree (Liriodendron tulipifera), opening buds of, 49 ; seed of, 216 , 284 ; seed shower from, 274.

Turtle-head (Chelone glabra), 227.

Twigs, among the winter, 257.

UMBEILLIFEROUS plants distinguished by butterfly, 84 .

Underground flowers, 63,167 .

VASE-MAKer wasp. See Wasp.

Violet, yellow (Viola rotundifolia), Bryant on, 20-22; blue (Viola cucullata), two sorts of flowers of, 205 ; cut-leaved variety of ; shooting seeds of, 206.

Vireo:-Red-eyed, $22 \mathrm{I}$; solitary, 224; white-eyed, 22I; winter tenants of nests, 232; nests and nest material of, analyzed, 212, 220.

Virginia-creeper (Ampleopsis quinquefolia) confounded with poison-sumach, 92, 93; distinguished from sumach, 92-95; many-leaved varieties of, 95 .

Virgin's-bower. See Clematis. 
WARBLERS :-Autumnal-streaked, black and yellow, Cape May, yellow redpoll, yellow-rumped, 21 3 ; Kentucky, prairie, yellow, worm-eating, nest materials of, 224.

Wasps :-Mud - dauber (Pelopaus), 74 ; nest and spider prisoners of, $156-161$; paralytic effect of sting on prey, 47, I60, I6I ; paper (refers here to Polistes), 74; vase-maker (Eumenes frater$n a), 46$; how to handle wasps without harm, 183; ichneumon wasps, 71, 72.

Water-beetle (Gyrinus). See Beetle.

Web caterpillars, 258.

Weeds :-In winter, 280; winter seeds of, food for birds, 280-284; worldwide travels of, I 50 .

Weevil, leaf-rolling of hazel. See Beetle.

White birch. See Birch.

White bunting, 213.

White-footed, or deer-mouse (Hesperomys leucopus), 248.

Whitlow-grass (Draba verna), 2 I.

Wild bean (Apios tuberosa), leaves at night, 126; Amphicarpea, or hog-peanut; underground flowers and pods of, $165-167$.

Wild carrot, 284.

Wild flowers, earliest, I-3, I9-24; latest, 202-210, 226; “" punctual” flowers, 22.

Wild geranium. See Cranesbill.

Wild-ginger (Asarum Canadense), 21, 22.

Wild lettuce (Lactuca elongata), seed of, I73.

Wild rose, 202; at night, I26.

Willow, catkins of, 48 ; seed cotton of, I70, 208 ; cone-gall of, 207.

Willow-herb. or fire-weed (Epilobium), 241.
Wilson on the drum of the partridge, 42.

Wind-flower (Anemone nemorosa), 21.

Winged seeds, I 70-I 74, 274, 283.

Winter calendar, 247-309.

Winter:-Insects of, 234; butterflies of, $34,184,270,289,292,305$; twigs of, 257 ; leaf-rosettes of, 240-243.

Winter food of the birds, $280-284$.

Winter-green, false. See Polygala.

Winter supplies for aquarium, 299.

Witch-brooms, 259.

Witch-hazel, blossoms of, 202, 210-226: shooting seeds of, $203,227$.

Woodbine. See Virginia-creeper.

Wood-boring ichneumon and its victim, 234-239.

Wood-frog, 52, I94.

Woodpecker, golden-winged, or flicker, 40.

Wood-sorrel (Oxalis), night attitude of leaves, 127.

"Woolly-bear," 234.

Worm-eating warbler, nest ingredients of, 224 .

Wormwood, Roman. See Ragweed, Small.

Wren, nest materials of, 224; goldencrested, nest of, 224 .

YELLOW-BILLED cuckoo, nest of, 224.

Yellow butterfly (Philodice), 84 .

Yellow-edge. See Butterfly (Antiopa).

Yellow-redpoll warbler, 213.

Yellow-rumped warbler, 213.

Yellow violet, 20, 22.

Yellow-warbler, nest materials of, 224. Yellow-winged sparrow. See Sparron 



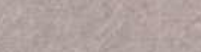

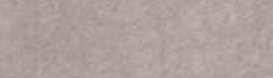

-

(1)

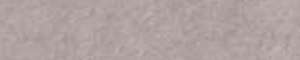

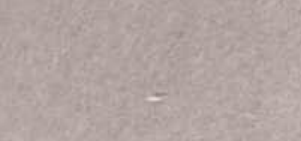

(3) 


\section{DAY USE \\ RETURN TO DESK FROM WHICH BORROWED BIOLOGY LIBRARY}

TEL. NO. 642-2532

This book is due on the last date stamped below, or on the date to which renewed.

Renewed books are subject to immediate recall.

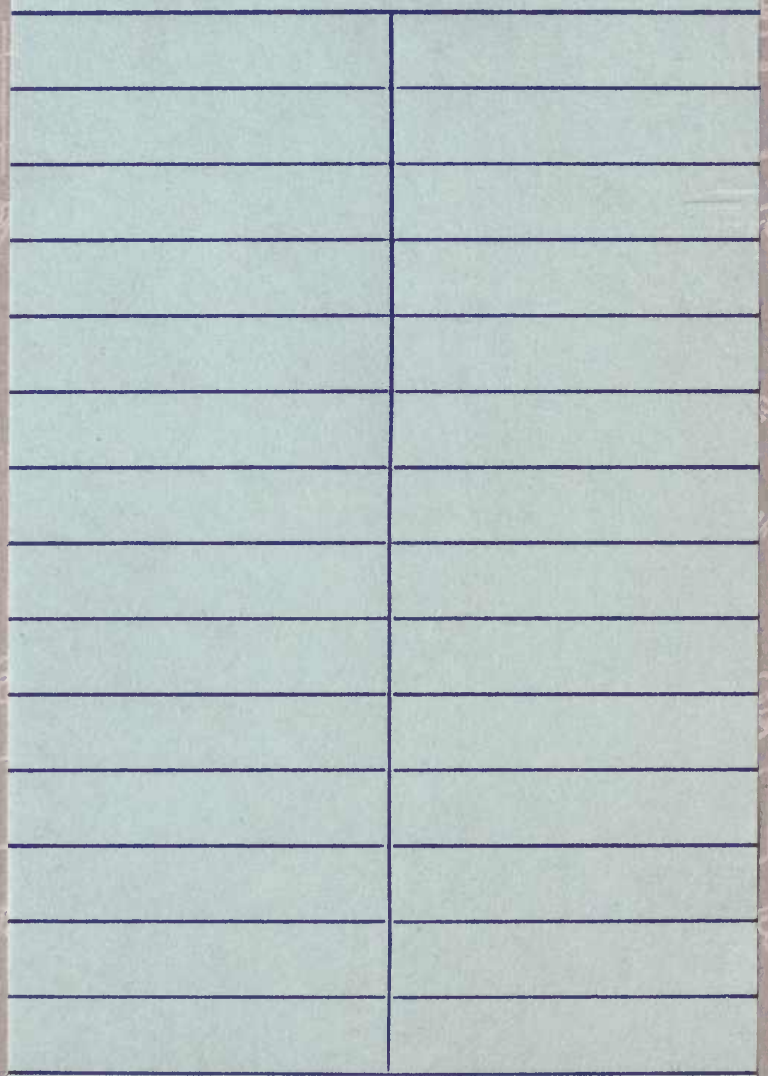

LD21A-6m-1,'75

(S3364s10) 476-A-32

General Library

University of California

Berkeley 


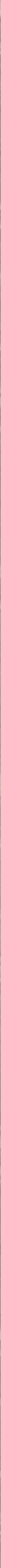


